Universidade de São Paulo

Instituto de Física

\title{
Estudo da Influência de Defeitos Estruturais nas Propriedades de Nanotubos de Carbono
}

\author{
Rodrigo Garcia Amorim
}

\begin{abstract}
Tese apresentada ao Instituto de Física para a obtenção do título de Doutor em Ciências
\end{abstract}

Orientador: Prof. Dr. Antônio José Roque da Silva

\section{Comissão Examinadora:}

Prof. Antônio José Roque da Silva (IF/USP)

Prof. Maria Cecília B. da S. Salvatori (IF/USP)

Prof. Andréa Brito Latgé (IF/UFF)

Prof. Ricardo Wagner Nunes (UFMG)

Prof. Roberto Hiroki Miwa (UFU)

São Paulo - 2009 


\title{
FICHA CATALOGRÁFICA \\ Preparada pelo Serviço de Biblioteca e Informação do Instituto de Física da Universidade de São Paulo
}

\author{
Amorim, Rodrigo Garcia
}

Estudo da Influência de Defeitos Estruturais nas Propriedades de Nanotubos de Carbono. São Paulo, 2009.

Tese (Doutorado) - Universidade de São Paulo. Instituto de Física. Depto. de Física dos Materiais e Mecânica.

Orientador: Prof. Dr. Antônio José Roque da Silva Área de Concentração: Física da Matéria Condensada

Unitermos: 1. Física do Estado Sólido; 2. Física do Estado Sólido - Defeitos estruturais; 3. Física do Estado Sólido Propriedades estruturais e mecânicas; 4. Nanotecnologia - Nanotubos; 5. Simulação computacional - Teoria do funcional da densidade.

$\mathrm{USP} / \mathrm{IF} / \mathrm{SBI}-088 / 2009$ 
Dedico esta tese ao meu irmão Guilherme. 

"Procure ser um homem de valor, em vez de ser um homem de sucesso. O sucesso é consequência." Albert Einstein 



\section{Agradecimentos}

Quero agradecer primeiramente a Deus.

Ao povo brasileiro que compõe esta nação e que paga imposto. A este povo que me proporcionou a oportunidade de estar na universidade pública.

Ao meu orientador Antônio José Roque da Silva, pela orientação e discussões ao longo desse período. Agradeço também ao professor Adalberto Fazzio pela colaboração e discussões.

A Maína e Gigi pela dedicação, paciência, motivação e companheirismo. Aos meus Pais, Wellington e Zenaide, e meus irmãos Cássio (Thalita e Ana) e Guilherme pelo incentivo e motivação. Agradeço os meus tios Silvano e Rose juntamente com meus primos Patrícia e Thiago. A Família Fantini: Marcos, Inês e Talita por me receber e me incentivar.

As pessoas que me receberam em São Paulo, em particular agradeço ao Marcelo e seu pais Reinaldo e Lucimar, por me acolher num momento de transição muito difícil.

Sou grato aos integrantes de Tongpura: Lucas, Rodrigo Ramos, Bahia, Vitor pela amizade.

Agradeço os amigos do Grupo SAMPA: Luana, Alberto, Thiago, Matheus, Edwin, Alexandre, Márcio, Zé Eduardo, Pedro, Amaury, Renato, James e Leandro. Em especial ao Thiago, Edwin, Luana, Alberto, Zé Eduardo, Alexandre, Márcio e Matheus pelas inúmeras discussões, ajudas, viagens e churrascos. Agradeço também a Marisa 
por estar sempre a disposição em ajudar.

A todos os meus amigos de São Paulo, em especial o Maurício, Priscila e Bahia por serem amigos incondicionais e também os amigos do DFMT Ferenc, Rafael, Marcelos, Jarlesson, Jeconias, Regina, Ricardo, Joelson e Rolando.

Aos meus amigos de São Carlos que apesar da distância sempre estão presente: Cacheffo, Veríssimo, Dodonov e Juracy pela amizade.

Aos amigos do Rio que desde o tempo de graduação estão sempre presente na minha vida acadêmica: Mago, Wells, Lidy, Davi, Mamour, Molim, Marcos, Fred e Juca.

Para finalizar, agradeço às agências de fomento CNPq, CAPES e FAPESP pelo financiamento da bolsa e pelos recursos para realizar a pesquisa. Agradeço aos centros de computação LCCA, CENAPAD-SP pelos recursos computacionais. 


\section{Resumo}

Nesse trabalho investigamos a influência de defeitos nas propriedades estruturais, eletrônicas e mecânicas de nanotubos de parede simples (SWCNT), em feixes de nanotubos e em nanotubos de parede múltipla (MWCNT). Todos os nossos resultados foram obtidos utilizando uma teoria de primeiros princípios de energia total, a Teoria do Funcional da Densidade (DFT). Investigamos as propriedades estruturais para quatro defeitos em nanotubos de parede simples: Stone-Wales (5577), monovacância e duas divacâncias (585) e (555777), e o comportamento da energia de formação em função do diâmetro para as quatro estruturas. Observamos que as divacâncias apresentam uma inversão de estabilidade, quando comparamos as energias de formação desses defeitos em nanotubos com o grafeno e, além disso, as divacâncias são os defeitos mais importantes na modificação das propriedades de transporte em SWCNT. Estudamos a estabilidade e as propriedades de transporte desses sistemas e observamos que o defeito 585 é menos estável em grafeno devido à quebra de duas ligações dos pentágonos do defeito. O defeito 555777 torna-se mais estável do que o 585 para os CNT armchair (zigzag) com o diâmetro $40 \AA$ (53 A).

Investigamos as propriedades estruturais e mecânicas de feixes de nanotubos com os defeitos do tipo vacância-vacância, $V_{2}^{1}$ e $V_{2}^{2}$. Devido à estrutura geométrica dos nanotubos, esses defeitos possuem energia de formação menores do que em grafeno. Apresentaremos como as conexões modificam o módulo de cisalhamento dos nanotubos e também mostraremos o processo de formação das conexões através 
do método "Nudged Elastic Band"- NEB.

Por fim, foram investigadas as propriedades estruturais e mecânicas de nanotubos de parede dupla (DWCNT) com defeitos do tipo vacância-interstício (defeito de Wigner) e os defeitos do tipo vacância-vacância (defeitos $V_{2}^{1}$ e $V_{2}^{2}$ ). Mostraremos que neste sistema existem várias possibilidades para o defeito de Wigner. Observamos que o defeito de Wigner mais estável é o que possui um pentágono no tubo interno e que os átomos do pentágono, formados pelo defeito, participam da conexão (WignerI-a). Investigamos a estabilidade desses defeitos em duas concentrações $\left(\rho_{d}=0.082\right.$ $\left[\operatorname{def} . \AA^{-1}\right]$ e $\left.\rho_{d}=0.164\left[\operatorname{def} . \AA^{-1}\right]\right)$. As propriedades mecânicas desses sistemas foram investigadas e constatamos uma melhora do módulo de cisalhamento por um fator de até 15, quando comparado com o sistema sem defeito e, quando dobramos a concentração de defeitos, o módulo de cisalhamento aumenta por um fator de 3 em relação ao sistema com a concentração inicial. Apresentaremos um estudo da transferência de tensão entre as paredes dos nanotubos através das conexões, e mostraremos que, dependendo da concentração de defeitos, a transferência de tensão pode chegar até $75 \%$ da tensão máxima. 


\section{Abstract}

We have investigated the influence of defects on structural, electronic and mechanical properties of single-walled carbon nanotubes (SWCNT), bundles of nanotubes and multi-walled carbon nanotubes (MWCNT). All our results were obtained with the first principles theory of total energy - Density Functional theory (DFT). We have investigated the structural properties of four defects in single-walled nanotubes: Stone-Wales (5577), monovacancy and two divacancies (585) and (555777). We show the behavior of the formation energy as a function of tube diameter for all structures. In this study, we have observed that divacancies have a stability reversal, when we compare the formation energies of these defects in nanotubes and graphene and, moreover, they are the most important defects in the modification of transport properties of SWCNT. We have studied the stability and transport properties of these systems. The defect 585 is less stable in graphene due to two breaks bonds in pentagons. We have observed that the 555777 becomes more stable than the 585 , for armchair (zigzag) with a diameter of about $40 \AA$ (53 $\AA)$, respectively.

We have studied the structural and mechanics properties of bundles of carbon nanotubes with vacancy-vacancy defects, $V_{2}^{1}$ and $V_{2}^{2}$. Due to carbon nanotube geometric structure these defects have lower formation energy than in graphene. These defects can form connections between the walls of this bunldes and we present how this imperfection can change the shear modulus of this nanotubes. We have also studied the barrier to form the connection with the method "Nudged Elastic 
Band'- NEB.

Finally, we have investigated the structural and mechanical properties of multiwalled nanotubes (MWCNT) with defects like vacancy-interstitial (Wigner defect) and vacancy-vacancy ( $V_{2}^{1}$ and $V_{2}^{2}$ defects). We show that this system have several possibilities for the Wigner defect. We observed that the more stable of all vacancyinterstitial defect is the case of the system that have a pentagon in the inner tube and the pentagon atoms participate in the connection (Wigner-Ia defect). We have studied the stability of these defects in two concentrations $\left(\rho_{d}=0.082\left[\operatorname{def} . \AA^{-1}\right]\right.$ and $\left.\rho_{d}=0.164\left[\operatorname{def} . \AA^{-1}\right]\right)$. In the study of mechanical properties in these systems, we observe the improvements in shear modulus by a factor of up to 15, compared with the system without connection. When we doubled the concentration of defects the shear modulus increases by a factor of 3 . We present a study of load transfer between the walls of DWCNT through the connections and we show that depending on the concentration of defects, the load transfer could be up to $75 \%$ of the maximum load. 


\section{Introdução}

Nesta tese abordaremos um estudo da influência dos defeitos nas propriedades estruturais, eletrônicas, mecânicas de nanotubos de carbono de parede simples (SWCNT), feixes de nanotubos, nanotubos de parede dupla (DWCNT). Mostraremos como os defeitos estruturais podem modificar e até mesmo melhorar algumas dessas propriedades. Primeiramente, vamos apresentar os objetos de estudo desta tese, começando pelo grafeno que é uma material bidimensional, composto por átomos de carbono dispostos de forma hexagonal, na forma de "favos de mel". Uma descrição detalhada será apresentada no capítulo 1. Apesar do grafeno ser teoricamente estudado há mais de 40 anos, os experimentais somente conseguiram separar uma única folha de grafeno neste século [1], com a técnica conhecida como clivagem micromecânica. Do ponto de vista de propriedades eletrônicas, o grafeno é um material metálico, e uma descrição detalhada dessa propriedade também será apresentada no capítulo 1. Um outro aspecto importante a ser destacado consiste na possibilidade de cortarmos o grafeno, obtendo assim uma nanofita de grafeno. Atualmente este sistema está sendo amplamente estudado por apresentar propriedades interessantes tais como a magnetização da borda, dependendendo de sua terminação.

O outro sistema que estudamos nesta tese é o nanotubo de carbono (CNT). Existem controvésias sobre quem de fato descobriu os nanotubos de carbono. Entretanto, não há dúvida que S. Iijima [2,3] popularizou o mesmo e, desde 1991, têm sido uma das estruturas químicas não biológicas, que mais tem despertado a curiosidade de 
pesquisadores de diferentes comunidades científicas tais como químicos, físicos e engenheiros. Para visualizar um CNT, podemos pensar em um cilindro oco de átomos de carbono, formados a partir de uma folha de grafeno enrolada. Ele pode ser caracterizado unicamente pelo vetor quiral. A classificação dos nanotubos é dada pelos índices $(n, m)$, que são números inteiros, e maiores detalhes sobre a estrutura dos nanotubos serão apresentados no capítulo 1. Quando $(n=m)$, teremos uma classe de CNT chamada de armchair, pois a sua terminação tem a forma de uma poltrona; no caso em que $(n \neq m=0)$, teremos os CNT chamados zigzag, que por sua vez possuem sua terminação em zigzag; e uma última possibilidade consiste na classe de nanotubos conhecidos como quirais e esses CNTs são classificados desta forma quando $(n \neq m)$. Os nanotubos podem ser sintetizados com uma única parede (nanotubos de parede simples - SWCNT), na forma de paredes múltiplas (MWCNT) e também na forma de feixes (bundles). Os nanotubos de paredes múltiplas são constituídos por dois ou mais nanotubos concêntricos, e os nanotubos na forma de feixes são dispostos de forma triangular [4]. Em ambos os casos, a distância típica entre os tubos é de aproximadamente $0.34 \mathrm{~nm}$. A interação responsável pela disposição tanto dos feixes quanto dos nanotubos de parede múltipla é a interação de van der Waals. Nesta tese estudaremos todas as formas de CNTs mencionadas acima, exceto os nanotubos quirais.

Os nanotubo possuem propriedades eletrônicas bem interessantes podendo ser metálicos ou semicondutores dependendo da maneira em que o tubo é enrolado. Uma maneira prática de sabermos se os nanotubos são metais ou semicondutores é, uma vez conhecida a quiralidade do nanotubo, índices $(n, m)$, calcularmos a diferença $(n-m)$, e se o resultado da diferença for um múltiplo de 3 , teremos nanotubos metálicos, como no caso de todos os nanotubos armchair. Por outro lado, se essa diferença não for um múltiplo de três, teremos nanotubos semicondutores. Além das propriedades eletrônicas dos nanotubos, merecem destaque as propriede- 
des mecânicas: os CNT possuem um módulo de Young da ordem de $1 T P a$ [5], e por apresentar tão elevada propriedade eles vêm sendo aplicados no desenvolvimento de cabos de alta performance [6-8]. Do ponto de vista de aplicações tecnológicas, os nanotubos estão sendo utilizados em nanoeletrônica, sendo possíveis candidatos à substituição do silício em transistores $[9,10]$, e também na criação de nanodispositivos e nanocontatos [11-13]. Em fotônica, o grande interesse em estudar nanotubos vem do fato de que os CNTs semicondutores possuem gap direto, e podem ser usados tanto para gerar quanto para detectar luz. De fato o nanotubo é uma material diferenciado, pois possui uma conjunção de propriedades interessantes, o que o torna um candidato em potencial à diferentes aplicações. Sendo assim, podemos citar outras aplicações tais como: emissor de campo, na fabricação de displays de LCD; em pontas de "Scanning Tunneling Microscopy" - STM; e na medicina, como uma fonte muito eficiente de elétrons para ferramentas de diagnósticos. São possíveis também aplicações na área de nanosensores $[14,15]$, onde moléculas de gases podem ser detectadas com a mudança na condutividade dos nanotubos.

Os materiais apresentados acima podem ser encontrados com defeitos estruturais [16] criados no processo de síntese ou quandos eles são expostos a processos de irradiação de íons. Basicamente estudaremos três tipos de defeitos: o primeiro é obtido através de uma (ou mais) rotação(ões) de átomos, como o defeito StoneWales [17-21]. Neste defeito, a rotação de átomos transforma localmente a rede hexagonal em um defeito composto por dois pentágonos e dois heptágonos (5577). A segunda classe de defeitos estudada está relacionada às vacâncias, que consistem na falta de um, dois ou mais átomos do cristal. Podemos citar alguns exemplos dessa classe de defeitos, tais como monovacâncias [22-26] e divacâncias [24,27-30]. A terceira classe de defeitos que estudaremos nesta tese consiste nos defeitos de Wigner [31-33], defeito este que é formado por um par de Frenkel - vacância-interstício (VI), onde um átomo do cristal é deslocado para a região intersticial. As vacâncias e 
o defeito de Wigner têm um papel importante no melhoramento das propriedades mecânicas dos nanotubos na forma de feixes, e também nos nanotubos de parede dupla. Uma vez apresentados os objetos de estudo desta tese, nanoestruturas de carbono e defeitos estruturais, a primeira pergunta surge naturalmente: como as propriedades dos nanotubos de carbono são modificadas na presença de defeitos estruturais?

Para definirmos as questões sobre a influência dos defeitos nas propriedades dos nanotubos, vamos dividir nosso estudo em três partes: (I) estudo de defeitos em nanotubos de parede simples; (II) defeitos em feixes de nanotubos de carbono; e (III) defeitos estruturais em nanotubos de parede dupla. Primeiramente falaremos sobre irradiação de íons, assunto que é comum às três etapas e, posteriormente, seguiremos com as questões fundamentais de cada uma das etapas acima.

Um processo de irradiação de íons pode ser pensado como um feixe de alguns $\mathrm{KeV}$ de íons, acelerados na direção de um sólido num processo de colisão inelástica, onde alguns eV são transferidos para um átomo. O produto final desse processo, dependendo das condições experimentais, pode ser uma deformação das paredes/superfície desse sólido gerada por defeitos estruturais. O estudo do processo de irradiação de íons surge, historicamente, com o intuito de entender como tal processo se comportava do ponto de vista da degradação induzida por irradiação de componentes de fissão nuclear [34]. Entretanto, estudos recentes têm mostrado que a irradiação, especialmente quando combinada com tratamento térmicos, pode trazer benefícios para materiais nanoestruturados.

Do ponto de vista experimental, esforços vêm sendo gastos no que diz respeito à caracterização dos defeitos em nanoestruturas de carbono [35-38]. Imagens de microscopia eletrônica de transmissão (TEM) em grafeno evidenciam a presença de defeitos estruturais [35] tais como monovacância e divacância. Nesta mesma linha de pesquisa, usando microscopia eletrônica de transmissão de alta resolução (HR- 
TEM) para nanotubos de carbono [36], foi observada a presença do defeito StoneWales na parede do nanotubo após o processo de irradiação de íons. Tipicamente, nos experimentos acima mencionados, os microscópios operam a 80 - $150 \mathrm{KeV}$ e de arcodo com os autores [38], a energia máxima transferida para o átomo é de aproximandamente $16 \mathrm{eV}$, energia suficiente para formar defeitos do tipo StoneWalles e não provocar rupturas ou danos nas estruturas das paredes dos nanotubos.

Os experimentos de irradiação de íons podem ser usados em processos de coalescência, e um exemplo desse processo é reportado por Ajayan [39,40]. O autor faz um estudo com um feixe de nanotubos - aproximadamente 15 tubos - exposto por alguns segundos em um feixe de íons de aproximadamente $1.25 \mathrm{MeV}$ a $800^{\circ} \mathrm{C}$. Após esta exposição, dois dos tubos de diâmetros 1.1 e $1.2 \mathrm{~nm}$, respectivamente, se juntam formando um único nanotubo de $2.0 \mathrm{~nm}$ de diâmetro. Uma outra aplicação em que a irradiação de íons vem sendo empregada é no processo de corte dos nanotubos [41]. Neste trabalho os autores irradiam íons, altamente energéticos, na parede de feixes de nanotubos, tendo observado que é possível cortá-los e, além disso, os autores mostram que é possível transformar feixes de nanotubos em nanotubos de paredes múltiplas.

Os processos de irradiação de íons podem criar defeitos estruturais nas paredes dos nanotubos. Essas imperfeições estruturais podem ser vacâncias, ligações pendentes, pares de Frankel, átomos intersticiais e rotações de ligações. Os defeitos podem ser usados para modificar as propriedades eletrônicas dos nanotubos. Uma outra aplicação, utilizando a irradiação de íons, consiste no melhoramento das propriedades mecânicas. Os nanotubos sem defeitos, tanto na forma de feixes quanto os nanotubos de paredes múltiplas, podem deslizar uns com relação os outros, pois a força que os mantém juntos é fraca (interação de van der Waals).

Experimentos mostram que interconexões podem ser criadas através de processos de irradiação de íons em nanotubos de parede múltipla [40,42], e também em nano- 
tubo na forma de feixes (bundles) [39,43]. O estudo [43] mostrou a surpreendente melhora nas propriededes mecânicas quando uma amostra de nanotubos na forma de feixes é exposta à irradiação de íons. Para determinada condição experimental, foi observado um aumento no módulo de flexão (bending) - por um fator de 30. Os autores atribuiram tal aumento à criação de interconexões entre as paredes dos nanotubos. Foram realizadas medidas do módulo de flexão em função da exposição à radiação, onde os autores mostraram que, para pequenas exposições de irradiação ${ }^{1}$ e um feixe de $80 \mathrm{KeV}$, o módulo de bending se mostrou com o melhor resultado para essa propriedades. Outros feixes foram testados, tal como o de $200 \mathrm{KeV}$, mas mesmo para pequenas doses de irradiação, a melhora no módulo de bending não foi tão significativa quanto o caso do feixe de $80 \mathrm{KeV}$.

Do ponto de vista teórico, simulações feitas com dinâmica molecular, utilizando potenciais empíricos $[40,44]$, vêm sendo empregadas para o entendimento do processo de irradiação de íons. Os autores simularam feixes de $\mathrm{CH}_{3}^{+}$e $\mathrm{Ar}^{+}$incidindo perpendicularmente na parede dos nanotubos (multiparede e/ou feixes (bundles)), onde foi observado que o produto destes impactos podem ser: moléculas adsorvidas nas paredes dos nanotubos; defeitos nas paredes dos tubos - vacâncias, interstício e pares de Frankel; e a formação de interconexões entre as paredes dos nanotubos através dos defeitos. Na mesma linha de pesquisa, simulações utilizando potenciais empíricos [41,44-51] vêm sendo extensivamente estudadas para entender o processo de formação dos defeitos. Foram testadas diferentes fontes ( $\mathrm{He}, \mathrm{Ne}, \mathrm{Ar}, \mathrm{Kr}$ e $\mathrm{Xe}$ ), variando a intensidade do feixe, e investigado como os defeitos são formados e qual é a densidade desses defeitos para cada configuração. Eles mostraram quais são os defeitos mais prováveis, variando a intensidade do feixe, constatando que, dentre todos os defeitos criados, os mais abundantes são monovacância e divacância. As

\footnotetext{
${ }^{1} \mathrm{O}$ autor considera pequenas doses de irradiação cerca de $10-50 \frac{e}{\mathrm{~cm}^{2}}$. Ao aumentar a dose de irradiação eles observaram que o bending diminui, e essa piora nas propriedades mecânicas é atribuida à degradação das paredes dos nanotubos.
} 
divacâncias aparecerem na maioria das colisões, em cerca de 30-40\% dos impactos.

Uma outra questão pertinente a ser destacada consiste no processo de migração dos defeitos. Simulações mostram que vacâncias isoladas podem migrar, uma em direção às outras, formando multivacâncias. Defeitos com ligações pendentes são energeticamente menos favoráveis do que defeitos sem esse tipo de ligação. O custo energético para remover um átomo de uma multivacância é de aproximadamente 7.5 eV. A monovacância é o único defeito móvel, pois sua energia de migração é cerca de $1.5 \mathrm{eV}$, enquanto que a divacância possui uma energia de migração de aproximadamente $5.0 \mathrm{eV}$.

Com base na questão fundamental desta tese de como os defeitos estruturais modificam as propriedades dos nanotubos, bem como as questões apontadas tanto experimentalmente quanto teoricamente (potenciais empíricos) sobre irradiação de íons, vamos definir as perguntas desta tese.

Na primeira parte desta tese mostraremos quatro defeitos em nanotubos de parede simples. Os defeitos que foram investigados são provenientes de rotações de ligação ou defeito Stone-Walles, defeitos com uma única falta de átomos ou monovacância. A monovacância em nanotubos reconstrói em um pentágono mais uma ligação pendente (ligação extremamente reativa). E a última classe de defeitos estudada nessa parte da tese foram os defeitos com duas vacâncias. Estudamos dois tipos desses defeitos, o defeito com duas recontruções de pentágono e um octágono ou defeito 585, e um outro defeito mais complexo com três reconstruções de pentágonos e três reconstruções de heptágonos. Chamaremos esse últumo defeito de 555777. A escolha desses defeitos está ligada à abundância destes no processo de irradiação de íons. A primeira questão acerca dos defeitos é sobre a estabilidade energética em nanotubos de parede simples e no grafeno. Qual é a sequência energética desses defeitos em nanotubos? A mesma sequência é obtida no grafeno? Como se comporta a energia de formação dos nanotubos quando variamos o seu diâmetro? Traba- 
lhos teóricos sobre vacâncias em nanotubos [30,52] surgiram discutindo a estrutura eletrônica das monovacâncias e divacâncias. O primeiro trabalho [52] discute a estabilidade da monovacância e divacância (585), bem como sua estrutura eletrônica tanto para nanotubos armchair quanto para zigzag. O segundo trabalho faz um estudo sistemático sobre a divacância 585, no qual é mostrado o comportamento da energia de formação em função do diâmetro do nanotubo. Esse estudo também foi realizado para nanotubos armchair e para zigzag, e mostra que, para nanotubos zig$z a g$, a energia de formação oscila conforme o seu tipo (metal ou semicondutor), uma vez que os nanotubos zigzag podem assumir as duas formas. Este efeito já foi reportado anteriormente [53]. Num outro trabalho sobre divacância que merece destaque, entretanto para grafeno [27], os autores mostram que a divacância pode assumir duas formas (585 e 555777). Este estudo foi realizado com dinâmica molecular tight binding, onde duas monovacâncias se juntam formando um divacância (585). Em altas temperaturas, o defeito 585 se transforma em um defeito mais complexo - o defeito 555777. Os autores realizaram um cálculo de primeiros princípios com as geometrias finais dos defeitos, onde mostraram que, para o grafeno, a estrutura que apresentou a menor energia de formação foi o defeito 555777 , e a diferença de energia de formação foi de aproximadamente $0.9 \mathrm{eV}$, comparado com o defeito 585. Essa estabilidade se mantém na mesma ordem em nanotubos de carbono? Caso a estabilidade seja contrária, ou seja, se o defeito 585 for mais estável em nanotubos, e considerando que o grafeno é um nanotubo de raio infinito, deverá existir um diâmetro para o qual a inversão de estabilidade ocorre. Por que ocorre essa inversão de estabilidade? Comentamos anteriormente que os defeitos mais prováveis em impactos de irradiação de íons são as divacâncias e, além disso, estudos recentes mostram que as divacância são os defeitos mais importantes no que diz respeito à mudança nas propriedades de transporte $[54,55]$. Pequenas concentrações de divacâncias, cerca de $0.03 \%$, podem modificar a condutância dos nanotubos de parede simples por 
três ordens de magnitude. Além disso a energia de formação das divacâncias (585 e 555777) é menor do que a energia de formação de uma única vacância, como veremos nos próximos capítulos. Todas essa questões apresentadas acima referentes à defeitos em nanotubos de parede simples serão apresentadas nos capítulos 2 e 3 .

A segunda parte desta tese é dedicada ao estudo de defeitos estruturais em feixes de nanotubos de carbono. Quando os nanotubos de carbono de parede simples (SWCNT) são produzidos, eles podem se agrupar em maços ou feixes. Entretanto, como já foi mencionado, a força que mantém os nanotubos nesta disposição é fraca - interação de van der Waals, e sendo assim, os nanotubos podem deslizar uns com relação aos outros, degradando as propriedades mecânicas dos feixes. Esta degradação é um dos grandes obstáculos para a fabricação de fibras de alta resistência $[6,7]$. Uma maneira prática para melhorar as propriedades mecânicas de feixes de nanotubos é através de irradiação de íons [43], e como também foi comentado, pequenas doses de feixes de irradiação de íons podem aumentar o módulo de flexão (bending) por um fator de 30. Essa melhora significativa da propriedade mecânica é atribuida à criação de interconexões entre as paredes dos feixes. Do ponto de vista teórico, poucos trabalhos têm abordado questões como os efeitos da irradiação de íons em nanotubos na forma de feixes, ou quais os principais tipos de defeitos que são criados durante o processo de irradiação de íons. A maior parte deste estudos foi feito utilizando simulações de dinâmica molecular, com as interações entre os átomos descritas por potenciais empíricos. Num exemplo dessas simulações de dinâmica molecular [4], os autores mostraram que ao incidir íons $\left(A r^{+}\right)$perpendicularmente à parede de alguns feixes de nanotubos, ocorre a criação de interconexões entre as paredes dos feixes. Os autores utilizaram diversas intensidedes de feixes $(0.1-1.0 \mathrm{KeV})$, e a maioria dos defeitos observados foram vacâncias. Um resultado interessante obtido neste trabalho foi o número de coordenação dos defeitos (quantidade de defeito produzida) em função da penetração no feixe (para 
um determinado feixe - $0.5 \mathrm{KeV}$ ), no qual observaram uma distribuíção de defeitos com máximos de intensidade em torno de 13 e $27 \AA$, o que representa distâncias típicas das paredes dos tubos $(10,10)$. Eles também mostram neste trabalho que o número de interconexões aumenta linearmente com a energia dos íons incidentes. $\mathrm{O}$ estudo mostrado anteriomente não caracteriza os defeitos, os autores somente dizem que o produto dos impactos provocam imperfeições nas paredes dos tubos do tipo vacâncias, interstícios e ligações pendentes. A primeira pergunta desta parte é sobre quais são os defeitos formados neste processo de irradiação. A fim de obtermos bons canditados a defeitos em feixes de nanotubos, vamos analisar dois estudos teóricos em grafite [31,32], utilizando cálculos de primeiros princípios. Neste estudo foram investigados defeitos do tipo vacância-interstício (VI) e do tipo vacância-vacância (VV). No primeiro trabalho [31], os autores estudaram o defeito de Wigner, defeito este que é formado por um par vacância-interstício. Foi mostrado que este defeito possui uma energia de formação de aproximadamente $10.8 \mathrm{eV}$ e, além disso, foi estudado como ocorre o processo de formação do defeito através do cálculo da barreira de recombinação. Foi obtida uma barreira de $1.3 \mathrm{eV}$, que está de acordo com resultados experimentais [56]. Foram estudados outros dois defeitos para grafite [32] oriundos de duas monovacâncias, uma em cada plano de grafeno e estes defeitos têm diferentes disposições das vacâncias, onde a primeira - $V_{2}^{1}$ - possui dois pentágonos, sendo que, a disposição dos mesmos em relação à interconexão, é na forma de $V$; no segundo defeito - $V_{2}^{2}$ - os pentágonos estão diametralmente opostos à interconexão entre os planos de grafite. Foram calculadas as enegias de formação para esses defeitos e encontrados 12.7 e 13.0 eV, respectivamente. As energias obtidas são menores do que duas vacâncias isoladas em grafite, entretanto maiores do que a do defeito de Wigner. Antes de discutir as questões desta seção, vamos apresentar um trabalho sobre o defeito de Wigner em feixes de nanotubos [33]. Neste trabalho os autores mostram que, neste caso, o defeito de Wigner em feixes de nanotubos é bem mais estável do 
que o mesmo defeito em grafite. A energia de formação obtida para este defeito é de aproximadamente $5.5 \mathrm{eV}$, metade do valor calculado para o grafite [31], mostrando que este defeito é mais provável em feixes de nanotubos. Foram calculadas as propriedades mecânicas através do módulo de cisalhamento, tendo sido observado um aumento por um fator de 14, entre o sistema sem interconexão e com conexão. O último resultado interessante deste trabalho foi a barreira de recombinação, no qual os autores obtiveram uma barreira de $2.4 \mathrm{eV}$, o que representa, segundo a estimativa dos autores, a temperatura para recombinar o defeito foi de $600^{\circ} \mathrm{C}$. Uma vez motivado o problema dos defeitos em feixes em nanotubos de carbono e, considerando a questão fundamental desta tese de como os defeitos modificam as propriedades dos nanotubos, passaremos para as questões abordadas no capítulo 4. A primeira questão consiste na estabilidade dos defeitos tipo vacância-vacância em feixes de nanotubos. Os defeitos $V_{2}^{1}$ e $V_{2}^{2}$ são estáveis/possíveis em feixes de nanotubos? Considerando que as conexões podem ser formadas, como se comportam as ligações químicas das conexões? Como os defeitos modificam as propriedades mecânicas dos feixes de CNTs? Existe uma barreira de recombinação destes defeitos? E ainda, existe uma barreira para que um átomo da região intersticial seja deslocado para a região do defeito, formando um tubo puro e uma divacância? Esses defeitos são estáveis a temperatura ambiente? Estas perguntas serão respondidas no capítulo 4.

Na terceira parte desta tese apresentaremos um estudo sobre a influência de defeitos estruturais nas propriedades dos nanotubos de paredes múltiplas (MWCNT); em especial estudaremos os nanotubos de parede dupla (DWCNT). A primeira pergunta desta seção refere-se à sua aplicação: por que os nanotubos de parede múltiplas são amplamente utilizados em cabos de alta performace [6,7], e também em aplicações como reforço em compósitos $[57,58]$ ? A resposta desta pergunta está associada ao processo de síntese. Os nanotubos de parede múltipla são facilmente manipuláveis, comparados com os nanotubos de parede simples, e este fato é atribuído ao grande 
tamanho dos MWCNT, quando são produzidos nos processos de síntese comparativamente com os SWCNT. Os nanotubos de paredes múltiplas possuem ligações fortes entre os átomos das paredes e, em contrapartida, a interação de van der Walls entre as paredes dos nanotubos é fraca. Sendo assim, cada nanotubo pode rodar ou deslizar um contra os outros, degradando a propriedade mecânica que cada tubo possui individualmente - os nanotubos possuem um módulo de Young da ordem de 1 TPa. A parede externa dos nanotubos (MWCNT) é, em princípio, responsável pela absorção da tensão aplicada à este sistema; no entanto, seria preferível que os nanotubos internos também absorvessem parte dessa tensão, particularmente quando estes MWCNTs são utilizados como reforços em compósitos. Uma forma de obter MWCNTs com as características citadas acima é através de irradiação de íons [59-66]. Tanto do ponto de vista experimental [65-71], quanto em modelagens teóricas $[59,64,66]$, esforços vem sendo gastos para um completo entendimento de como melhorar as propriedades mecânicas, tais como o módulo de cisalhamento e a transferência de tensão (load transfer) entre as paredes desses tubos.

Nos experimentos são realizados ensaios para testar a transferência de tensão entre as paredes dos MWCNTs. No entanto, o aparato experimental para realização dessas medidas é extremamente sofisticado, como podemos ver no estudo realizado recentemente $[65,66]$. Os autores desses trabalhos possuem um sistema nanoeletromecânico, acoplado a um microscópio eletrônico de transmissão (TEM), capaz de realizar medidas de força e deslocamentos com resolução menores que $12 \mathrm{nN}$ e $1 \mathrm{~nm}$, respectivamente. Foram analisadas diferentes amostras de alta qualidade, amostras livre de oxidação e com o mínimo de defeitos em duas situações distintas: amostras sem sofrer algum processo de irradiação e amostras irradiadas. Em ambos os casos, os nanotubos foram soldados no nanomanipulador através de deposição induzida por feixes de elétrons de carbono, e deslocamentos na amostra são realizados até que uma falha ou ruptura seja constatada ${ }^{2}$. Para as amostras sem irradiação, os

\footnotetext{
${ }^{2} \mathrm{~A}$ identificação desta falha/ruptura é feita visualmente pelas imagens de TEM ou pela variação
} 
autores quantificaram os seguintes resultados: (I) mediram a distância entre as paredes dos CNTs por volta de $3.4 \AA$; (II) constataram a falha de apenas uma parede do tubo, a parede externa (este resultado é um indicativo de que a tensão está sendo aplicada apenas na parede externa); (III) a força necessária para puxar o nanotubo externo após o rompimento. Para as amostras irradiadas os autores observaram que três camadas foram rompidas, para uma determinada amostra, o que significa que as paredes estavam interconectadas e por esse motivo elas também romperam. Eles mostraram ainda que a força máxima normalizada ${ }^{3}$ aumentou por um fator de 2.5-12, dependendo da exposição à irradiação. Este estudo comprova, experimentalmente, que a criação de interconexões através da irradiação de íons melhora as propriedades mecânicas dos MWCNTs.

Estudos teóricos de dinâmica molecular [59,63-66], utilizando potenciais empíricos, investigaram como o processo de irradiação modifica a estrutura e as propriedades mecânicas dos MWCNTs através da criação de conexões entre as paredes dos tubos. Os autores do trabalho [64] mostraram que a força necessária para que as paredes dos MWCNT iniciem um deslizamento pode variar entre 0.4 à $8.0 \mathrm{nN}$, dependendo da concentração e do tipo de defeito. Entretanto neste trabalho os autores não caracterizam os defeitos estudados. Um outro trabalho teórico importante [66], os autores caracterizam três defeitos distintos: i) defeito formado a partir de um átomo intersticial; ii) defeito de Wigner tipo vacância-interstício (V-I); e iii) defeito tipo vacância-vacância $(\mathrm{V}-\mathrm{V})$ - em particular o defeito $V_{2}^{2}$. Esses defeitos são os mesmo apresentados na seção II. Além da caracterização dos defeitos, os autores realizaram um estudo das propriedades de transferência de tensão (load transfer) entre as paredes dos nanotubos. Esses cálculos foram realizados com dinâmica molecular clássica - potenciais empíricos - para o defeito de Wigner em diferentes concentrações do valor da tensão.

${ }^{3} \mathrm{~A}$ força normalizada é a definida como $\frac{F}{F_{0}}$, onde $F_{0}=100 \mathrm{GPa}$ que corresponde a força esperada para ruptura de um único nanotubo. 
dos defeitos. Para realizar esse cálculo, os autores puxaram o nanotubo externo até que as conexões se rompessem. Eles mostraram que a transferência de tensão entre as paredes dos nanotubos aumenta com a densidade de defeitos e, além disso, uma grande concentração de defeitos mantém a transferência de tensão no seu valor ótimo - próximo ao valor máximos, até a degradação da conexão. Os autores concluem que o conhecimento preciso dos tipos de defeitos, em diferentes concentrações, é fundamental para o entendimento do processo de transferência de tensão. Com base nos trabalhos acima, podemos levantar as questões fundamentais desta seção. Como os nanotubos de parde dupla possuem dois raios diferentes, a questão sobre estabilidade é mais específica: em qual parede os defeitos de Wigner preferem ser criados? Quais são os possíveis defeitos de Wigner que podem ser criados? Como é a estabilidade dos defeitos em nanotubos de parede dupla, comparativamente com o grafite? Se aumentarmos a concentração dos defeitos, como estes novos sistemas se comportam? Uma vez obtida a estabilidade dos defeitos, a segunta pergunta refere-se às propriedades mecânicas. Como o módulo de cisalhamento (shear modulos) se comporta nos DWCNT com as conexões? E para os sistemas sem defeitos? Como são as ligações químicas? Se aplicarmos deslocamentos relativos da ordem do tamanho de uma célula, o que acontece com os defeitos? A completa descrição do problema abordado acima, bem como a discussão detalhada e as respostas para essas perguntas estão no capítulo 5 .

Os estudos experimentais servem como motivação para nossas perguntas, bem como os trabalho feitos com potenciais empíricos. Todos os trabalhos teóricos descritos anteriormente são relevantes e servem como um indicativo de que estes processos podem ocorrer, mesmo não sendo possível descrever adequadamente características tais como rehibridização, distribuição de carga, religações químicas. Descrever essas características é de fundamental importâncias, uma vez que os processos de irradiação de íons causam quebra de ligação química, estresse de ligações e combinações 
de átomos formando novas ligações químicas. Um outro aspecto marcante destes sistemas baseados em carbono, vem do fato deles possuirem diversas hibridizações, o que não é descrito com potenciais empíricos e, além disso, as energias de formação também não são descritas satisfatoriamente. Por todas as razões apresentadas acima, será utilizado nesta tese uma descrição totalmente quântica da estrutura eletrônica dos sistemas. Escolhemos a Teoria do Funcional da Densidade para realizarmos todos os cálculos desta tese, pois esta teoria pondera a acurácia com custo computacional, de maneira satisfatória, tornando factível o estudo dos nossos sistemas.

Esta tese está dividida da seguinte maneira: no primeiro capítulo vamos mostrar alguns métodos de síntese para nanotubos de carbonos; será apresentado um modelo atomístico para o grafeno e para os nanotubos de carbono; discutiremos a estrutura eletrônica desses materiais com o método tight-binding. No final desse capítulo discutiremos as propriedades mecânicas dos nanotubos de carbono e algumas aplicações para este sistema. A metodolologia da tese e alguns outros aspectos relevantes serão apresentados nos apêndices. No segundo capítulo apresentamos quatro defeitos em nanotubos de parede simples, a estabilidade desses defeitos e o comportamento da energia de formação em função do diâmetro dos tubos. No capítulo seguinte, mostraremos um estudo detalhado das propriedades das divacâncias e será discutido o impasse sobre a mudança de estabilidade entre os defeitos 585 e 555777 . Também serão mostradas as proprieades de transporte eletrônico para as divacâncias. No quarto capítulo serão investigados dois defeitos tipo (VV), $V_{2}^{1}$ e $V_{2}^{2}$, em feixes de nanotubos de carbono. Apresentaremos a estabilidade energética, as propriedades mecânicas, e também serão apresentadas as barreiras de recombinação dos defeitos. O quinto capítulo será dedicado ao estudo dos defeitos em nanotubos de paredes duplas. Investigaremos diferentes defeitos de Wigner (VI) e dois defeitos tipo V-V. Mostraremos como os defeito modificam suas propriedades mecânicas. 


\section{Capítulo 1}

\section{Estrutura e propriedades de}

\section{nanotubos}

Nesta tese apresentaremos como os defeitos estruturais modificam as propriedades de nanomateriais baseados em carbono, em especial grafeno e os nanotubos de carbono. Antes de começarmos com as questões relacionadas ao tema desta tese, é preciso definir teoricamente os sistemas de interesse, bem como quais são os principais parâmetros que caracterizam esses materiais. Além disso, precisamos conhecer como são as propriedades destes materiais na sua forma pura ou sem defeitos. Sendo assim, este capítulo é dedicado ao estudo da síntese, estrutura e das propriedades dos nanotubos de carbono e grafeno. Na primeira seção faremos uma breve discussão acerca do elemento que compõe estes nanomateriais - o Carbono. Na segunda seção falaremos da "descoberta" destes materiais e também serão discutidos os principais processos de síntese para os nanotubos de carbono. A terceira seção foi destinada à questões relacionadas a estrutura destes materiais: discutiremos um modelo atomístico para o grafeno, mostrando os principais parâmetros deste material. Como os nanotubos podem ser obtidos à partir do grafeno, vamos descrevê-los em função dos parâmeros do grafeno. Apresentaremos os tipos de na- 
notubos e também as formas mais comuns deste material. De posse da estrutura, discutiremos na quarta seção, a estrutura eletrônica desses sistemas através de uma modelagem tight-binding para os elétrons $\pi$. Finalizaremos o capítulo falando sobre outras propriedades dos nanotubos e possíveis aplicações tecnológicas para esses materiais.

\subsection{O Carbono}

O carbono é um elemento químico abundante na natureza e de importância ímpar para a vida. Este fato está intimamente ligado ao modo como o carbono se combina com os outros elementos químicos para formar moléculas complexas. Para exemplificar essa versatilidade do carbono, basta compará-lo como outros elementos químicos. O Carbono pode se combinar com até quatro átomos, enquanto que o Hidrogênio geralmente pode ligar-se com um elemento, o Oxigênio, pode unir-se a apenas dois átomos. Este fato faz com que o carbono consiga formar uma variedade, quase que infinita, de moléculas complexas de diferentes tamanhos e formas. Uma outra possibilidade para o Carbono é se combinar com ele mesmo de diferentes formas, através de diferentes tipos de ligações químicas. A possibilidade de fazer ligações químicas distintas e de poder gerar estruturas complexas estão associadas com as diferentes formas de hibridização que o átomo de carbono pode assumir. O carbono possui seis elétrons e está na coluna IV da tabela periódica. Esses elétrons podem ocupar os orbitais $1 s, 2 s$ e $2 p$, sendo que dois deles são fortemente ligados $\left(1 s^{2}\right)$ e são considerados como elétrons de caroço. Os demais são considerados elétrons de valência, geralmente responsáveis pelas ligações químicas. Como podemos ver na figura 1.1, o carbono pode assumir as seguintes hibridizações: $s p, s p^{2}$ e $s p^{3}$.

A hibridização $s p$ envolve a mistura de um orbital $s$ com um $p$, formando dois orbitais híbridos disposto a um ângulo de $180^{\circ}$. Um exemplo deste tipo de hibritização é observado no acetileno $(H C \equiv C H)$. Quando o carbono se hibridiza na forma $s p^{2}$, 

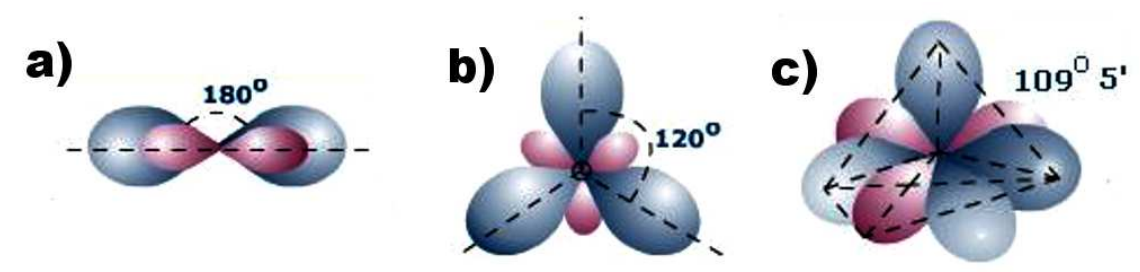

Figura 1.1: Hibridizações para o átomo de Carbono. A primeira possibilidade é mostrada em (a) sp; (b) O segundo tipo é conhecido com $\mathrm{sp}^{2}$; e finalmente, o terceiro tipo de hibridização para o Carbono (c) $s p^{3}$.

um orbital $s$ se combina com outros dois $p$, formando três orbitais orientados de maneira triagonal, formando um ângulo de $120^{\circ}$. Os nanotubos e fulerenos possuem este tipo de orbitais. O terceiro tipo de hibridização feita pelo carbono chama-se $s p^{3}$, no qual um orbital $s$ se mistura com outros três orbitais $p$, formando quatro orbitais híbridos $s p^{3}$. Estes orbitais estão orietados de forma tetragonal e com um ângulo de $109.5^{\circ}$.

Podemos citar alguns exemplos de materiais baseados em carbono e com propriedades bem distintas uns dos outros: fulereno (0D), nanotubos e nanofitas (1D), grafeno (2D), grafite e diamante (3D). Na figura 1.2 mostramos quatros dessas estruturas citadas acima.

O grafeno, por exemplo, é um material de gap zero e possui hibridização $s p^{2}$, e por outro lado temos o diamante, que é um material isolante e possui hibridização $s p^{3}$. São dois materiais compostos por átomos de Carbono apenas e que possuem propriedades bem distintas. Apresentados os tipos de hibridizações que o átomo de Carbono pode assumir, agora vamos estudar os principais processos de síntese para os nanotubos de carbono, e também a história de sua descoberta. 


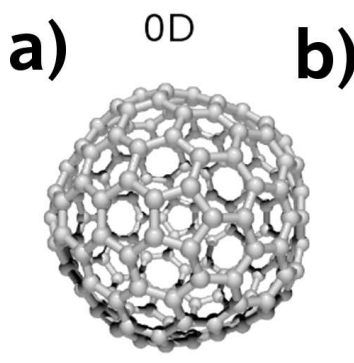

Fulereno

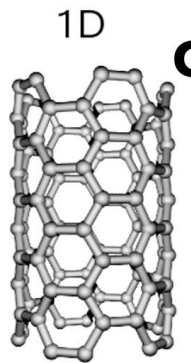

Nanotubo

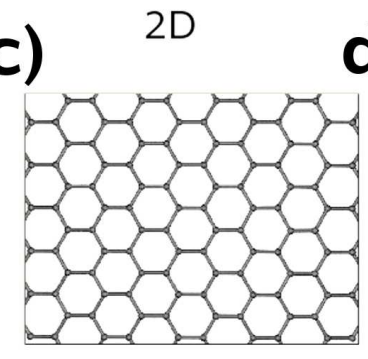

Grafeno d) $3 \mathrm{D}$

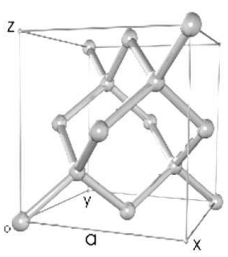

Diamante

Figura 1.2: Quatro estruturas formadas por átomos de carbono. Em (a) mostramos uma molécula - o Fulereno; Em (b) apresentamos um material unidimensional Nanotubos; Um material bidimensional é exibido em (c), o grafeno, e finalemente em (d) o diamante.

\subsection{Síntese dos nanotubos de carbono}

Em 1991 S. Iijima [2] apresentou um trabalho sobre tubos cilíndricos e concêntricos formados por átomos de carbono. Os primeiro nanotubos observados por Iijima foram os de parede múltipla (MWCNT), e estes tubos possuem um espaçamento entre as paredes de aproximadamente $0.34 \mathrm{~nm}$, e esta distância é a mesma encontrada entre os planos de grafeno em grafite. Os nanotubos de parede simples foram descobertos dois anos mais tarde simultaneamente por dois grupos, S. Iijima [3] e Bethume [72] . Os nanotubos de parede simples foram descobertos posteriormente devido ao fato de que eles precisam de um processo catalítico quando são sintetizados.

Mostramos na figura 1.3 os nanotubos observados por Iijima: as três primeiras imagens representam os nanotubos de paredes múltiplas de seu primeiro trabalho [2]. Logo abaixo observamos as suas respectivas paredes concêntricas. A última imagem da figura 1.3-d mostra o nanotubo de parede simples do segundo trabalho de Iijima [3]. 


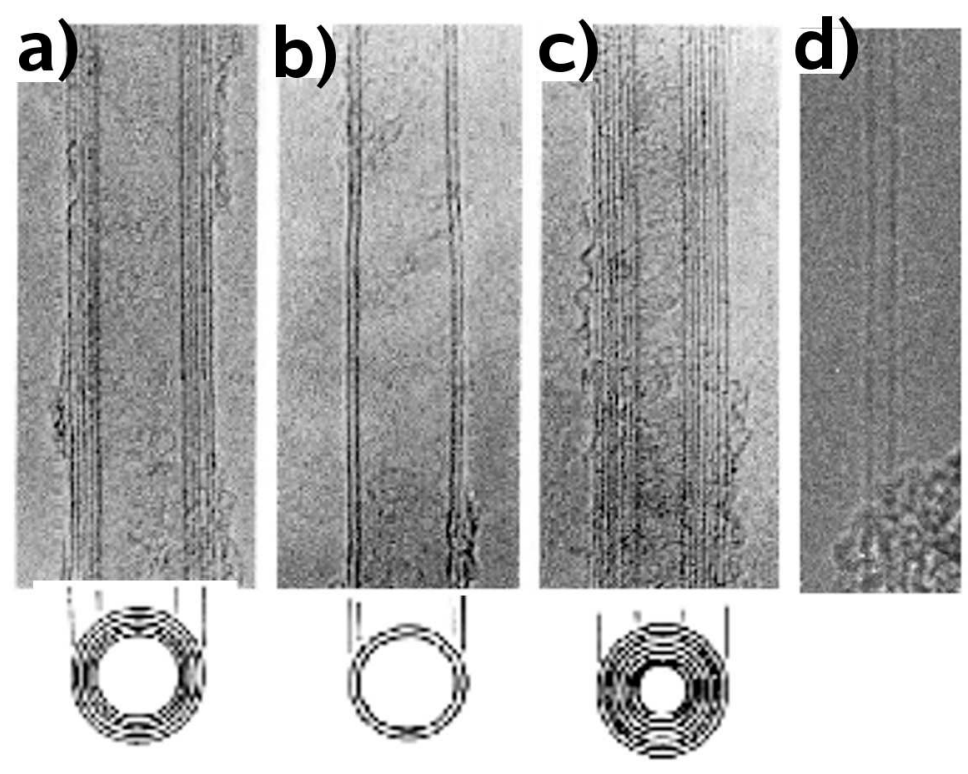

Figura 1.3: Imagens de TEM, reoportadas por S. Iijima, de nanotubos de carbono. (a) Nanotubo de parede múltipla (MWCNT) com cinco paredes; (b) MWCNT com duas paredes; (c) MWCNT com sete paredes; (d) Nanotubo de parede simples.

A síntese de nanotubos de carbono é um assunto de grande interesse da comunidade científica, pois apesar dos tubos terem sido descobertos a quase duas décadas, ainda não existe um protocolo que consiga controlar totalmenente a quiralidade, a quantidade e a qualidade dos nanotubos sintetizados. Os primeiros processos usados na síntese de nanotubos de carbono tanto na sua forma de paredes múltiplas quanto na forma de parede simples foram descarga por arco e ablação por laser. Nesses processos são criadas estruturas de carbono além dos nanotubos, o carbono amorfo e, por isso, necessitam de uma etapa de purificação. Para obter nanotubos de parede simples há uma exigência adicional que consiste em acessar regiões termicamente proibidas para esse tipo de reação. Para tornar isso possível é necessário utilizar um metal catalizador, tal como $\mathrm{Fe}, \mathrm{Ni}$ ou $\mathrm{Co}$, que é inserido à amostra. Uma outra técnica que comentaremos aqui é conhecida como deposição química à vapor (CVD). Este processo também utiliza catalizadores e permite um 
maior controle do processo de crescimento das amostras. Além disso, esse método não necessita da etapa de purificação, pois os nanotubos produzidos possuem um grau de pureza elevado, e ainda são produzidas a temperaturas menores do que dos outros processos. Devido a este último fato do método CVD, existe uma potencialização nas aplicações/utilizações dos nanotubos em microeletrônica na fabricação de dispositivos com tubos sintetizado por este método.

A seguir descreveremos as principais técnicas que são utilizadas para fabricação de nanotubos. Faleremos da (I) descarga por arco; (II) ablação por laser e (III) deposição química à vapor (CVD).

\subsubsection{Descarga por Arco}

A técnica de descarga por arco tem sua importância histórica, pois esta possibilitou a descoberta dos nanotubos de parede múltipla por S. Iijima. Esta técnica é usada para sintetizar nanotubos de parede simples e de parede múltiplas, onde a alta temperatura é utilizada para vaporizar átomos de carbono em plasma. Neste método $[5,73]$, como o próprio nome sugere, aplica-se uma voltagem (DC) entre dois eletrodos que estão em uma atmosfera inerte (tipicamente 500-600 mbar de $\mathrm{He}$ ). A voltagem é suficientemente grande $(20-25 \mathrm{~V})$ para induzir uma separação dielétrica dos gases entre os eletrodos causando uma corrente de aproximadamente $100 \mathrm{~A}$, que flui na forma de descarga por arco cuja temperatura é de aproximadamente $3000^{\circ} \mathrm{C}$. Na figura 1.4 mostramos esquematicamente o experimento de descarga por arco.

O anodo é gradualmente consumido no processo, e os átomos evaporados redepositam no catodo e nas paredes da câmara na forma de carbono amorfo, nanopartículas de grafite, fulerenos e em menor quantidade nanotubos de parede múltipla. O mesmo método pode ser usado para sintetizar nanotubos de parede simples, no entanto é necessário o uso de catalizadores. O catalizador pode ser um metal de transição $(C o, F e$ e $N i)$ ou ainda terra rara $(Y$ ou $G d)$, que é misturado ao anodo 


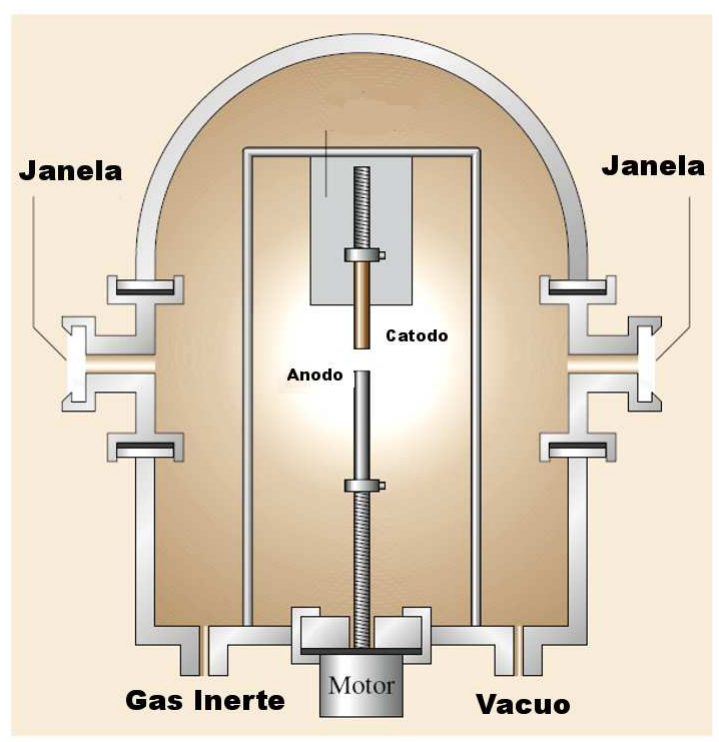

Figura 1.4: Esquema do aparato experimental para da técnica de descarga por arco. Esta figura foi extraída da referência [74].

em baixas concentrações. Em 1997, Journet et al. [75] conseguiram sintetizar uma grande quantidade de nanotubos de parede simples utilizando esta técnica. Eles utilizaram misturas de catalizadores $C o / N i, C o / Y$ e $N i / Y$ e a melhor combinação obtida por Journet foi a que possuía uma concentração de $1 \%$ de $Y$ e $4,2 \%$ de Ni. O método de descarga por arco, apesar de precisar de um processo de purificação, produz nanotubos com boa qualidade estrutural.

\subsubsection{Ablação por laser}

A segunda técnica para obtenção de nanotubos que apresentaremos nesta tese é conhecida como ablação por laser. Basicamente, a técnica de ablação por laser [5,73] é feita no interior de um forno onde um laser pulsado vaporiza um alvo de grafite. Este forno, por sua vez, contém um gás inerte - geralmente é utilizado $H e$ ou $A r$. O aparato experimental consiste em um forno tubular, que é mantido a uma temperatura de $1200^{\circ} \mathrm{C}$, onde flui um gás inerte que mantém a pressão constante, e 
um laser pulsado de alta potência (Laser Nd:YAG operando com $532 \mathrm{~nm}, 30 \mathrm{~Hz}$ e aproximadamente $500 \mathrm{~mJ}$ por pulso) percorre a superfície da amostra. Para obter os nanotubos de parede simples, o alvo de grafite é impregnado com material catalítico. O processo acontece da seguinte maneira: o gás inerte arrasta as espécies de carbono produzidas no processo de ablação, que se encontram na região de alta temperatura, para a região onde encontra-se a superfície coletora. As espécies de carbono são depositadas numa superfície coletora resfriada por água. Esquematicamente apresentamos um diagrama da técnica de ablação a laser na figura 1.5.

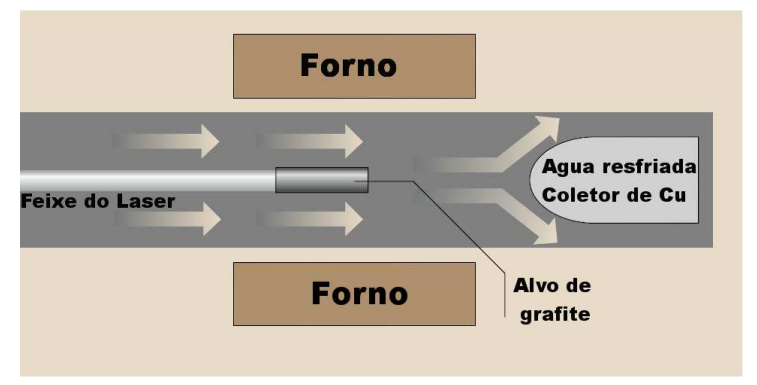

Figura 1.5: Esquema do aparato experimental para da técnica de ablação por laser. Esta figura foi extraída da referência [74].

Essa técnica produz amostras mais puras, comparada com as produzidas pela técnicas de descargas por arco, mas mesmo assim não descarta a necessidade de purificação das amostras. Tipicamente, a ordem de grandeza das amostras produzidas com essa técnica, para nanotubos de parede múltiplas, são: o comprimento dos tubos da ordem de $\mu m\left(L_{z} \geq 0.2 \mu m^{1}\right)$, e cerca de 4 a 25 paredes para os MWCNTs.

Na próxima seção apresentaremos a técnica conhecida com deposição química à vapor $(\mathrm{CVD})$.

\footnotetext{
${ }^{1}$ Consideramos $L_{z}$ como o comprimento do nanotubo
} 


\subsubsection{Deposição química à vapor - CVD}

O método de síntese conhecido por deposição química à vapor é atualmente o processo de crescimento de nanotubos mais promissor no que diz respeito á fabricação em escala industrial. Este fato é atribuído a duas caracterísiticas importantes deste método: o primeiro é o baixo custo (preço/unidade), comparativamente com os outro métodos; e o segundo é devido ao fato de que na CVD os nanotubos podem ser crescidos diretamente sobre o substrato desejado. O método de CVD vem sendo usado desde 1959 para carbono, no entanto somente em 1993 os experimentais conseguiram sintetizar nanotubos com este método. No processo de CVD [74,76] utiliza-se um substrato preparado com uma camada de partículas metálicas catalíticas - em geral é usado $\mathrm{Ni}, \mathrm{Co}$ ou $\mathrm{Fe}$ ou alguma mistura. O diâmetro dos nanotubos que irão crescer estará relacionado com o tipo de partícula do metal que for usado no substrato. No processo de síntese o substrato é aquecido, em geral entre $800-1000^{\circ} \mathrm{C}$ e, para que o processo de síntese se inicie, dois gases são misturados dentro do reator: em geral um gás do tipo hidrogênio, nitrogênio ou amônia e um gás precurssor (metano, acetileno ou etileno). Os gases precursores são quebrados e os átomos seguem para as bordas das partículas metálicas, onde os nanotubos são crescidos. Na figura 1.6-d apresentamos esquematicamente o processo descrito acima.

Existem diferente tipos de CVD, no entanto, como podemos classificar ou distiguir esses processos? A maneira adotada pelos especialistas é considerar a forma de ativação das espécies químicas. Um processo feito num forno, por exemplo, é classificado como termicamente ativado. No caso em que o processo é ativado por plasma, este é conhecido como (PECVD) e este ainda pode ser feito de três maneiras: radiofrequência, corrente direta ou microondas.

As amostras que são crescidas sem o uso do plasma no processo de ativação, produzem, geralmente, nanotubos orientados aleatoriamente. Por outro lado, quando se faz uso do plasma, as amostra podem ser crescidas perpendicularmente ao substrato, 


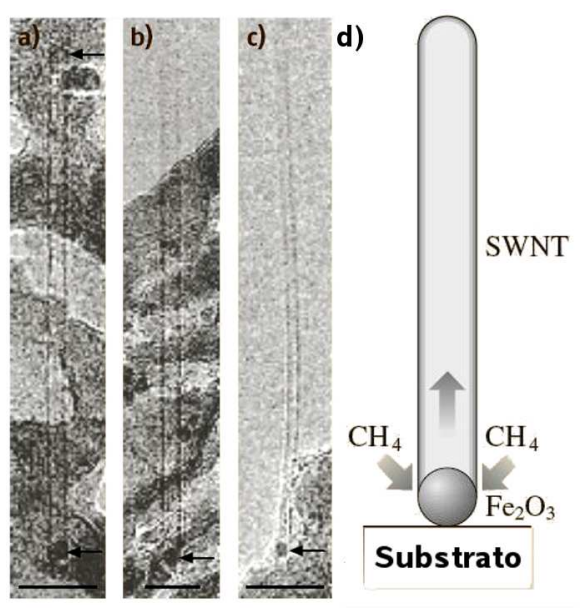

Figura 1.6: Esquema do processo do crescimento de nanotubos através do método de CVD. Em (a), (b) e (c) observamos uma partícula metálica e um nanotubo sendo crescido ao redor dessa partícula; e em (d) um esquema de um processo de crescimento.

apenas ajustando a geometria do reator etc. Isto ocorre porque quando o plasma é gerado, é aplicado um campo elétrico muito forte e os nanotubos acompanham a direção deste campo, no processo de crescimento. Não iremos entrar em maiores detalhes sobre os processos de crescimento de nanotubos de carbono porque este não é o objetivo desta tese, mas é importante destacar que essa área possui várias questões em aberto, e que são assuntos de pesquisa. Questões relacionadas ao processo de purificação, à produção de predeterminadas quiralidades, dos mecanismos microscópicos de crescimento e de como atuam os catalisadores continuam sendo investigadas.

Na próxima seção apresentaremos um modelo atomístico para o grafeno e para os nanotubos de carbono, bem como os principais parâmetro que caracterizam essas estruturas. 


\subsection{Estrutura dos nanomaterias}

Nesta seção apresentaremos a estrutura dos materiais estudados nesta tese. O primeiro material que mostraremos será o grafeno, pois a partir dele é que serão definidos os nanotubos de carbono. Os principais parâmetros, classificações e as representações atomística dos sistemas serão discutidas.

\subsubsection{Estrutura do grafeno}

O grafeno consiste em um plano de átomos de carbono, dispostos de forma hexagonal, numa rede do tipo "favos de mel" (honeycomb). A célula unitária do grafeno é descrita por apenas dois átomos, que poderemos chamar de $A$ e $B$. Na figura 1.7 mostramos a rede direta e o espaço recíproco do grafeno.

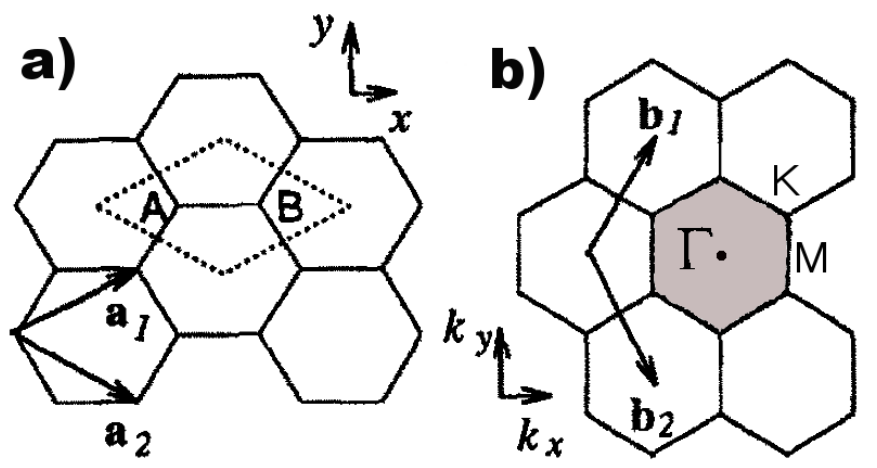

Figura 1.7: Em (a) apresentamos a rede direta de uma estrutura hexagonal; em (b) exibimos o espaço recíproco da mesma rede.

Os vetores que caracterizam a rede direta são $\overrightarrow{a_{1}}=\left(\frac{\sqrt{3} a}{2}, \frac{a}{2}\right)$ e $\overrightarrow{a_{2}}=\left(\frac{\sqrt{3} a}{2},-\frac{a}{2}\right)$, e a constante de rede é definida como $a=d_{c c} \times \sqrt{3} \approx 2.46 \AA$. Os vetores do espaço recíproco são obtidos a partir dos vetores da rede direta $\overrightarrow{a_{i}} \cdot \overrightarrow{b_{j}}=2 \pi \delta_{i j}$. Então, estes vetores podem ser escritos como: $\overrightarrow{b_{1}}=\left(\frac{2 \pi}{\sqrt{3} a}, \frac{2 \pi}{a}\right)$ e $\overrightarrow{b_{2}}=\left(\frac{2 \pi}{\sqrt{3} a},-\frac{2 \pi}{a}\right)$, e a constante de rede no espaço recíproco é $\frac{4 \pi}{\sqrt{3} a}\left[\AA^{-1}\right]$. O grafeno é um material bidimensional e pode ser definido no plano $(x, y)$. A representação dos vetores no espaço recíproco também 
é feita num plano bidimensional, no entanto serão definidos no plano dos vetores $\mathrm{k}$ $\left(k_{x}, k_{y}\right)$. A primeira zona de brillouin é mostrada na figura 1.7-b, e esta consiste no hexágono hachurado. Os últimos pontos importantes a serem destacados no grafeno são seus pontos de alta simetria $(\Gamma, K$ e $M)$. Estes pontos serão de fundamental importância para o entendimento da sua estrutura eletrônica.

Apresentados os parâmetros necessários para descrever o grafeno, partiremos para caracterização dos nanotubos de carbono. Na próxima seção mostramos os principais parâmetros que caracterizam os nanotubos de carbono e classificaremos com relação a quiralidade e a forma em que os tubos podem ser geometricamente dispostos.

\subsubsection{Estrutura dos nanotubos}

Teoricamente o nanotubo de carbono pode ser pensado como uma folha de grafeno enrolada na forma de um cilindro. O referido cilindro não é enrolado de maneira aleatória, e por isso define-se um vetor quiral $\left(\overrightarrow{C_{h}}\right)$. Este vetor quiral caracteriza o nanotubo, e pode ser definido em função dos vetores unitários do grafeno $\left(\overrightarrow{a_{1}} \mathrm{e}\right.$ $\left.\overrightarrow{a_{2}}\right)$, e dois números inteiros $(n, m)$. Sendo assim podemos definir o vetor quiral da seguinte maneira:

$$
\overrightarrow{C_{h}}=n \overrightarrow{a_{1}}+m \overrightarrow{a_{2}}
$$

Para formar o nanotubo desejado basta enrolar o vetor quiral, o que significa conectarmos a origem do vetor com o final do mesmo $(\overrightarrow{0 A})$ na figura 1.8 , definindo assim uma circunferência para o tubo. Então, para obtermos um dado nanotubo, como por exemplo o tubo $(5,5)$, basta deslocamos 5 vezes na direção $\overrightarrow{a_{1}}$, e 5 vezes na direção $\overrightarrow{a_{2}}$, definindo assim o vetor quiral $\left(\overrightarrow{C_{h}^{(5,5)}}=5 \cdot \overrightarrow{a_{1}}+5 \cdot \overrightarrow{a_{2}}\right)$. Na figura 1.8 mostramos o vetor quiral e o vetor de translação do nanotubo em uma folha de grafeno. 


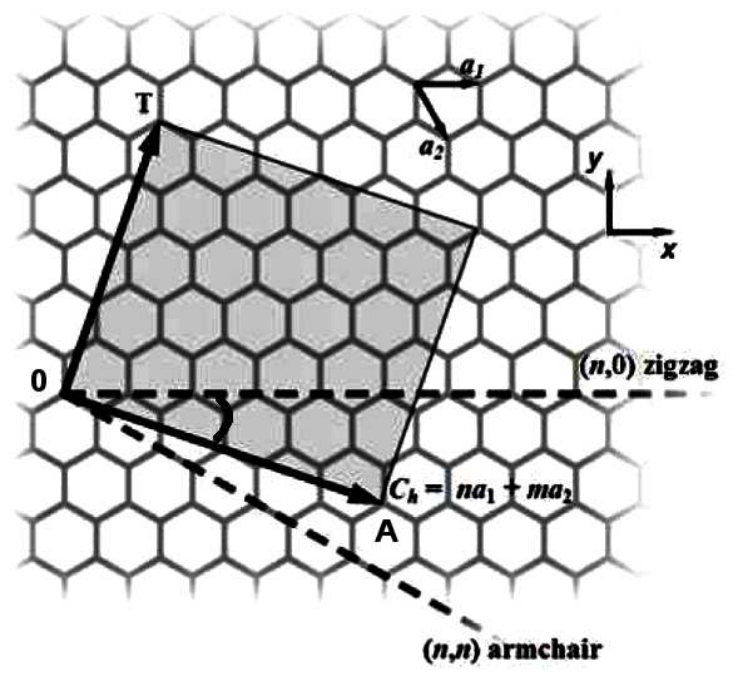

Figura 1.8: Representação esquemática de um grafeno. Observamos os vetores primitivos do grafeno $\left(\vec{a}_{1}\right.$ e $\left.\vec{a}_{2}\right)$, vetor quiral $\left(\vec{C}_{h}\right)$ e o vetor de translação $(\vec{T})$.

Os nanotubos de carbono podem ser classificados com relação à quiralidade, e para isto basta conhecer os números inteiros $n$ e $m$. Esses números definem a forma com que o vetor é enrolado. Existem basicamente dois tipos de nanotubos de carbono: os quirais e os aquirais. Os nanotubos quirais são definidos por dois números inteiros, diferentes entre si, e não nulos $(n \neq m \neq 0)$. No caso dos nanotubos aquirais, eles podem ser classificados em dois tipos: os armchair - quando o índices são iguais e não nulos $(m=n)$, e os nanotubos zigzag, quando os nanotubos possuem o índice $n$ qualquer e não nulo, e o índice $m$ necessariamente nulo $(n \neq m=0)$. Os nanotubos armchair e zigzag ganharam esses nomes devido às suas terminações: o primeiro tem a terminação no formato de poltrona, e o segundo, zigzag. Na figura 1.9 apresentamos a geometria dos tipos de nanotubos classificados acima.

Uma vez obtido o vetor quiral, vamos definir outros parâmetros em função deste. 


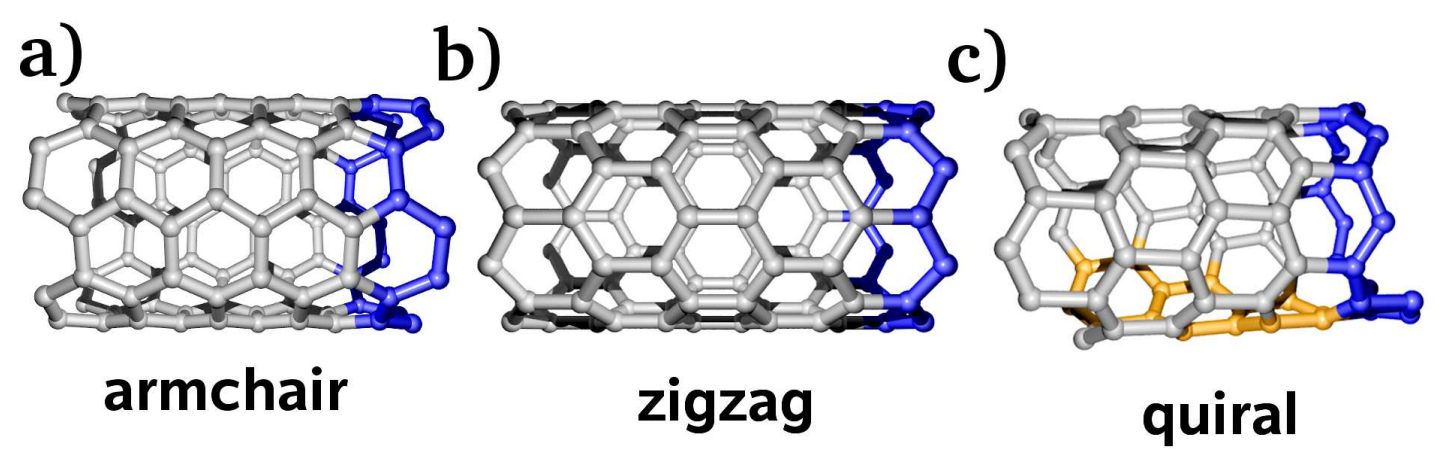

Figura 1.9: Representação atomística dos nanotubos. Em (a) apresentamos um nanotubo aquiral armchair; Em (b) mostramos um nanotubo aquiral zigzag e em (c) exibimos um nanotubo quiral.

O diâmetro do nanotubo $\left(d_{t}\right)$ pode ser definido da seguinte maneira:

$$
d_{t}=\frac{L}{\pi}=\frac{a}{\pi} \sqrt{n^{2}+m n+m^{2}}
$$

onde L é comprimento da circunferência $\left(L=\left|\vec{C}_{h}\right|=\sqrt{\vec{C}_{h} \cdot \vec{C}_{h}}\right)$. Para um nanotubo $(10,10)$, usando a equação 1.2 , obtemos um diâmetro de $13.73 \AA$. Os diâmetros típicos dos CNT são entre 0.7 - $10 \mathrm{~nm}$ e algumas centenas de $\mu m$ de comprimento, e a razão entre o comprimento e o diâmetro é da ordem de $10^{4}-10^{5}$. Ainda precisamos definir duas grandezas apresentadas na figura 1.8, sendo que a primeira consiste no ângulo quiral $\theta$, que consiste no ângulo entre a direção zigzag do grafeno $\left(\overrightarrow{a_{1}}\right)$ e o vetor quiral $\left(\vec{C}_{h}\right)$. Este ângulo pode assumir valores entre $0 \leq \theta \leq 30^{\circ}$, devido à simetria hexagonal da rede do grafeno. O produto interno entre $\vec{C}_{h}$ e $\overrightarrow{a_{1}}$ é que define o ângulo quiral:

$$
\cos \theta=\frac{\vec{C}_{h} \cdot \overrightarrow{a_{1}}}{\left|\vec{C}_{h}\right|\left|\overrightarrow{a_{1}}\right|}=\frac{2 n+m}{2 \sqrt{n^{2}+m n+m^{2}}}
$$

Antes de definir o vetor de translação $\vec{T}$, vamos analisar os valores que este ângulo 
pode assumir de acordo com a classificação apresentada anteriormente. Todos os nanotubos zigzag $(n, 0)$, possuem um ângulo quiral de $\theta=0^{\circ}$. No caso dos nanotubos armchair $(n, n)$, o ângulo quiral assume o valor de $30^{\circ}$. Para os nanotubos do tipo quirais $(n, m)$, o ângulo quiral pode assumir valores no intervalo $0<\theta<30^{0}$.

O vetor de translação $(\vec{T})$, como pode ser visto na figura 1.8 , está disposto perpendicularmente ao vetor quiral. Este vetor define o período $(t)$ do nanotubo ao longo do seu eixo, e também é definido em função dos vetores unitários $\overrightarrow{a_{1}}$ e $\overrightarrow{a_{2}}$.

$$
\vec{T}=t_{1} \overrightarrow{a_{1}}+t_{2} \overrightarrow{a_{2}}
$$

e para obter os números $t_{1}$ e $t_{2}$, usaremos o produto escalar entre $\vec{C}_{h} \cdot \vec{T}=0$. Sendo assim, obtemos $t_{1}=\frac{2 m+n}{N_{R}}$ e $t_{2}=-\frac{2 n+m}{N_{R}}$, onde $N_{R}$ é o máximo divisor comum entre dois números inteiros $(2 m+n, 2 n+m)$. O comprimento do vetor translacional $t$ é dado por:

$$
t=|\vec{T}|=\frac{\sqrt{3} a \sqrt{n^{2}+n m+m^{2}}}{N_{R}}=\frac{\sqrt{3} L}{N_{R}} .
$$

A última grandeza que vamos definir consiste no número de hexágonos por célula unitária $N$, e esta variável depende dos índice $n$ e $m$ da seguinte maneira:

$$
N=\frac{\left|\vec{C}_{h} \times \vec{T}\right|}{\left|\overrightarrow{a_{1}} \times \overrightarrow{a_{2}}\right|}=\frac{2\left(n^{2}+m^{2}+n m\right)}{N_{R}}=\frac{2 L^{2}}{a^{2} N_{R}}
$$

ou seja, a área da célula unitária dividida pela área de um hexágono definem o número de hexágonos. A última classificação desta seção é no tipo de disposição dos nanotubos. Como já foi mostrado, os nanotubos podem ser apresentamos na forma de uma única parede, ou nanotubos de parede simples (SWCNT); a segunda forma consiste nos nanotubos de múltiplas paredes (MWCNT); e finalmente os nanotubos podem ser dispostos na forma de feixes (bundles). Na figura 1.10 mostramos as três formas em que os nanotubo podem ser obtidos. 


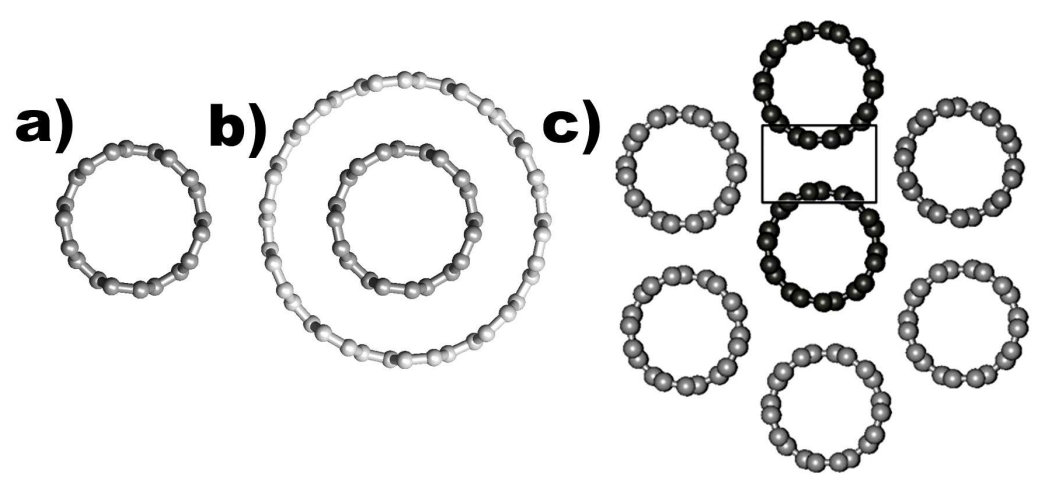

Figura 1.10: Representação atomística dos nanotubos. Em (a) apresentamos um nanotubo de parede simples; Em (b) mostramos o nanotubo de parede dupla e em (c) um feixe de nanotubos.

Definimos os principais parâmetros que caracterizam o grafeno e os nanotubos e também classificamos os nanotubos de acordo com sua quiralidade e seu arranjo. Na próxima seção apresentaremos a estrutura eletrônica do grafeno e a partir dela obteremos a estrutura eletrônica dos nanotubos. Para isso, faremos uma modelagem tight-binding considerando somente os orbitais $p_{z}$ para o grafeno. Mostraremos resultados para a relação de dispersão obtidas com este método.

\subsection{Estrutura eletrônica do grafeno e do nano- tubo}

Esta seção é dedicada ao estudo da estrutura eletrônica dos sistemas de interesse desta tese. Para este fim, aplicaremos o método tight-binding (TB), sem discutirmos as parametrizações, para o grafeno e posteriormente para nanotubos. Um desenvolvimento detalhado do método é apresentado no apêndice B. 


\subsubsection{Estrutura eletrônica do grafeno}

Pretendemos apresentar uma aplicação do método TB de maneira simplificada, utilizando a aproximação de Hückel. É importante salientar que apesar de estarmos fazendo simplicações para obter a estrutura eletrônica do grafeno, este método nos fornece resultados qualitativamente corretos no que diz respeito às propriedades eletrônicas.

Vamos voltar à estrutura do grafeno, apresentada na figura 1.7, com dois átomos na célula unitária $(A$ e $B)$. Faremos algumas suposições antes de apresentar a estrutura eletrônica do grafeno. A primeira consiste em considerar apenas interações com os primeiros vizinhos. Vamos supor também que possuimos somente um orbital por sítio $\left(2 p_{z}\right)$. Então, utilizando o método tight-binding (mostrado no apêndice B), com as considerações descritas acima, a relação de dispersão do grafeno pode ser escrita da seguinte maneira:

$$
\varepsilon\left(k_{x}, k_{y}\right)=\alpha \pm \beta \sqrt{1+4 \cos \left(\frac{a \sqrt{3}}{2} k_{x}\right) \cos \left(\frac{a}{2} k_{y}\right)+4 \cos ^{2}\left(\frac{a}{2} k_{y}\right)},
$$

e onde o termo $\alpha$ é diagonal $H_{\mu \mu}$ (ver apêndice B) e considerado o mesmo para todos os átomos envolvidos $\left(H_{\mu \mu}=\alpha\right)$, o que representa a energia do elétron ligado ao sítio onde está localizado o orbital $\mu$, devido a presença dos outros centros atômicos, e o termo $\beta$ é conhecido como termo de hopping. Na figura 1.11 mostramos a relação de dispersão de energia para o grafeno.

Como já foi mencionado, o grafeno possui dois átomos por célula unitária. Cada átomo contribui com um elétron proveniente de $2 p_{z}$. Observamos que no ponto $K$, a banda de valência toca a banda de condução, resultando na degenerescência da energia. Este fato indica que o grafeno é um sistema de gap zero. É importante observar que os vetores de onda do grafeno $\left(k_{x}\right.$ e $\left.k_{y}\right)$, podem assumir qualquer valor dentro da primeira zona de Brillouin, não havendo restrições impostas sobre eles. 

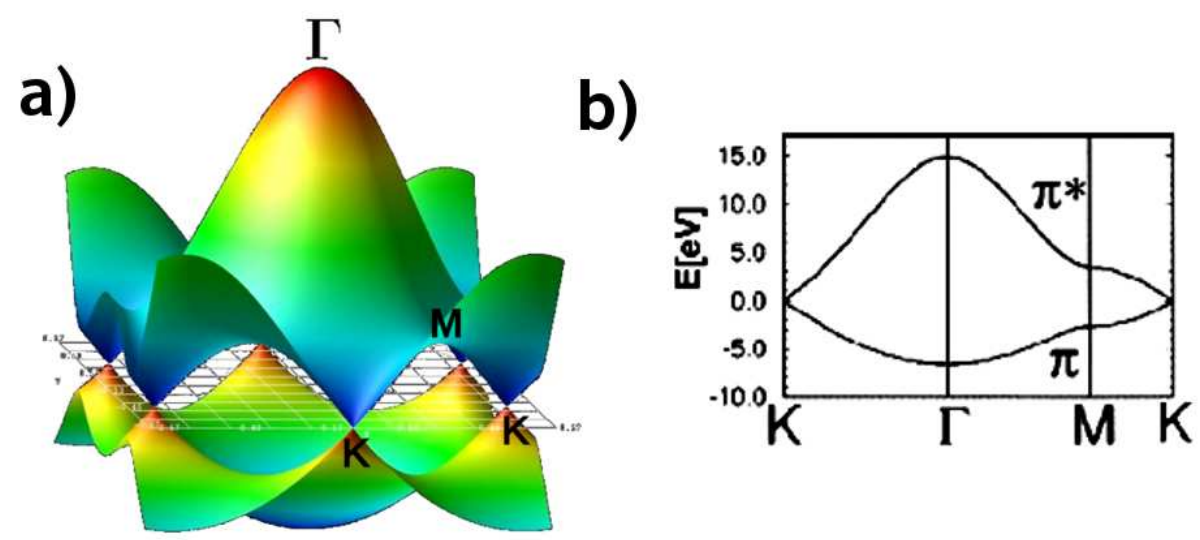

Figura 1.11: Gráfico da energia em função dos vetores de onda. Em (a) mostramos a superfície de energia em função dos vetores de onda do grafeno e seus pontos de alta simetria ( $\Gamma, M$ e $K$ ); Em (b) mostramos as bandas $\pi$ e $\pi^{*}$ do grafeno ao longo das direções de alta simetria.

Isto será evocado na próxima seção quando analisaremos a estrutura eletrônica dos nanotubos de carbono a partir do grafeno.

\subsubsection{Estrutura eletrônica do nanotubo de carbono}

Na seção sobre a estrutura dos nanotubos de carbono, apresentamos um modelo teórico para obter o CNT a partir de um grafeno. Este procedimento consistiu em enrolar o grafeno através do vetor quiral $\left(\vec{C}_{h}\right)$. Uma pergunta surge naturalmente quando isso é feito. O que ocorre na estrutura eletrônica do grafeno quando ele é enrolado? Desta forma, vamos partir da estrutura eletrônica do grafeno para obtermos a dos nanotubos. Como mostrado na seção anterior, o grafeno é um sistema metálico, pois nos seis vértices do hexágono (pontos $K$ da primeira zona de Brillouin), a banda de valência toca a banda de condução. Ao enrolar o grafeno, os vetores de onda que outrora eram todos permitidos, sofrerão restrições e apenas alguns serão aceitos. O ato de enrolar o grafeno faz com que dois novos vetores sejam importantes: os vetores de onda k perpendiculares $\left(k_{\perp}\right)$, na direção da circu- 
fenrência dos nanotubos; e os vetores k paralelos $\left(k_{\|}\right)$, que se encontram na direção do eixo do nanotubo. A consequência de enrolar o grafeno é que os vetores $k_{\perp}$ serão quantizados, e nesta direção somente alguns valores desses k serão permitidos. Na figura 1.12 mostramos um nanotubo com a direção do novos vetores.

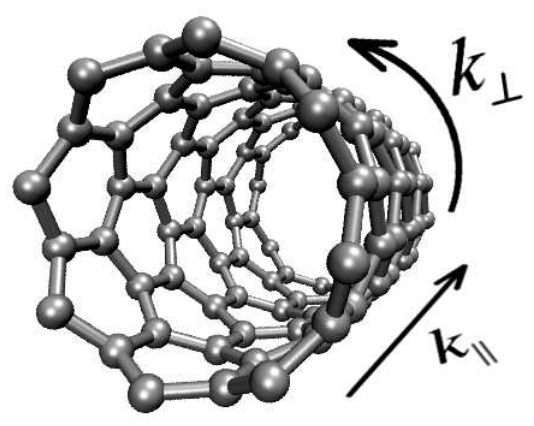

Figura 1.12: Representação de um nanotubo com os novos vetores de onda $k_{\perp}$ e $k_{\|}$.

Para entender o que acontece quando dobramos o grafeno, vamos analisar a região onde a banda de valência toca a banda de condução, isto é, os vértices do hexágono no espaço recíproco. Os valores permitidos do vetor de onda dependerão do modo como o vetor quiral será enrolado, ou seja, como será a condição de quantização do vetor $k_{\perp}$. Na figura 1.13 mostramos um esquema dos vetores de onda permitidos.

As linhas que cortam o hexágono na figura 1.13-a correspondem aos valores permitidos para os k's. As linhas ou parábolas que passam pelos cones podem cruzar o ponto de alta simetria ou não. Para determinar se o nanotubo é metal ou semicondutor, basta analisar o ponto K. Se o vetor $\vec{k}_{\perp}$ permitido passar pelo ponto K (figura 1.13-b), os nanotubos que apresentarem esse comportamento serão metálicos; caso contrário (figura 1.13-c) os nanotubos serão semicondutores.

Depois dessa discussão sobre os vetores de onda quantizados na direção perpendicular ao eixo do nanotubo, faremos uma análise matemática das condições de periodicidade. Para isto, vamos definir os vetores da rede recíproca $\vec{k}_{\perp}$ e $\vec{k}_{\|}$, na direção da circunferência do nanotubo e ao longo do eixo do nanotubo, respec- 

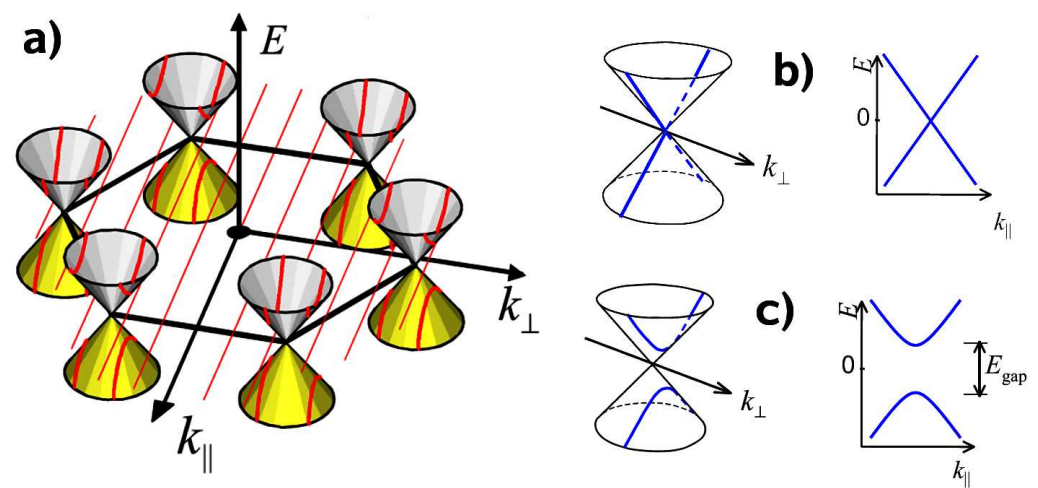

Figura 1.13: a) Mostramos os seis vértices do hexágono do espaço recíproco, e as linhas na superfícies dos cones correspondem aos k's permitidos; Se essas linhas tocam ao pontos de simetria $K$, este sistema será metálico (b); caso contrário (c) o nanotubo será semicondutor.

tivamente. Podemos escrever o produto escalar $\vec{R}_{i} \cdot \vec{K}_{j}=2 \pi \delta_{i j}$, e usando o fato de:

$$
\begin{array}{ll}
\vec{C}_{h} \cdot \vec{k}_{\perp}=2 \pi & T \cdot \vec{k}_{\perp}=0 \\
\vec{C}_{h} \cdot \vec{k}_{\|}=0 & T \cdot \vec{k}_{\|}=2 \pi,
\end{array}
$$

podemos escrever os vetores $\vec{k}_{\perp}$ e $\vec{k}_{\|}$em função dos vetores unitários da rede recíproca:

$$
\begin{aligned}
\vec{k}_{\perp} & =\frac{1}{N}\left(-t_{2} \overrightarrow{b_{1}}+t_{1} \overrightarrow{b_{2}}\right) \\
\vec{k}_{\|} & =\frac{1}{N}\left(m \overrightarrow{b_{1}}-n \overrightarrow{b_{2}}\right)
\end{aligned}
$$

onde $N$ é o número de hexágonos por célula unitária, definido previamente.

Para determinar a estrutura eletrônica dos nanotubos, partiremos da relação B.25 do apêndice B. Usando o fato de que nanotubo é uma folha de grafeno enrolada, com a circunferência deste sendo o vetor quiral, os vetores de onda na direção da 
circunferência são quantizados em um número finito de estados $\mathrm{k}$, enquanto o vetor $\vec{k}$ associado ao vetor de translação, ao longo do eixo do nanotubo, permanece contínuo. Sendo assim, podemos escrever:

$$
\varepsilon_{p}^{t u b o}(k)=\varepsilon^{\text {grafeno }}\left(k \frac{\overrightarrow{K_{\|}}}{\left|\overrightarrow{K_{\|}}\right|}+p \overrightarrow{K_{\perp}}\right),
$$

onde $p=1,2, . ., N-1$ e $\frac{\pi}{T}<k<\frac{\pi}{T}$.

O primeiro exemplo que iremos considerar é quando $n=m$ (CNT armchair). Para garantir a periodicidade do nanotubo teremos:

$$
\vec{C}_{h} \cdot \vec{k}=2 \pi q
$$

e $q$ é, neste caso, um número inteiro, sendo $\vec{k}$ um vetor do grafeno na primeira zona de Brillouin. Logo, o comprimento da circunferência $L=\left|\vec{C}_{h}\right|=\sqrt{\vec{C}_{h} \cdot \vec{C}_{h}}=$ $\sqrt{n^{2}+m^{2}+m n}$, para o caso dos nanotubos armchair, será dado por:

$$
L=a \sqrt{3} n
$$

o que nos leva à seguinte relação:

$$
a \sqrt{3} n k_{x}=2 \pi q
$$

e, se substituirmos a relação 1.13 na equação B.25, obtemos uma relação de dispersão para os nanotubos armchair.

$$
\varepsilon_{q}^{n, n}(k)=\alpha \pm \beta \sqrt{1+4 \cos \left(\frac{q \pi}{n}\right) \cos \left(\frac{k a}{2}\right)+4 \cos ^{2}\left(\frac{k a}{2}\right)},
$$

$\operatorname{com} \frac{-\pi}{a}<k<\frac{\pi}{a}$ e $q=1,2, \ldots, 2 n$. Para um nanotubo $(5,5)$, teremos a seguinte relação de dispersão: 


$$
\varepsilon_{q}^{5,5}(k)=\alpha \pm \beta \sqrt{1+4 \cos \left(\frac{q \pi}{5}\right) \cos \left(\frac{k a}{2}\right)+4 \cos ^{2}\left(\frac{k a}{2}\right)} .
$$

A estrutura eletrônica do nanotubo $(5,5)$ é apresentada na figura 1.14.

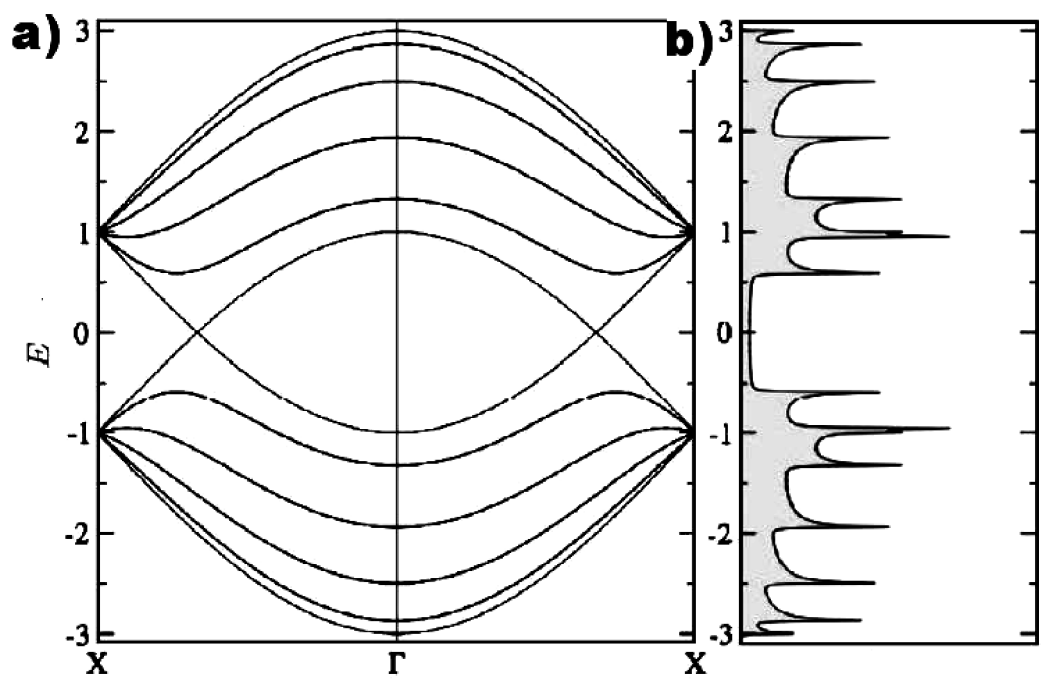

Figura 1.14: Em (a) mostramos a estrutura de bandas do nanotubo (5,5); em (b) mostramos a densidade de estados do mesmo nanotubo.

Observamos, na figura 1.14-a, seis bandas de condução e o mesmo número de bandas de valência. Existem quatro bandas degeneradas em cada caso, totalizando dez bandas de valência e dez de condução. Este resultado é consistente com os dez hexágonos ao longo da circunferência e vinte átomos por célula unitária do nanotubo $(5,5)$. Os nanotubos metálicos exibem uma grande degenerescência no ponto $X\left(k=\frac{\pi}{a}\right)$, e as bandas se cruzam aproximadamente a $\frac{2}{3}$ do segmento $\Gamma X$.

E na figura 1.14-b mostramos a densidade de estados (DOS) $\Delta N / \Delta E$ do nanotubo $(5,5)$, que representa o número de estados disponíveis $\Delta N$ em um determinado intervalo de energia $\Delta E(\Delta E \longrightarrow 0)$. A forma da DOS depende da dimensionalidade do material em questão e, para materiais unidimensionais, a DOS diverge, para algumas energias, com o inverso da raiz quadrada da energia $\left(\frac{1}{\sqrt{E}}\right)$. Na figura 
1.14-b mostramos tais singularidades conhecidas como singularidades de Van Hove.

Para nanotubos zigzag $(n, 0)$, a relação de dispersão é obtida da mesma maneira que a dos CNT armchair, entretanto, a condição de periodicidade agora será:

$$
n k_{y} a=2 \pi q, \quad q=1, . ., 2 n .
$$

Então, se substituirmos a equação 1.16 na B.25, obtemos a relação de dispersão para os nanotubos zigzag.

$$
\varepsilon_{q}^{n, 0}(k)=\alpha \pm \beta \sqrt{1+4 \cos \left(\frac{\sqrt{3} k a}{2}\right) \cos \left(\frac{q \pi}{n}\right)+4 \cos ^{2}\left(\frac{q \pi}{n}\right)} .
$$

onde $q=1, . ., 2 n$ corresponde à parte do vetor de onda discreta, e a parte contínua é dada por $-\frac{\pi}{\sqrt{3}}<k<\frac{\pi}{\sqrt{3}}$.

\subsection{Propriedades mecânicas}

Os nanotubos de carbono são materiais com propriedades mecânicas bem interessantes. Podemos notar essas características quando comparamos suas propriedades com as do aço, por exemplo: notamos que os CNTs são mais resistentes por um fator de vinte e seis vezes mais leves. No entanto, quais são as propriedades mecânicas que fazem dos nanotubos materiais tão especiais e promissores? O nanotubo de parede simples possui um módulo de Young da ordem de 1.0 TPa [5], um failure stress da ordem de $100 \mathrm{GPa}$ e um failure strain da ondem de 11\% [65]. Essas propriedades mecânicas bem pronunciadas são decorrentes do arranjo estrutural perfeito dos seus átomos de carbono, e também pela força de interação entre estes átomos. Como foi dito na introdução, os nanotubos vêm sendo aplicados na produção de cabos de alta resistência e também como reforço em matriz de compósitos. Na literatura encontramos alguns trabalhos experimentais sobre propriedades mecânicas de nanotubos 
de carbono, no entanto existem dificuldades para realização dos experimentos. Este fato pode acarretar uma discrepância dos resultados. Para termos uma idéia do que estamos comentando, em um dos primeiros experimentos para medir o módulo elástico [77] de nanotubos de parede múltipla, foram obtidos valores para esta propriedade na faixa de $0.4-4.15 \mathrm{TPa}$, e um valor médio de $1.81 \mathrm{TPa}$. Esta medida possui um desvio padrão extremamente grande. Este fato é atribuido à dificuldade das medidas experimentais bem como do procedimento utilizado. Para uniformizar a linguagem, vamos apresentar uma série de ensaios mecânicos que podem ser realizados. Na figura 1.15 mostramos os tipos de ensaios mecânicos que podem ser feitos para nanotubos de carbono.
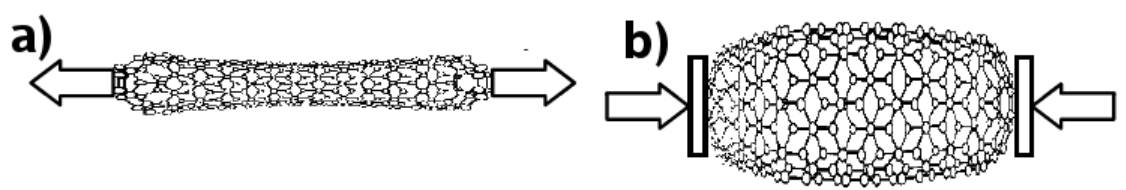

c)
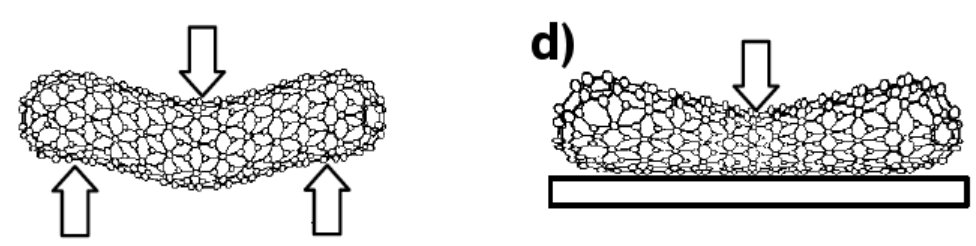

e)

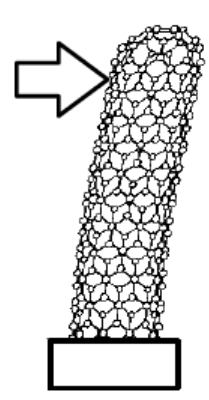

f)

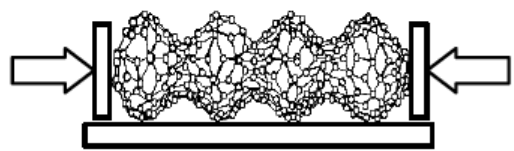

Figura 1.15: Apresentamos os tipos de caracterizações das propriedades mecânicas para nanotubos. (a) strain axial; (b) compressão axial (diameter buckling); (c) flexão simétrica (bending symmetrical); (d) compressão radial; (e) flexão elástica (elastic deviation) e (f) deformação de Euler. A presente figura foi extraída da referência [78]. 
O principal parâmetro que caracteriza a ruptura (figura 1.15-a) é o módulo de Young longitudinal $E$, definido da seguinte maneira:

$$
E=\frac{\sigma}{\epsilon}=\frac{N}{2 \pi R h \epsilon}
$$

onde $\sigma$ representa a tensão (stress) longitudinal, $N$ é a força aplicada a área da seção transversa, $\epsilon$ é a tensão relativa (associada à mudança de comprimento) do nanotubo devido a ação da força, $R$ é o raio do nanotubo e o $h$ coresponde à espessura da parede. Uma outra propriedade importante dos nanotubos é o chamado coeficiente de Poisson $(\nu)$, que é definido como a razão entre a compressão transversal relativa $\epsilon^{\prime}$ e a tensão longitudinal relativa $\epsilon$ :

$$
\nu=\frac{\epsilon^{\prime}}{\epsilon} .
$$

Uma força compressiva muito grande resulta em uma mudança brusca na estrutura da parede do nanotubo (figura 1.15-f), e a forma dessa compressão, acompanhada de uma mudança estrutural, é conhecida como "deformação de Euler" e tem um caráter de instabilidade. O módulo elástico correspondente à deformação lateral - flexão (bending), (figura 1.15-d-f), pode ser escrito em função do módulo de Young $E$ e do coeficiente de Poisson $\nu$. A rigidez de flexão de um cilindro oco é dada pela seguinte relação:

$$
D=\frac{E h^{3}}{12\left(1-\nu^{2}\right)}
$$

O último parâmetro que queremos comentar consiste na capacidade de um cilindro de resistir a uma tensão lateral. Essa quantidade é definida por:

$$
C=E h \text {. }
$$

As propriedades mecânicas descritas acima são referentes aos nanotubos de pa- 
rede simples. No entanto, do ponto de vista de aplicação, tanto em cabos de alta performace quanto em reforço em matriz de compósitos, são usados nanotubos na forma de feixes e nanotudos de paredes múltiplas. Em ambos os casos, quando estes nanotubos estão na sua forma sem defeitos, as propriedades mecânicas são degradadas devido à possibilidade dos tubos deslizar um contra os outros, dificultando eventuais aplicações. Como foi extensivamente comentado na introdução, uma maneira para melhorar as propriedades mecânicas é através de interconexões entre as paredes dos nanotubos. Ao criar conexões entre as paredes destes sistemas é interessante estudar propriedades que, de certa forma, consigam quantificar essa degradação mecânica provocada pelo deslizamento de um tubo em relação a outro, por exemplo. Uma propriedade interessante que será investigada é o módulo de cisalhamento (shear moduli), que consiste numa tensão resultante de forças aplicadas em nanotubos adjacentes. Estas forças causam ou têm a tendência de causar um deslizamento paralelo entre dois tubos vizinhos. Nos capítulos sobre propriedades mecânicas mostraremos esta propriedade para nanotubos de paredes múltiplas e para feixes. Um outro ponto importante que merece destaque consiste na transferência de tensão entre dois tubos através de conexões. Na literatura essa grandeza é conhecida como transferência de tensão (LT) (load transfer). Essa grandeza mede a eficiência da conexão, uma vez que existe uma valor máximo de tensão que pode ser transferida. A transferência de tensão é definida com a razão entre a força interna pela força externa dos nanotubos MWCNT. Para nanotubos de parede múltipla faremos um estudo mostrando como caracterizar esta propriedade.

Na próxima seção falaremos de algumas aplicações dos nanotubos de carbono baseadas em suas propriedades. 


\subsection{Aplicações}

O nanotubo de carbono, em todas as suas possíveis formas, é um material muito promissor do ponto de vista de aplicações. Este fato é devido à conjunção de diversas propriedades num mesmo material. Na introdução e neste capítulo mencionamos algumas das aplicações que os nanotubos podem ter, e nesta seção vamos ampliar esta discussão.

Do ponto de vista de aplicações em nanoeletrônica, o nanotubo é um dos principais candidatos à substituição do silício em transistores. Como mencionamos na seção de estrutura eletrônica, os nanotubos podem ser metais ou semicondutores dependendo da sua quiralidade. Nas atuais arquiteturas dos microprocessadores ${ }^{2}$, um chip possui cerca de um bilhão de transistores, e mais ainda, a camada isolante entre a porta (gate) e o silício é de apenas três planos atômicos. A diminuição desta camada está praticamente no limite e, segundo a lei de Moore, o número de transistores baseados em silício deve saturar em 2016. Em 1998 pesquisadores [9, 10,79] mostraram que é possível fazer um transistor com nanotubos. Os autores [79] fabricaram um transistor com nanotubos de carbono de parede simples e também com nanotubo de paredes múltiplas. Aplicando uma voltagem de gate eles conseguiram variar a condutância por até cinco ordens de magnitude. Neste trabalho eles mostraram que os nanotubos de paredes múltiplas não apresentam essa característica, mas acredita-se que defeitos estruturais possam modificar essas propriedades. Existe um universo de questões sobre este tipo de aplicação, por exemplo: como seriam as conexões entre os transistores? No entanto esse trabalho foi um marco zero nesse tipo de aplicação.

Os nanotubos possuem estruturas perfeitas e podem ser usados como antena, emissor de elétrons ou ponta de microscópios [73]. Em ferramentas de diagnósticos, como por exemplo raio-x, os nanotubos podem ser aplicados como um tubo de raio-X

\footnotetext{
${ }^{2}$ Nos dias atuais os microprocessadores produzidos são da ordem de $45 \mathrm{~nm}$.
} 
emissor de campo em miniatura [73].

Aplicações na área de nanosensores $[14,15,80]$ vêm sendo extensivamente estudadas, pois ele é um material com uma área específica muito grande (razão da área pelo volume). Este fato possibilita a estocagem de gases e isso, aliado as suas propriedades elétricas, os tornam candidatos em potencial para esse tipo de aplicação.

Os nanotubos vêm sendo aplicados como reforço em materiais compósitos [57, $58,73]$ para melhorar as propriedeades mecânicas desses materiais. Em aplicações mecânicas existem trabalhos experimentais onde os autores fizeram um tecido com nanotubos, e também cabos de alta performace [6-8].

As propriedades óticas dos nanotubos também merecem destaque. Os nanotubos podem ser aplicados como marcadores pois são materiais luminescentes. O nanotubo é um material de gap direto o que também serve tanto como gerador quanto receptor de luz. A empresa Samsung fez um display de LCD com nanotubos de carbono e em breve teremos televisores com essa tecnologia.

No próximo capítulo apresentaremos nossos primeiros resultados acerca dos defeitos em nanotubos de parede simples. Discutiremos a estabilidade energética de quatro defeitos estruturais e também investigaremos o comportamento da energia de formação em função do diâmetro do nanotubo. 


\section{Capítulo 2}

\section{Defeitos em CNT de parede simples}

No capítulo anterior apresentamos as propriedades de nanotubos de parede simples (SWCNT) na sua forma pristina, sem defeitos estruturais. Como é sabido, nem sempre os nanotubos se apresentam sem imperfeições estruturais, podendo conter defeitos em sua parede. Basicamente, os defeitos estruturais podem ser gerados de duas formas distintas: a primeira maneira consiste no processo de síntese (dependendo do método de crescimento as amostras podem possuir defeitos estruturais $[66,73,74])$; a segunda forma é através de irradiação de íons, como as descritas na introdução. No entanto, para escolha de bons candidatos para nosso estudo, vamos recorrer a alguns trabalhos da literatura. Do ponto de vista teórico, simulações empíricas de dinâmica molecular $[41,81]$ mostram que, ao incidir um feixe de íons de alguns $\mathrm{KeV}$, perpendicularmente à parede dos nanotubos de carbono, os produtos finais desses impactos são basicamente átomos intersticiais, rotação de ligações químicas, monovacâncias e divacâncias. Os autores observaram uma abundância de monovacâncias e divacâncias na maioria dos impactos realizados. Experimentalmente existem alguns trabalhos onde os autores $[36,37,82]$ tentam caracterizar esses defeitos. Nos 
trabalhos $[36,82]$, os autores mostram imagens de microscopia eletrônica de transmissão de alta resolução (HR-TEM), onde um estudo sobre defeitos estruturais em grafeno é realizado, onde eles mostraram os prováveis defeitos após processos de irradiação (monovacâncias, divacâncias e átomo adsorvido) e, no trabalho [37], são apresentados os mesmos defeitos observados em grafeno nas paredes dos nanotubos. Na figura 2.1 mostramos alguns defeitos obtidos pelos experimentais [36, 82] em grafeno.

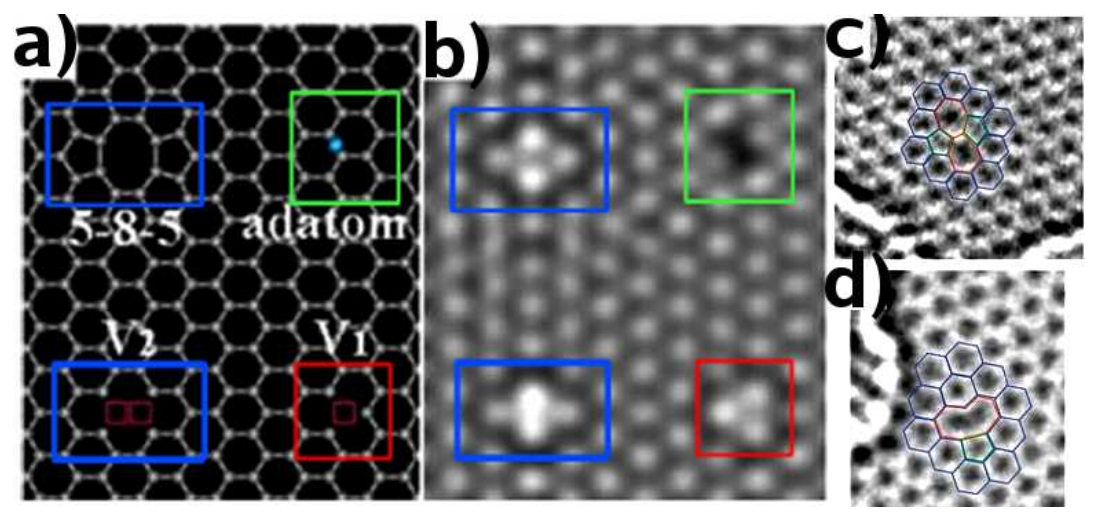

Figura 2.1: Mostramos imagens de microscopia eletrônica de transmissão de alta definição (HR-TEM) em grafeno. Em (a) apresentamos uma representação atomistica dos defeitos mostrados em (b); (b) (HR-TEM) dos defeitos: átomo adsorvido (adatom) - em verde, monovacância (vermelho) e divacâncias (azul); (c) (HR-TEM) do defeito Stone-Wales; e (d) (HR-TEM) da monovacância.

Podemos observar nas figuras 2.1-b, 2.1-c e 2.1-d os defeitos estruturais gerados nas paredes do grafeno após um processo de irradiação que, neste caso, são os mesmos defeitos gerados em impactos de íons em nanotubo de carbono (trabalhos teóricos utilizando dinâmica molecular). Segundo os autores, e tendo a figura 2.1-a como guia, o defeito apresentado em verde consite em um átomo adsorvido, em vermelho é mostrada uma monovacância, e em azul divacâncias. Nas figuras 2.1-c e 2.1-d são apresentados os defeitos Stone-Wales e a monovacância, respectivamente.

Neste capítulo estudaremos os nanotubos de parede simples com diferentes de- 
feitos estruturais, onde o ponto de partida serão as imperfeições mostradas previamente. Queremos responder questões associadas a estes defeitos estruturais. Como é a estabilidade energética, em nanotubos armchair e zigzag, desses defeitos estuturais? Qual é a sequência de estabilidade desses defeitos? Como a energia de formação se comporta em função do diâmetro? Comparado com o grafeno, a sequência de energia para tais defeitos é a mesma?

Para responder a essas questões, faremos um estudo sistemático para quatro defeitos em nanotubos de parede simples. Antes de apresentar os resultados, na próxima seção falaremos sobre o protocolo de simulação e, posteriormente partiremos para os nossos resultados.

\subsection{Protocolo de simulação}

Nesta seção todos os resultados foram obtidos com a teoria de primeiros princípios de energia total - teoria do funcional da densidade (DFT) [83, 84], implementada no código VASP $[85,86]$. Utilizamos os pseudopotencias ultrasuaves de Vanderbilt [87] e, para a energia de correlação e troca, usamos a aproximação generalizada dos gradientes (GGA). Maiores detalhes sobre a metodologia empregada nesta tese encontram-se no apêndice A. A supercélula utilizada foi de aproximadamente $12 \AA$ e a distância utilizada entre as imagens dos nanotubos foi de aproximadamente 15 A. A energia de corte utilizada foi de $250 \mathrm{eV}$ e as optimizações das geometrias foram procedidas até que as componentes da força, em cada átomo, fossem menores que $0.02 \mathrm{eV} / \AA$. A escolha dessa teoria se baseia no fato de que estamos interessandos no estudo de defeitos estruturais e, neste caso, tais processos possuem recombinações de ligações químicas, rehibridizações e quebra de ligação, que metodologias empíricas não descrevem tais situação. Sendo assim, um estudo completamente quântico se faz necessário para descrição dos defeitos em nanotubos de carbono. 


\subsection{Defeitos}

Nesta seção apresentaremos quatro defeitos em nanotubos de parede simples, mas antes de descrevê-los, os classificaremos de acordo com o número de vacâncias. A primeira classe consiste nos defeitos que não possuem vacâncias, mas sua rede é distorcida através de uma rotação da ligação química, e o defeito que estudaremos desta classe é conhecido como Stone-Wales [17-21]. A segunda classe, por sua vez, é caracterizada pela falta de um único átomo, e este defeito é conhecido na literatura como monovacância [22-26]. E por fim, a terceira classe de defeitos é caracterizada pela falta de dois átomos ou divacâncias [27-30] e, para esta última classe, foram investigados dois tipos destes defeitos: 585 e 555777. Na figura 2.2 mostramos os quatro defeitos estudados.

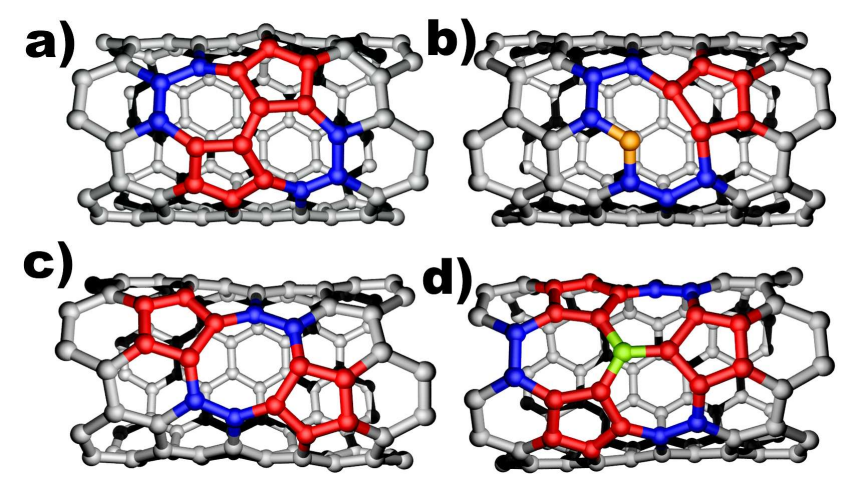

Figura 2.2: Apresentamos as geometrias finais dos defeitos estudados em nanotubos de parede simples armchair (5,5). Em (a) mostramos o defeito Stone-Wales; em (b) a monovacância; em (c) a divacância - 585; e em (d) divacância - 5557rry.

Na figura 2.2-a mostramos o defeito Stone Walles que, por sua vez, é obtido através da rotação de uma ligação química da rede hexagonal, o que acarreta uma mudança estrutural. Essa modificação transforma quatro hexágonos em um sistema composto por dois pentágonos e dois heptágonos (5577). O segundo defeito mostrado na figura 2.2-b é conhecido como monovacância, onde um átomo da rede hexagonal é 
eliminado possibilitando a reconstrução em um pentágono e, além disto, um átomo fica com uma ligação pendente (apenas dois vizinhos). Esta ligação pendente é altamente reativa e, sendo assim, este sítio é o primeiro candidato a funcionalização deste tipo de sistema. Os últimos dois defeitos, mostrados na figura 2.2-c e 2.2d, são as divacâncias. A primeira divacância mostrada (figura 2.2-c) é composta por dois pentágonos reconstruídos em torno de um octágono e chamaremos este defeito de 585. O último defeito estudado neste capítulo também foi uma divacância mas, neste caso, composta por três pentágonos e três heptágonos, e esta divacância será designada daqui por diante como 555777. Esta divacância foi obtida a partir da divacância 585 fazendo a rotação de uma ligação química do octágono, como podemos observar na figura 2.2-d. Na próxima seção discutiremos a estabilidade desses defeitos.

\subsection{Estabilidade dos SWCNT na presença de de- feitos}

Para investigar a estabilidade dos defeitos apresentados acima, precisamos definir uma quantidade que, independente do número de átomos, possamos comparar suas energias. Essa variável é conhecida como energia de formação e podemos defini-la da seguinte maneira:

$$
E_{\text {form }}(D)=E_{\text {tot }}(C N T+D)-E_{t o t}(C N T)+D \mu_{C}
$$

e onde $E_{t o t}(C N T+D)$ e $E_{t o t}(C N T)$ são as energias totais do sistema com defeito e sem defeito (tubo perfeito), respectivamente. O potencial químico do carbono $\left(\mu_{C}\right)$ é calculado a partir do sistema puro, ou seja, é definido como a energia total do sistema puro dividido pelo número total de átomos do sistema. Para o defeito Stone-Wales o valor de D é zero, pois não temos nenhuma vacância e, neste caso, 
a sua energia de formação será composta pelos dois primeiros termos da equação acima. Para os outros defeitos (monovacância e divacância), os valores de $D$ serão iguais ao número de vacâncias existentes e, nesses casos, serão 1 e 2 , respectivamente.

Analisando a estabilidade dos defeitos constatamos que o sistema mais estável, dentre os apresentados acima, é o Stone-Wales (SW), em todos os casos estudados (grafeno, armchair e zigzag). Comparando a energia de formação deste defeito, em um CNT armchair $(5,5)$, com os demais notamos que o defeito SW apresenta uma energia de formação menor que a da monovacância por $2.6 \mathrm{eV}$. No caso das divacâncias, o defeito SW é mais estável do que o defeito 585 por 1.0 eV e 1.7 eV mais estável do que a divacância 555777. Quando comparamos a energia de formação do SW em CNT $(5,5)$ com o mesmo defeito no grafeno, a energia deste sistema em tubos é aproximadamente $2.0 \mathrm{eV}$ mais estável.

Na tabela 2.1 apresentamos as energias de formação para o grafeno, para o nanotubo armchair $(5,5)$ e para o nanotubo zigzag $(8,0)$, de todos os defeitos estudados.

Tabela 2.1: Energia de formação dos diferentes defeitos, em eV, para o grafeno, nanotubo $(5,5)$ armchair $(d=6.78 \AA)$ e para o nanotubo $(8,0)$ zigzag $(d=6.26 \AA)$.

\begin{tabular}{c|c|c|c}
\hline \hline Defeito & Grafeno & CNT $(5,5)$ & CNT (8,0) \\
\hline SW & 5.04 & 3.07 & 2.78 \\
$1 \mathrm{v}$ & 7.92 & 5.67 & 5.34 \\
$2 \mathrm{v}-585$ & 7.76 & 4.10 & 3.61 \\
$2 \mathrm{v}-555777$ & 7.00 & 4.81 & 5.19 \\
\hline \hline
\end{tabular}

Estamos comparando as energias de formação dos nanotubos $(5,5)$ e $(8,0)$ porque os diâmetros nos dois casos possuem valores bem próximos. O grafeno também entra na comparação pois este sistema é considerado como um limite superior (seria um nanotubo de raio infinito).

Comparando a estabilidade dos defeitos, verificamos que as duas divacâncias são mais estáveis do que a monovacância. A presença de uma ligação pendente na mono- 
vacância torna este defeito menos favorável energeticamente quando comparado com as divacâncias. No caso das divacâncias no grafeno, notamos que o defeito 555777 é mais estável do que o defeito 585 por aproximadamente $0.8 \mathrm{eV}$. Quando comparamos os mesmos defeitos nos nanotubos de carbono estudados esta estabilidade se inverte, e o defeito mais estável passa a ser o 585. No próximo capítulo iremos explicar por que isto acontece. Em todos os casos, os defeitos apresentaram uma menor energia de formação em nanotubos do que em grafeno e, com isso, concluimos que essas imperfeições podem ser mais facilmente encontrados em nanotubos do que em grafite, quando esses sistemas são expostos à irradiação.

Com base nos resultados apresentados sobre a estabilidade energética destes defeitos para os quatro casos acima mostraremos o comportamento da energia de formação em função do diâmetro dessas imperfeições. Na figura 2.3 mostramos um gráfico da energia de formação em função do diâmetro para nanotubos armchair.

Comparando nossos resultados da energia de formação com o da referência [29], observamos um bom acordo para energia de formação da divacância (585) no tubo $(5,5)$, o resultado obtido pelos autores diferiu dos nossos por $0.07 \mathrm{eV}$. Para o trabalho apresentado na referência [30], a variação da energia de formação, para o mesmo defeito, foi de $0.1 \mathrm{eV}$. Neste trabalho, os autores utilizaram o funcional LDA, enquanto que no nosso foi utilizado o GGA. Os autores mostram o comportamento em função do diâmetro, e também observam um comportamento similar ao do gráfico da figura 2.3. Para a monovacância, os nossos resultados também são parecidos com os encontrados na literatura, como o trabalho da refererência [23]. Neste trabalho, os autores obtiveram uma energia de formação para monovacância de $5.5 \mathrm{eV}$ em um nanotubo $(5,5)$ de $\approx 22.2 \AA$ de compri mento. Nossos resultados foram obtidos para o mesmo sistema porém, o comprimento do nosso tubo foi de $12.3 \AA$, e a nossa energia diferiu da dos autores por 0.1 eV. Para a divacância 555777 não exitem trabalhos utilizando esse defeito em nanotubos. 


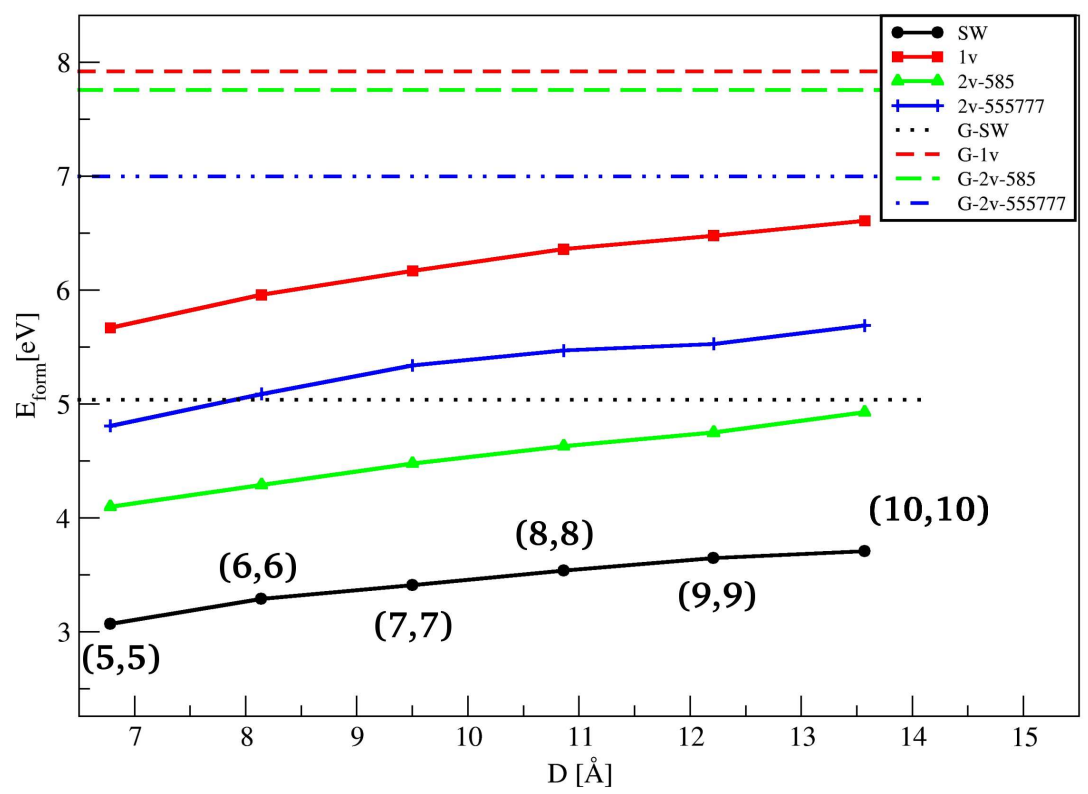

Figura 2.3: Gráfico da energia de formação em função do diâmetro para nanotubos armchair. Na legenda apresentamos as seguintes siglas: $S W$ (Stone-Wales), $1 v$ (monovacância), 2v-585 (divacância-585), 2v-555777 (divacância-555777) e as siglas com a letra $G$ referem-se ao grafeno.

Foram calculadas as energias de formação para diferentes diâmetros, a partir do nanotubo $(5,5)$ até o $(10,10)$, e esse intervalo corresponde a uma variação nos diâmetros de 6.78 - 13.56 A. Mostramos simultaneamente os quatro defeitos apresentados acima nos nanotubos de carbono e também os limites de raio infinito (grafeno), que são representado pelas linhas horizontais pontilhadas. O comportamento da energia de formação em função do diâmetro é similar nos quatro casos, e sem grandes oscilações.

Para obtermos uma estimativa do comportamento da energia de formação em função dos diâmetros dos tubos, para diâmetros grandes, vamos apresentar um modelo para descrever tal processo, para os defeitos SW e a monovacância e, para as divacâncias, mostraremos um estudo detalhado no próximo capítulo. Observamos na figura 2.3 que a energia varia lentamente nesse intervalo e, em todos os casos, 
notamos que o limite de raio infinito (grafeno) está aproximadamente $1.5 \mathrm{eV}$ acima do maior valor considerado no intervalo. Para o defeito Stone-Wales, no nanotubo armchair $(5,5)$, observamos que os comprimentos das ligações, na região do defeito, não variam significativamente quando comparamos com as mesmas ligações no grafeno. Observamos que as variações nos comprimento das ligações são no máximo de $0.05 \AA$. No caso da monovacância, as ligações também não variam muito, exceto uma ligação do pentágono que, no tubo, possui um comprimento de ligação de 1.56 A . A mesma ligação no grafeno possui um comprimento de $2.01 \AA$, uma diferença de aproximadamente $0.45 \AA$. Desta forma, vamos propor que o comportamento da energia de formação em função do diâmetro, para o defeito SW, varia com o inverso do diâmetro. Então para o defeito Stone-Wales propomos a seguinte expressão:

$$
E_{f}^{S W}=E_{\infty}+\frac{A}{d}
$$

No caso da monovacância, vamos propor que o comportamento da energia de formação varia com o inverso do diâmetro e, além disso, sugerimos também um termo adicional do tipo exponecial. Propomos que o comportamento da energia de formação em função do diâmetro para monovacância seja dado por:

$$
E_{f}^{1 v}=E_{\infty}+\frac{A}{d}+E_{0} e^{-\frac{d}{d_{0}}}
$$

A justificativa para as expressões acima estão associadas a curvatura dos nanotubo, para o termo $\frac{1}{d}$, e para a expressão que possui o termo exponencial, este fator está associado com a ligação que é "rompida" a medida em que o diâmetro aumenta. Como o decaimento das funções de onda atômicas tem um comportamento exponencial, propomos que a contribuição dessa ligação $(C-C)$ que se "rompe" tenha um caráter também exponencial com o diâmetro.

Com estas expressões podemos ter uma estimativa do comportamento da energia de formação em função do diâmetro dos nanotubos, e este comportamento pode ser 
visto na figura 2.4 .
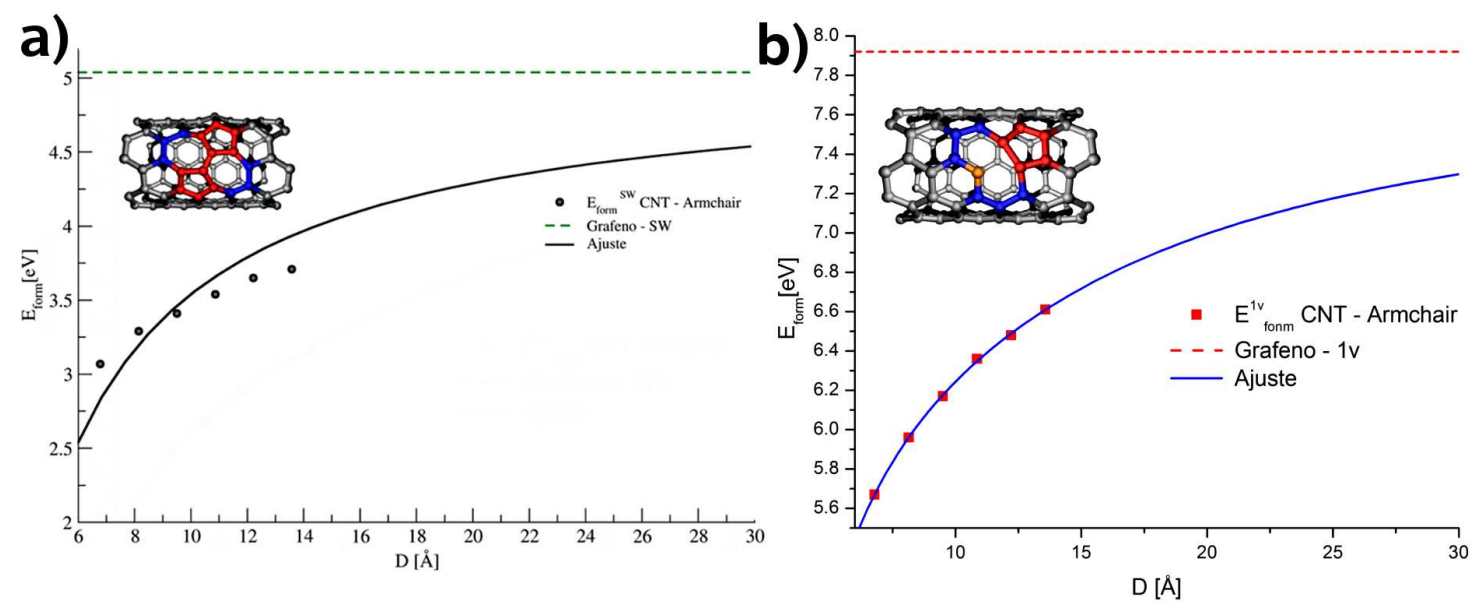

Figura 2.4: Gráfico da energia de formação em função do diâmetro para nanotubos armchair. Em (a) mostramos o comportamento para o defeito $S W$ com os seguintes parâmetros: $A=-14.98[\mathrm{eV} \cdot A]$; em (b) apresentamos o mesmo gráfico para a monovacância com os seguintes parâmetros $A=-18.68[\mathrm{eV} \cdot \AA]$ ] $E_{0}=3.9[\mathrm{eV}] \mathrm{e}$ $d_{0}=3.3[\AA]$. Consideramos a $E_{\infty}$ como $E_{\text {form }}^{G}$ para os defeitos $S W$ e monovacâncias, que de acordo com a tabela 2.1 são: 5.04 e 7.92 eV, respectivamente.

No gráfico figura 2.4-a observamos o comportamento da energia de formação em função do diâmetro para o defeito Stone-Wales no intervalo de diâmetros de 6 - 30 A. Notamos que a energia de formação varia lentamente neste intervalo. Para o diâmetro de $30 \AA$ A, o defeito possui a energia de formação de $0.5 \mathrm{eV}$ menor do que o limite superior (energia de formação do grafeno para o defeito SW). A monovacância, figura 2.4-b, possui um comportamento similar, no entanto, a curva ajustada passa por todos os pontos da simulação e, para o diâmetro de $30 \AA$, a diferença de energia de formação obtida quando comparado com o mesmo defeitos em grafeno é de 0.6 eV. Os parâmetros ajustados são apresentados nas legendas.

Na próxima seção discutiremos a estabilidade dos defeitos em nanotubos zigzag. 


\subsection{Estabilidade e orientação dos defeitos em CNT zigzag}

Antes de discutir a estabilidade dos defeitos em nanotubos zigzag, vamos apresentar as geometrias mais estáveis dos quatro defeitos em nanotubos. No capítulo 1 apresentamos como os nanotubos são formados a partir do vetor quiral e, além disso, classificamos estes nanotubos como quirais ou aquirais. No caso dos CNT aquirais, ainda classificamos em duas classes armchair e zigzag, e o que difere estas classes de tubos é a maneira com que eles são enrolados. No caso do armchair o ângulo quiral possui o valor de $\theta=30^{\circ}$, e para os tubos zigzag esse ângulo é zero. Sendo assim, defeitos estruturais possuem orientações diferentes nos dois casos. Na figura 2.5 mostramos as geometrias finais do defeitos para o nanotubo $(8,0)$ zigzag.

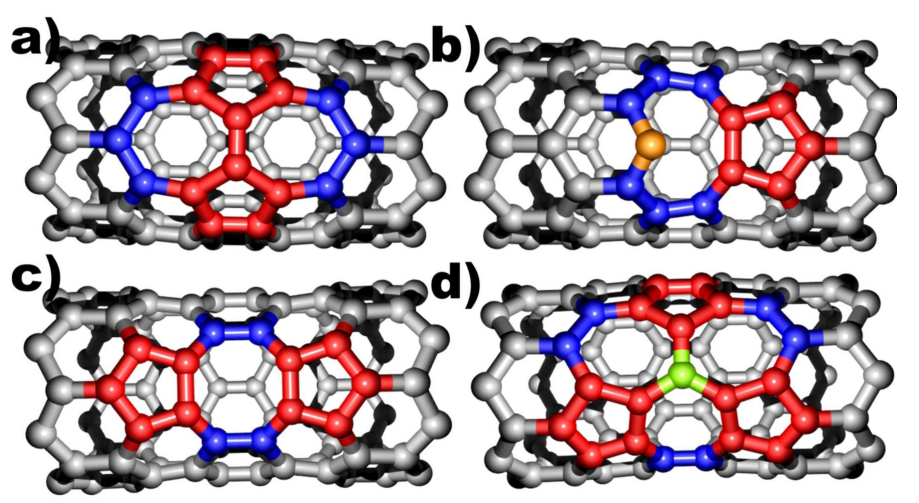

Figura 2.5: Apresentamos as geometrias finais para o nanotubo zigzag (8,0). Em (a) mostramos o defeito Stone-Wales; em (b) apresentamos a monovacância; e finalmente exibimos as divacâncias (c) 585 e (d) 55577 r

Os defeitos mais estáveis, que eram inclinados no nanotubo armchair são paralelos à direção do eixo nos tubos zigzag. As geometrias inclinadas continuam existindo, mas são menos estáveis do que as paralelas ao eixo. Para exemplificar o que estamos falando vamos analisar a divacância (585), defeito este que possui as orientações inclinada e paralela em relação ao eixo do nanotubo zigzag. No entanto, a geometria 
paralela deste defeito é mais estável do que a inclinada por aproximadamente 2.5 eV em nanotubos zigzag. Sendo assim, descartamos as geometrias menos estáveis e daqui por diante utilizaremos somente as estruturas mais estáveis.

A sequência de estabilidade (energia de formação) em nanotubos zigzag, para os defeitos discutidos no capítulo 2, seguem a mesma ordem dos nanotubos armchair, assim como o comportamento da energia de formação em função do diâmetro é o mesmo. No caso das divacâncias, notamos uma pequena oscilação da energia de formação para o tubo $(12,0)$, e este fato está relacionado com a possibilidade dos CNTs zigzag poderem ser metálicos ou semicondutores. Uma discussão detalhada desse comportamento será apresentada no capítulo 3. Na figura 2.6 observamos o comportamento da energia de formação em função do diâmetro para os nanotubos zigzag.

Analisando o nanotubo $(8,0)$, podemos comparar as energias de formação do defeito Stone-Wales com a monovacância, onde observamos que o defeito SW é mais estável por aproximadamente $2.6 \mathrm{eV}$. No caso da divacância 585, o defeito SW é mais estável por $0.8 \mathrm{eV}$, e mais estável por $2.4 \mathrm{eV}$ quando comparado com a divacância 555777. Os valores das energias de formação para esses defeitos em um nanotubo $(8,0)$ são apresentados na tabela 2.1 .

Para estudar o comportamento da energia de formação em função do diâmetro, vamos utilizar o mesmo modelo apresentado na seção anterior, pois o comportamento da energia de formação dos tubos zigzag não diferiu muito dos armchair, e também por assumirem os mesmos limites de raio infinito. Na figura 2.7 mostramos como a energia de formação dos defeitos (SW e monovacância) se comporta em função do diâmetro.

Foram obtidos o seguinte parâmetro para o defeito SW $(A=-13.97[\mathrm{eV} \cdot \AA]$; e para a monovacância encontramos as seguintes parâmetros $(A=-26.0[\mathrm{eV} \cdot \AA]$, $E_{0}=8.6[\mathrm{eV}]$ e $\left.d_{0}=3.7[\AA]\right)$. Novamente, observamos que o nosso modelo é bem 


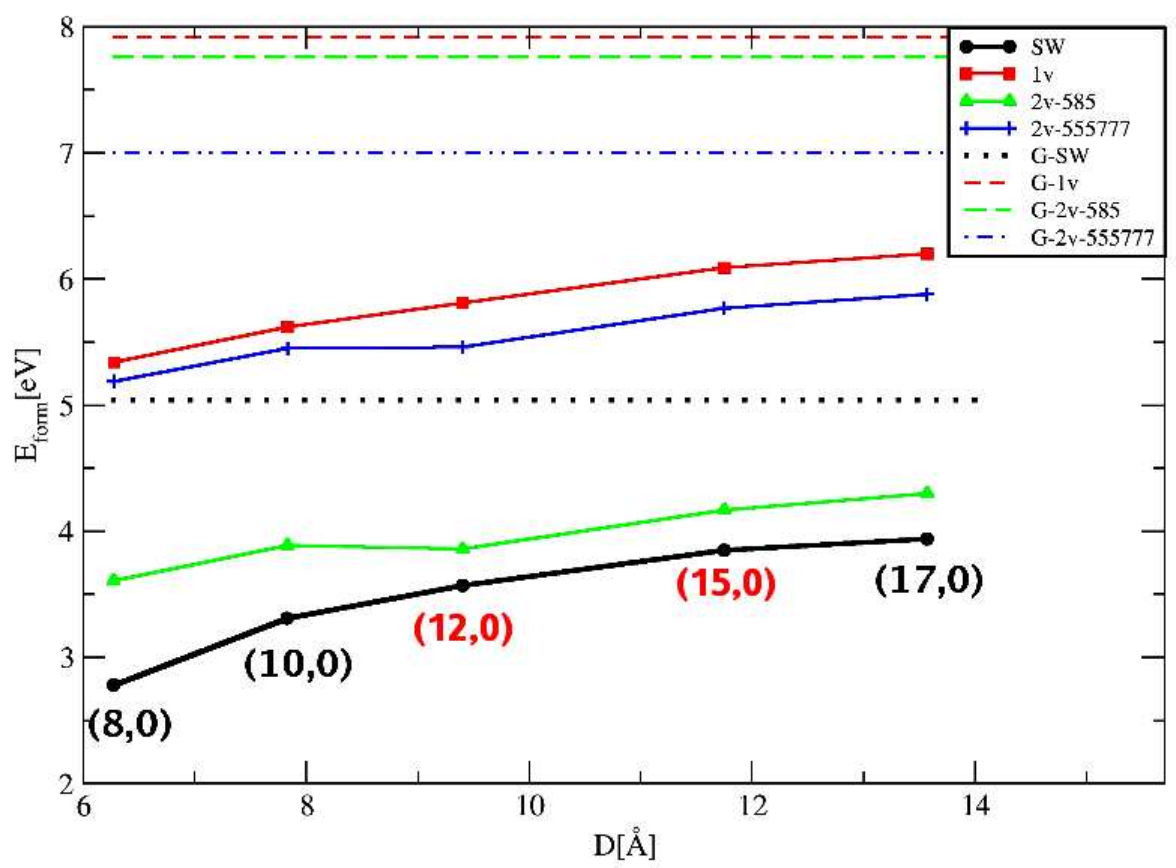

Figura 2.6: Apresentamos o gráfico da energia de formação em função do diâmetro para nanotubos zigzag. Na legenda apresentamos as seguintes siglas: $S W$ (stone-wales), $1 v$ (monovacância), 2v-585 (divacância-585), 2v-55577ry (divacância555 r77) e as siglas com a letra $G$ referem-se ao grafeno.

ajustável aos pontos calculados, e que a variação da energia de formação ocorre lentamente para o limite de diâmetros grandes.

Neste capítulo apresentamos a estabilidade estrutural de quatro defeitos em nanotubos de carbono. Uma questão importante sobre a estabilidade das divacâncias surgiu quando comparamos os defeitos em nanotubos de carbono e no grafeno. A sequência energética das divacâncias se inverte no grafeno, isto é, o defeito 585 é mais estável do que o 555777 nos nanotubos, contrariando o comportamento observado no grafeno que, neste caso, apresentou como mais estável o defeito 555777. Por que ocorre essa inversão de estabilidade? Esta questão nos leva a outras perguntas como por exemplo: em qual diâmetro de tubo a sequência de estabilidade das divacâncias será igual a do grafeno? Como são as propriedades de transporte eletrônico das 

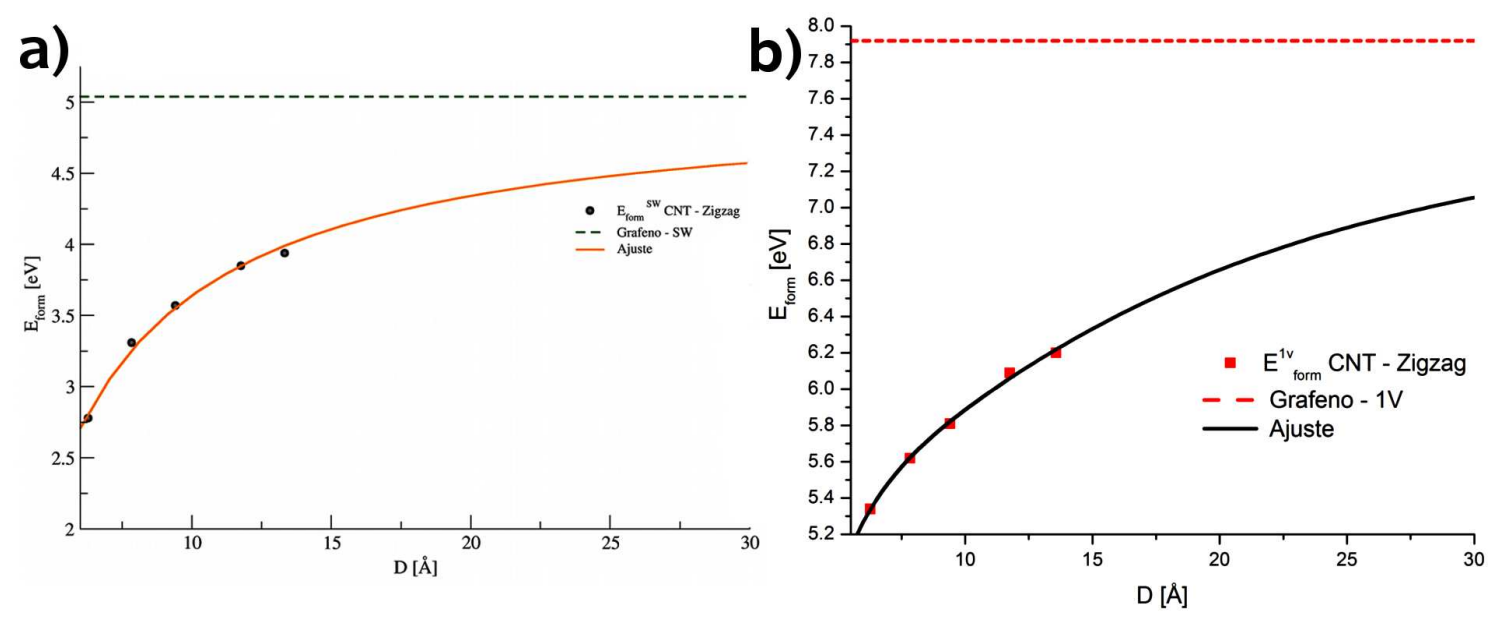

Figura 2.7: Mostramos o gráfico da energia de formação em função do diâmetro para nanotubos zigzag. Em (a) mostramos o comportamento da energia de formação para o defeito $S W$; e em (b) o mesmo gráfico mostrado e (a) para a monovacância.

divacâncias?

Para responder essas e outras questões, no próximo capítulo apresentaremos um estudo detalhado sobre as divacâncias em nanotubos de carbono e em grafeno. 


\section{Capítulo 3}

\section{Divacâncias em CNT de parede simples}

No capítulo anterior apresentamos um estudo sobre a estabilidade estrutural de quatro defeitos em nanotubos de parede simples. O defeito mais estável, dentre os defeitos estudados no capítulo 2, foi o defeito Stone Wales [17]. No entanto, ao compararmos o defeito proveniente de uma única vacância com os defeitos que possuem duas vacâncias, observamos que as divacâncias possuem energias de formação menores do que a monovacância.

Trabalhos recentes $[54,55]$ mostraram que as divacâncias são os defeitos mais importantes no que diz respeito a mundanças nas propriedades de transporte. Uma pequena concentração de divacância, cerca de $0.03 \%$, pode mudar a condutância por até 3 ordens de magnitude. Uma maneira de modificar as propriedades eletrônicas dos nanotubo é através de irradiação de íons [4,39,40,43-51,59,81], como foi apresentado na introdução. Os autores da referência [54] irradiaram feixes de íons em CNT onde, posteriormente, fizeram medidas de resistência à baixa voltagem em função do comprimento do nanotubo. Eles mostraram um comportamento exponencial de 
tais medidas, o que é um indicativo de um regime de localização forte de Anderson ${ }^{1}$, e eles atribuiram esse comportamento devido a criação de vacâncias na parede do tubo.

Simulações $[50,55,81]$ de irradiação de íons $\left(A r^{+}\right)$em nanotubos de carbono, têm mostrado que os defeitos mais prováveis formados nos processos de colisões são vacâncias e divacâncias, sendo que, em $30-40 \%$ dos impactos, os defeitos compostos por duas vacâncias estavam presentes. Uma das divacâncias que vamos considerar neste estudo possui dois pentágonos e um octágono (585), como foi mostrada no capítulo 2. Em um estudo recente [27], utilizando dinâmica molecular "tight-binding", os autores mostraram que duas vacâncias isoladas em grafeno podem formar o defeito 585. Esta configuração, contudo, reconstrói-se em uma configuração um pouco mais complexa, composta por três pentágonos e três heptágonos, a qual foi denominada no capítulo 2 por 555777. Os autores mostraram através de cálculos ab initio que o defeito 555777 é mais estável do que o defeito 585 por 0.9 $\mathrm{eV}$.

Considerando que as divacâncias modificam substancialmente as propriedades de transporte, e que o defeito 555777 é mais estável do que o defeito 585 no grafeno, e ainda, como foi mostrado no capítulo 2, que o defeito 585 é mais estável do que o 555777 nos nanotubos, as seguintes questões tornam-se importantes para o entendimento deste problema: por que ocorre a inversão de estabilidade nas divacâncias quando comparamos as energias de formação nos nanotubos com o grafeno? Deve existir um diâmetro em que essa inversão de estabilidade acontece, uma vez que o grafeno pode ser pensado com um nanotubo de raio infinito. Em que diâmetro ocorre esse cruzamento? Como as propriedades de transporte são modificadas pelas

\footnotetext{
${ }^{1}$ Localização de Anderson ou localização forte de Anderson consiste na ausência de difusão de ondas em um meio aleatório - comumente encontrados em sistemas onde o grau de aleatoriedade das impurezas ou defeitos é suficientemente grande. A localização de Anderson é um fenômeno geral da onda que se aplica ao transporte de onda eletromagnética, onda acústica, onda de spin etc.
} 
divacâncias?

Nas próximas seções faremos um estudo detalhado sobre as divacâncias em nanotubos de carbono e em grafeno afim de responder as questões apresentadas acima.

\subsection{Protocolo de simulação}

Para responder as questões apresentadas na seção anterior, foram feitos cálculos de primeiros princípios baseados na teoria do funcional da densidade [83, 84] (DFT). Utilizamos os pseudopotencias ultra suaves de Vanderbilt [87] e, para a energia de correlação e troca, usamos a aproximação generalizada dos gradientes (GGA). Maiores detalhes sobre a metodologia empregada nesta tese encontram-se no apêndice A. Os cálculos referentes as propriedades estruturais foram feitos com o código VASP $[85,86]$, e os cálculos de transporte de cargas, utilizamos um código desenvolvido em nosso grupo [88] (TRANSampa), baseado em funções de Green fora do equilíbrio (NEGF-DFT), onde a parte de DFT foi descrita utilizando o código Siesta [89].

\subsection{Estabilidade das Divacâncias}

Nesta seção vamos apresentar os resultados sobre a estabilidade energética dos defeitos compostos por duas vacâncias. Faremos uma discussão sobre a orientação dos defeitos tanto em grafeno quanto em nanotubos de carbono. Mostraremos o comportamento da energia de formação em função do diâmetro para nanotubos armchair e zigzag. Posteriormente, mostraremos um modelo de cruzamento para determinar um diâmetro em que a inversão de estabilidade energética ocorre. 


\subsubsection{Divacâncias em Grafeno}

Na figura 3.1 mostramos as geometrias das duas divacâncias (585 e 555777) em grafeno, estudadas neste capítulo. Utilizamos uma supercélula contendo nove repetições $^{2}$, o que equivale a 162 átomos de carbono. O grafeno é um material bidimensional e, por este motivo, não existe uma orientação preferencial dos defeitos.

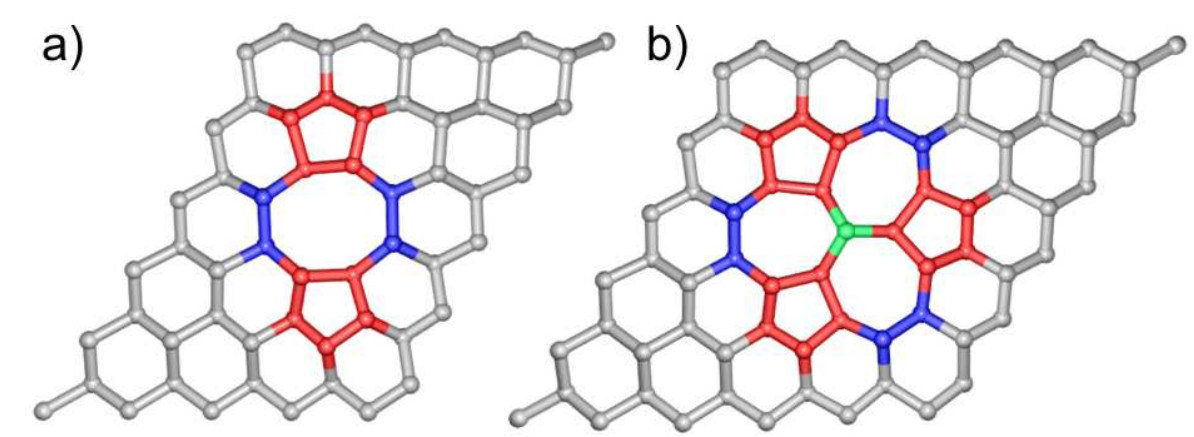

Figura 3.1: Mostramos a geometria de duas divacâncias no grafeno: em (a) o defeito 585 ; e em (b) o defeito 555777.

Calculamos a energia de formação para as duas divacâncias no grafeno e observamos que o defeito 555777 é 0.8 eV mais estável que o defeito 585 . Este resultado comfirma o cálculo feito por Gun-Do Lee et al. [90]. A pequena diferença entre o nosso cálculo e o de Gun-Do Lee et al. pode ser atribuída a diferentes amostragens de pontos $k$ e à diferença no tamanho da super célula utilizada nos cálculos.

Uma vez confirmada essa estabilidade das divacâncias no grafeno, vamos discutir, nas próximas seções, o comportamento da estabilidade desses defeitos em nanotubos de carbono (armchair e zigzag) num intervalo de diâmetros de $7-15 \AA$.

\subsubsection{Defeitos em SWNTs armchair}

O primeiro caso estudado foi para o nanotubo do tipo armchair em que todos os tubos são metálicos. Neste caso, o defeito 585 pode assumir duas possíveis ori-

\footnotetext{
${ }^{2} \mathrm{O}$ grafeno é descrito por dois átomos na célula unitária e, considerando uma supercélula com nove repetições, o número total de átomos é de $9 \times 9 \times 2=162$.
} 
entações, e uma análise sobre a estabilidade energética dessas possíveis orientações se faz necessária. Estudamos, portanto, as seguintes orientações : i) inclinada e ii) perpendicular ao eixo de crescimento do SWNTs, como podemos constatar na figura 3.2 .
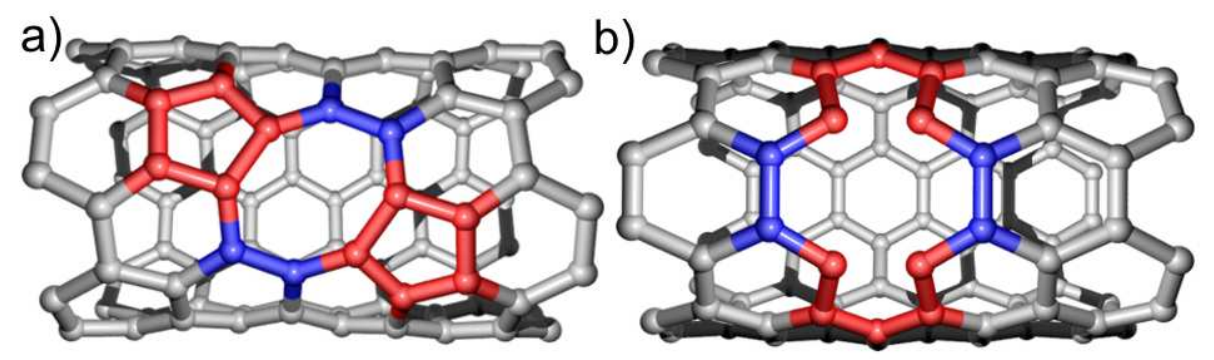

Figura 3.2: Apresentamos as geometrias finais dos defeitos 585 em nanotubos $(5,5)$ armchair: em (a) mostramos o defeito 585 inclinado; e em (b) o defeito 585 perpendicular ao eixo de crescimento do nanotubo.

A geometria inclinada possui duas formas equivalentes, isto é, a inclinação pode ser tanto para direita quanto para esquerda. Mostramos a geometria inclinada do defeito 585 na figura 3.2-a. A outra possibilidade para este defeito é mostrada na figura 3.2-b, que consiste no defeito orientado perpendicularmente ao eixo de crescimento do tubo. A energia de formação para essa orientação do defeito 585 é maior do que o mesmo defeito inclinado, ou seja, a diferença de energia entre eles é de aproximadamente $3.5 \mathrm{eV}$. Sendo assim, daqui por diante usaremos somente o defeito 585 inclinado e descartaremos as geometrias perpendiculares. No caso do defeito 555777 (figura 3.3), observamos uma simetria $C_{3}$ associada ao átomo que se encontra ao centro do defeito (átomo em verde) e este fato torna as três orientações possíveis equivalentes.

Calculamos a energia de formação para as duas divacâncias em nanotubos de carbono armchair $(5,5)$, onde constatamos que o defeito 585 é 0.7 eV mais estável do que o defeito 555777. Analisando a energia de formação das divacâncias no grafeno e no nanotubo de carbono, notamos que ocorreu uma inversão de estabilidade 


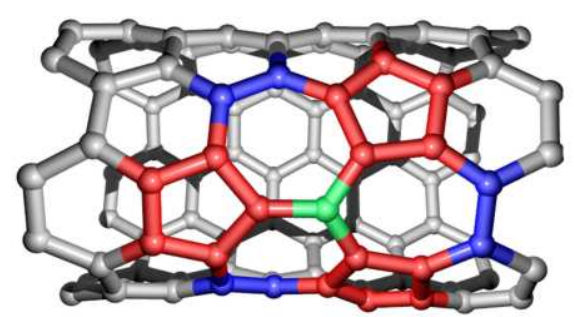

Figura 3.3: Apresentamos a geometria final da divacância 555777 para SWNTs armchair $(5,5)$.

energética. A causa dessa inversão será apresentada nas próximas subseções.

Na figura 3.4 mostramos o comportamento da energia de formação em função do diâmetro (d) para os nanotubos armchair. Nos cálculos utilizamos os nanotubos $(5,5)$ ao $(10,10)$, que equivalem a um intervalo de diâmetros de $d=7-15 \AA$, aproximadamente. Na mesma figura são mostrados os limites superiores, que são as energias de formação do grafeno.

Analisando o gráfico da figura 3.4 podemos observar que ambos os defeitos são mais estáveis nos nanotubos do que no grafeno, o que é um indicativo de que eles podem ser mais facilmente criados em tubos. Observamos que a energia de formação cresce monotonicamente com o aumento do diâmetro e, no intervalo considerado, ocorreu uma variação de energia de aproximadamente $0.8 \mathrm{eV}$. Quando comparamos a diferença de energia entre os dois defeitos, para todos os diâmetros, esta diferença permaneceu praticamente constante (cerca de $0.7 \mathrm{eV}$ ). As curvas da figura 3.4 para a energia de formação dos nanotubos são basicamente lineares, o que é um indicativo de que a inversão de estabilidade deverá ocorrer, provavelmente, para diâmetros grandes. Em todos os nossos cálculos estamos utilizando 5 células unitárias para os nanotubos armchair. Testes foram feitos aumentando o tamanho da célula unitária para 9. Como conseqência deste aumento, observamos uma diminuição de aproximadamente $0.3 \mathrm{eV}$ para a energia de formação em ambos os defeitos. Essa diminuição da energia de formação não altera o resultado apresentado até o presente momento. 


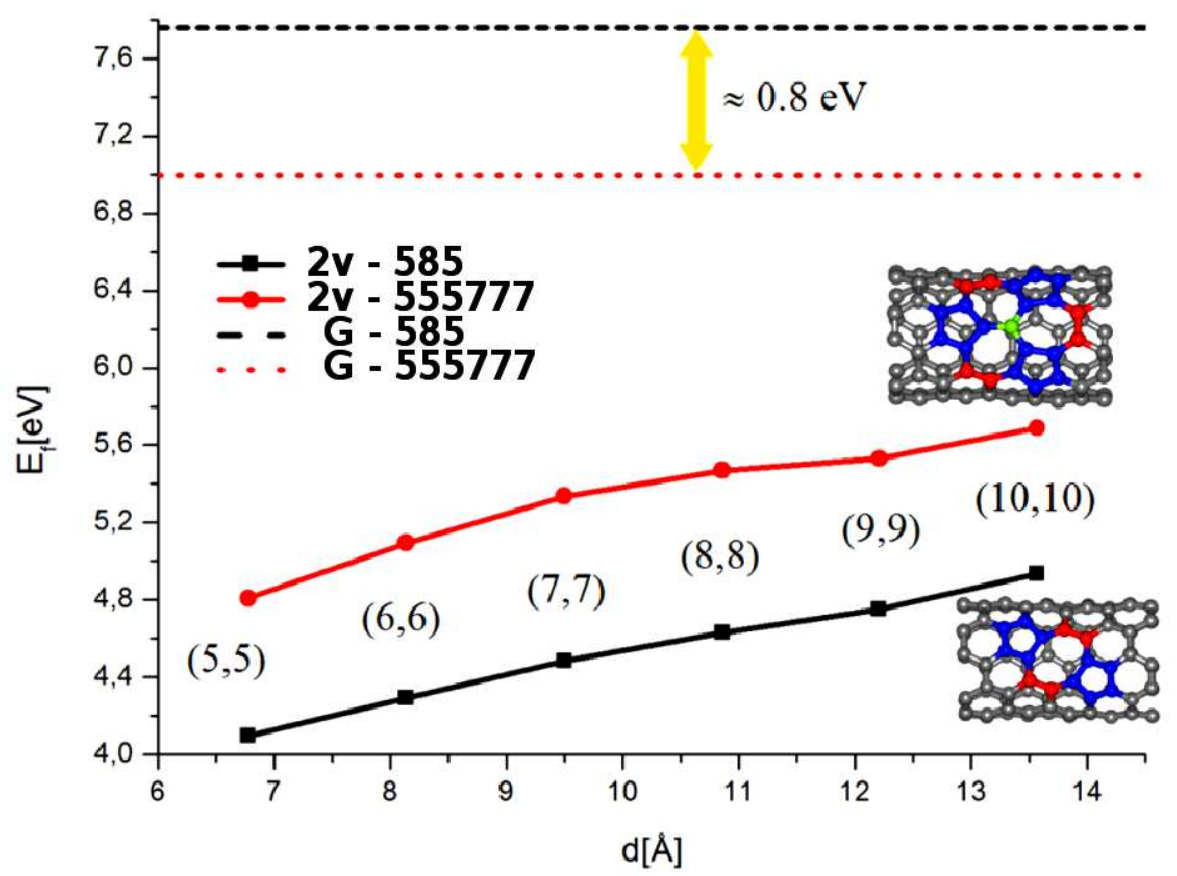

Figura 3.4: Apresentamos o gráfico da energia de formação em função do diâmetro para as divacâncias (585 e 555777) dos nanotubos armchair. Os limites superiores, energia de formação do grafeno (G), são apresentados por linhas pontilhadas.

Para estimar o diâmetro $(d)$ onde o defeito 555777 tona-se mais estável do que o 585 , isto é, onde ocorre a inversão de estabilidade, vamos propor um modelo para o comportamento da energia de formação em função do diâmetro. Para o defeito 585 propomos o seguinte comportamento:

$$
E_{f}^{585}=E_{\infty}+\frac{A}{d}+E_{0} e^{\frac{-d}{d_{0}}}
$$

onde os parâmetros $A, E_{0}$ e $d_{0}$ foram ajustados e o $E_{\infty}=E_{f}^{G-585}=7.76 \mathrm{eV}$ corresponde à energia de formação do defeito 585 no grafeno.

Para a divacância 555777, propomos a seguinte lei:

$$
E_{f}^{555777}=E_{\infty}+\frac{A}{d}
$$


e, neste caso $E_{\infty}=E_{f}^{G-555777}=7.0 \mathrm{eV}$ é a energia de formação do defeito 555777 para o grafeno.

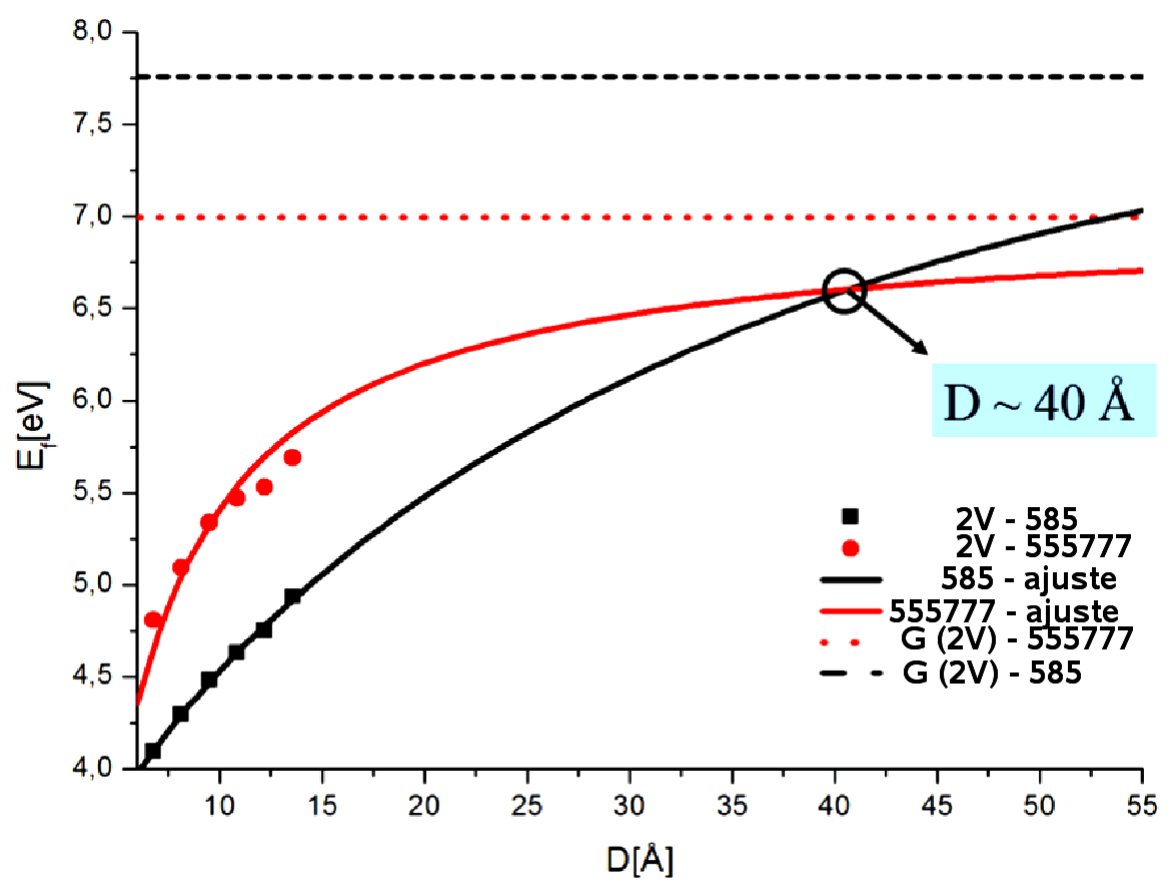

Figura 3.5: Mostramos neste gráfico o comportamento da energia de formação em função do diâmetro das divacâncias em CNTs. Para o defeito 585 encontramos os seguintes parâmetros: $A=-1.97 \mathrm{eV} . \AA, E_{0}=-4.21 \mathrm{eV}, d_{0}=30.37 \AA$. No caso do defeito 555777 encontramos o parâmetro $A=-15.86 \mathrm{eV} . \AA$.

A justificativa para o comportamento da energia de formação em função do diâmetro, para o defeito 585, foi baseada no comportamento das ligações químicas deste defeito no grafeno. Neste sistema, o defeito 585 possui duas ligações químicas, pertencentes ao pentágono, com distâncias grandes ( 1.77 A). Essas ligações são grandes comparadas com a distância de equilíbrio dos átomos de carbono para o grafeno, que é de aproximadamente $~ 1.42$ Å. Para o defeito 555777 essas ligações químicas com tamanhos grandes não ocorrem. Como o decaimento das funções de onda atômicas tem um comportamento exponencial, propomos que a contribuição dessas duas ligações $C-C$ que se "rompem" tenham um caráter também exponencial com o diâmetro. Além disso, deve existir uma componente com dependência do tipo 
lei de potência, associada à variação de curvatura do nanotubo. No caso do 555777 , vamos consider apenas a contribuição do termo do tipo lei de potência devido à variação de curvatura do nanotubo. Na figura 3.5 mostramos as curvas ajustadas pelas equações (3.1) e (3.2) para os defeitos 585 e 555777.

Utilizando as relações acima que descrevem o comportamento da energia de formação em função do diâmetro, para diâmetros grandes, podemos estimar o diâmetro em que a ordem da estabilidade será a mesma para tubos e grafeno. Para os nanotubos armchair obtemos um diâmetro de aproximadamente $40 \AA$, o que corresponde a um SWNTs armchair $(30,30)$.

\subsubsection{Defeitos em SWNT zigzag}

O segundo caso estudado foi o nanotubo do tipo zigzag que, além de poder ser metálico, também pode ser semicondutor, como foi mostrado no capítulo 1. Faremos o mesmo estudo realizado para os nanotubos armchair, começando com a discussão sobre as possíveis orientações das divacâncias neste sistema. Para os nanotubos zigzag, o defeito 585 também possui duas possíveis disposições, entretanto, neste caso, podendo assumir a orientação inclinada e a paralela em relação à direção de crescimento do tubo. Na figura 3.6, podemos observar as duas possíveis orientações do defeito 585 nos nanotubos zigzag.
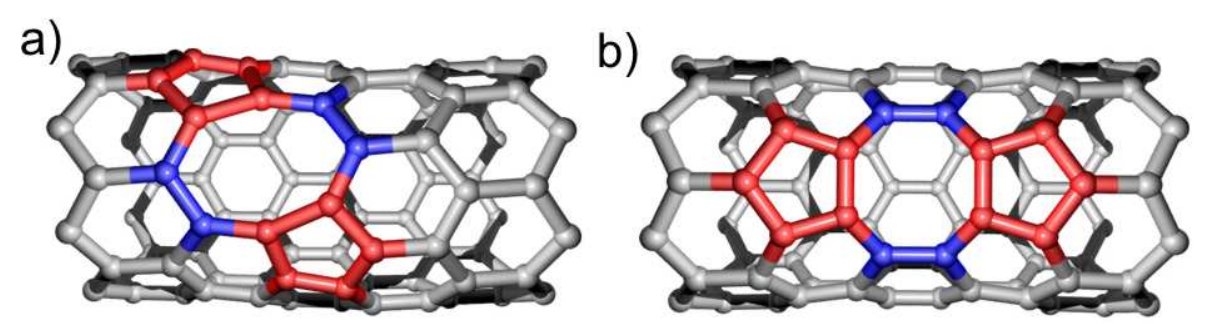

Figura 3.6: Apresentamos as duas possiveis orientações do defeito 585 para os nanotubos zigzag: em (a) o defeito 585 inclinado; e em (b) o defeito 585 paralelo ao eixo de crescimento do tubo. 
A orientação mais estável para o defeito 585, no caso do tubos zigzag, é a paralela em relação ao eixo, onde esse defeito se mostrou aproximadamente $2.7 \mathrm{eV}$ mais estável do que o defeito inclinado. A disposição do defeito 585 paralelo possui uma relaxação atômica melhor do que no caso inclinado, resultado do defeito se "encaixar" simetricamente, afundando a parede do nanotubo, como podemos observar na figura 3.7. No caso do defeito inclinado não é observado tal comportamento. Desta forma, utilizaremos daqui por diante somente as geometrias paralelas para os defeitos 585 .

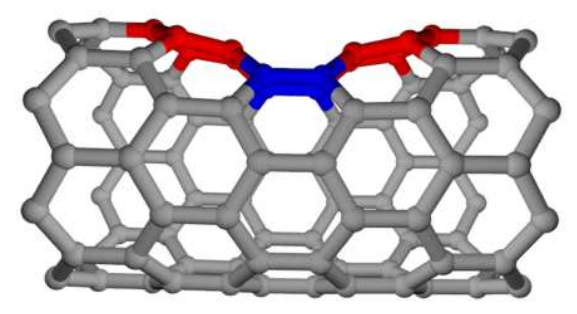

Figura 3.7: Mostramos em detalhe a geometria do defeito 585, com a orientação paralela em relação ao eixo do nanotubo. Constatamos que este defeito afunda a parede do nanotubo.

No caso do defeito 555777, observamos o mesmo comportamento dos tubos armchair, e novamente constatamos que o átomo que se encontra no centro do defeito possui uma simetria $C_{3}$. O átomo em verde é um centro de rotação para tal simetria, e qualquer rotação de $120^{\circ}$, em torno desse átomo, mantém a disposição do defeito inalterada. Sendo assim, as três possíveis orientações são esquivalentes. Na figura 3.8 mostramos a geometria final para o defeito 555777 no nanotubo zigzag.

Calculamos a energia de formação em função do diâmetro para nanotubos zigzag, onde selecionamos quatro tubos metálicos e quatro semicondutores, num intervalo de diâmetros entre $7-15 \AA$. Na figura 3.9 podemos observar o comportamento da energia de formação em função do diâmetro para o nanotubo zigzag, e para identificar os tipos de nanotubos, usaremos a seguinte nomenclatura no gráfico: os nanotubos que estão escritos em preto são semicondutores e os que estão em vermelho são 


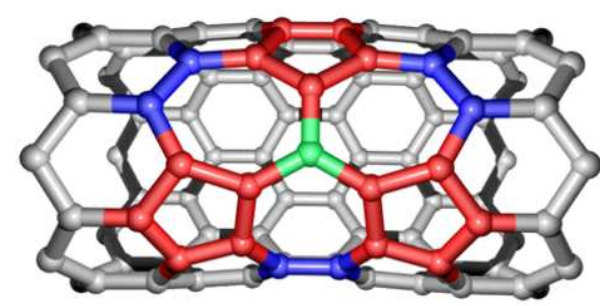

Figura 3.8: Exibimos a geometria final do defeito 555777 para o nanotubo zigzag. metálicos.

Observando o gráfico da figura 3.9, e comparando com o mesmo problema para tubos armchair, notamos duas características distintas.

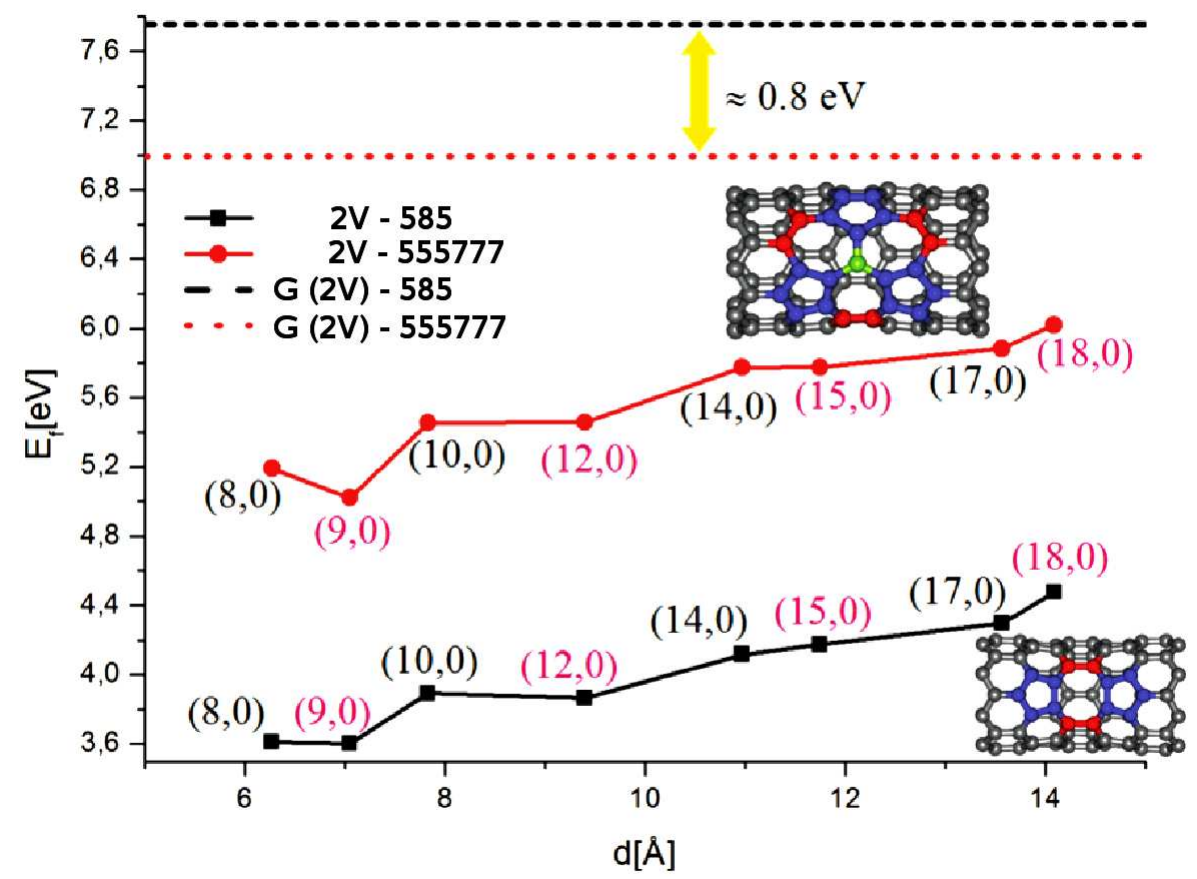

Figura 3.9: Mostramos o gráfico da energia de formação versus diâmetro para 585 e 555777 no caso de SWNTs zigzag.

A primeira é referente à diferença de energia entre as duas divacâncias nos nanotubos que, neste caso, é de aproximadamente $1.6 \mathrm{eV}$. Esta diferença é praticamente o dobro da encontrada para os tubos armchair, e este fato é atribuido às relaxações 
atômicas ao redor do defeito serem maiores neste caso. A segunda diferença observada refere-se à oscilação na energia de formação, que está relacionada com a alternância entre nanotobos metálicos e semicondutores. Concomitantemente com o nosso trabalho, outros autores $[30,53]$ também observaram oscilações na energia de formação de divacâncias em nanotubos zigzag. Uma outra observação, refere-se a um comportamento análogo aos dois tipos de nanotubos, ou seja, para os tubos zigzag também verificamos a inversão de estabilidade entre as divacâncias 585 e 555777 quando comparamos com o grafeno. Foram feitos testes aumentando o tamanho da célula unitária de 3 para 5 e, para o defeito 585, a energia de formação ficou inalterada, e para o defeito 555777 houve uma diminuição na energia de formação de aproximadamente $0.1 \mathrm{eV}$. Esses resultados não alteram nossas conclusões sobre a estabilidade dos defeitos provenientes de divacâncias, uma vez que a diferença de energia de formação entre os dois defeitos continua maior do que $1.5 \mathrm{eV}$.

Desta forma, vamos aplicar o modelo proposto previamente para estimar o diâmetro $(d)$ em que ocorre a inversão de estabilidade entre as divacâncias. Na figura 3.10 podemos observar o comportamento da energia de formação em função do diâmetro dos sistemas estudados.

Os parâmetros obtidos para o defeito 585 foram: $A=-1.36 \mathrm{eV} . \AA$, $E_{0}=-5.30$ eV e $d_{0}=32.64 \AA$; e para o defeito 555777 , o parâmetro $A=-13.04 \mathrm{eV} . \AA$. Como no caso dos nanotubos armchair, consideramos as energias de formação do grafeno como sendo de um nanotubo de raio infinito. Sendo assim, estimamos que a inversão de estabilidade deverá ocorrer para um diâmetro de aproximadamente $53 \AA$, no caso dos tubos zigzag, e esse diâmetro corresponde a um nanotubo de carbono $(117,0)$.

Nas duas últimas seções foram feitos estudos detalhados sobre a estabilidade das divacâncias em nanotubos armchair e zigzag. Mostramos que para os defeitos provenientes de duas vacâncias existe uma inversão de estabilidade e, sendo assim, estimamos o diâmetro em que poderá ocorrer tal inversão. Na próxima seção vamos 


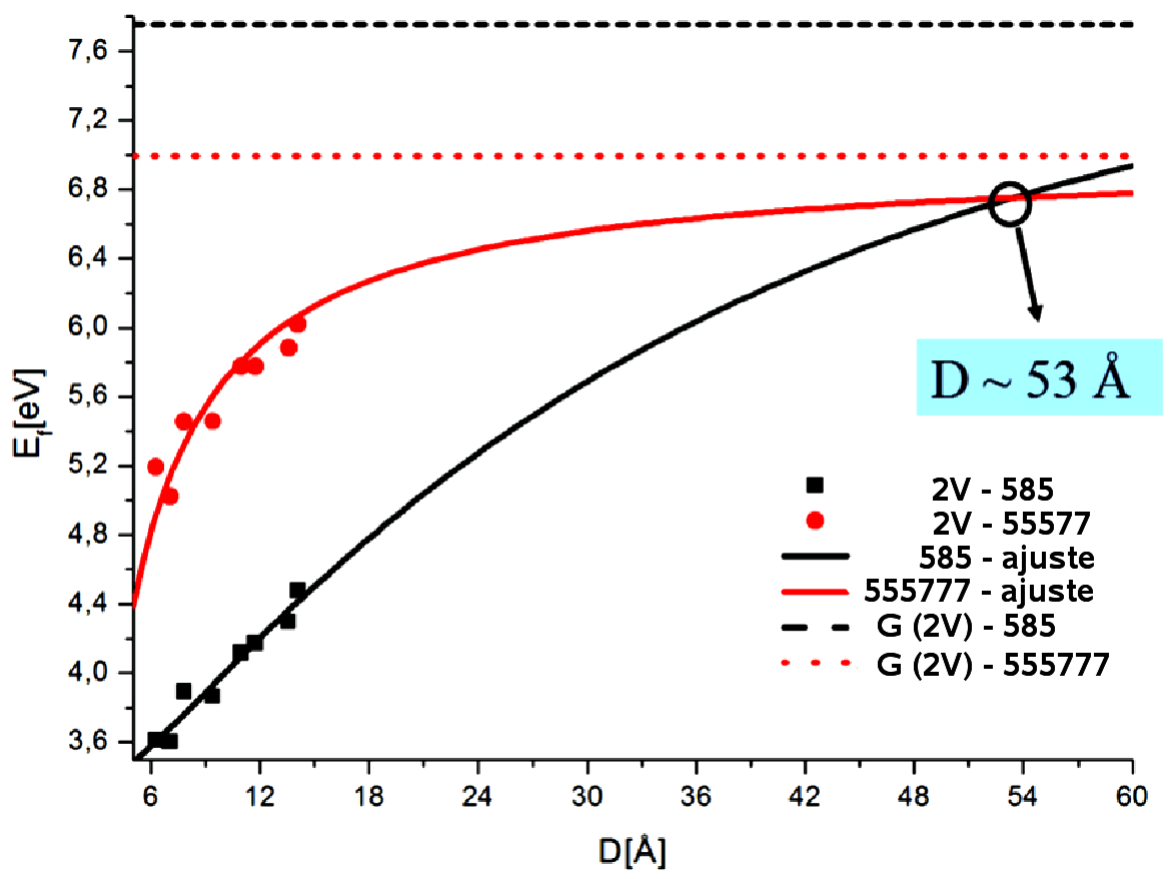

Figura 3.10: Mostramos o gráfico da energia de formação em função do diâmetro, baseado no modelo apresentado acima, para as divacâncias 585 e 555777 no caso dos tubos zigzag.

responder uma questão fundamental que surgiu neste capítulo: por que ocorreu a inversão de estabilidade destes sistemas?

\subsection{Modelo teórico para inversão de estabilidade}

Nesta seção responderemos à pergunta sobre a inversão da estabilidade das divacâncias e, para isso, foram feitos diversos histogramas para analisarmos a distribuição das distâncias dos átomos nos nanotubos e no grafeno. Primeiramente, vamos analisar os histogramas para os nanotubos de carbono $(5,5)$ e $(8,0)$. Na figura 3.11 podemos observar a distribuição de distâncias $\left(d_{c c}\right)$ para os nanotubos armchair e zigzag, com a divacância 585 ou 555777.

Fazendo uma análise dos histogramas da figura 3.11, observamos, em ambos 

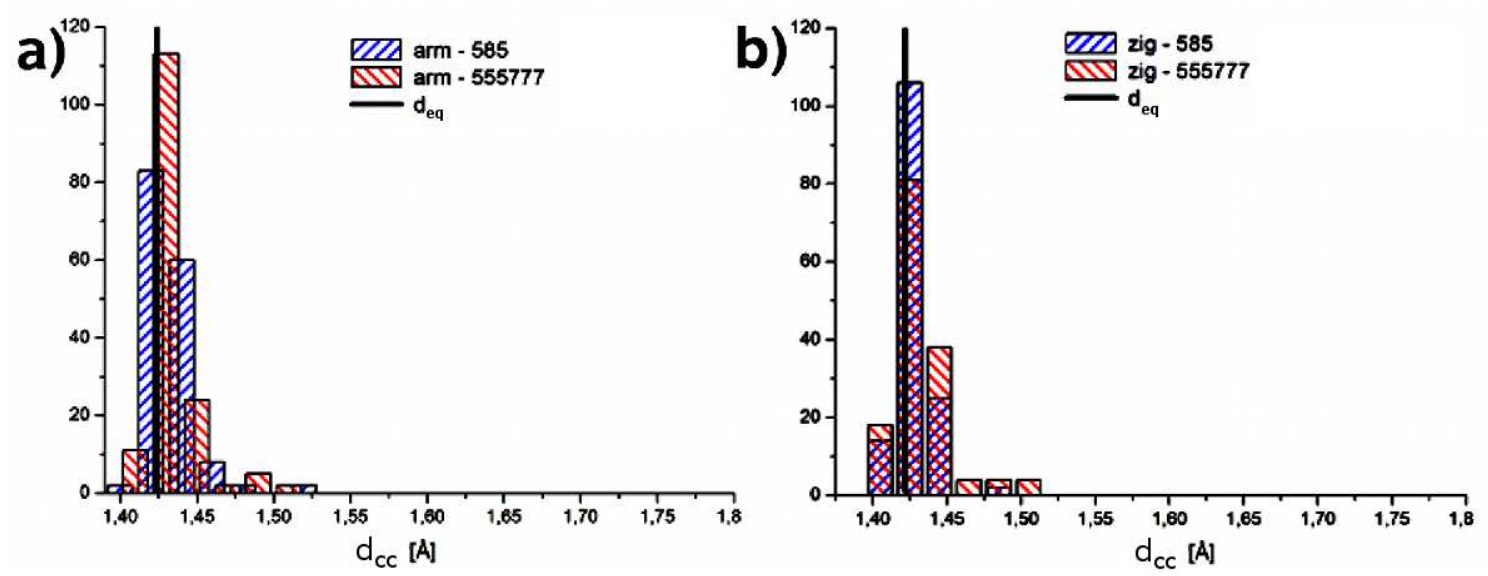

Figura 3.11: Mostramos dois histogramas das distâncias $\left(d_{c c}\right)$ para os nanotubos de carbono com o defeito 585 ou 555777. Em (a) apresentamos a distribuição das distâncias $\left(d_{c c}\right)$ para o tubo armchair $(5,5)$; e em (b) exibimos a distribuição das distâncias para o nanotubo zigzag (8,0). A linha sólida vertical representa a distâncias de equilíbrio $\left(d_{e q}\right)$ para o nanotubo sem defeito.

os casos, uma distribuição dos valores $\left(d_{c c}\right)$ em torno da distância de equilíbrio $\left(d_{e q} \simeq 1.42 \AA\right)$ do tubo puro, com uma variação de $\pm 0.2 \AA$, tanto para o defeito 585 quanto para o 555777. Observamos também, um pouco mais à direita, algumas ligações da ordem de 1.50 - $1.52 \AA$, que são devidas aos pentágonos formados pelos defeitos.

Quando fazemos a mesma análise para o grafeno, constatamos um comportamento análogo aos obtidos para os tubos, no entanto, observamos a presença de duas ligações da ordem de $1.77 \AA$ para o defeito 585. Estas ligações são referentes aos pentágonos do defeito 585, como podemos visualizar na figura 3.12.

O fato observado acima é um indicativo da provavél razão pela qual o defeito 585 é menos estável em grafeno.

Para confirmar essa idéia, vamos investigar um modelo simplificado. Primeiro, vamos estimar a diferença de energia elástica $\left(\Delta E_{\text {harm }}^{S}\right)$ entre as duas divacâncais estudadas, para cada estrutura. Para tal, utilizamos um modelo baseado numa Hamiltoniana simplificada de mecânica molecular para a energia elástica associada 


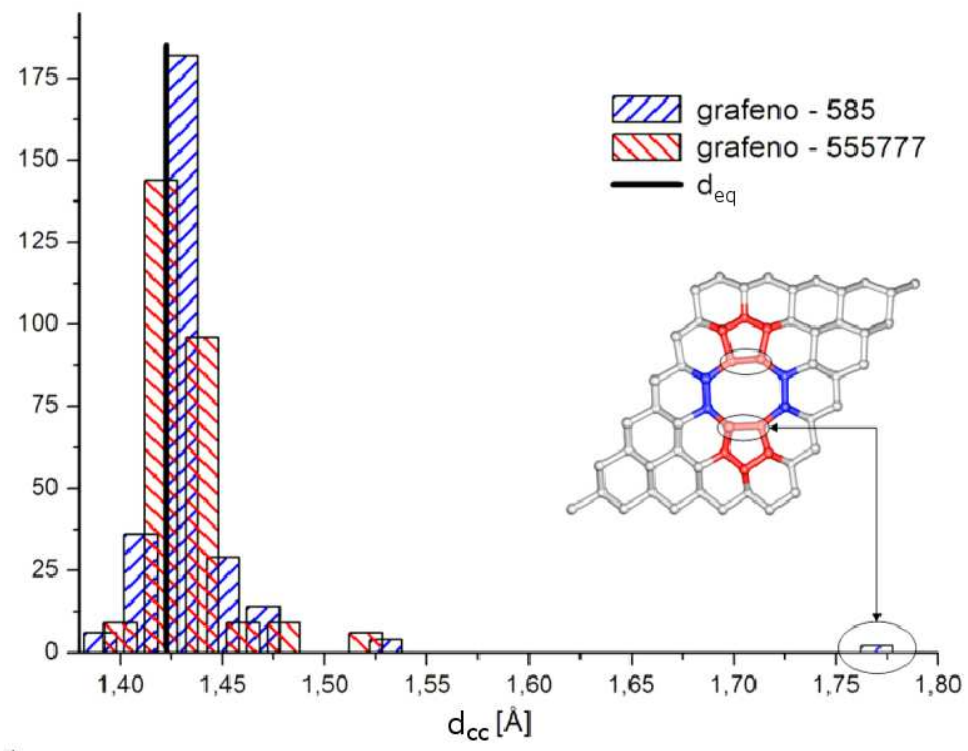

Figura 3.12: Apresentamos o histograma das distâncias $\left(d_{c c}\right)$, no grafeno, para os defeitos 585 e 555777. Em detalhe, mostramos as duas distâncias grandes que o defeito 585 possui.

às variações dos ângulos entre as ligações químicas, bem como às variações dos tamanhos das ligações. Iremos considerar três sistemas $S(\mathrm{~S}=$ grafeno, $\mathrm{CNT}(5,5)$ e CNT $(8,0))$, e dois defeitos $D(\mathrm{D}=585$ e 555777). A energia elástica (harmônica) total é definida como:

$$
\Delta E_{\text {harm }}^{S}(D)=\Delta E_{r}^{S}(D)+\Delta E_{\theta}^{S}(D)
$$

e, cada termo da equação acima pode ser definido como:

$$
\Delta E_{r}^{S}(D)=\frac{1}{2} \sum k_{r}\left(r_{c c}^{S}(D)-r_{0}^{S}\right)^{2}
$$

onde $r_{c c}$ são as distâncias das ligações $(C-C)$. A energia elástica angular é definida como:

$$
\Delta E_{\theta}^{S}(D)=\frac{1}{2} \sum k_{\theta}\left(\theta_{c c}^{S}(D)-\theta_{0}^{S}\right)^{2}
$$


e, neste caso, a variável $\theta_{c c}^{S}$ corresponde ao ângulo entre as ligações químicas $(C-C)$.

Os somatórios considerados nas equações acima são sobre as distâncias dos primeiros vizinhos e os ângulos, com uma restrição para as duas ligações grandes do defeito 585 que, neste caso, não serão consideradas. As distâncias e os ângulos foram obtidos a partir da geometria final de cálculos de primeiros princípios, e os valores das constantes elásticas ${ }^{3}\left(k_{r}\right.$ e $\left.k_{\theta}\right)$ foram extraídos da referência [91]. Os valores de $r_{0}^{S}$ e $\theta_{0}^{S}$, foram obtidos a partir de cálculos de primeiros princípios para os sistemas pristinos. A partir da expressão 3.3, calculamos a diferença $\left(\Delta E_{\text {harm }}^{S}=\right.$ $\left.\Delta E_{\text {harm }}^{S}(555777)-\Delta E_{\text {harm }}^{S}(585)\right)$ e, além disso, também obtemos a mesma diferença de energia total usando cálculos ab initio $\left(\Delta E_{t}^{S}=\Delta E_{t}^{S}(555777)-\Delta E_{t}^{S}(585)\right)$. Na tabela 3.1 apresentamos os resultados obtidos para a energia elástica $\left(\Delta E_{\text {harm }}^{S}\right)$ e para a energia total de primeiros princípios $\left(\Delta E_{t}^{S}\right)$.

Tabela 3.1: Mostramos os resultados obtidos para a diferença de energia elástica $\left(\Delta E_{\text {harm }}^{S}\right)$, e para diferença de energia total ab initio $\left(\Delta E_{t}^{S}\right)$ no caso dos defeitos 555777 e 585. As energias apresentadas abaixo são expressas em eV.

\begin{tabular}{c|c|c}
\hline \hline Sistema (S) & $\Delta E_{\text {harm }}^{S}[\mathrm{eV}]$ & $\Delta E_{t}^{S}[\mathrm{eV}]$ \\
\hline CNT $(5,5)$ & 0.6 & 0.7 \\
CNT $(8,0)$ & 2.0 & 1.7 \\
Grafeno & 1.0 & -0.8 \\
\hline \hline
\end{tabular}

Os resultados obtidos através de cálculos de primeiros princípios contêm dois tipos de contribuições: harmônica e não harmônica. A contribuição não harmônica está relacionada com as ligações químicas muito esticadas ou até mesmo "rompidas" e, por isso, atribuiremos a esse tipo de contribuição um caráter químico. Sendo assim, podemos dizer que: (i) a contribuição da energia elástica sempre favorece o defeito 585; e (ii) representa a maior parte da energia obtida através dos cálculos

\footnotetext{
${ }^{3}$ As constantes elásticas utilizadas neste trabalho assumem os seguintes valores: $\frac{1}{2} k_{r}=$ $469\left[\frac{\mathrm{kcal}}{\mathrm{mol} \cdot \AA^{2}}\right]$ e $\frac{1}{2} k_{\theta}=63\left[\frac{\mathrm{kcal}}{\mathrm{mol} \cdot \mathrm{rad}^{2}}\right]$.
} 
ab initio; (iii) no caso do grafeno, deve haver uma contribuição química que causa a inversão de estabilidade e, provavelmente, deve estar relacionada com os pentágonos do defeito 585. Para investigar a última hipótese apresentada vamos analisar a densidade de carga dos pentágonos nos sistemas estudados. Na figura 3.13 mostramos os pentágonos dos principais sistemas estudados.

a)

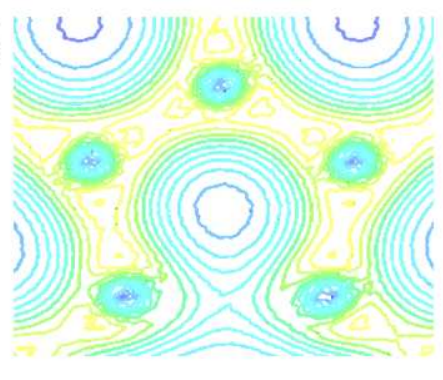

c)

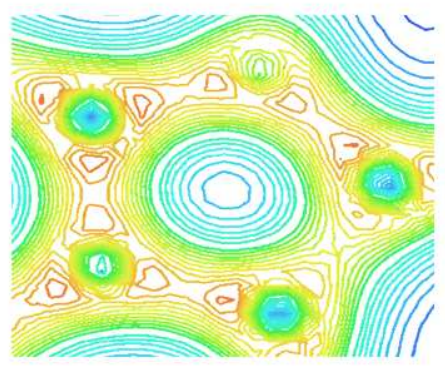

b)

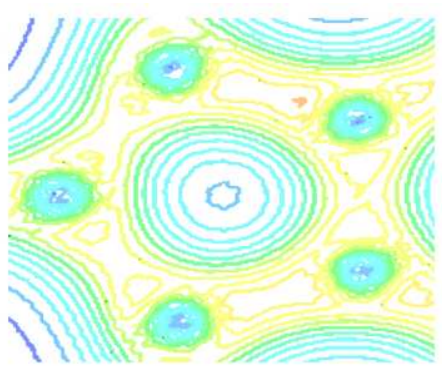

d)

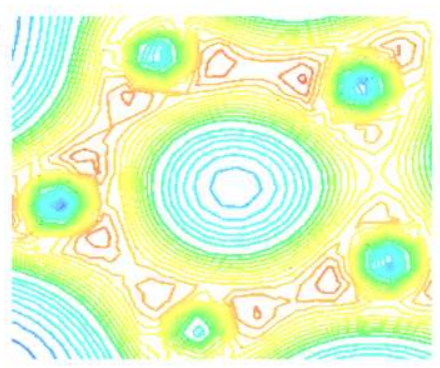

Figura 3.13: Apresentamos a densidade de carga eletrônica através das isolinhas, em um plano que passa pelos átomos de carbono do pentágono dos defeitos 585 e 555777. Em (a) e (b) apresentamos a densidade de cargas para o grafeno, para os defeitos 585 e 555777, respectivamente; as figuras (c) e (d) são referentes aos pentágonos do defeito 585 para tubos armchair $(5,5)$ e zigzag $(8,0)$, respectivamente.

De acordo com as densidades de carga da figura 3.13 observamos que, em todos os casos, as ligações químicas são fortes, exceto para a divacância 585 no grafeno (figura 3.13-a). Neste último caso, notamos uma menor concentração de isolinhas na ligação principal do pentágono.

Para estimar a contribuição química, vamos considerar a molécula $C_{5} H_{5}$ (Ciclopentadianil) como um sistema modelo. Na figura 3.14 mostramos a variação da energia total em função da distância $(d)$ entre os átomos de carbono de um dos 


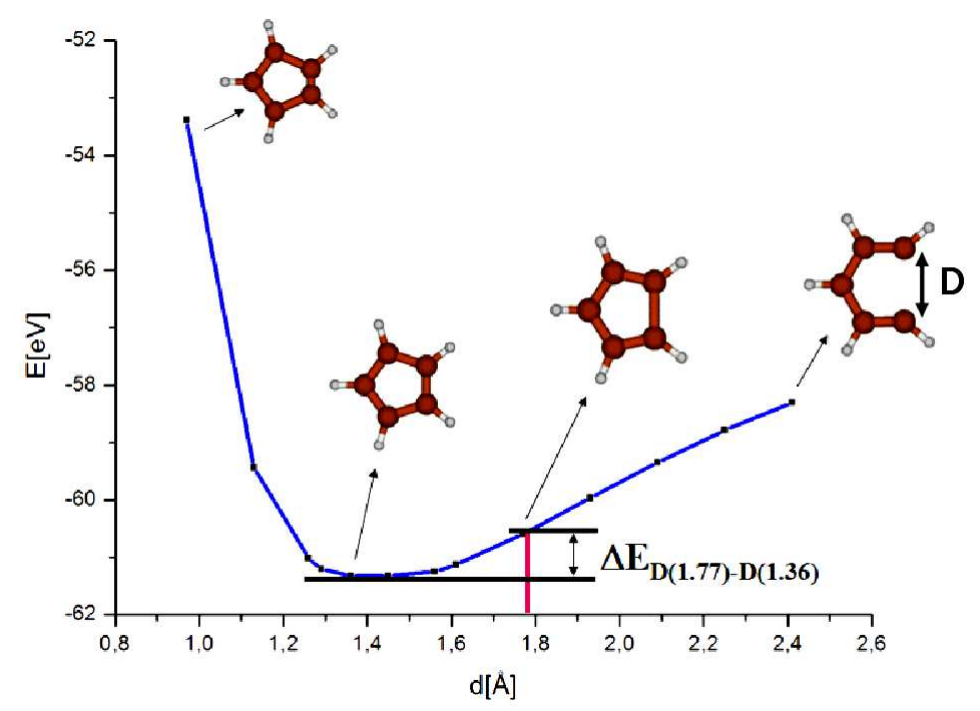

Figura 3.14: Apresentamos o gráfico da energia total em função da distância $\left(d_{c c}\right)$ do ciclopentadianil.

lados do pentágono da molécula $\left(C_{5} H_{5}\right)$. A diferença de energia entre a distância de equilíbrio $(1.36 \AA$ ) e a posição $1.77 \AA$ é $\approx 0.75 \mathrm{eV}$. Como no grafeno o defeito 585 possui duas ligações dessa ordem, a contribuição para energia total será $\approx 1.5 \mathrm{eV}$. Analisando as contribuições estudadas constatamos que, no grafeno, a contribuição da energia elástica faz com que o defeito 555777 seja menos estável do que o defeito 585 por aproximadamente $1.0 \mathrm{eV}$ (como em todos os sistemas estudados). No entanto, no caso do grafeno existe uma contribuição devido ao rompimento de duas ligações químicas do defeito 585, devido à sua característica planar. A contribuição química torna o defeito 585 menos estável que o defeito 555777 por aproximadamente $1.5 \mathrm{eV}$. A diferença entre a contribuição da energia elástica (harmônica) e a química, no grafeno $\left(\Delta E^{\text {grafeno }}=\Delta E_{\text {harm }}^{\text {grafeno }}-\Delta E_{\text {quim }}^{\text {grafeno }}\right)$, nos fornece o seguinte resultado:

$$
\Delta E^{\text {grafeno }}=1.0-1.5=-0.5-\mathrm{eV}
$$

que agora está de acordo com nossas previsões utilizando cálculos de primeiros 
princípios $\left(\Delta E_{t}^{\text {grefeno }}=-0.8 \mathrm{eV}\right)$. Em outras palavras, o defeito 585 é menos estável do que o defeito 555777 no grafeno devido à quebra de duas ligações químicas dos pentágonos e, neste caso, a contribuição química domina a elástica.

Na próxima seção vamos apresentar os resultados de como os defeitos estruturais modificam as propriedades de transporte eletrônico em nanotubos de parede simples.

\subsection{Propriedades de transporte eletrônico das di- vacâncias}

Nesta seção apresentaremos um estudo sobre a influência das divacâncias nas propriedades de transporte eletrônico em nanotubos de carbono armchair. Como foi dito na parte introdutória desse capítulo, pequenas concentrações de divacâncias (0.03\%) podem modificar significativamente as propriedades de transporte eletrônico [54]. No entanto, como apresentado nas seções anteriores, existem duas possíveis configurações para as divacâncias (585 e 555777). Sendo assim, investigaremos as propriedades de transporte para esses sistemas.

O formalismo utilizado para realização desses cálculos foi baseado em funções de Green fora do equilíbrio (NEGF) combinada com a teoria do funcional da densidade (DFT), implementadas no código TranSAMPA [88]. Este código foi desenvolvido em nosso grupo de pesquisa e sua implementação usa o código Siesta [89] como plataforma.

Para esses cálculos utilizamos um nanotubo $(5,5)$, no qual três células unitárias (u.c.), no lado esquerdo e direito, são dos eletrodos conectados à região central (supermolécula) contendo 7 u.c., onde são criados os defeitos. Na figura 3.15 mostramos a geometria utilizada nos cálculos.

Estamos interessados no cálculo da transmitância, $T(E)$, que é definida [92] como a probabilidade de um canal de elétrons passar do eletrodo esquerdo para o eletrodo 
a)

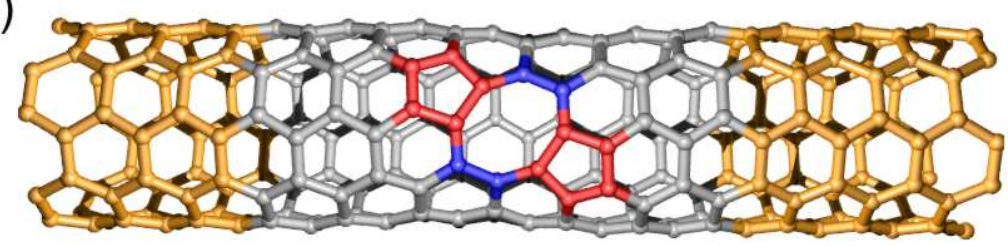

b)

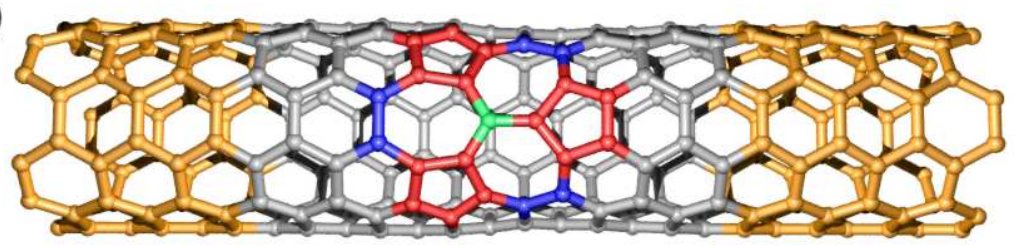

Figura 3.15: Mostramos as geometrias para o nanotubo $(5,5)$ utilizadas nos cálculos de transporte. Os eletrodos são representados pelos átomos em laranja e a região da supermolécula está entre os eletrodos. Apresentamos em (a) o defeito 585; e em (b) o defeito $55577 \%$.

direito. A transmitância pode ser escrita como:

$$
T(E)=\operatorname{Tr}\left[\Gamma_{L} G_{R} \Gamma_{R} G_{a}\right]
$$

onde, os $\Gamma_{L(R)}$ farão os acoplamentos dos eletrodos com a supermolécula. A função de Green retardada é escrita em função de H e S da supermolécula e das autoenergias $\Sigma_{L(R)}$ dos eletrodos, ou seja, podemos escrever esta função como:

$$
G_{R}=\left(H-E S-\Sigma_{R}-\Sigma_{L}\right)^{-1}
$$

No caso da função de Green adiantada, podemos obtê-la a partir da função de Green retardada $\left(G_{A}=G_{R}^{\dagger}\right)$. Para calcular a transmitância, precisamos da matriz de acoplamento $\Gamma_{L(R)}=i\left[\Sigma_{L(R)}-\Sigma_{L(R)}^{\dagger}\right]$ e da função de Green retardada $\left(G_{R}\right)$.

Do ponto de vista prático, o procedimento utilizado para o cálculo da transmitância foi o seguinte: (i) foi feito um cálculo padrão com três células unitárias e condições periódicas de contorno. Quando a autoconsistência é obtida, calculamos as autoenergias dos eletrodos, que serão armazenadas em um arquivo para futuras 
aplicações (as autoenergias serão utilizadas para construir a matriz de acoplamento Г; (ii) montamos a configuração para o cálculo de transporte (eletrodo esquerdo, supermolécula e eletrodo direito). Para a região da supermolécula inserimos algumas células extras para garantir que, na região de fronteira, os elementos do Hamiltoniano e a densidade de carga sejam os mesmos dos eletrodos. De posse dos acoplamentos podemos calcular a função de Green retardada e, por fim, a função de transmissão, $T(E)$, usando a equação 3.7. Calculamos a transmitância para um nanotubo pristino, e o resultado obtido para este sistema foi $2 G_{0}$, onde $G_{0}=2 e^{2} / h$.

Partimos para o objetivo central dessa seção, que é o cálculo da transmitância para as duas divacâncias, e o resultados são apresentados na figura 3.16.

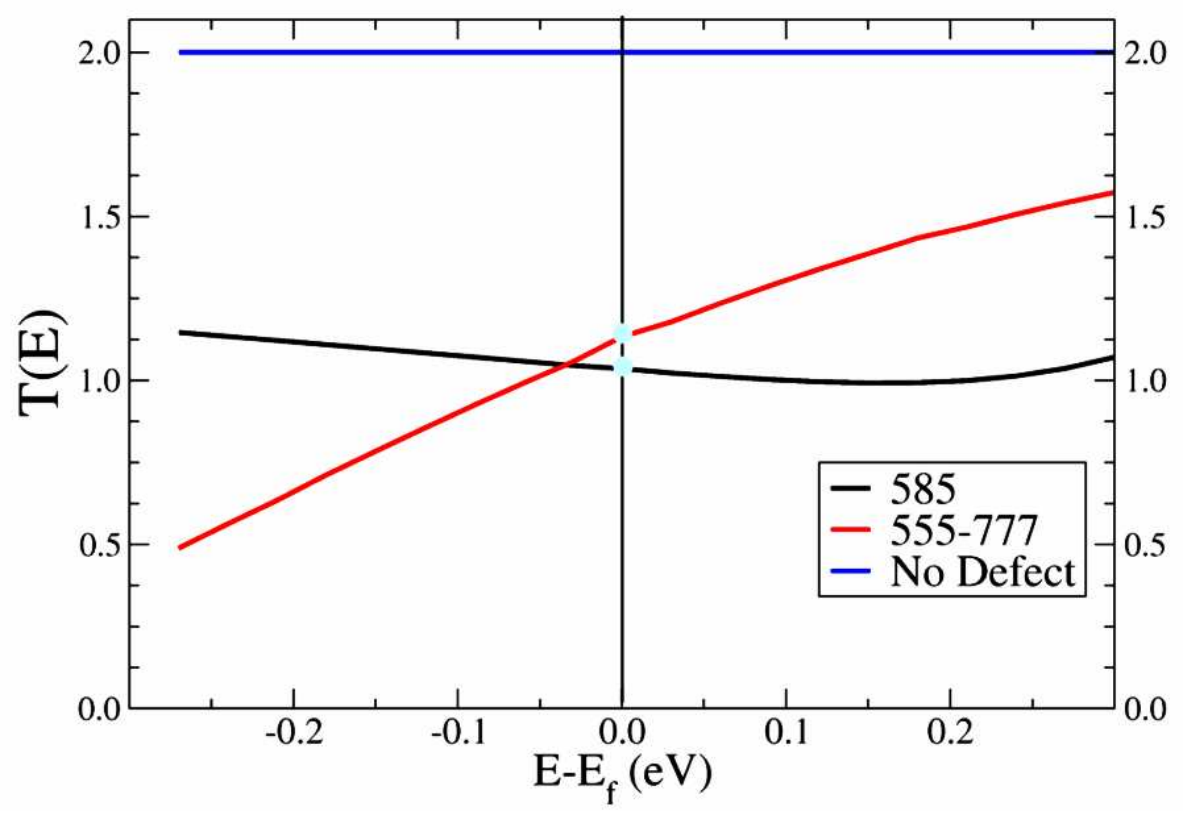

Figura 3.16: Apresentamos o gráfico da transmitância em função da energia, para o nanutubo $(5,5)$ pristino, divacância 585 e 555777. A transmitância é apresentada em unidades de $G_{0}$.

Para ambos os defeitos notamos uma diminuição significativa no valor da transmitância no nível de Fermi, $E_{\text {fermi }}$, como observado para o defeito 585 em outros trabalhos [54]. É importante frisar que medidas de baixa voltagem provavelmente 
não sejam capazes de distinguir os dois defeitos, mas o defeito 555777 tem um comportamento ligeiramente distinto para a transmitância em função da voltagem, e ele pode nos fornecer sinais distintos. Para uma maior compreensão do comportamento desses dois defeitos, uma análise mais detalhada das propriedades de transporte se faz necessária através de cálculos de sistemas desordenados variando as orientações e a concentração destes defeitos. 


\section{Capítulo 4}

\section{Defeitos em feixes de CNTs}

Os nanotubos de parede simples (SWCNT), desde a sua descoberta, vêm chamando a atenção da comunidade científica pela sua versatilidade em agregar diversas propriedades interessantes, e este fato torna-o um candidato em potencial para diferentes tipos de aplicações. Nos dois capítulos anteriores mostramos como os defeitos estruturais modificam as propriedades dos nanotubos de parede simples e, em especial, discutimos a estabilidade, as propriedades eletrônicas e também as influência das divacâncias no transporte eletrônico. No entanto, os nanotubos possuem outras propriedades que merecem destaque. Do ponto de vista de propriedades mecânicas, um nanotubo possui um módulo Young [5] da ordem de $1.0 \mathrm{TPa}^{1}$. Para aplicar nanotubos em ensaios mecânicos, dificilmente teremos um único tubo e, sendo assim, uma maneira para fazer essa aplicação é através de feixes de nanotubos ou, como são conhecidos na literatura, "bundles". Na utilização desse arranjo de nanotubos em ensaios mecânicos, foi observado que os feixes fornecem uma performance ruim comparados com um único tubo pois, neste caso, eles podem deslizar uns contra os outros degradando as propriedades mecânicas. A força que mantém os nanotubos

\footnotetext{
${ }^{1} \mathrm{O}$ módulo de Bulk do Diamante [93] é aproximadamente 432 GPa. Fazendo uma compararação deste valor e o correspondente em nanotubos, observamos que esta propriedade em tubos é, pelo menos, duas vezes maior do que em diamante.
} 
juntos é fraca, do tipo van der Waals. Recentemente pesquisadores [43] descobriram que, usando irradiação de íons em feixes de nanotubos, eles podem criar conexões entre as paredes dos nanotubos. A criação dessas conexões aumenta o módulo de flexão (bending) por um fator de 30. Esse resultado é um indicativo de que, criar conexões nas paredes de nanotubos, pode abrir um novo caminho no que diz respeito à fabricação de fibras ultrarresistentes. Experimentalmente, alguns grupos $[6,7,94]$ usam feixes de nanotubos juntamente com nanotubos de paredes múltiplas para produzir cabos de alta resistência mas, segundo os autores, a grande dificuldade encontrada para esta aplicação é, como já foi mencionado acima, que esses tubos podem deslizar uns com relação aos outros, degradando as propriedades mecânicas.

A irradiação de íons tem sido usada por diversos grupos experimentais [34,36, 37, 39-41, 43, 59] e teóricos [4,33, 40,41, 46, 48, 59] para modificar as propriedades dos nanotubos de carbono. Entretanto, o conhecimento microscópio detalhado dos defeitos criados neste processo é necessário para que possamos, cada vez mais, ter um maior controle desses materiais. Precisamos de um estudo rigoroso dos defeitos em feixes de nanotubos, onde propriedades tais como energia de formação, estabilidade, geometria e estrutura eletrônica sejam amplamente investigadas para que possamos prever os principais defeitos nesses sistemas e como esses defeitos modificam as propriedades mecânicas dos feixes de nanotubos.

Na literatura encontramos poucos estudos teóricos que, de fato, caracterizam os possíveis defeitos que possam ser criados em processos de irradiação e, na grande maioria desses trabalhos, os autores utilizaram dinâmica molecular, onde as interações entre os átomos são descritas por potenciais empíricos. Estes trabalhos têm grande importância para entendermos o processo de criação dos defeitos através dos impactos de íons nas paredes do nanotubos e também são um indicativo de que processos podem ocorrer. Como foi dito na introdução, esse tipo de modelagem não considera religação de ligações químicas, redistribuição de cargas, processo de 
rehibridização, que na irradiação de íons particularmente ocorrem.

Portanto, embora alguns trabalhos teóricos $[4,33,40,41,46,48,59]$ já tenham previsto que conexões podem ser criadas após esses processos de irradiação de íons, um estudo detalhado sobre como a influência dos defeitos estruturais em feixes podem modificar as propriedades mecânicas desse sistema e, além disso, a caracterização e o entendimento do processo de formação dessas conexões se faz necessária.

Neste capítulo, apresentaremos um estudo detalhado de defeitos em feixes de nanotubos de carbono. Vamos investigar a influência desses defeitos nas propriedades mecânicas e, além disso, mostraremos o caminho de reação do processo de formação das conexões. Basicamente, queremos responder questões fundamentais para o problema tais como: quais são o principais defeitos em feixes de nanotubos? Do ponto de vista de estabilidade, qual dos defeitos é o mais estável, e como são as energias de formação desses defeitos quando comparamos com os mesmos no grafite? As ligações químicas das conexões são fortes? Como o módulo de cisalhamento se comporta em feixes de nanotubos sem defeitos? Como essa mesma propriedade é modificada quando inserimos defeitos estruturais? Nestes sistemas existe uma barreira de recombinação de energia para desfazer os defeitos? Os defeitos são estáveis à temperatura ambiente?

Apresentado o problema, nas próximas seções responderemos às questões mais relevantes sobre defeitos em feixes de nanotubos de carbono.

\subsection{Protocolo de simulação}

Para este estudo utilizamos cálculos de primeiros princípios baseados na teoria do funcional da densidade [83,84] (DFT). Utilizamos os pseudopotencias ultra suaves de Vanderbilt [87] e, para a energia de correlação e troca, usamos a aproximação da densidade local (LDA). Maiores detalhes sobre a metodologia empregada nesta tese encontra-se no apêndice A. Os nanotubos utilizados são do tipo armchair $(5,5)$ 
com cinco células unitárias e cerca de 200 átomos. Foram utilizados 6 pontos k, sendo que três deles na direção z (direção do eixo do CNT) e dois pontos k na direção y. Os cálculos referentes as propriedades estruturais foram feitos com o código VASP $[85,86]$ e, para os cálculos do caminho de reação, utilizamos o método Nudged Elastic Band (NEB) [95,96] implementado no código VASP.

\subsection{Defeitos}

Os feixes de nanotubos de carbono são constituídos por tubos dispostos de forma hexagonal, como mostrado na figura 4.1-a. A distância entre as paredes foi otimizada, e o valor encontrado para a mesma foi de $0.34 \mathrm{~nm}$. Esse espaçamento entre nanotubos dispostos na forma de feixes é o mesmo obtido entre folhas de grafeno em grafite. Na supercélula utilizamos 200 átomos e cinco células unitárias na direção do eixo do nanotubo de modo que a linha de contato, isto é, as fileiras de átomos de cada tubo, estejam uma sobre a outra. Esta escolha não é restritiva por dois motivos, tanto pelo fato da interação entre os tubos ser fraca (de característica van der Waals) quanto pelo fato de que, em temperaturas ambientes, teremos uma grande liberdade rotacional para os nanotubos. O ponto importante no que diz respeito à estabilidade dos defeitos em feixes é a curvatura que os nanotubos possuem.

No capítulo anterior, apresentamos um trabalho onde os autores [81] mostraram que os principais produtos após a colisão de íons em nanotubos são: átomos intersticiais, monovacâncias e divacâncias. Um ponto de partida para obtermos bons candidatos a defeitos em feixes de nanotubos são os que possuem algum dos tipos de defeitos mencionados acima. Para grafeno, existem alguns trabalhos onde os autores $[31,32]$ estudam diversos defeitos estruturais. Basicamente, eles investigaram os seguintes defeitos: um do tipo vacância-interstício (VI), conhecido como defeito de Wigner, e dois do tipo vacância-vacância (VV), que chamaremos de $V_{2}^{1}$ e $V_{2}^{2}$. Esses defeitos são bons candidatos para nosso estudo pois, de certo modo, possuem átomos 
intersticiais ou vacâncias, o que também corrobora com a hipótese do trabalho [81]. Os autores mostraram a estabilidade dos defeitos em grafite e, além disso, fizeram uma discussão sobre a barreira de formação para o caso do Wigner. Na figura 4.1 mostramos o defeito de Wigner.

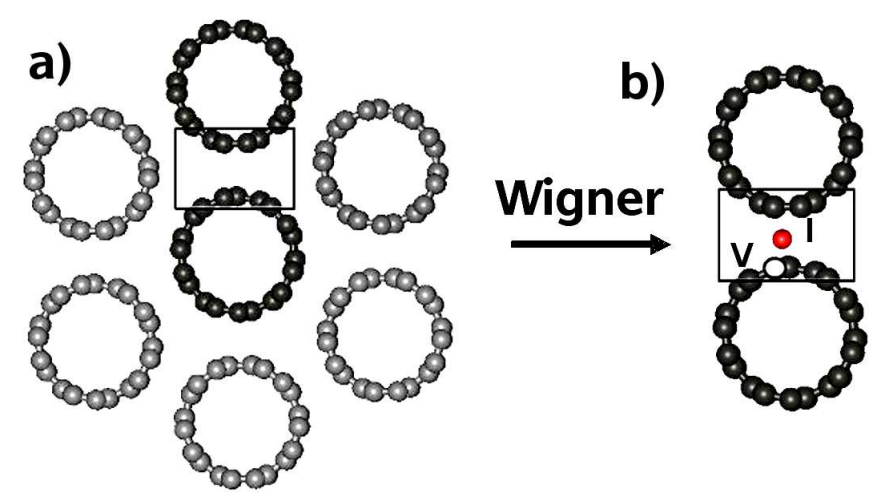

Figura 4.1: Apresentamos a geometrias de um feixe de nanotubos armchair (5,5). Em (a) mostramos a representação atomistica de um feixe de nanotubos; em (b) apresentamos dois nanotubos do feixe e o retângulo representa a região intersticial.

O defeito de Wigner é formado por um par de Frenkel, onde um átomo do cristal é deslocado para região intersticial (átomo em vermelho na figura 4.1). No caso do grafite essa região fica entre os planos dos grafenos e, para os feixes de tubos, a região intersticial fica entre as paredes dos nanotubos, como podemos ver na figura 4.1b. Um estudo detalhado desse defeito em feixes de nanotubos, utilizando métodos de primeiros princípios, foi realizado no nosso grupo [33] e, posteriormente, vamos compará-lo com o presente trabalho. A segunda classe de defeitos em grafeno, estudada pelos autores na referência [32], foram as que possuem duas vacâncias, sendo uma em cada folha de grafeno. No capítulo 2, mostramos que a monovacância possui um átomo com uma ligação pendente e, que essa ligação era extremamente reativa. Os defeitos do tipo $(\mathrm{V}-\mathrm{V})$ possuem duas monovacâncias, e cada uma das ligações pendentes estão sobre uma linha de contato adjacente (uma sobre a outra). Quando isso ocorre, é possível que uma conexão entre os sistemas se estabeleça 
através desses átomos. Para que essa discussão fique mais clara, vamos analisar um esquema no grafeno dos defeitos do tipo (VV) através da figura 4.2.

a)
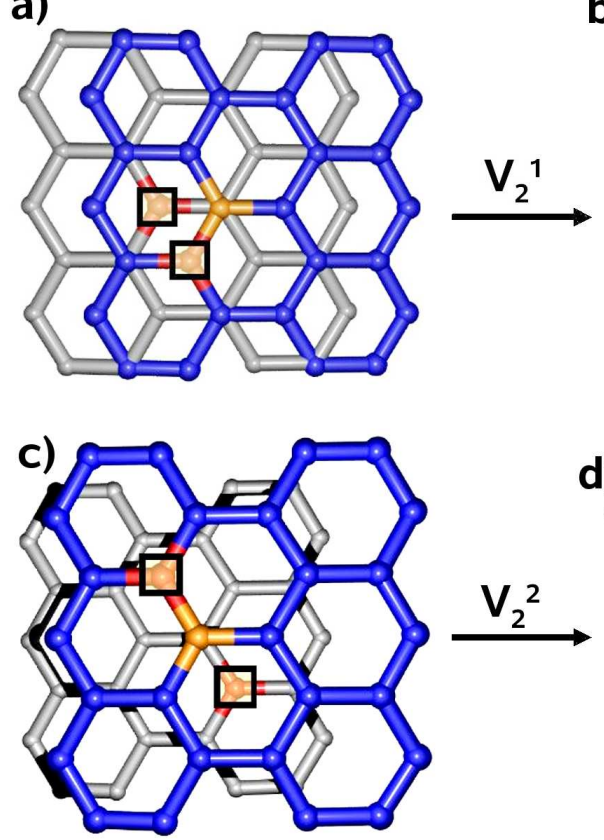

b)

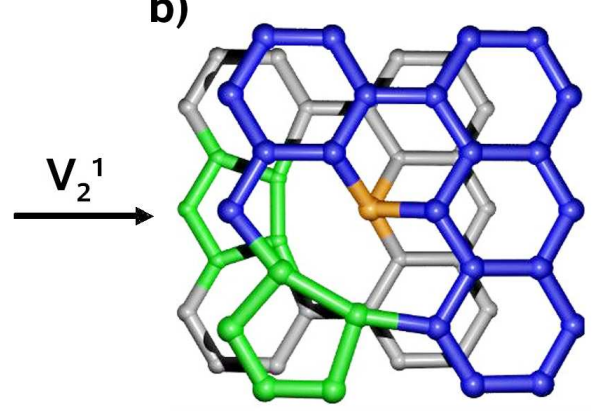

d)

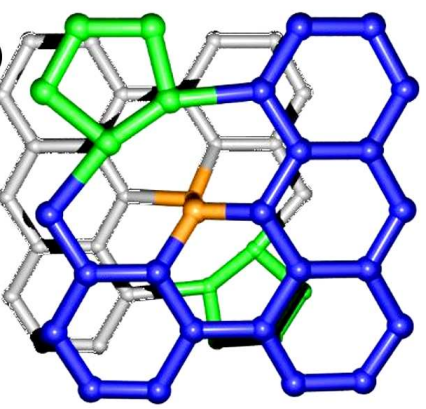

Figura 4.2: Mostramos dois defeitos do tipo vacância-vacância em grafeno. Em todas as figuras, apresentamos os quadrados que representam os locais onde serão feitas as vacâncias e em laranja o átomo que possivelmente fará a conexão. Em (a) exibimos um esquema, antes de subtrair os átomos, para o defeito $V_{2}^{1}$; em (b) mostramos o defeito $V_{2}^{1}$, com os pentágonos reconstruídos e a conexão estabelecida; (c) apresentamos o mesmo esquema mostrado em (a) para o defeito $V_{2}^{2}$; e em (d) o defeito $V_{2}^{2}$.

O defeito $V_{2}^{1}$ é mostrado esquematicamente nas figuras 4.2-a e 4.2-b, onde notamos que o átomo em laranja, por estar numa linha de contato, encontra-se sobre outro que pertence ao plano inferior. Quando as vacâncias são criadas ocorre um rearranjo das ligações formando os pentágonos, e os átomos em laranja ficam com ligações pendentes que, por sua vez, serão responsáveis pelas conexões. O mesmo processo ocorre para o defeito $V_{2}^{2}$ e, a diferença principal entre eles é o posicionamento dos pentágonos reconstruídos. Em relação aos átomos em laranja, os 
pentágonos reconstruídos se encontram na forma de $V$ (figura 4.2-c), para o defeito $V_{2}^{1}$, enquanto que para o defeito $V_{2}^{2}$ (figura 4.2-d) os pentágonos ficam diametralmente opostos à conexão formada pelos átomos em laranja.

Mostramos os defeitos do tipo vacância-vacância em grafeno pois assim temos uma melhor visualização dos mesmos. Na figura 4.3 podemos observar, em detalhe, os defeitos $V_{2}^{1}$ e $V_{2}^{2}$ em feixes de nanotubos de carbono.

a)

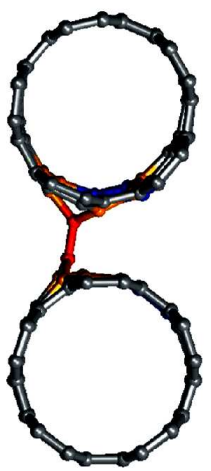

b)

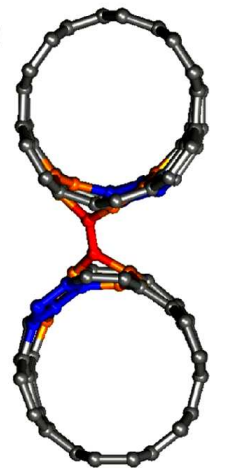

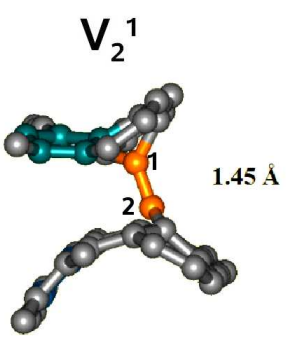

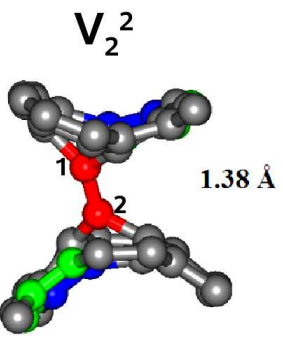

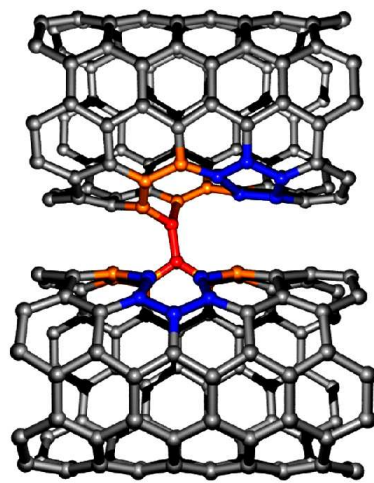

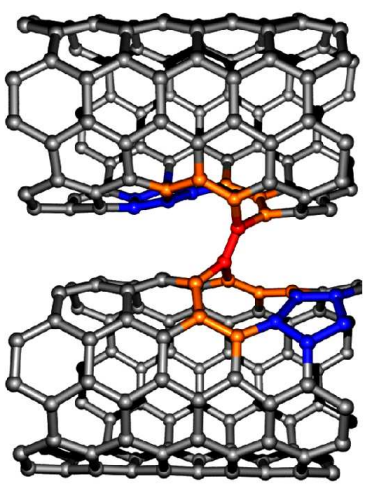

Figura 4.3: Apresentamos dois defeitos do tipo $V V$ em feixes de nanotubos. Em (a) mostramos o defeitos $V_{2}^{1}$ e, no detalhe, a conexão formada; em (b) exibimos o defeito $V_{2}^{2}$ e também o detalhe da conexão entre os tubos.

Em ambos os casos observamos os pentágonos formados após a criação da conexão (em azul) e, em detalhe, as ligações entre as paredes dos tubos. Devido à curvatura do tubo, os átomos que participam da conexão tendem a retroceder à posição original e, para que isso não aconteça, os átomos responsáveis pelas formação 
dos defeitos são mantidos fixos nos primeiros passos de relaxação.

$\mathrm{O}$ defeito $V_{2}^{2}$ apresentou a menor ligação química para os átomos da conexão ${ }^{2}$ $\left(d_{12}\right)$, cerca de $1.38 \AA$, enquanto que para o defeito $V_{2}^{1}$, essa foi de $1.45 \AA$. Em ambos os casos as flutuações em relação à distância de equilíbrio (1.42 A) foram de no máximo de $0.4 \AA$. Na próxima seção vamos apresentar a estabilidade dos defeitos do tipo (VV) para feixes de nanotubos de carbono.

\subsection{Estabilidade dos Defeitos}

Na seção precedente apresentamos dois defeitos do tipo $\mathrm{VV}, V_{2}^{1}$ e $V_{2}^{2}$, em feixes de nanotubos de carbono e também mostramos os comprimentos de ligação dos átomos responsáveis pela conexão entre as paredes dos tubos. Antes de discutir a estabilidade dos defeitos através da energia de formação, vamos analisar as densidades de carga através de um plano que passa pela ligação da conexão formada. Estamos interessados em analisar a intensidade dessa ligação e, para este fim, mostramos na figura 4.4 as densidades de carga para o tubo puro e para os defeitos $V_{2}^{1}$ e $V_{2}^{2}$.

Na figura 4.4-a mostramos a densidade de carga em um plano passando perpendicularmente ao eixo do feixes de nanotubos, onde observamos cinco ligações do tipo $(C-C)$ para cada nanotubo do feixe. Essas ligações são representadas pela forte intensidade da densidade de carga sobre essas ligações. Ao lado de cada figura de densidade de cargas mostramos também a representação atomística correspondente para servir de guia e facilitar o entendimento da mesma. Para o defeito $V_{2}^{1}$, constatamos na figura 4.4-b que a conexão que liga as paredes dos nanotubos possui valores máximos da densidade de carga na conexão criada entre os tubos e, neste caso, cada tubo permanece com quatro ligações idênticas a do nanotubo puro, e um anél de cada tubo é conectado pela ligação dos átomos 1 e 2 mostrada na figura 4.3. No caso do defeito $V_{2}^{2}$, observamos o mesmo comportamento para a densidade de

\footnotetext{
${ }^{2}$ Os índices são referentes aos átomos com seus respectivos rótulos da figura 4.3.
} 


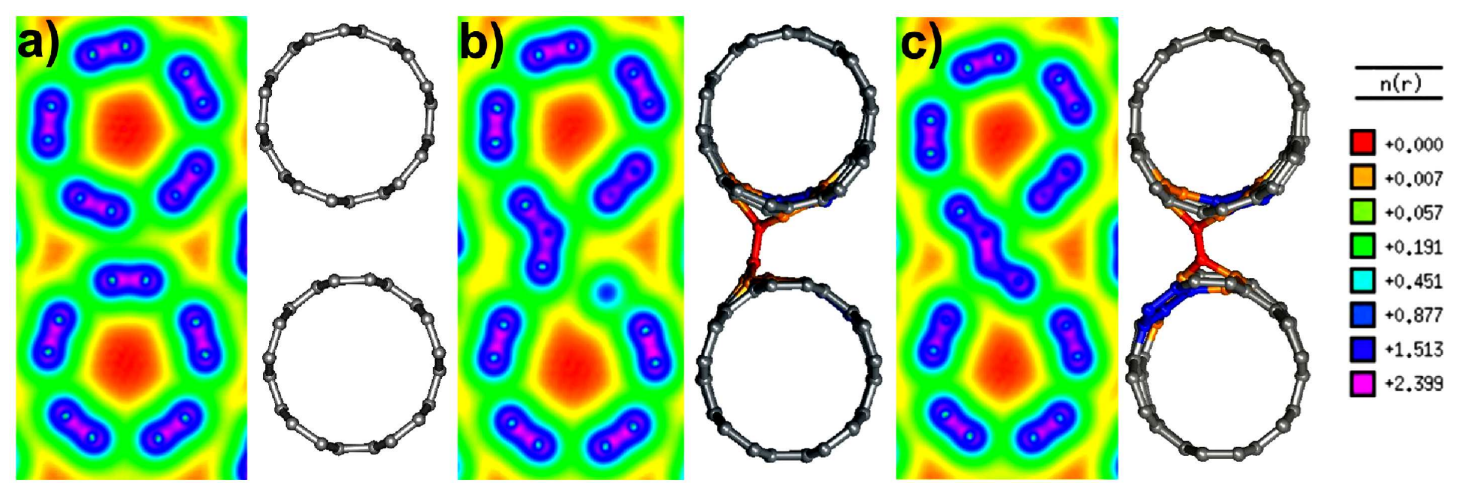

Figura 4.4: Mostramos a densidade de carga, em elétron/ $\AA^{3}$, para $C N T(5,5)$ na forma de feixes e suas respectivas representações atomísticas. Em (a) apresentamos a densidade de carga do feixe de tubos sem defeito; em (b) exibimos a densidade de carga para o defeito $V_{2}^{1}$ numa visão perpendicular ao eixo do CNT; e em (c) mostramos a densidade de carga para o defeito $V_{2}^{2}$.

cargas (figura 4.4-c), e a única diferença está na disposição da conexão em relação aos átomos que são recombinados. O presente resultado, em ambos os casos, é um indicativo de que as conexões entre os nanotubos são fortes.

Calculamos a energia de formação para os defeitos e constatamos que, em ambos os casos, eles são mais estáveis do que os mesmos defeitos em grafite [32], e esse resultado é um indicativo de que eles podem ser produzidos mais facilmente em feixes de nanotubos quando são expostos a processos de irradiação. O defeito $V_{2}^{1}$ é cerca de $2.8 \mathrm{eV}$ mais estável em feixes do que em grafite e, no caso do defeito $V_{2}^{2}$, observamos uma energia de formação $5.5 \mathrm{eV}$ mais estável do que em grafite. Como vimos no capítulo 2, a energia de formação de uma única vacância em um nanotubo $(5,5)$ é de aproximadamente $5.7 \mathrm{eV}$. Considerando que nesses defeitos possuímos duas monovacâncias $(11.7 \mathrm{eV})$, o custo energético para formar os defeitos acima apresentados é menor do que duas monovacâncias isoladas. Na tabela 4.1 mostramos todas as energias de formação dos sistemas estudados.

Dentre todos os defeitos em feixes de nanotubos estudados, o que apresentou a menor energia de formação foi o defeito de Wigner [33], estudado em nosso grupo, 
Tabela 4.1: Apresentamos na presente tabela as energias de formação, dadas em $\mathrm{eV}$, e a distância da ligação intertubos $\left(d_{12}\right)$, em $\AA$, para o defeito de Wigner nos feixes de nanotubos [33] e para os defeitos do tipo vacância-vacância no grafite [32] e nos feixes de nanotubos.

\begin{tabular}{|c|c|c|c|c|c|c|}
\hline \multirow[t]{2}{*}{ Defeito } & \multicolumn{2}{|c|}{ Wigner } & \multicolumn{2}{|c|}{$\bar{V}_{2}^{1}$} & \multicolumn{2}{|c|}{ 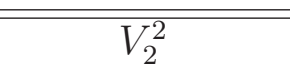 } \\
\hline & $E_{F}$ & $d_{12}$ & $E_{F}$ & $d_{12}$ & $E_{F}$ & $d_{12}$ \\
\hline Grafite & 10.8 & 1.33 & 12.7 & 1.43 & 13.0 & 1.38 \\
\hline Feixe (CNT) & 5.5 & 1.36 & 9.9 & 1.45 & 7.5 & 1.38 \\
\hline
\end{tabular}

cuja energia de formação é cerca de $5.5 \mathrm{eV}$, isto é, da ordem de uma monovacância em um tubo $(5,5)$.

Uma vez apresentados os resultados sobre a estabilidade dos defeitos em feixes, bem como feita uma discussão dos resultados comparando com os mesmos defeitos em grafite, vamos apresentar na próxima seção como é o processo de formação da conexão através do caminho de reação.

\subsection{Processo de formação dos defeitos}

Nesta seção, vamos investigar o processo de formação do defeito e que também está ligado à estabilidade do mesmo. Para isso, vamos voltar ao grafite onde os autores na referência [97] propuseram que o defeito responsável pela liberação de energia a $200^{\circ}$ C, é o defeito de Wigner, e esse valor está associado à barreira de energia obtida experimentalmente $(1.4 \pm 0.4 \mathrm{eV})$. Resultados teóricos [32] confirmaram o valor obtido experimentalmente e, associaram à barreira de energia experimental à recombinação do defeito, onde o valor obtido foi de $1.3 \mathrm{eV}$.

Para estimar a barreira de recombinação para os defeitos do tipo VV, vamos utilizar um método para encontrar o caminho de reação química ou, como é conhecido na literatura, Nudged Elastic Band (NEB) [95,96]. Para estimar a barreira, fazemos 
uma interpolação linear geométrica das coordenadas de dois estados de interesse, o inicial que consiste no nanotubo com dois defeitos, mas sem a conexão estabelecida, e o estado final que consiste na geometria final de um dos defeitos estudados $\left(V_{2}^{1}\right.$ ou $\left.V_{2}^{2}\right)$. Com a interpolação são gerados estados intermediários através das respectivas imagens e, no nosso trabalho, calculamos dez imagens. Para encontrar o caminho de reação a partir do método NEB, associamos uma mola a cada imagem intermediária, e esta se conecta com um estado precedente e posterior. Com isso impomos um vínculo aos estados intermediários. No entanto, o primeiro e o último estado somente se conectam com uma única imagem. Na figura 4.5 apresentamos um esquema do método NEB.

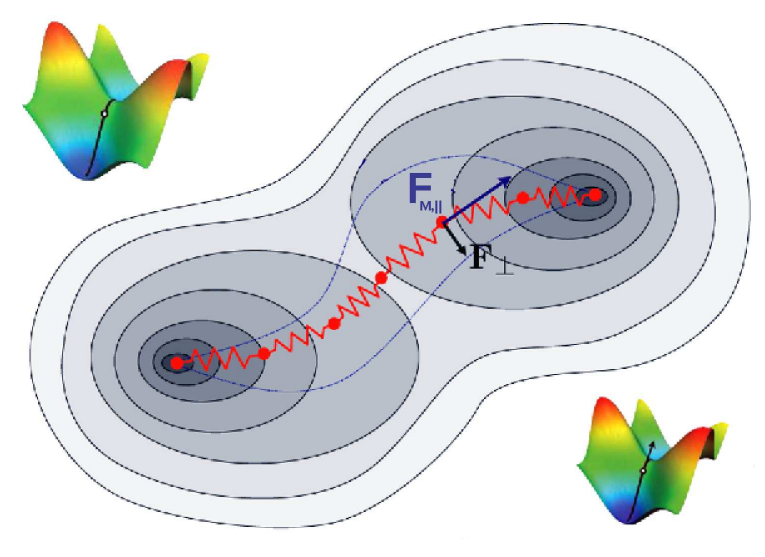

Figura 4.5: Esquematicamente apresentamos o método NEB através de dois mínimos locais e suas imagens conectadas por molas. As imagens intermediárias são obtidas a partir de uma interpolação linear geométrica.

Neste método otimizamos uma nova força , $F_{N E B}$, que dependerá da força das molas e de uma outra força perpendicular, como mostramos no esquema da figura 4.5, obtendo assim o caminho de reação. Para termos uma idéia do tamanho do problema que queremos resolver, considerando as dez imagens, este cálculo corresponde a uma simulação ab initio de 2000 átomos. Não entraremos em maiores detalhes a respeito deste método, e para um maior detalhamento do método NEB seguem as 
referências $[95,96]$.

Estamos interessados em dois processos: o primeiro é a barreira de recombinação do defeito. Este processo possui a imagem inicial como sendo um feixe de nanotubos com duas vacâncias e com a conexão entre as paredes não estabelecidas e o estado final consiste no mesmo defeito mas neste caso os tubos possuem uma conexão (parte I); o segundo processo parte do estado final da parte I, e tem como estado final um feixe com um tubo puro e uma divacância (parte II). Esse último processo corresponde à energia necessária para subtrair um átomo da conexão para um dos tubos, tornando-o sem defeitos, e no outro formando a divacância 585, como mostrado nos capítulos anteriores.

$\mathrm{Na}$ figura 4.6 apresentamos os dois processos discutidos acima em um único gráfico para o defeito do tipo $V_{2}^{1}$. No gráfico da figura 4.6 mostramos a diferença de energia em função da coordenada de reação que, neste caso, escolhemos como sendo o deslocamento relativo do átomo $\left(C_{1}\right)$ que forma a conexão; posteriormente é subtraído para um dos nanutobos. Estamos considerando que o defeito foi criado num processo de irradiação, então, vamos analisar o quão estável é a conexão do defeitos $V_{2}^{1}$ através da análise da barreira de recombinação. Esta barreira seria a energia necessária para desfazer a conexão, resultando em um feixe de nanotubos com uma vacância em cada tubo, e para tal processo obtemos $2.5 \mathrm{eV}$. O segundo processo seria a energia para desfazer a conexão e obtendo como produto um sistema formado por um tubo puro e um tubo com uma divacância, a barreira obtida neste processo foi de $2.7 \mathrm{eV}$.

Se considerarmos que a recombinação desse defeito também está associada com à liberação de energia, como no caso do grafite [97], e que para observar tal processo seria necessária a mesma taxa de recombinação do grafite, então é possível estimar a temperatura para cada processo ${ }^{3}$.

\footnotetext{
${ }^{3}$ Estimamos a temperatura através da lei de Arrenius [34], onde a mobilidade de uma vacância ou um interstício possui uma dependência da temperatura da seguinte maneira:
} 


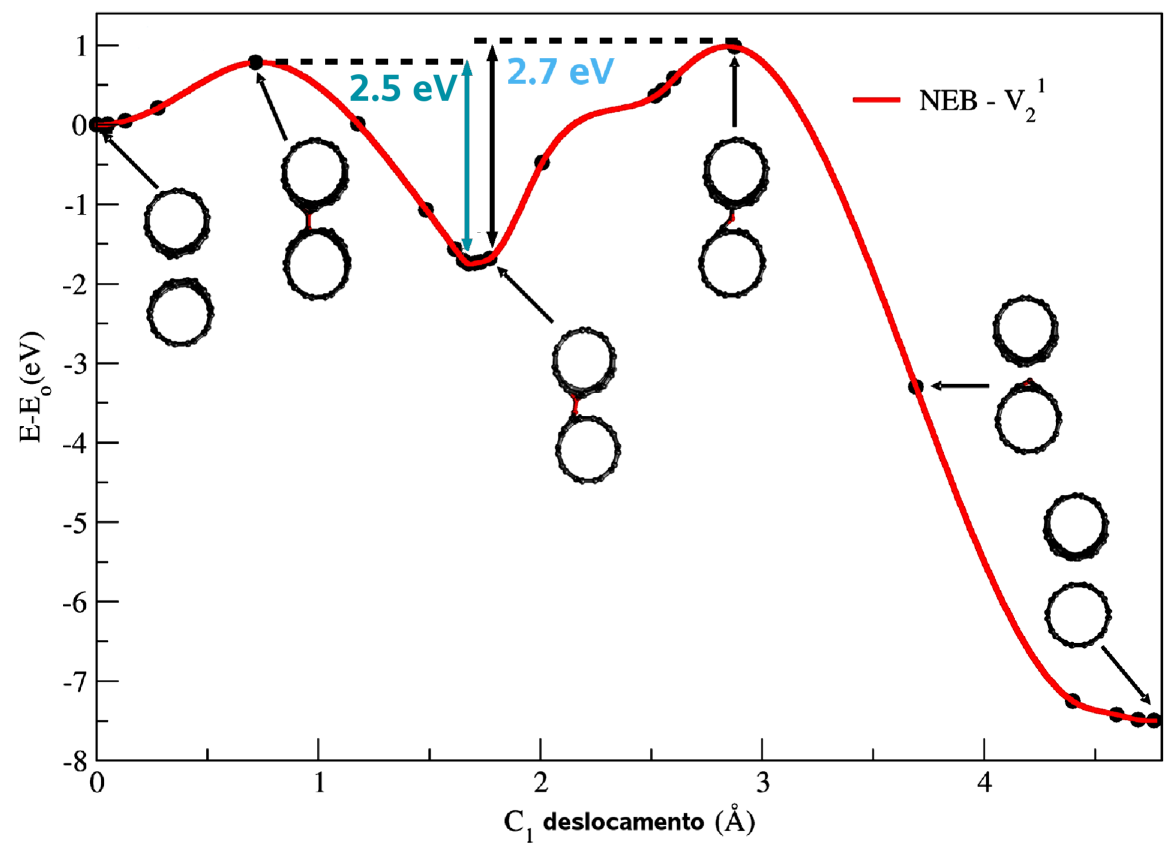

Figura 4.6: Apresentamos a barreira de reconstrução para o defeito $V_{2}^{1}$, obtida através do método $N E B$, de dois processos discutidos acima. O primeiro processo ocorre até o primeiro mínimo e o segundo parte deste ponto até o final do eixo das coordenadas (distância do $C_{1}>4.5 \AA$ ).

Para o primeiro caso, tal liberação de energia deve ser observada a $630^{\circ} \mathrm{C}$, enquanto que, para o segundo processo, será por volta de $710^{\circ} \mathrm{C}$.

O segundo sistema estudo foi o defeito $V_{2}^{2}$, calculamos a barreira de recombinação através do NEB e, neste caso, não existe barreira para formar a conexão. Este resultado é um indicativo de que tal processo ocorra espontaneamente.

Mostramos na figura 4.7 a barreira de formação para o defeito de Wigner em feixes de nanotubos de carbono. Este gráfico foi extraido do trabalho [33], desenvolvido em nosso grupo.

$$
D=D_{0} \cdot e^{\frac{-E_{b}}{K_{B} T}}
$$

e onde $D_{0}$ é o taxa de recombinção, $E_{b}$ é a energia de recombinação, $K_{B}$ é a constante de Boltzmann e $T$ é a temperatura. 


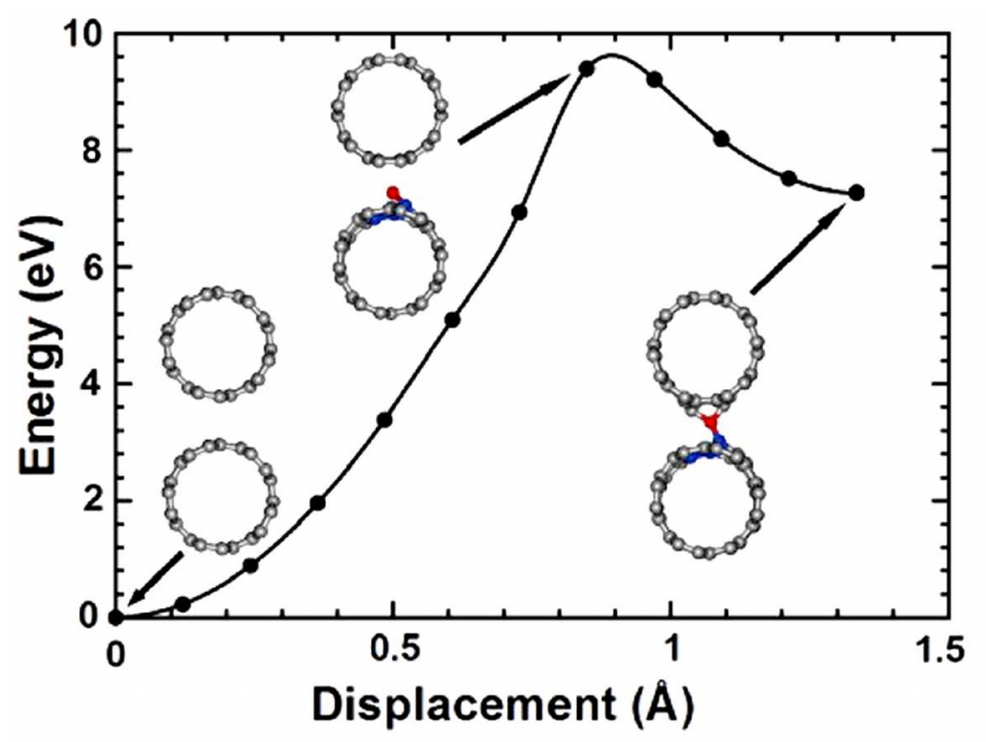

Figura 4.7: Apresentamos a barreira de formação para o defeito de Wigner obtida pelos autores na referência [33].

No caso do defeito de Wigner em feixes de CNT, os autores calcularam uma barreira de $2.4 \mathrm{eV}$. Comparando as barreiras de recombinação dos defeitos VI e VV em feixes e em grafite observamos o defeito $V_{2}^{1}$ em feixes de CNT apresentou a maior barreira de recombinação. Esse resultado é um indicativo que a conexão do defeito $V_{2}^{1}$, em feixes de CNT, é defeito mais difícil ser desfeita. No entanto, por não apresentar barreira de formação, o defeito $V_{2}^{2}$ em feixes de CNT é o defeito mais provável de ser encontrado.

Na próxima seção vamos apresentar os resultados das propriedades mecânicas dos defeitos do tipo $V V$ em feixes de nanotubos de carbono.

\subsection{Propriedades Mecânicas}

Nesta seção trataremos de uma questão que foi uma das principais motivações desse capítulo: a influência das conexões (defeitos) nas propriedades mecânicas de feixes 
de nanotubos de carbono. Para tal, primeiro vamos analisar o feixe puro, sem defeitos, considerando dois tubos do feixe (cerca de 200 átomos), onde deslocamos um deles, tanto positivamente em relação a estrutura inicial (sem deslocamento), quanto negativamente. Em ambos os casos esses deslocamentos foram realizados com uma angulação de $30^{\circ}$, pois os tubos são organizados de maneira hexagonal (figura 4.1-a). Foi mantido fixo um anel de átomos de cada tubo para que os CNTs não retornassem à posição de equilíbrio; posteriormente relaxamos a estrutura para obter a energia total para cada deslocamento empregado. O mesmo procedimento foi realizado para os feixes de nanotubos com os defeitos do tipo VV. Fizemos o gráfico da diferença de energia divida pelo comprimento do nanotubo em função dos deslocamentos realizados. A derivada segunda desse gráfico é o módulo de cisalhamento (shear modulus), que é a propriedade mecânica de interesse. Na figura 4.8 podemos observar o gráfico para os dois defeitos do tipo $\mathrm{VV}\left(V_{2}^{1}\right.$ e $\left.V_{2}^{2}\right)$.

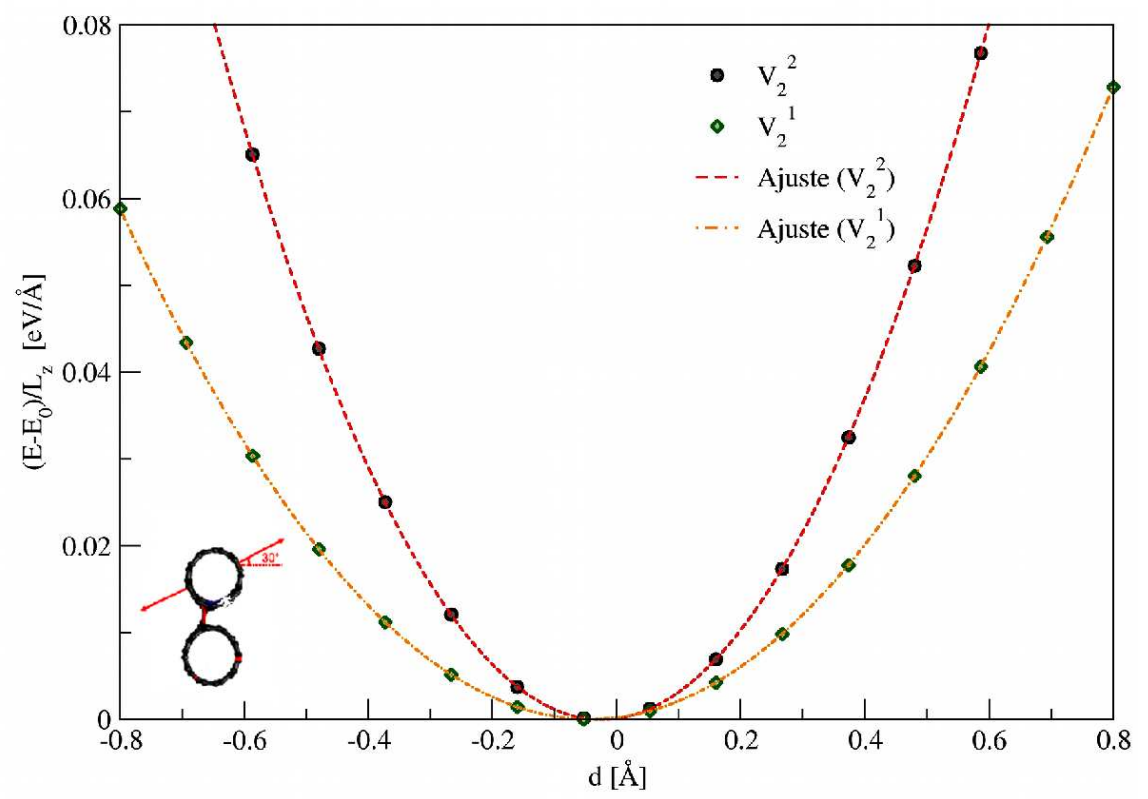

Figura 4.8: Apresentamos o gráfico da diferença de energia dividido pelo comprimento do nanotubo $\left(L_{z}\right)$ em função de deslocamentos a $30^{0}$. Mostramos os dois defeitos do tipo $V V$ em feixes de nanotubo. 
Para o caso do nanotubo sem defeito, o sistema apresentou um módulo de cisalhamento da ordem de $7 \mathrm{GPa}$ [33]. Ao inserir os defeitos, o valor dessa propriedade aumentou significativamente e, para o defeito $V_{2}^{1}$, obtivemos um aumento de aproximadamente 5 vezes e, para o defeito $V_{2}^{2}$, esse aumento foi de aproximadamente 10 vezes. Na tabela 4.2 mostramos os valores do módulo de cisalhamento para os defeitos em feixes.

Tabela 4.2: Módulo de cisalhamento, em GPa, para os feixes de nanotubos de carbono puro, contendo o defeito de Wigner [33], e para os defeitos do tipo $V V: V_{2}^{1}$ e $V_{2}^{2}$. Em todos os casos consideramos os deslocamentos com uma angulação de $30^{\circ}$.

\begin{tabular}{cc|c|cc}
\hline \hline Deslocamento & Puro & Wigner & $V_{2}^{1}$ & $V_{2}^{2}$ \\
\hline $30^{\circ}$ & 7.0 & 97.0 & 33.0 & 68.0 \\
\hline \hline
\end{tabular}

Notamos que o defeito que apresentou o maior aumento no módulo de cisalhamento foi o defeito de Wigner. O ponto importante é que as conexões melhoram o módulo de cisalhamento em todos os casos, e que neste trabalho conseguimos caracterizar quais são os defeitos, e como cada um pode modificar essas propriedades.

Fazendo um sumário dos resultados apresentados neste capítulo, primeiro, caracterizamos dois defeitos do tipo vacância-vacância e mostramos que, para ambos os casos, a energia de formação desses defeitos em feixes é menor do que os mesmos defeitos em grafite. Mostramos que os defeitos são estáveis e que as conexões entre as paredes dos feixes, através das densidades de cargas, são fortes pois apresentam valores máximos dessa densidade nessas ligações. Apresentamos dois caminhos de reação através do método NEB, o primeiro, a partir de um sistema com duas vacâncias até um sistema conectado e, um segundo caminho, partindo do sistema conectado até um sistema composto por um nanotubo puro mais um tubo com uma divacância. Para o defeito $V_{2}^{1}$, no primeiro caminho de reação, obtivemos uma barreira de cerca de $0.8 \mathrm{eV}$, que é três vezes menor do que a do defeito de Wigner em grafeno e 0.2 
eV do que o defeito de Wigner em CNTs. Ainda com esse sistema, analisamos o segundo processo - o sistema inicial sendo com a conexão estabelecida e o sistema final sendo formado por uma divacância e um tubo puro, esse sistema apresentou uma barreira de $2.7 \mathrm{eV}$. O defeito $V_{2}^{2}$ não apresentou uma barreira de recombinação para o primeiro processo. Finalmente, calculamos como as conexões influenciam nas propriedades mecânicas, e em particular, no módulo de cisalhamento desses defeitos.

No próximo capítulo vamos continuar investigando as propriedades mecânicas de nanotubos dos carbonos; no entanto, estudaremos os defeitos em nanotubos de múltiplas paredes (MWCNT). Atualmente, do ponto de vista de aplicação, esses sistemas são utilizados com maior frequência devido ao seu maior comprimento comparado com os demais tipos de nanotubos, como foi dito na introdução. Vamos caracterizar os principais tipos de defeitos neste sistema que, por sua vez, diferem do estudado neste capítulo pois, como o sistema é formado por tubos concêntricos possuem diâmetros/curvatura diferentes. Vamos analisar como tais conexões modificam as propriedades mecânicas e faremos um estudo aumentando a concentração de defeitos; por fim faremos um ensaio deslocando um dos tubos para investigar o quanto de tensão conseguimos transferir entre as paredes dos MWCNT, através da conexão que os liga. 


\section{Capítulo 5}

\section{Defeitos em CNT de parede dupla}

No capítulo anterior investigamos a influência de defeitos estruturais na estabilidade e nas propriedades mecânicas de nanotubos de carbono na forma de feixes. Neste capítulo continuaremos com as investigações das propriedades mecânicas em nanotubos de carbono, porém, estudaremos os nanotubos de parede dupla (DWCNT). A motivação para este estudo surge nas possíveis aplicações que este sistema pode ser empregado, como por exemplo: em compósitos (reforço em matriz de polímeros) e também na fabricação de cabos de super-resistentes. Basicamente, nessas aplicações são utilizados feixes de nanotubos e nanotubos de paredes múltiplas que, por possuírem tamanhos grandes $(>100 \mu m)$ no processo de síntese, são mais facilmente manipuláveis. Uma das dificuldades encontradas pelos experimentais nessas aplicações é a possibilidade dos tubos poderem deslizar uns contra os outros, degradando as propriedades mecânicas desses sistemas. Conexões entre as paredes dos nanotubos podem ser criadas após a irradiação de íons, impedindo que esses tubos possam deslizar e, assim, melhorando suas propriedades mecânicas. Nos primeiros trabalhos [40, 59] sobre irradiação de íons em tubos de paredes múltiplas, os autores irradiaram com diferentes feixes de íons e mostraram que diferentes conexões entre as paredes de nanotubos de parede múltipla podem ser criadas após a colisão de íons. No entanto, 
não foi investigada nenhuma propriedade mecânica desses sistemas, nem foi feita uma caracterização dos principais defeitos gerados nestes processos. Simulações de dinâmica molecular clássica [98] mostraram que diferentes tipos de defeitos podem ser responsáveis por gerar conexões entre as paredes dos DWCNT. Os mesmos autores também investigaram a força típica para iniciar o deslizamento das paredes dos DWCNT em alguns casos: defeito com uma vacância $(0.08-0.4 \mathrm{nN})$; defeito composto por duas vacâncias $(6.4-7.8 \mathrm{nN})$ e defeito intersticial $(4.9-6.3 \mathrm{nN})$. Apesar de terem estudado três casos, os autores não discutem a estabilidade desses defeitos e, assim, há necessidade de uma detalhada caracterização de cada tipo de defeitos. Para exemplificarmos essa possibilidade, destacamos o defeito do tipo vacância-vacância $\mathrm{V}-\mathrm{V}$ que possui duas formas possíveis em nanotubos $\left(V_{2}^{1}\right.$ e $\left.V_{2}^{2}\right)$. Neste estudo os autores apresentam esse defeito mas não mostram qual deles é estudado e, por isso, uma análise mais detalhada para cada caso se faz necessária. Além disso, a modelagem que foi empregada pelos autores, dinâmica molecular clássica (empírica), não fornece uma boa descrição para as energias de formação dos defeitos, nem mesmo os efeitos de recombinação de ligações química, hibridizações e quebra de ligações presentes nestes sistemas, pois não são bem descritas por este tipo de modelagem. Uma abordagem puramente quântica desse problema se faz necessária.

Do ponto de vista experimental, os autores das referências $[65,66]$ mostram uma aparato nanoeletromecânico extremamente sofisticado, acoplado a um microscópio eletrônico de transmissão (TEM), capaz de realizar medidas de força e deslocamentos com resolução menores que $12 \mathrm{nN}$ e 1 nm, respectivamente. Foram analisadas diferentes amostras de alta qualidade, amostras livre de oxidação e com o mínimo de defeitos em duas situações distintas: amostras sem sofrer algum processo de irradiação e amostras irradiadas. Eles discutem um ensaio mecânico em nanotubos de paredes múltiplas antes e depois da irradiação de íons. As paredes externas desse sistema são fixadas e deslocamentos são feitos até que a parede externa se 
rompa. Na amostra sem irradiação de íons, eles observam o rompimento de uma única parede do nanotubo de parede múltipla e, para a amostra irradiada, foram observadas três paredes rompidas ${ }^{1}$. Este fato é um indicativo de que as amostras irradiadas possuem conexões e, quando submetidas a tensões, as conexões entre as paredes transferem parte das tensões empregadas na parede externa para os tubos internos e, por isso, no segundo caso foram observadas três paredes rompidas. Neste mesmo trabalho, eles modelam três candidatos para as conexões entre as paredes dos nanotubos e, ainda, eles investigam diferentes concentrações de defeitos. Eles estudadaram o defeito do tipo Frenkel (vacância-interstício) - defeito de Wigner, um defeito do tipo vacância-vacância $\left(V_{2}^{2}\right)$ e um defeito intersticial sem a recombinação de pentágonos. Eles mostraram que os dois primeiros defeitos possuem uma maior transferência de tensão e, para o defeito de Wigner, eles mostram como é o comportamento dessa transferência de tensão em função do strain, para diferentes concentrações deste defeito. Eles realizaram esses cálculos com dinâmica molecular clássica e sem condições periódicas de contorno, onde foi mostrado que existe um limite superior para a transferência de tensão de um nanotubo $(5,5) @(10,10)$. Eles consideraram que cada um dos tubos possui molas conectadas em paralelo, sendo que, para o nanotubo interno, a mola possui uma constante elástica com a metade do valor do tubo externo $\left(k_{(5,5)}=k_{(10,10)} / 2\right)$. Considerando que a força total do sistema é dada pela somas das forças dos sistemas $\left(F_{T}=F_{(5,5)}+F_{(10,10)}\right)$, a fração máxima da força total que pode ser transferida para o nanotubo interno $(5,5)$ é $\frac{1}{3}$, enquanto que para o nanotubo externo $(10,10)$ essa fração é $\frac{2}{3}$.

Diante das questões apresentadas na introdução sobre nanotubos de parede múltipla, bem como as apresentadas acima, neste capítulo vamos estudar dois tipos de defeitos: o defeito de Wigner (VI) e o defeito do tipo (VV). Os defeitos neste sistema apresentam uma configuração adicional quando comparamos com os feixes

\footnotetext{
${ }^{1}$ Em algumas amostras irradiadas foram observadas mais de três paredes rompidas.
} 
de nanotubos: o diâmetro do tubo externo é diferente do tubo interno, implicando em curvaturas distintas. Deste modo a questão sobre estabilidade tem que levar em conta a parede em que os defeitos são criados. Nas próximas seções queremos responder questões tais como: em qual parede os defeitos de Wigner preferem ser criados? Qual é a sequência energética dos defeitos de Wigner e dos defeitos do tipo vacância-vacância? Para os casos mais estáveis, como se comportam esses sistemas quando a concentração de defeitos é aumentada? Como são as ligações químicas das conexões entre as paredes dos tubos? Como são as propriedades mecânicas desses defeitos (em especial o módulo de cisalhamento)? Quais são as forças máximas que as conexões suportam antes de sofrer uma ruptura? Como se comporta a transferência de tensão entre as paredes dos nanotubos para os casos acima?

Nas próximas seções vamos responder às questões apresentadas acima com uma modelagem puramente quântica. Então, começaremos apresentando o protocolo de simulação na próxima seção.

\subsection{Protocolo de simulação}

Para este estudo utilizamos cálculos de primeiros princípios baseados na teoria do funcional da densidade [83,84] (DFT). Utilizamos os pseudopotencias ultrassuaves de Vanderbilt [87] e, para a energia de correlação e troca, usamos a aproximação local da densidade (LDA). Maiores detalhes sobre a metodologia empregada nesta tese encontram-se no apêndice A. Os nanotubos utilizados são do tipo armchair de parede dupla $(10,10) @(5,5)$ com cinco células unitárias e cerca de 300 átomos. Os cálculos referentes às propriedades estruturais foram feitos com o código VASP $[85,86]$. 


\subsection{Defeitos em DWCNT}

Os primeiros defeitos estudados neste capítulo foram os compostos por uma par de Frenkel (vacância-interstício) conhecidos como defeitos de Wigner. O defeito de Wigner consiste no deslocamento de um átomo do cristal para a região intersticial e, normalmente, a posição do átomo deslocado não é ocupada por outro. No capítulo 4 apresentamos este defeito em feixes de nanotubos e, naquele caso, os tubos possuem o mesmo diâmetro. Neste caso, estamos estudando um tubo de parede dupla $(5,5) @(10,10)$, cujos diâmetros são 6.78 e $13.56 \AA$, respectivamente. As curvaturas são diferentes e, por isso, foram estudadas duas classes de defeitos de Wigner, e daqui por diante vamos classificá-los: a primeira classificação considerada refere-se a que tubo (externo ou interno) o átomo foi deslocado, ou seja, onde se localiza o pentágono formado após o deslocamento do átomo para região intersticial. Quando o defeito for no tubo interno, vamos chamá-lo, daqui por diante, por Wigner-I e, no tubo externo, chamaremos de Wigner-II. Entretanto, ainda podemos classificálos com relação aos átomos que participam das ligação da conexão entre paredes. Se a conexão entre paredes do DWCNT contar com a participação de átomos do pentágono, este sistema receberá o rótulo de $a$, caso contrário, se as ligações entre as paredes não contarem com a presença dos átomos do pentágono, chamaremos de $b$. Na figura 5.1-a mostramos um DWCNT sem as ligações entre as paredes; na figura-5.1-b apresentamos um DWCNT com ligação entre as paredes; e nas figuras 5.1-c e 5.1-d exibimos as geometrias finais para os defeitos de Wigner-I-a e WignerII-a; e, finalmente, nas figuras 5.1-e e 5.1-f mostramos as geometrias dos defeitos de Wigner-I-b e Wigner-II-b, respectivamente.

A segunda classe de defeitos que estudamos foram os do tipo vacância-vacância, $V_{2}^{1}$ e $V_{2}^{2}$. Esses defeitos são os mesmos apresentados no capítulo 4, entretanto, no presente sistema existe uma vacância no tubo externo $(10,10)$ e uma vacância no tubo interno $(5,5)$. Como foi dito no capítulo anterior, a principal diferença entre 


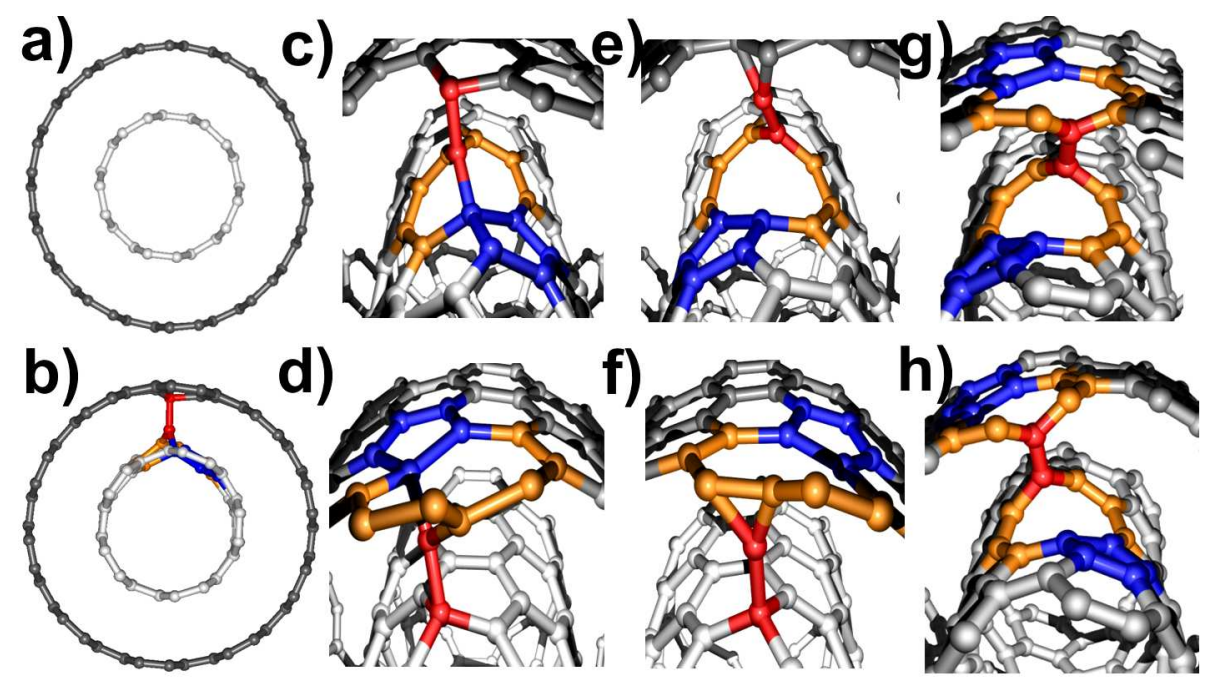

Figura 5.1: Apresentamos as geometrias dos defeitos do tipo (VI) e (VV). Em vermelho mostramos as ligações entre os nanotubos; o pentágono é mostrado em azul e as ligações próximas à conexão e ao pentágono são mostradas em laranja. Em a) exibimos um nanotubo de parede dupla (DWCNT) sem defeitos (puro); em b) mostramos um DWCNT com a conexão entre CNTs; Em c) apresentamos o defeito de Wigner-I-a; em d) Wigner-II-a; em e) Wigner-I-b; em f) Wigner-II-b; em g) apresentamos o defeito do tipo $V V V_{2}^{1}$ e finalmente em $f$ ) mostramos o defeito $V_{2}^{2}$.

esses dois tipos de defeitos é a disposição dos pentágonos, formados após a subtração do átomo, em relação à conexão. A geometria final, em detalhe, do defeito $V_{2}^{1}$ é apresentada na figura 5.1-g, onde a disposição dos pentágonos está posicionada na forma de $V$ com relação aos átomos da conexão entre os CNT. No caso do defeito $V_{2}^{2}$ (5.1-h), os pentágonos estão dispostos de maneira oposta em relação aos átomos da conexão principal. Apresentamos os principais defeitos que podem gerar conexões entre as paredes dos nanotubos e, na próxima seção, apresentaremos a estabilidade desses defeitos. 
Tabela 5.1: Energias de formação para todos os defeitos estudados, em eV, em nanotubos de parede dupla e no grafite.

\begin{tabular}{|c|c|c|c|c|c|}
\hline & Wig-I-a & Wig-I-b & Wig-II-b & $V_{2}^{1}$ & $V_{2}^{2}$ \\
\hline Grafite & & $10.67^{1}$ & & $12.70^{2}$ & $13.00^{2}$ \\
\hline DWCN & 7.60 & 8.10 & 10.55 & 10.80 & 10.23 \\
\hline
\end{tabular}

${ }^{1} \mathrm{O}$ presente resultado foi extraído da referência [32]; ${ }^{2}$ Este resultado foi extraído da referência [33];

\subsection{Estabilidade energética}

Primeiramente, faremos uma análise energética das estruturas apresentadas na seção anterior para saber qual delas é a mais estável. O defeito de Wigner-I-a, da figura 5.1-c, apresentou a menor energia de formação, e a primeira conclusão acerca do posicionamento das vacâncias no nanotubo é que o defeito prefere ser criado no CNT interno. Este resultado já era esperado, uma vez que para criar uma monovacância em um nanotubo $(10,10)$ é necessário mais energia do que para o mesmo processo num tubo $(5,5)$. Comparando as energias de formação, o defeito Wigner-I-a se mostrou 2.9 eV mais estável do que o Wigner-II-b e, ainda, 0.5 eV mais estável do que o defeito de Wigner-I-b. Para o defeito Wigner-II-a, observamos que este sistema não forma conexão entre os tubos, pois no processo de otimização da geometria ele se transforma num defeito do tipo Stone-Wales, no CNT externo.

Para os defeitos do tipo vacância-vacância fizemos a mesma análise das energias de formação, e constatamos que, em ambos os casos $\left(V_{2}^{1}\right.$ e $\left.V_{2}^{2}\right)$, esses sistemas são mais estáveis do que os mesmos defeitos no grafite. Entretanto, comparando a energia de formação para os dois defeitos em DWCNT, o defeito $V_{2}^{2}$ é mais estável do que o $V_{2}^{1}$ por $0.6 \mathrm{eV}$.

Na tabela 5.1 mostramos um sumário de todas as energias de formação dos defeitos apresentados acima. As energias de formação para os defeitos do tipo VV são tipicamente mais altas do que os defeitos do tipo VI, pois esses defeitos envolvem 
duas vacâncias, uma em cada CNT. Se considerarmos que as energias de formação de uma monovacância nos tubos isolados $(5,5)$ e $(10,10)$ são $(5.7 \mathrm{eV})$ e $(6.6 \mathrm{eV})$, respectivamente, a energia necessária para criar duas vacâncias isoladas nesses sitemas é de aproximadamente $12.3 \mathrm{eV}$, enquanto que a energia de formação para criar os defeitos $V_{2}^{1}$ e $V_{2}^{2}$ é menor do que estes contituintes isolados, como podemos ver na tabela 5.1. Ao compararmos as energias de formação dos defeitos em DWCNT com os mesmos defeitos em grafite, observamos que, em todos os casos, as energias de formação nos tubos são menores do que no grafite. Este resultado é um indicativo de que esses defeitos são mais prováveis de serem encontrados em nanotubos do que em grafite, após o processo de irradiação de íons.

Vamos analisar os comprimentos de ligação dos principais átomos dos defeitos apresentados acima e, para isso, mostramos em detalhe na figura 5.2-a as ligações mais importantes com seus respectivos rótulos. Exibimos na tabela 5.2 os compri-
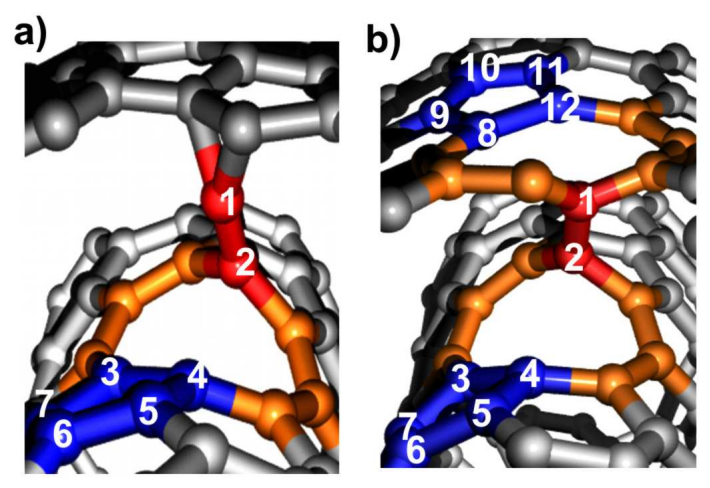

Figura 5.2: Em detalhe mostramos as principais geometrias com seus respectivos rótulos; em vermelho a ligação principal entre as paredes dos CNT; em azul, o pentágono; os átomos entre os pentágonos e a ligação principal são apresentados em laranja. a) CNT de parede dupla - defeito de Wigner (V-I) b) DWCNT - defeitos tipo vacância-vacância $(V-V)$.

mentos de ligação dos átomos mostrados na figura 5.2, onde apresentamos os três possíveis defeitos de Wigner para o DWCNT e o defeito Wigner-b no grafite. Note que no caso do grafite não apresentamos a classificação (I ou II) pois as duas pare- 
des são equivalentes. Os átomos $C_{1}-C_{2}$ formam a conexão entre as paredes dos

Tabela 5.2: Apresentamos as distâncias interatômicas, em $\AA$, dos defeitos de Wigner (V-I) para as geometrias discutidas acima. As geometrias estão nas Figura-5.1-c, Figura-5.1-e e Figura-5.1-f.

\begin{tabular}{l||crc|l}
\hline \hline Ligação & Wigner-I-a $^{1}$ & Wigner-I- $^{2}$ & Wigner-II-b $^{3}$ & Grafite $^{4}$ \\
\hline$C_{1}-C_{2}$ & 1.57 & 1.32 & 1.46 & 1.32 \\
$C_{3}-C_{4}$ & 1.60 & 1.54 & 1.63 & 2.00 \\
$C_{4}-C_{5}$ & 1.39 & 1.42 & 1.42 & 1.39 \\
$C_{5}-C_{6}$ & 1.41 & 1.40 & 1.39 & 1.40 \\
$C_{6}-C_{7}$ & 1.39 & 1.40 & 1.39 & 1.40 \\
$C_{7}-C_{3}$ & 1.54 & 1.42 & 1.42 & 1.39 \\
\hline \hline
\end{tabular}

${ }^{1}$ Defeito de Wigner em CNT parede dupla - Figura 5.1-c; ${ }^{2}$ Defeito de Wigner em CNT de parede dupla - Figura 5.1-e; ${ }^{3}$ Defeito de Wigner em CNT de parede dupla - Figura 5.1-f; ${ }^{4}$ Defeito de Wigner no grafite - veja referência [32]. .

CNTs, e estes são mostrados, em vermelho, na figura 5.2-a. Considerando que a distância de equilíbrio das ligações $\left(d_{C-C}\right)$ nos nanotubos é de aproximadamente $(\approx 1.41 \AA)$, para o defeito mais estável, Wigner-I-a, essa ligação $\left(d_{C_{1}-C_{2}}\right)$ é grande (cerca de $1.57 \AA$ ), quando comparada com a distância de equilíbrio $d_{C-C}$. Este fato é um indicativo de que essa ligação seja do tipo $\mathrm{H}_{3} \mathrm{C}-\mathrm{CH}_{3}$. Entretanto, para o defeito de Wigner-II-b esta mesma ligação possui um comprimento bem próximo à ligação de equilíbrio, mas aproximadamente 0.1 A menor do que a mesma distância no defeito Wigner-I-a. Por outro lado, para o defeito de Wigner-I-b, a ligação da conexão é menor do que a distância de equilíbrio $d_{C-C}$, e da mesma magnitude dessa ligação no grafite. Esse fato sugere que esta ligação seja do tipo $s p^{2}$, ligação dupla, uma vez que, para a molécula de $\mathrm{H}_{2} \mathrm{C}=\mathrm{CH}_{2}$, a distância entre os carbonos é de aproximadamente $1.34 \AA$. Outra ligação importante é a $d_{C_{3}-C_{4}}$, a ligação do pentágono, como podemos ver na figura-5.2-a em azul. Para os defeitos de Wigner-I $a$ e $b$, o pentágono está no nanotubo interno e para o defeito Wigner-II-b, no CNT 
externo; sendo assim, o defeitos de Wigner-I-b e o Wigner-II-b possuem distâncias comparáveis as das monovacâncias em nanotubo $(5,5)$ e $(10,10)$, respectivamente. Por outro lado, o defeito mais estável, Wigner-I-a, possui essa ligação maior do que a de uma monovacância em um tubo $(5,5)$. Isso acontece porque o átomo $C_{3}$ é tetracoordenado, compartilhando carga com outros quatro átomos ao invés de três, e esse tipo de sistema geralmente possui comprimentos de ligação maiores do que $1.54 \AA$ (ligação do tipo $s p^{3}$ ). As demais distâncias do pentágono possuem valores bem próximos à distância de equilíbrio do carbono. Comparando as distâncias dos defeitos de Wigner em nanotubos com o mesmo defeito em grafite, na tabla 5.2, observamos que o comprimento de ligação $d_{C_{3}-C_{4}}$ é maior em grafite do que em todos os casos em tubos. Para o defeito Wigner-II-b, o valor desta ligação é maior do que a mesma ligação dos defeitos (Wigner-I-a e Wigner-I-b), nos tubos, porque o pentágono desse sistema se encontra no tubo externo $(10,10)$ e, nos demais casos, o pentágono está no tubo interno. Comparando os defeitos de Wigner que possuem o pentágono no tubo interno, o defeito Wigner-I-a possui os comprimentos de ligação $\left(d_{C_{1}-C_{2}}, d_{C_{3}-C_{4}}\right.$ e $\left.d_{C_{7}-C_{3}}\right)$ maiores que o defeito Wigner-I-b. Este fato está associado a coordenação dos átomos 1 e 3 no defeito Wigner-I-a que, por serem tetracoordenados, as ligações que envolvem esses átomos têm a tendência de serem maiores do que a distância de equilíbrio $d_{C-C}$, pois os comprimentos típicos para esse tipo de ligação é $1.54 \AA$.

Na figura 5.2-b mostramos, em detalhe, o defeito tipo (V-V) com seus respectivos rótulos para analisarmos as distâncias das ligações e, na tabela 5.3, apresentamos as principais distâncias das ligações dos defeitos $V_{2}^{1}$ e $V_{2}^{2}$.

Neste caso, podemos começar nossa análise pela distância da ligação da conexão $d_{C_{1}-C_{2}}$, ou seja, para ambos os defeitos, teremos comprimentos de ligação menores do que a distância de equilíbrio $d_{C-C}$. Para o defeito $V_{2}^{1}$ este comprimento é 0.01 $\AA$ menor que $d_{C C}$, e para o defeito $V_{2}^{2}$ essa ligação é $0.05 \AA$ menor. No defeito 
Tabela 5.3: Mostramos as distâncias interatômicas, em A, para os defeitos tipo vacância-vacância, $V_{2}^{1}$ e $V_{2}^{2}$. Os defeitos que possuem o rótulo CNT referem-se aos nanotubos e os que possuem a letra $G$ são referentes aos grafites.

\begin{tabular}{l|cr|cc}
\hline \hline ligação & $\left(V_{2}^{1}-\mathrm{CNT}\right)^{1}$ & $\left(V_{2}^{2}-\mathrm{CNT}\right)^{2}$ & $\left(V_{2}^{1}-\mathrm{G}\right)^{3}$ & $\left(V_{2}^{2}-\mathrm{G}\right)^{3}$ \\
\hline$C_{1}-C_{2}$ & 1.40 & 1.36 & 1.43 & 1.38 \\
$C_{3}-C_{4}$ & 1.54 & 1.52 & - & - \\
$C_{4}-C_{5}$ & 1.43 & 1.42 & - & - \\
$C_{5}-C_{6}$ & 1.40 & 1.40 & - & - \\
$C_{6}-C_{7}$ & 1.40 & 1.40 & - & - \\
$C_{7}-C_{3}$ & 1.42 & 1.43 & - & - \\
$C_{8}-C_{12}$ & 1.63 & 1.65 & - & - \\
$C_{8}-C_{9}$ & 1.42 & 1.42 & - & - \\
$C_{9}-C_{10}$ & 1.39 & 1.39 & - & - \\
$C_{10}-C_{11}$ & 1.39 & 1.39 & - & - \\
$C_{11}-C_{12}$ & 1.43 & 1.43 & - & - \\
\hline \hline
\end{tabular}

${ }^{1}$ Geometria referente a figura-5.1-g.; ${ }^{2}$ Defeito referente a figura-5.1-h.; ${ }^{3}$ As distâncias de ligação da conexão dos defeitos $V_{2}^{1}$ e $V_{2}^{2}$ no grafite foram extraídas da referência [32].

$V_{2}^{2}$ a distância $d_{C_{1}-C_{2}}$ é menor do que a mesma distância no defeito $V_{2}^{1}$, como pode ser visto na tabela 5.3. A segunda distância de ligação que vamos analisar é a $d_{C_{3}-C_{4}}$, que refere-se à ligação principal do pentágono num nanotubo interno $(5,5)$, ou seja, comparando este comprimento de ligação com a mesma ligação de uma monovacância em um tubo $(5,5)$, que possui uma distância da ordem de $(\approx 1.56 \AA)$, nos referidos defeitos, as distâncias obtidas são variações $( \pm 0.04 \AA)$ deste valor, como podemos observar na tabela 5.3. Fazendo a mesma análise para a ligação $d_{C_{8}-C_{12}}$, mas agora para a ligação principal do pentágono do tubo $(10,10)$, onde a mesma distância para a monovacância é de aproximadamente $(\approx 1.65 \AA)$, comparando com os defeitos em DWCNT, notamos também, pequenas variações $( \pm 0.02 \AA)$ em torno deste valor. E, para as demais ligações dos pentágonos, obtivemos comprimentos de ligação muito parecidos com a ligação de equilíbrio $\left(d_{C-C}\right)$, isto é, variações $( \pm 0.03$ A) do comprimento de ligação em torno deste valor. 
Cada defeito apresentado até o presente momento foi estudado em uma supercélula de $L_{z}=12.205 \AA$, ou seja, a cada $L_{z}$ possuímos um único defeito e esta configuração nos fornece uma densidade de defeitos de aproximadamente $\rho_{d}=0.082$ [def. $\left.\AA^{-1}\right]$. Vamos considerar uma situação onde teremos dois defeitos diametralmente posicionados. Faremos este estudo para os defeitos mais estáveis de cada tipo (VV e VI) - Wigner-I-a e $V_{2}^{2}$, aumentamos a densidade de defeitos para $\rho_{d}=0.164$ [def. $\left.\AA^{-1}\right]$. Vamos designar $(2 l)$ para os defeitos que possuem duas conexões. Então, neste novo caso teremos dois defeitos para cada tamanho de supercélula $\left(L_{z}\right)$. Na figura 5.3 mostramos a geometria final dos defeitos: (a) Wigner-I-a-2l (2 conexões) e (b) $V_{2}^{2}-2 l$.
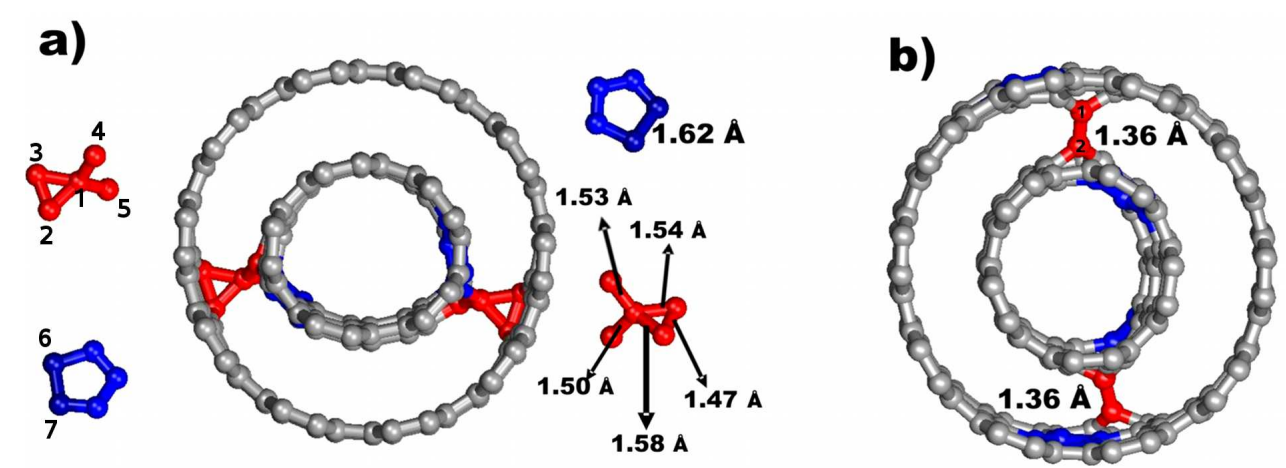

Figura 5.3: Geometria final dos nanotubos de parede dupla com uma concentração de defeitos de $\rho_{d}=0.164$ [def. $\left.\AA^{-1}\right]$. Em (a) apresentamos o defeito de Wigner-I-a-2l com duas conexões, as distâncias das ligações, mostradas ao lado da figura, possuem o mesmo comprimentos. Por isso, o rótulo dos átomos se encontram a esquerda $e$ os comprimentos são mostrados à direita; e em (b) mostramos a geometria final do defeito $V_{2}^{2}-2 l$.

O defeito de Wigner-I-a-2l é mostrado na figura 5.3-a, onde observamos, ao lado da figura, a representação da conexão e do pentágono dos dois defeitos. Neste caso, o presente defeito apresentou uma energia de formação menor do que a de dois defeitos de Wigner-I-a isolados, onde a diferença constatada foi de $1.6 \mathrm{eV}$. O defeito $V_{2}^{2}-2 l$ é mostrado na figura 5.3-b, onde notamos que os defeitos estão dispostos 
Tabela 5.4: Apresentamos as energias de formação para os defeitos de Wigner-I-a e para o defeito $V_{2}^{2}-2 l$, em eV, para nanotubos de parede dupla. Nesta tabela exibimos os resultados para diferentes concentrações $\left(\rho_{d}=0.082\right.$ [def. $\AA^{-1}$ ] e $\rho_{d}=$ $0.164\left[\right.$ def. $\left.\left.\AA^{-1}\right]\right)$ de defeitos.

\begin{tabular}{l|cr|cl}
\hline \hline & Wig-I-a & Wig-I-a-2l & $V_{2}^{2}$ & $V_{2}^{2}-2 l$ \\
\hline DWCN & 7.60 & 13.57 & 10.23 & 20.48 \\
\hline \hline
\end{tabular}

praticamente opostos um ao outro. A energia de formação, neste caso, é equivalente a de dois defeitos $V_{2}^{2}$ isolados. O defeito $V_{2}^{2}-2 l$ possui a energia de formação $4 \mathrm{eV}$ mais baixa do que 4 monovacâncias isoladas.

Na tabela 5.4 apresentamos as energia de formação, em eV, para os defeitos de Wigner-I-a (1 e 2 conexões) e também para o defeito $\left(V_{2}^{2}\right.$ e $\left.V_{2}^{2}-2 l\right)$.

Em ambos os casos apresentados, as duas conexões dos defeitos são idênticas. Sendo assim, as ligações químicas equivalentes dos defeitos possuem praticamente o mesmo tamanho. Na figura 5.3-a mostramos as principais ligações químicas do defeito de Wigner-I-a-2l e, para os átomos das conexões com o átomo 1, observamos que os comprimento de ligação com esses átomos $\left(d_{C_{1}-C_{2}}, d_{C_{1}-C_{3}}, d_{C_{1}-C_{4}}\right.$ e $\left.d_{C_{1}-C_{5}}\right)$ são da ordem de $1.54 \pm 0.04 \AA$. O comprimento da maior ligação $\left(d_{C_{1}-C_{3}}=1.58\right)$, neste defeito, é da mesma ordem da ligação da conexão principal do defeito de Wigner-I-a $(\approx 1.57 \AA)$. A ligação principal do pentágono $\left(d_{C_{6}-C_{7}}\right)$ deste defeito é da mesma ordem do comprimento da mesma ligação do defeito de Wigner-I-a. Para o defeito $V_{2}^{2}-2 l$, os principais comprimentos de ligação são equivalentes aos de um único defeito apresentado na tabela 5.3.

Na próxima seção vamos analisar a densidade de carga da conexão dos defeitos apresentados nessa seção. 


\subsection{Propriedades eletrônicas das conexões}

$\mathrm{Na}$ seção anterior mostramos as geometrias dos possíveis defeitos de Wigner e também os defeitos do tipo vacância-vacância em nanotubos de parede dupla. Foi apresentada também a estabilidade desses defeitos com diferentes concentrações. Fizemos uma análise dos principais comprimentos de ligação nessas estruturas. Na presente seção, vamos analisar as conexões do ponto de vista químico através da densidade de cargas eletrônica.

Na figura 5.4 mostramos a densidade de cargas eletrônica em um plano perpendicular ao eixo de um DWCNT sem defeito, e também para todos os defeitos de Wigner apresentados na figura 5.1.

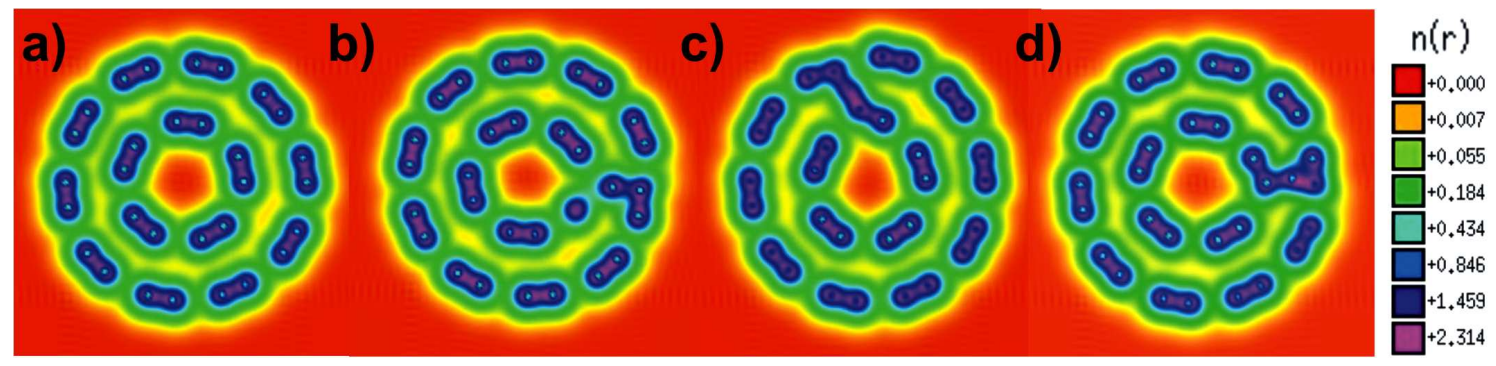

Figura 5.4: Apresentamos a densidade de cargas eletrônica, em e/ $\AA^{3}$, em um plano perpendicular ao eixo do nanotubo. Em (a) exibimos um DWCNT sem defeito; em (b) mostramos o defeito de Wigner-I-a; em (c) apresentamos o defeito de WignerI-b; e em (d) defeito de Wigner-II-b.

Analisando as densidades de carga, notamos que o DWCNT sem defeito (figura 5.4-a) possui cinco anéis no CNT interno e dez anéis no CNT externo, todos idênticos e com grande intensidade de densidade de carga no centro. Quando existe um defeito, percebemos que, em cada tubo, há um novo compartilhamento de cargas, formado pela conexão. Em todos os casos apresentados na figura 5.4, mostramos que a conexão principal possui valores máximos de densidade de carga nessas ligações, como podemos ver nas figuras (5.4-b), (5.4-c) e (5.4-d), referentes aos defeito Wigner- 
I-a, Wigner-I-b e Wigner-II-b, respectivamente. Este fato é um indicativo de que as ligações químicas das conexões são fortes.

Para os defeitos do tipo vacância-vacância $\left(V_{2}^{1}\right.$ e $\left.V_{2}^{2}\right)$, fizemos a mesma análise da densidade de cargas eletrônica, através de um plano perpendicular ao eixo do DWCNT, como podemos ver na figura 5.5.
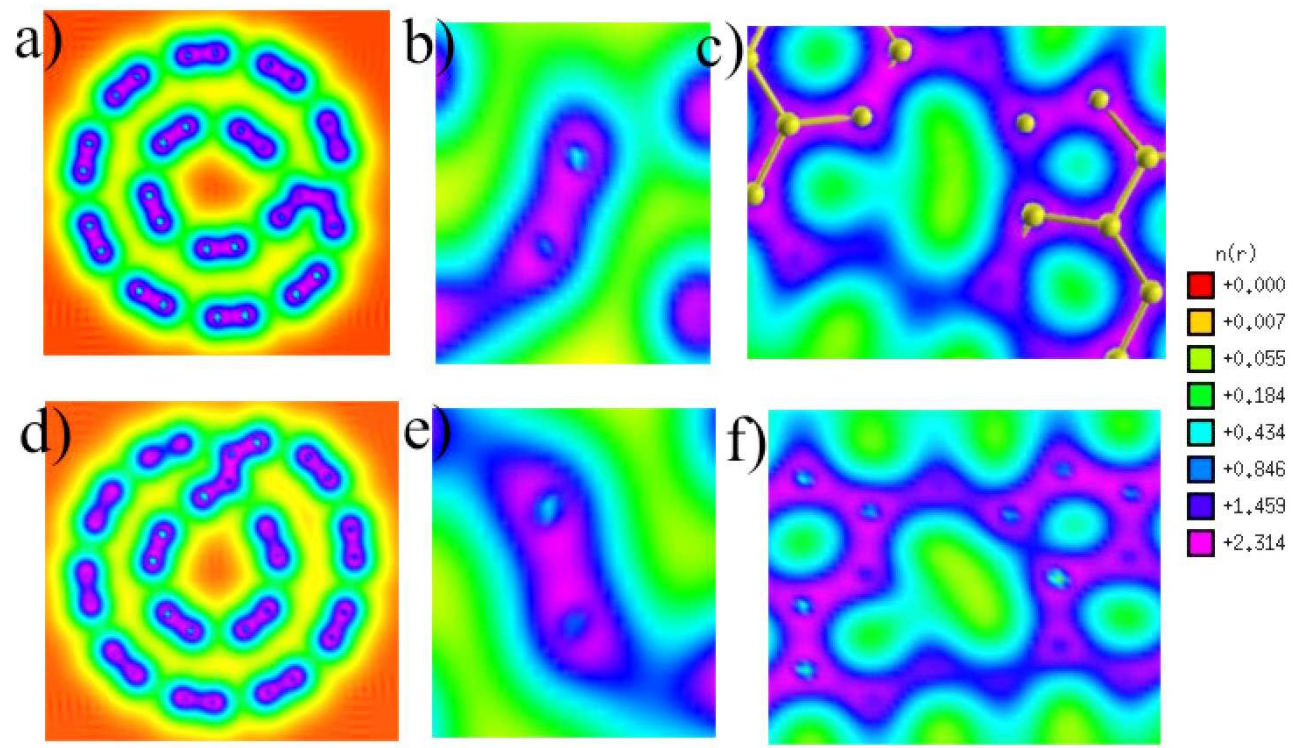

$\square+0,846$

$\square+1,459$

$\square+2.314$

Figura 5.5: Apresentamos a densidade de carga, em e/ $\AA^{3}$, através de um plano perpendicular ao eixo do DWCNT, para os defeitos $V_{2}^{1}$ e $V_{2}^{2}$. Em (a) e (b) e (c) mostramos um plano de cargas do defeito $V_{2}^{1}$; e em $(d)$, (e) e $(f)$ exibimos um plano de cargas para o defeito $V_{2}^{2}$.

$\mathrm{Na}$ figura 5.5-a e b apresentamos a densidade de cargas em um plano perpendicular ao plano do eixo do DWCNT para o defeito $V_{2}^{1}$, onde constatamos que a conexão possui valores máximos de densidade de carga. O mesmo comportamento é observado para as figuras 5.5-(d e e), para o defeito $V_{2}^{2}$. Nas figuras 5.5-(c e f) mostramos um plano de cargas passando pelos átomos do pentágono externo dos defeitos $V_{2}^{1}$ e $V_{2}^{1}$, respectivamente. Observamos que, apesar dos comprimentos de ligação para esses átomos serem grandes, os valores da densidade de carga têm valo- 
res altos. Diante desses resultados, para a densidade de cargas dos defeitos do tipo VV, as conexões entre as paredes dos DWCNT têm um indicativo de serem fortes, como no caso dos defeitos do tipo VI.

Finalmente, para os defeitos mais estáveis de cada tipo, analisamos a densidade de carga em um plano perpendicular ao eixo do DWCNT para uma densidade de defeitos de $\rho_{d}=0.164$ [def. $\AA^{-1}$ ]. Na figura 5.6 mostramos essas densidades de carga para o defeito Wigner-I-a-2l e para o defeito $V_{2}^{2}-2 l$.

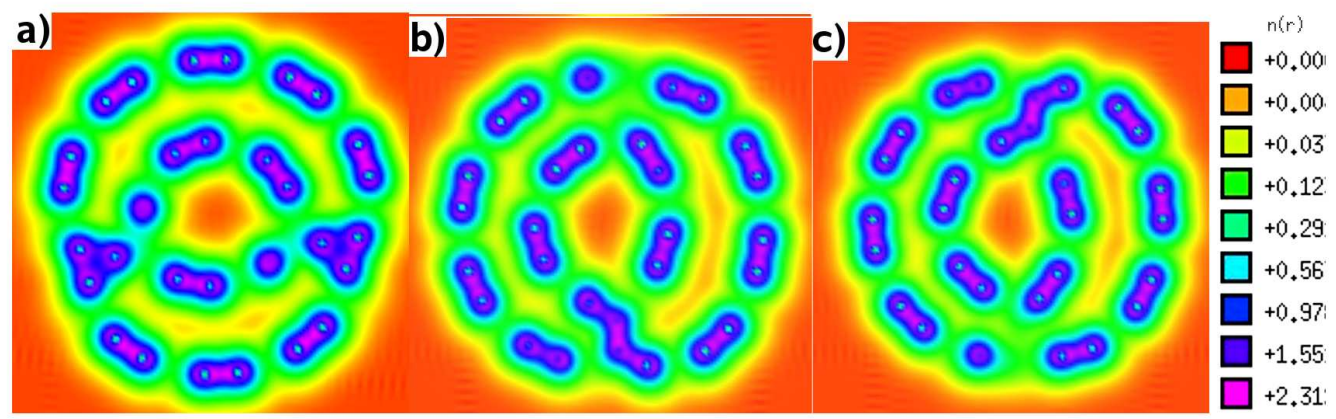

Figura 5.6: Apresentamos a densidade de carga, em e/ $\AA^{3}$, através de um plano perpendicular ao eixo do DWCNT, para os defeitos: Wigner-I-a-2l na figura (a); e $V_{2}^{2}-2 l$ nas figuras (b) e (c).

Para o defeito de Wigner-I-a-2l, as conexões entre as paredes do tubos estão num mesmo plano, como podemos observar na figura 5.6-a, onde também notamos valores máximos de densidade de carga. Para o defeito $V_{2}^{2}-2 l$, as conexões se encontram em planos diferentes e, por isso, as densidades de carga são mostradas em duas figuras 5.6-b e 5.6-c. Como nos demais casos, notamos que as ligações das conexões possuem valores máximos de densidade de carga. Esse fato é, novamente, um indicativo de que as ligações entre as paredes dos CNT são fortes.

Uma vez apresentada a análise das densidades de carga para todos os defeitos estudados até o presente momento e, ainda, analisando diferentes concentrações de defeitos, na próxima seção vamos apresentar os resultados das propriedades mecânicas 
para cada um dos sistemas estudados.

\subsection{Propriedades Mecânicas}

Nesta seção vamos investigar as proprieadedes mecânicas dos nanutubos de parede dupla. Como foi dito nos capítulos anteriores, a força que mantém os feixes de nanotubos e os nanotubos de paredes múltiplas juntos é fraca, de característica de van der Waals. Então, os nanotubos podem deslizar uns contra os outros degradando as suas propriedades mecânicas. Foi mencionado na introdução desse capítulo que processos de irradiação de íons podem criar conexões, e essas podem melhorar as propriedade mecânicas. Nesta seção, vamos investigar o módulo de cisalhamento $(\sigma)$ dos nanotubos de parede dupla, e esta propriedade foi calculada da mesma forma do capítulo 4; no entanto, naquela ocasião foram feitos deslocamentos transversais com um ângulo de $30^{\circ}$. Neste caso, estamos considerando deslocamento longitudinais (ao longo do eixo z). Na figura 5.7 mostramos o gráfico da diferença de energia $\left(E-E_{0}\right)$ dividida pelo comprimento do tubo $\left(L_{z}\right)$ em função do deslocamento relativo longitudinal. A energia $E_{0}$ refere-se ao sistema sem deslocamentos.

Na figura 5.7, mostramos três curvas referentes ao DWCNT puro (linha pontilhada preta), defeito de Wigner-I-a (linha sólida em vemelho) e Wigner-I-a-2l (linha sólida verde). O objetivo dessa seção é investigar a influência das conexões nas propriedades mecânicas dos DWCNT. Para o nanotubo de parede dupla sem defeito, calculamos o módulo de cisalhamento, onde obtivemos 2.0 GPa. Comparando este resultado com o defeito mais estável (Wigner-I-a - $\rho_{d}=0.082\left[\right.$ def. $\left.\AA^{-1}\right]$ ), observamos que essa conexão aumenta o módulo de cisalhamento por um fator de 17, e ainda, se aumentarmos a concentração desse defeito para $0.164\left[\right.$ def. $\left.\AA^{-1}\right]$, esse aumento é ainda maior, sendo que o módulo de cisalhamento aumenta por um fator de 50 comparado com o DWCNT sem conexão. Para o defeito de Wigner-I-b observamos um aumento do módulo de cisalhamento por um fator de 10. Para os defeitos do tipo 


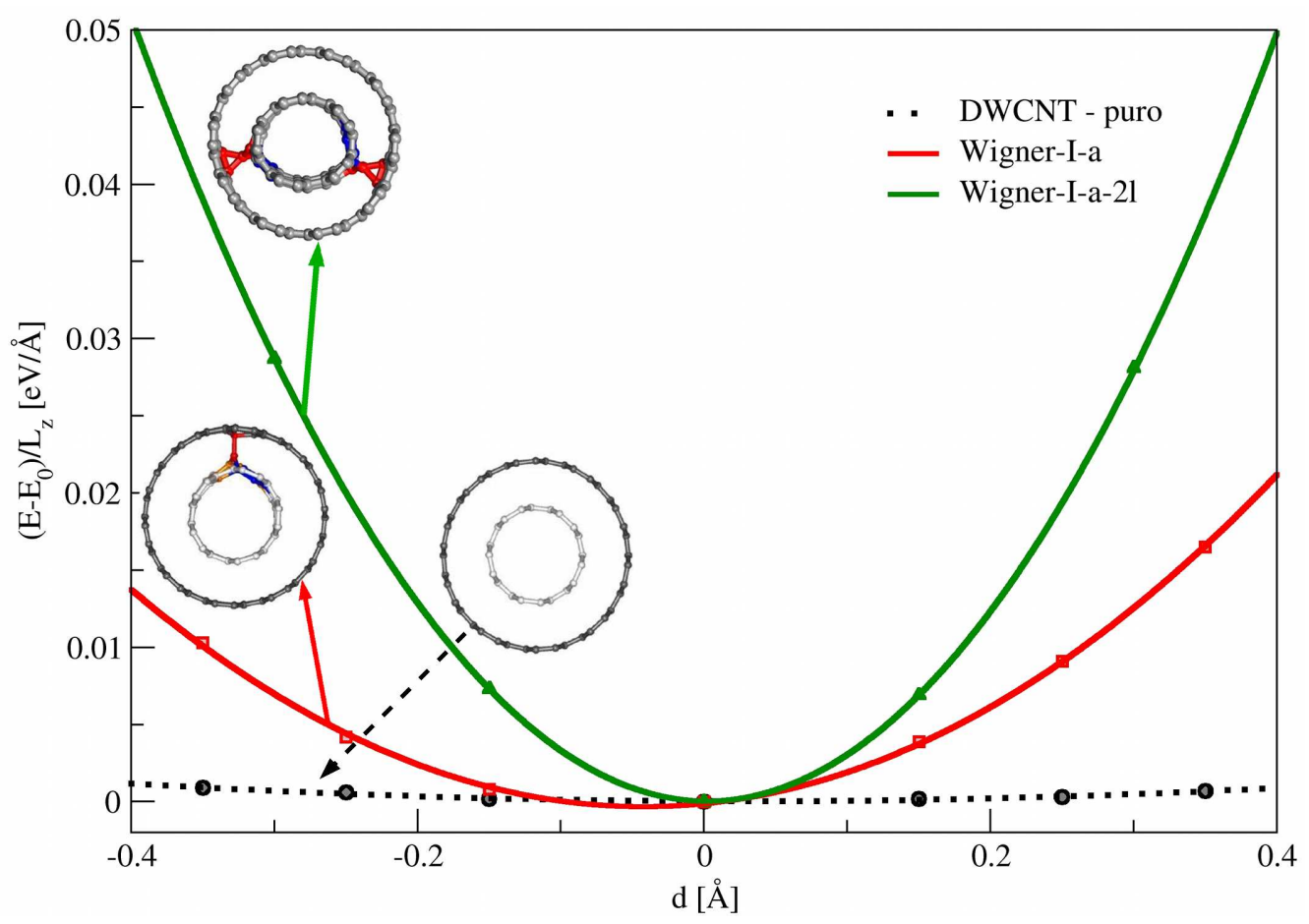

Figura 5.7: Apresentamos o gráfico da diferença de energia $\left(E-E_{0}\right)$ dividida pelo comprimento do tubo $L_{z}$ em função do deslocamento longitudinal para o DWCNT puro, para o defeito de Wigner-I-a e para o defeito Wigner-I-a-2l.

VV também observamos uma melhora no módulo de cisalhamento. Observamos, para o defeito $V_{2}^{1}$, um aumento por um fator de 15 , e para o defeito $V_{2}^{2}$, por um fator de 11. Aumentamos a concentração de defeitos para 0.164 [def. $\AA^{-} 1$ ], no caso do defeito mais estável $V_{2}^{2}$, e observamos uma melhora do módulo de cisalhamento por um fator de 34, comparado com o sistema sem conexão. Na tabela 5.5 observamos o módulo de cisalhamento de todos os defeitos estudados acima.

Na tabela 5.5, podemos observar alguns aspectos importantes referente às propriedades mecânicas dos defeitos: primeiro refere-se à melhora significativa do módulo de cisalhamento em todos os casos estudados, a melhora da propriedade mecânica variou de 10 - 50 vezes a do sistema sem conexão; o segundo aspecto observado refere-se à mudança não linear do módulo de cisalhamento quando dobramos a con- 
Tabela 5.5: Apresentamos o módulo de cisalhamento ( $\sigma$ ), em GPa, para o DWCNT puro, sem defeito, e para os defeitos estudados acima em DWCNT. Nesta tabela exibimos os resultados para diferentes concentrações $\left(\rho_{d}=0.082\right.$ [def. $\AA^{-1}$ ] e $\rho_{d}=$ $0.164\left[\right.$ def. $\left.\left.\AA^{-1}\right]\right)$ de defeitos.

\begin{tabular}{r|c|cr|c|c|cl}
\hline \hline & Puro & Wig-I-a & Wig-I-a-2l & Wig-I-b & $V_{2}^{1}$ & $V_{2}^{2}$ & $V_{2}^{2}-2 l$ \\
\hline$\sigma$ & 2.0 & 35 & 100.7 & 20.8 & 29.9 & 23.3 & 68.4 \\
\hline \hline
\end{tabular}

centração de defeitos, e observamos que, quando a densidade de defeitos é dobrada, o módulo de cisalhamento aumenta por um fator de 3. Este resultado foi observado em dois sistemas distintos.

\subsection{Deslocamento relativo entre os tubos}

Na seção anterior mostramos como as conexões podem melhorar as propriedades mecânicas dos nanotubos de parede dupla. No entanto, precisamos conhecer as limitações de cada um dos sistemas estudados e, para isso, realizamos deslocamentos relativos até que as conexões possam ser rompidas e/ou reconstruidas. Antes de descrever o modelo, vamos chamar a atenção para as condições em que estamos realizando tal procedimento. Estamos considerando condições periódicas de contorno e, desta forma, nosso sistema é infinito na direção do eixo do nanotubo, e a cada $12.205 \AA$, o sistema é repetido periodicamente. Vamos considerar o seguinte sistema esquematizado na figura 5.8.

Na figura 5.8-a mostramos um nanotubo de parde dupla hipotético, e suas diversas conexões, antes do deslocamento. Considerando que o tubo externo é deslocado por uma força externa $\left(F_{\text {ext }}\right)$ e, devido à ligação entre as paredes dos tubos, o tubo interno desloca juntamente com o externo. O comportamento da conexão pode ser pensado de acordo com o esquema da figura 5.8-b, dependendo da situação, a conexão vai esticar até o rompimento. 


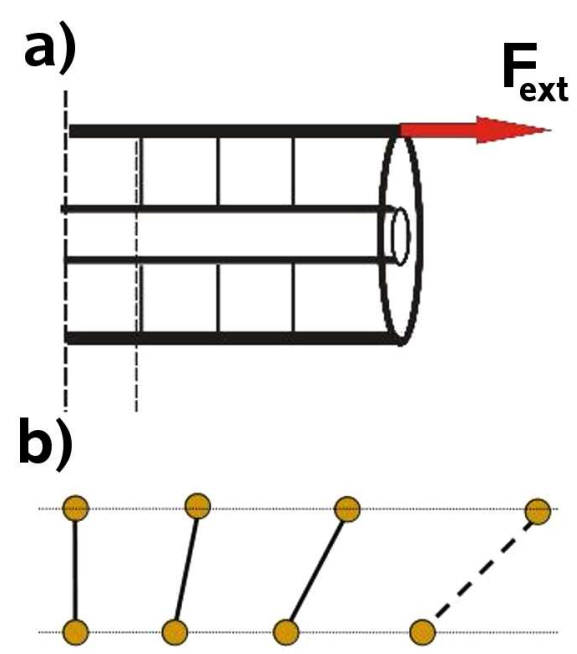

Figura 5.8: Apresentamos um esquema de um nanotubo de parede dupla e o comportamento da conexão. Em (a) mostramos um nanotubo na situação inicial sem deslocamentos; e em (b) exibimos o provável comportamento da conexão principal em função do deslocamento.

Dentro das nossas limitações, impostas pelas condições periódicas de contorno, deslocamos um tubo em relação ao outro. Foi feita uma relaxação da estrutura, mantendo os átomos da borda fixos para que o sistema não retornasse a posição de equilíbrio. Para os principais sistemas discutidos acima, fizemos uma análise da diferença de energia e da força em função do deslocamento longitudinal, onde consideramos deslocamentos de até $( \pm 2.3 \AA)$.

Na figura 5.9 podemos observar os gráficos mencionados acima para o defeito de Wigner-I-a com uma única conexão $\left(\rho_{d}=0.082\left[\right.\right.$ def. $\left.\left.\AA^{-1}\right]\right)$.

Observamos na figura 5.9-a o gráfico da diferença de energia em função do deslocamento longitudinal e, para ambas as direções deslocadas, constatamos uma descontinuidade no gráfico devido ao rompimento da conexão. Na figura 5.9-b apresentamos o gráfico da força em função do deslocamento e, quando a conexão se rompe, a força se anula, como esperado. Estimamos a força de rompimento da conexão para deslocamentos positivos e negativos $(0.68$ e $-0.55 \AA)$ em relação ao eixo do 

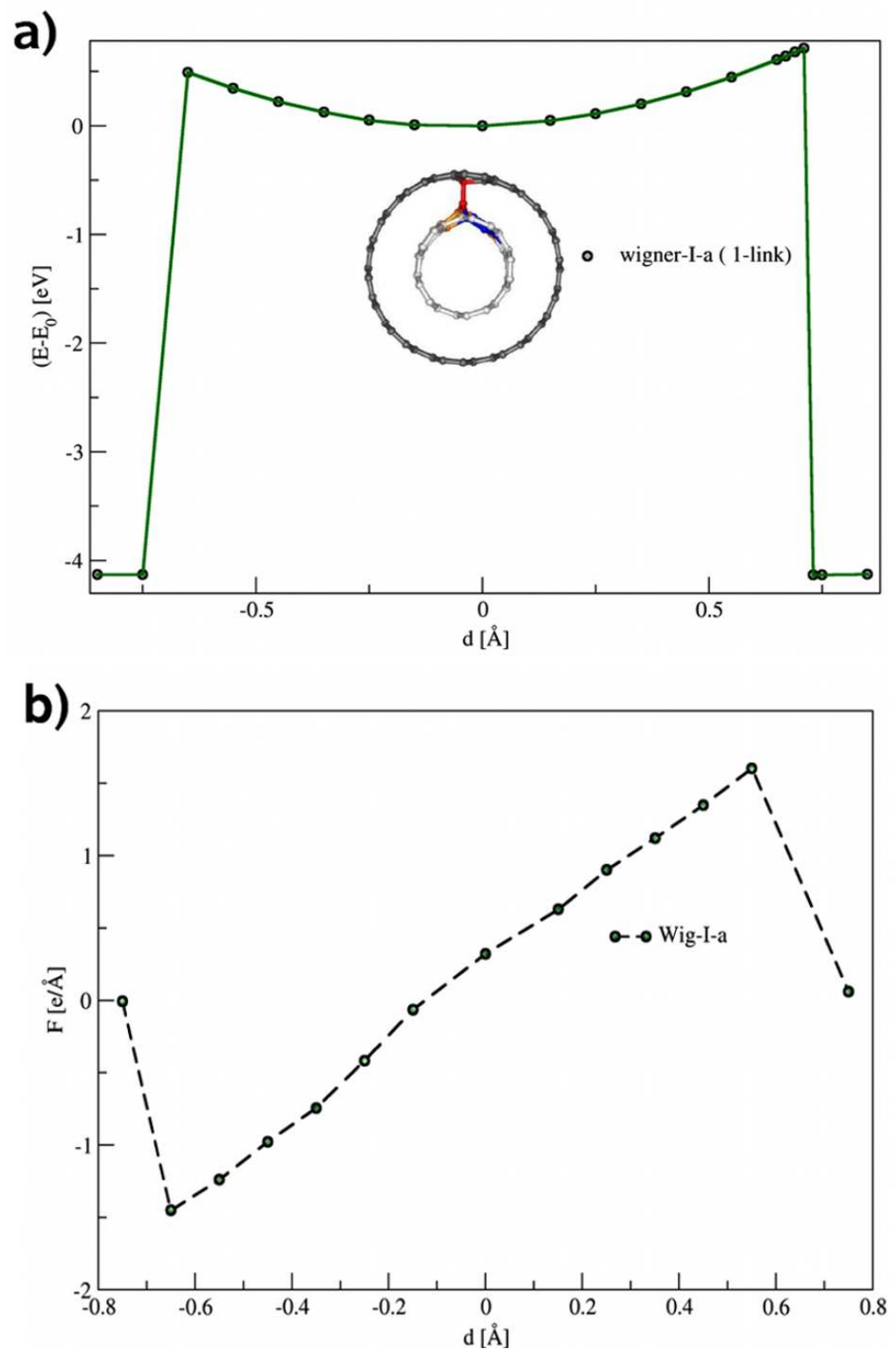

Figura 5.9: Apresentamos os gráficos da diferença de energia (a) e da força (b) em função do deslocamento longitudinal, para os defeito de Wigner-I-a a concentração $\rho_{d}=0.082\left[\right.$ def. $\left.\AA^{-1}\right]$.

DWCNT como sendo de $\approx 2.96 \mathrm{nN}$ e $\approx-2.2 \mathrm{nN}$, respectivamente. Investigamos o comportamento da densidade de carga eletrônica em função do deslocamento longitudinal, a partir da posição de equilíbrio até o romprimento da conexão, como 
podemos observar na figura 5.10.
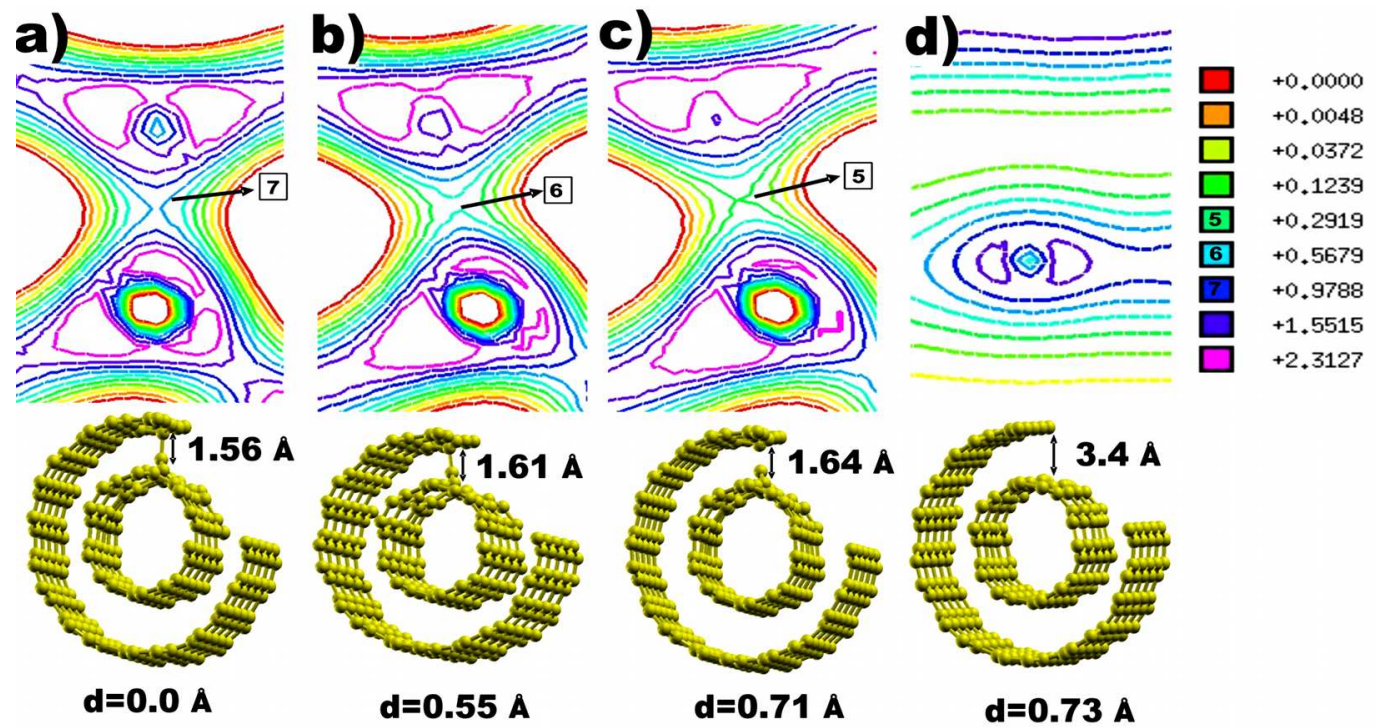

Figura 5.10: Apresentamos a densidade de cargas eletrônica, em e/ $\AA^{3}$, para o defeito de Wigner-I-a $\left(\rho_{d}=0.082\left[\right.\right.$ def. $\left.\left.\AA^{-1}\right]\right)$, considerando deslocamentos longitudinais até o rompimento da conexão. Na figura d refere-se ao deslocamento relativo longitudinal empregada a um dos tubos; em cada estrutura mostramos o comprimento de ligação da conexão até essa sofrer o rompimento; e na densidade de carga o número refere-se a uma determinada isolinha, como rotulada na legenda.

Na figura 5.10 observamos que, com o aumento do deslocamento, há uma diminuição no número de isolinhas. Para deslocamento maiores de $0.71 \AA$, constatamos um rompimento completo da conexão para este defeito. Na mesma figura, observamos a evolução do comprimento da conexão entre as paredes dos DWCNT.

O mesmo procedimento foi realizado para o defeito de Wigner-I-a-2l, com uma concentração de defeitos de $\left(\rho_{d}=0.164\left[\operatorname{def} . \AA^{-1}\right]\right)$ e, na figura 5.11 podemos observar o comportamento para este defeito.

Neste caso, observamos duas descontinuidades no gráfico da energia (figura 5.11a) onde, a primeira refere-se ao primeiro rompimento da conexão e, a segunda, é devido ao segundo. No gráfico da força (figura 5.11-b), observamos o mesmo comportamento do defeito de Wigner-I-a, mas com uma etapa intermediária devido 

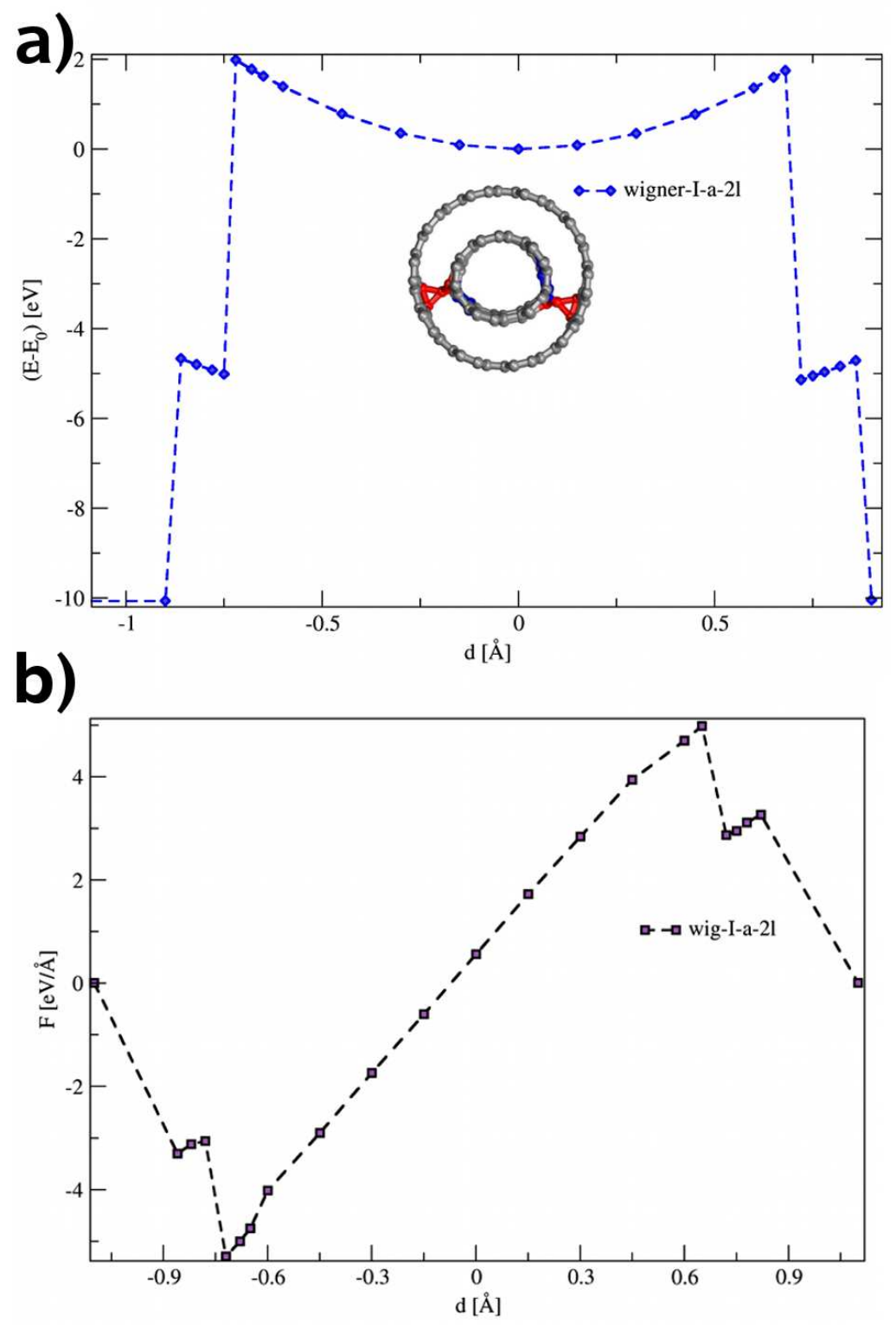

Figura 5.11: Apresentamos os gráficos da diferença de energia (a) e da força (b) em função do deslocamento longitudinal para os defeito de Wigner-I-a-2l ( $\rho_{d}=0.164$ $\left[\right.$ def. $\left.\left.\AA^{-1}\right]\right)$.

ao rompimento da primeira conexão. Quando todas as conexões são rompidas, a força tem valor nulo. Fizemos uma estimativa da força de rompimento da conexão e, para deslocamentos positivos 0.64 e $0.82 \AA$, obtivemos uma força de 7.9 e $5.2 \mathrm{nN}$, 
respectivamente. Quando deslocamos um dos tubos negativamente em relação ao eixo do DWCNT observamos o rompimento em deslocamentos -0.72 e $-0.86 \AA$, para a força de -8.5 e $-5.3 \mathrm{nN}$, respectivamente. Notamos que com o aumento da concentração de conexões a força necessária para romper a primeira conexão aumenta por um fator de 3, aproximadamente.

O próximo defeito que analisaremos será o Wigner-I-b $\left(\rho_{d}=0.082\left[\right.\right.$ def. $\left.\left.\AA^{-1}\right]\right)$. Apresentamos os gráficos da energia e da força, desses defeitos, na figura 5.12.

O defeito de Wigner-I-b apresentou um comportamento distinto do Wigner-I-a e, como podemos observar no gráfico da figura 5.12-a, num certo intervalo de deslocamentos, a energia varia parabolicamente. Notamos duas descontinuidades, para ambos os deslocamento (positivo e negativo), onde uma nova parábola é formada. Este processo refere-se à recombinação das ligações da conexão quando deslocamos um dos nanotubos. No final do processo voltamos ao mesmo estado inicial, isto é, o defeito sofreu uma translação para o sítio posterior para ambos os delocamentos. O gráfico da força é mostrados no gráfico da figura 5.12-b.

Para os sistemas do tipo vacância-vacância, vamos apresentar o resultado para o defeito $V_{2}^{2}$ em duas concentrações $\left(\rho=0.082\right.$ [def. $\AA^{-1}$ ] e $\rho_{d}=0.164$ [def. $\left.\left.\AA^{-1}\right]\right)$. O primeiro caso que apresentaremos é para o de menor concentração. Na figura 5.13 podemos observar os gráficos da energia e da força em função do deslocamento longitudinal relativo.

Observamos que o gráfico da figura 5.13-a o comportamento parabólico da diferença de energia em finção do deslocamento. Para deslocamentos positivos ocorre a recombinação do defeito, enquanto que para deslocamentos negativos a conexão se rompe. A explicação para este fato é que quando empregamos deslocamentos positivo a ligação pendente do tubo interno, por estar posicionada para fora do tubo, ela se recombina com os átomos da parede do tubo externo, formando um defeito do tipo Winger. Para os deslocamentos negativos, observamos que a conexão é rom- 

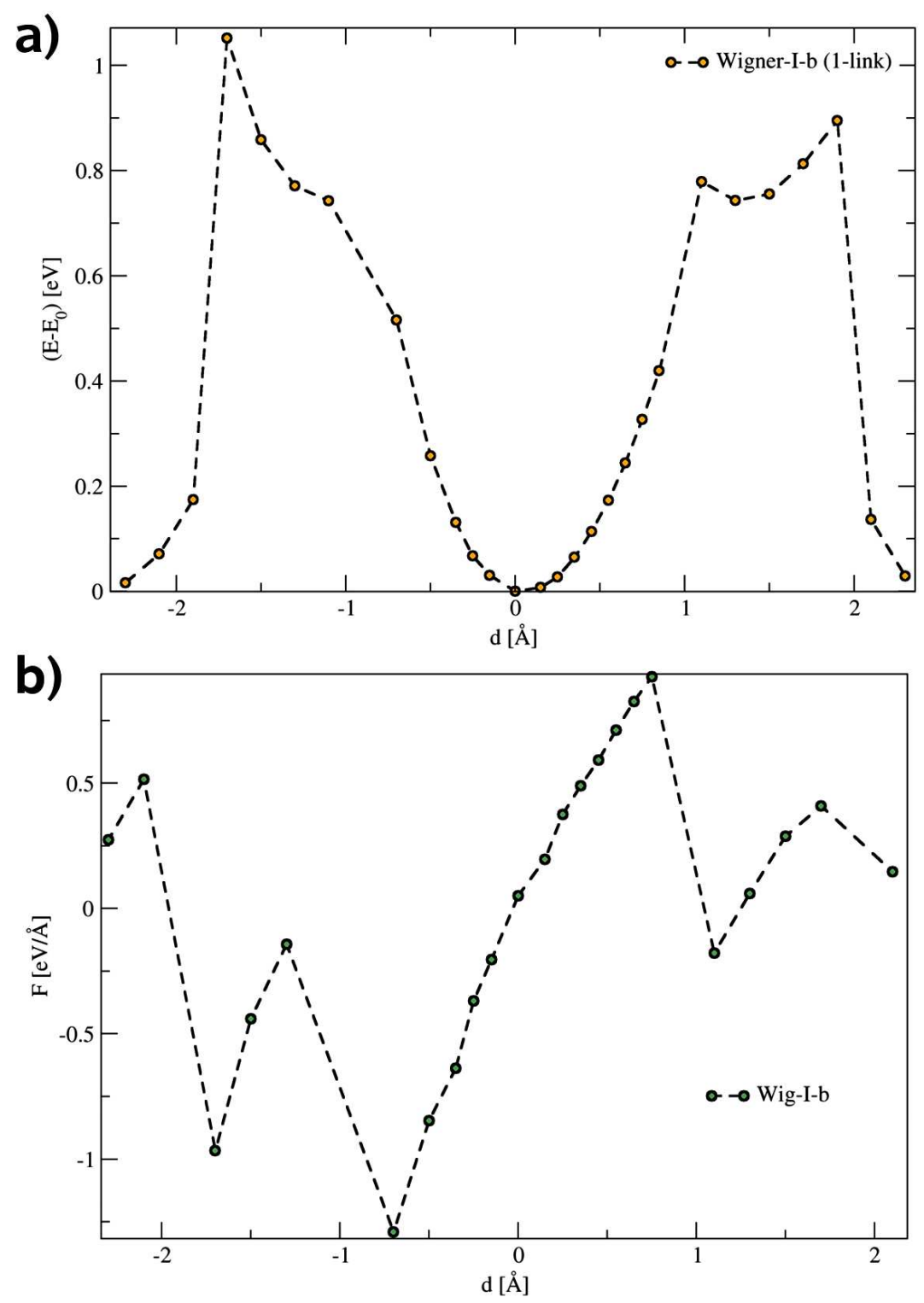

Figura 5.12: Apresentamos os gráficos da diferença de energia (a) e da força (b) em função do deslocamento longitudinal, para os defeito de Wigner-I-b (concentração $\rho_{d}=0.082\left[\right.$ def. $\left.\left.\AA^{-1}\right]\right)$.

pida, e a ligação pendente fica exatamente em sobre o nonágono da monovacância do tubo externo, impossibilitando a reconstrução com os átomos. Observando as forças do sistema, notamos que a conexão se rompe e a força tende a zero, e na situação 

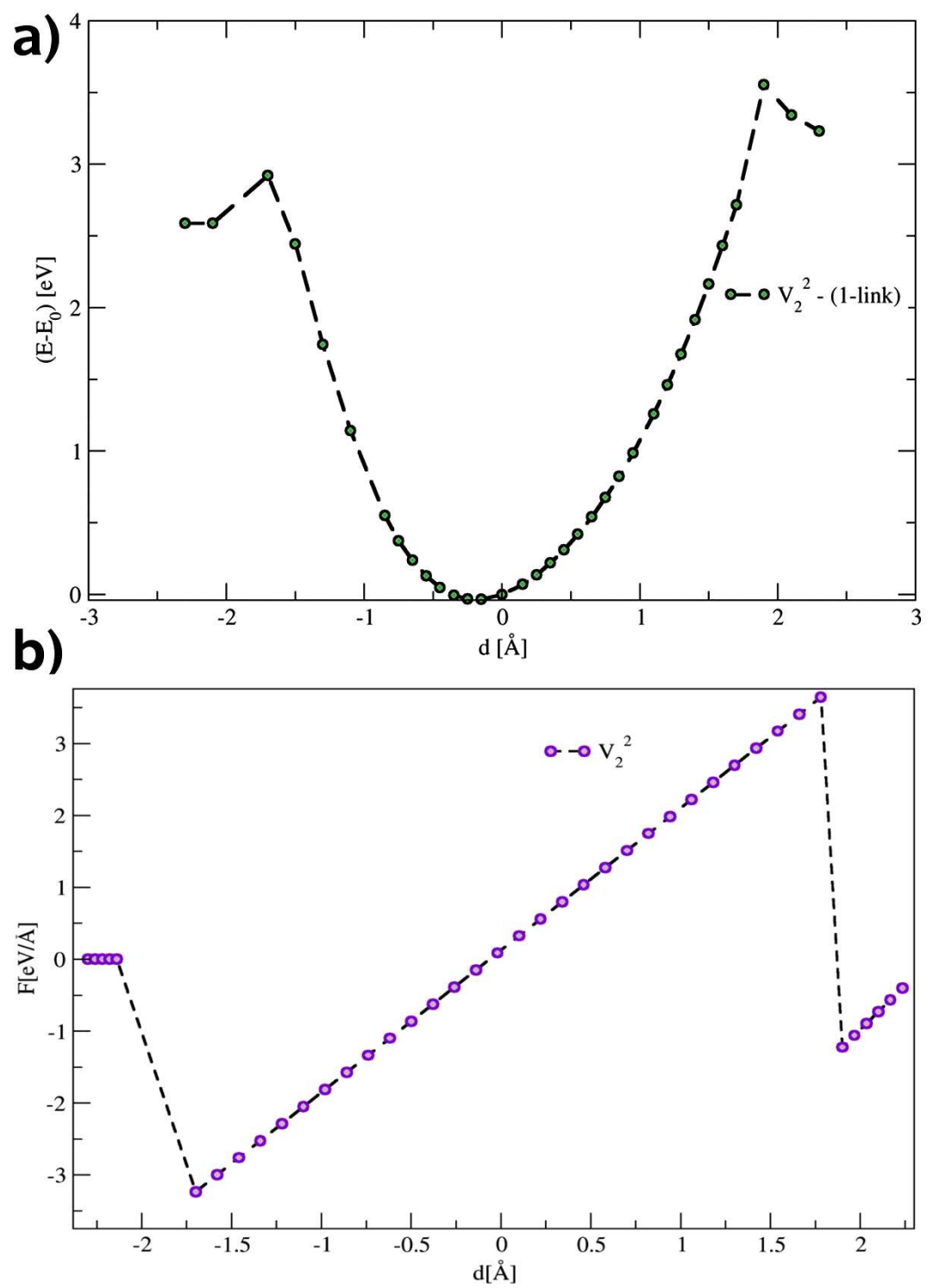

Figura 5.13: Apresentamos os gráficos da diferença de energia (a) e da força (b) em função do deslocamento longitudinal, para os defeito de $V_{2}^{2}$ (concentração $\rho_{d}=0.082$ $\left.\left[\operatorname{def} \cdot \AA^{-1}\right]\right)$.

em que a conexão é reconstruída existirá uma força devido esta nova conexão. Na figura 5.14 apresentamos o gráfico da energia e da força em função do deslocamento para o defeito $V_{2}^{2}$. 

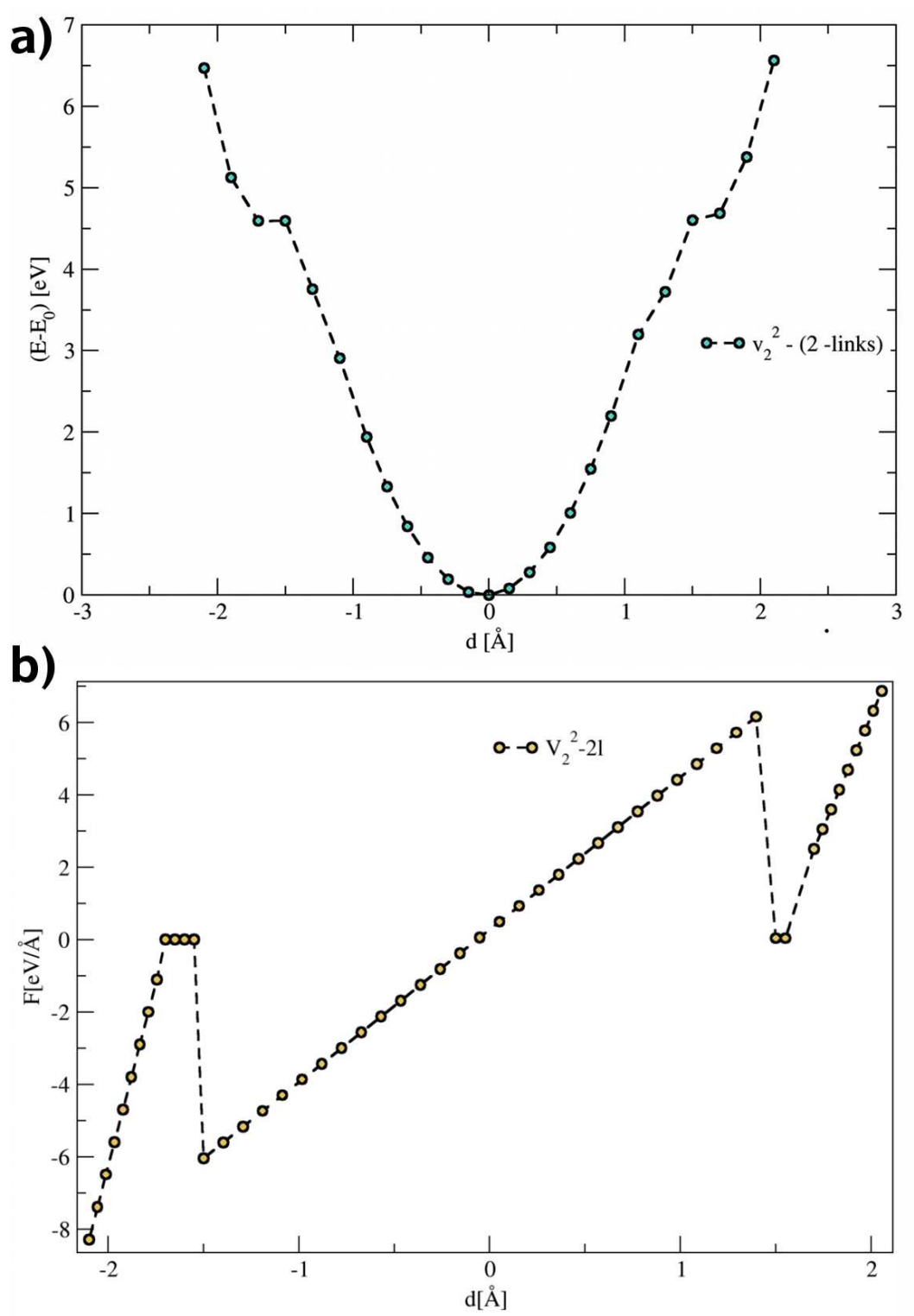

Figura 5.14: Apresentamos os gráficos da diferença de energia (a) e da força (b) em função do deslocamento longitudinal para o defeito $V_{2}^{2}-2 l\left(\rho_{d}=0.164\right.$ [def. $\left.\left.\AA^{-1}\right]\right)$.

O defeito $V_{2}^{2}-2 l$ apresenta uma descontinuidade da energia para o deslocamento longitudinal positivo e negativo, como podemos observar no gráfico da figura 5.14-a, e esse efeito é devido ao rompimento de uma das conexões desse defeito. Quando continuamos deslocando um dos tubos, ocorre uma recombinação do defeito que não 
rompeu para o sítio seguinte. O defeito que rompe não recombina, pois o átomo da ligação pendente tende a sair do nanotubo e, por isso, a distância para recombinar aumenta dificultando tal processo. Para o defeito oposto, o átomo do tubo interno também tende a sair, no entanto, ele fica mais perto da parede do tubo externo, refazendo a conexão. No gráfico da figura 5.14-b, mostramos o comportamento da força em função do deslocamento, onde observamos uma descontinuidade devido ao rompimento das conexões. Estimamos a força para romper uma das conexões, isto é, para os deslocamentos 0.9 e $-1.1 \AA$, onde observamos forças de 8 e $7.8 \mathrm{nN}$, respectivamente.

Na próxima seção vamos investigar a transferência de tensão para os defeitos apresentados acima.

\subsection{Transferência de Tensão}

Na seção anterior mostramos o comportamento dos defeitos em DWCNT quando um dos tubos é submetido a uma translação longitudinal. Este estudo foi realizado com o intuito de analisamos o processo de rompimento/recombinação da conexão, para diferentes defeitos e para duas concentrações. No entanto, precisamos entender o processo de transferência de tensão através das conexões. Como foi dito na introdução, a transferência de tensão máxima de um tubo externo para um tubo interno, considerando que o sistema $(5,5) @(10,10)$, é 0.33 . Vamos apresentar um modelo para o comportamento da transferência de tensão entre as paredes dos tubos através da conexão e, para isso, vamos analisar a seguinte situação da figura 5.15.

É importante salientar que a presente situação é diferente da mostrada na figura 5.8. Nesse modelo os nanotubos são esticados devido a força externa empregada e, como consequência das ligações das conexões, o tubo interno também é esticado, como podemos ver na figura 5.15-b. Vamos considerar a hipótese de que quando os nanotubos são aumentados, podemos usar deslocamentos relativos. 


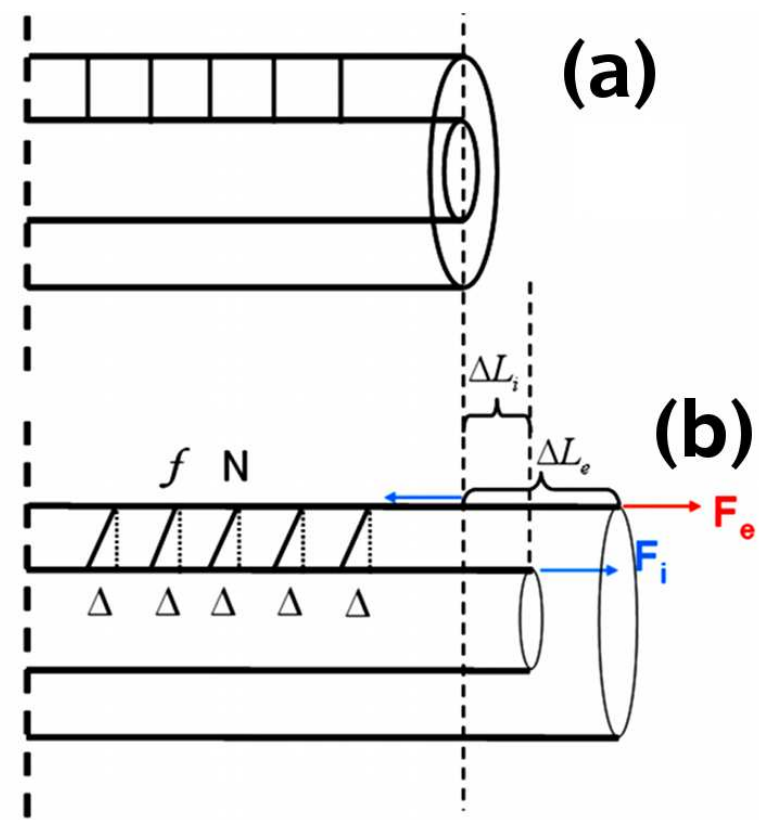

Figura 5.15: Apresentamos um esquema de um nanotubo de parede dupla e o comportamento das conexões quando uma força é aplicada. Em (a) mostramos um nanotubo na situação inicial sem forças aplicadas; e em (b) exibimos o provável comportamento das conexões com o aumento do tubo provocado por uma força aplicada.

Considerando que os nanotubos são formados por molas, então, ao esticar o CNT externo através de uma força $F_{e}$ aplicada ao nanotubo externo e, pelo fato do nanotubo interno estar ligado ao tubo externo pela conexão, uma força interna se opõe ao movimento do tubo. No equilíbrio a força resultante desse processo pode ser escrita como:

$$
F_{e}-F_{i}=k_{e} \Delta L_{e}
$$

onde o $F_{i}$ é a força interna, $k_{e}$ é a constante elástica do tubo exteno, $\Delta L_{e}$ é a variação de comprimento do tubo externo. Considerando que o sistema possui $\mathrm{N}$ defeitos idênticos, e cada um fornece a mesma resposta $(f)$ quando estes são esticados, podemos escrever: 


$$
F_{i}=k_{i} \Delta L_{i}=N f(\Delta),
$$

e, neste caso, o $k_{i}$ é a constante elástica do tubo interno, $\Delta L_{i}$ é o aumento do tubo interno e $f$ é a força de cada conexão. Considerando que o estiramento dos $\mathrm{N}$ defeitos pode ser escrito como:

$$
N \Delta=\Delta L_{e}-\Delta L_{i}
$$

Podemos definir a transferência de tensão (LT) da seguinte maneira:

$$
L T=\frac{F_{i}}{F_{e}}
$$

ou seja, a razão entre a força interna pela força externa. Substituindo as expressões 5.1, e 5.2 na equação 5.4, podemos escrever a expressão para a transferência de tensão em função de apectos intrínsecos dos defeitos da seguinte maneira:

$$
L . T=\frac{k_{i} \Delta L_{i}}{F_{i}+k_{e} \Delta L_{e}} .
$$

Substituindo a equação 5.3 na 5.5 e rearranjando os termos, podemos escrever uma expressão para a transferência de tensão:

$$
L T=\frac{1}{1+\frac{k_{e}}{k_{i}}+\frac{k_{e} \cdot \Delta}{f}} .
$$

Considerando um nanotubo de parede dupla $(5,5) @(10,10)$, com a razão entre os k's sendo igual a 2, a situação ideal seria uma transferência de tensão máxima, isto é, ao aplicar uma força a um dos tubos, ambos se esticariam por um mesmo tamanho. Nessa situação, o $\Delta$ se anula e a equação 5.6 nos fornece uma transferência máxima (0.33).

Podemos aplicar essa metodologia para os nossos sitemas, onde o $f(\Delta)$ é extraído 
dos gráficos da força em função do deslocamento, mostrados na seção anterior.

Queremos comparar os nossos resultados com os obtidos na literatura pelos autores $[65,66]$. Eles estudaram o defeito de Wigner no nantubo $(5,5) @(10,10)$ para diversas concentrações de defeitos utilizando um tubo com 72.7 Å. Os cálculos foram realizados com dinâmica molecular utilizando o potencial Tersoff-Brenner de segunda geração (MTB-G2). No gráfico da figura 5.16 apresentamos o resultado para o defeito de Wigner obtido pelos autores da referência [66]

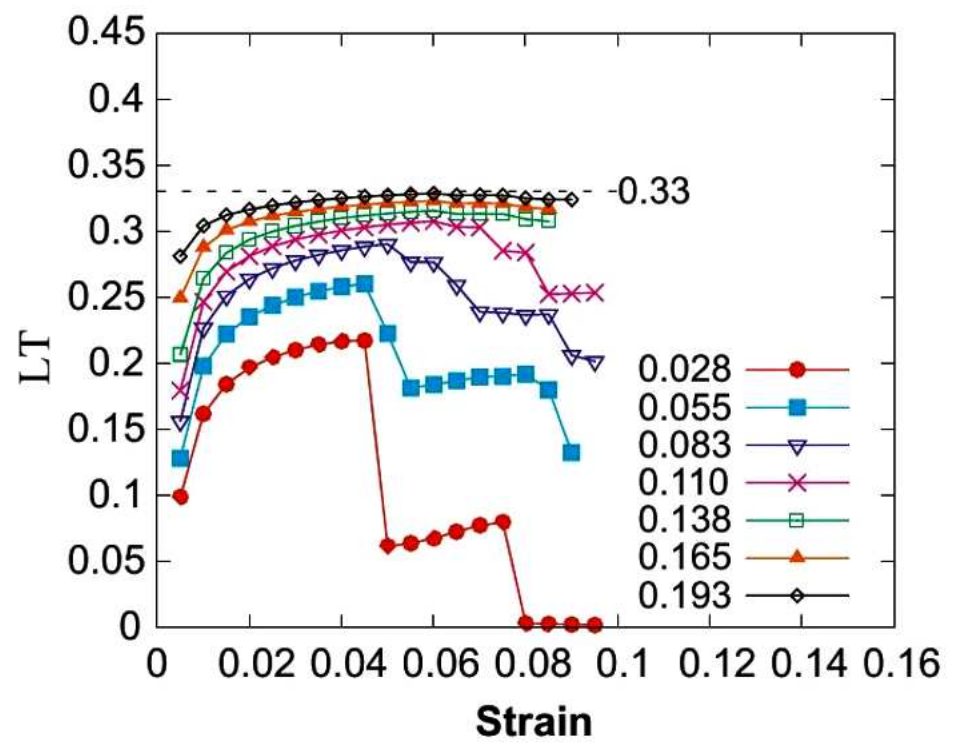

Figura 5.16: Apresentamos o gráfico da transferência de tensão (LT) em função do "strain" para o defeito de Wigner para diferentes concentrações de defeitos. Resultado extraído da referência [66].

Observamos no gráfico da figura 5.16 o limite teórico da transferência de tensão para este sistema (0.33) e o resultado para diferentes concentrações de defeitos. Para altas concentrações, a tranferência de tensão é perto do valor máximo permitido. Nos casos em que a concentração de defeitos é baixa, observamos algumas descontinuidades atribuidas a quebra da conexão.

Calculamos o valor do $k_{e}$ para um nanotubo $(10,10)$ aumentando o tamanho da 
caixa de simulação por até $1.5 \AA$. Nesse cálculo obtivemos um $k_{e}=60\left[\mathrm{eV} . \AA^{-2}\right]$, e para compararmos os nossos resultados com o dos autores, vamos considerar um $k_{e}=10\left[\mathrm{eV} . \AA^{-2}\right]$, pois o tubo simulado pelos autores é seis vezes maior do que o nosso.

Vamos analisar os gráficos da transferência de tensão para os defeitos de WignerI-a e $V_{2}^{2}$, em diferentes concentrações de defeitos, em função do "strain" $\left(\frac{\Delta}{L_{z}}\right)$. Na figura 5.17 mostramos a transferência de tensão (LT) em função do " strain" para os defeitos de Wigner-I-a e $V_{2}^{2}$ em duas concentrações.

Na figura 5.17-a apresentamos os resultados do LT para o defeito de Wigner-I-a, em uma concentração de $\rho_{d}=0.082$ [def. $\left.\AA^{-1}\right]$. Observamos que o presente sistema apresenta um transferência de tensão de $\approx 0.15$ e, como observado nos gráficos da figura 5.9, no gráfico da transferência de tensão verificamos a mesma descontinuidade observada para na seção anterior devido ao rompimento da conexão. Quando ocorre o rompimento o LT se anula, como esperado. No mesmo gráfico mostramos o defeito de Wigner-I-a com uma concentração de $\rho_{d}=0.164$ [def. $\left.\AA^{-1}\right]$. A transferência de tensão obtida para este sistema foi de $\approx 0.26$, e este valor não variou muito até o primeiro rompimento da conexão, que ocorreu para um strain de $(\approx 0.06)$. Neste ponto, o LT diminuiu para $\approx 0.18$, onde permaneceu constante até o segundo rompimento da conexão onde, novamente, o LT se anulou. Para o defeito do tipo $V-$ $V\left(V_{2}^{2}\right)$ mostramos o mesmo gráfico na figura 5.17-b. No nanotubo com o defeito $V_{2}^{2}$, com uma concentração $\rho_{d}=0.082$ [def. $\AA^{-1}$ ], observamos uma transferência de tensão de $\approx 0.12$ e, como a conexão foi recombinada no sítio posterior, notamos que o LT se mantém constante. Quando aumentamos a concentração $\left(\rho_{d}=0.164\left[\operatorname{def} . \AA^{-1}\right]\right)$, observamos um LT de 0.22 até o rompimento da primeira conexão e, como a segunda conexão não é romprida, o LT sofre uma oscilação em torno de 0.14. Calculamos para o defeito de Wigner-I-b e para o de defeito $V_{2}^{1}\left(\rho_{d}=0.082\left[\right.\right.$ def. $\left.\left.\AA^{-1}\right]\right)$, onde obtivemos uma transferência de tensão de 0.09 e 0.1, respectivamente. 

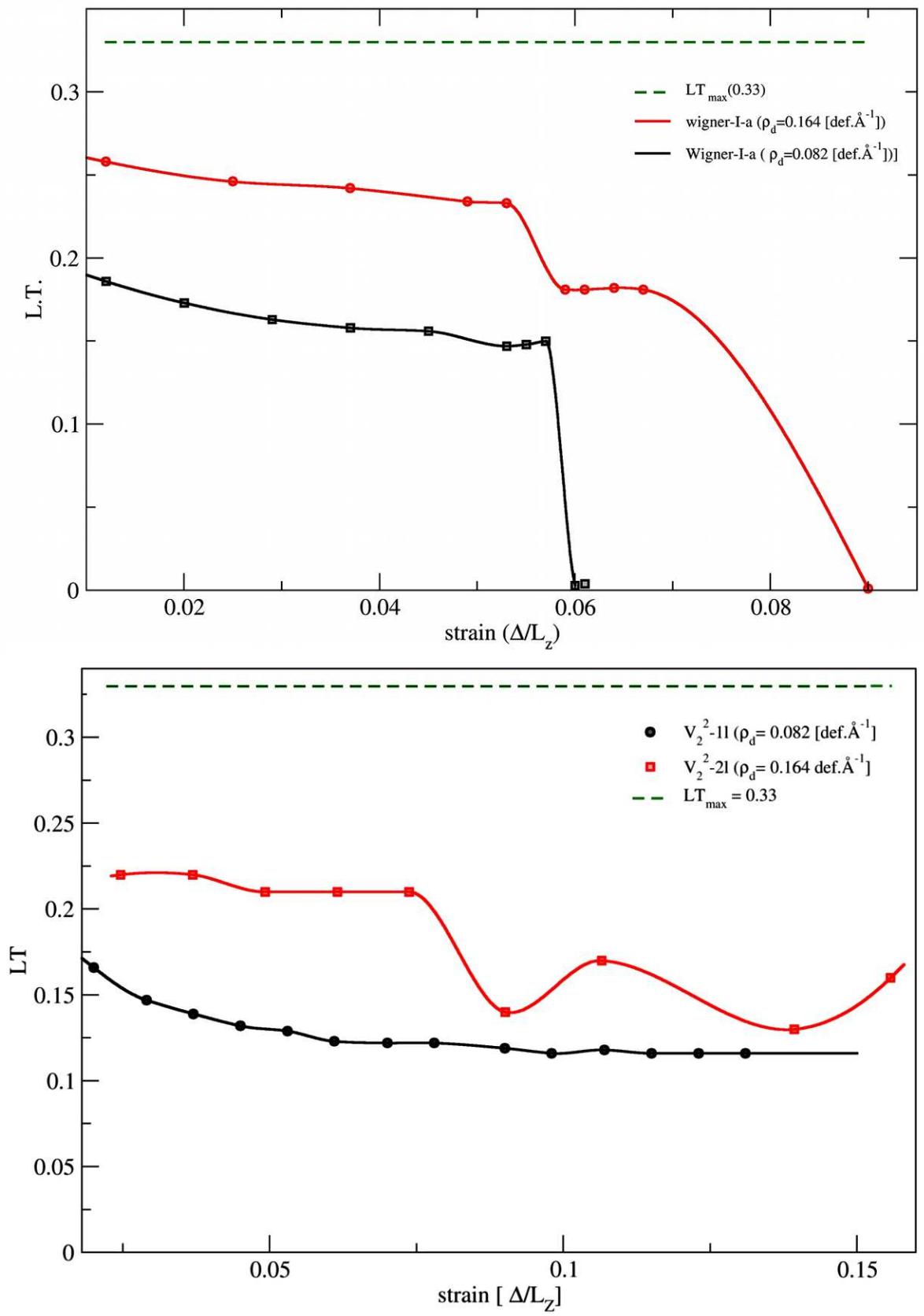

Figura 5.17: Apresentamos o gráfico da transferência de tensão (LT) em função do "strain" para o defeito de Wigner-I-a (a) e para o defeito $V_{2}^{2}$, em duas concentrações $\left(\rho_{d}=0.082\right.$ e $\rho_{d}=0.164$ [def. $\left.\left.\AA^{-1}\right]\right)$. 
Os melhores resultados foram obtidos para o defeito Wigner-I-a com a concetração de $\rho_{d}=0.164\left[\right.$ def. $\AA^{-1}$ ], cerca de $75 \%$ da tensão pode ser transmitida do tubo exteno para o interno. O LT diminui quando a primeira conexão é rompida onde, para uma conexão deste mesmo sistema, a tensão tranferida para 54\%. Comparando com o resultado dos autores [66], os nossos resultados são simulares aos obtidos por eles. O defeito de Wigner que o autores apresentaram, com a mesma concentração, apresentou um LT de $\approx 0.27$. Para os defeitos com uma concentração $\rho_{d}=0.082\left[\right.$ def. $\left.\AA^{-1}\right]$, observamos que o que possui o maior LT também é o WignerI-a. Este sistema possui uma transferência de tensão 18\% maior do que o defeito Wigner-I-b e $10 \%$ melhor que o defeito $V_{2}^{2}$.

O presente resultado é um indicativo de que esses defeitos em DWCNT serão bons candidatos à aplicações em materiais cujas propriedades mecâncias queiram ser melhoradas pois, como foi mostrado, as conexões aumentam o módulo de cisalhamento consideravelmente e, além disso, as conexões possuem uma boa transferência de tensão entre as paredes dos nanotubos. 


\section{Capítulo 6}

\section{Conclusões}

Nesta tese investigamos a influência de defeitos nas propriedades de nanotubos de carbono utilizando cálculos de primeiros princípios baseados na Teoria do Funcional da Densidade. Investigamos o comportamento de quatro defeitos estruturais Stone-Wales, monovacância, divacância (585), divacância (555777) em nanotubos de parede simples armchair e zigzag. Em ambos os casos, a ordem energética obtida para os defeitos foi: $E_{f}^{\text {Stone-Wales }}<E_{f}^{\text {divac-585 }}<E_{f}^{\text {divac-555777 }}<E_{f}^{1 v}$. Comparando os quatro defeitos em tubos com os mesmos em grafeno observamos que, em todos os casos, os defeitos em tubos são mais estáveis do que os respectivos defeitos em grafeno. Esse é um indicativo de que essas imperfeições são mais fáceis de serem criadas em nanotubos. Mostramos o comportamento da energia de formação em função do diâmetro para os quatro defeitos e em um intervalo de $(6-15 \AA)$. Fizemos uma estimativa para o comportamento da energia de formação em função do diâmetro, considerando o intervalo estudado, e também o limite de um nanotubo infinito ( $E_{f}$ do grafeno). O mesmo procedimento foi feito para os nanotubos zigzag.

Mostramos que a energia de formação das divacâncias são menores do que a da monovacância e, além disso, quando comparamos as energia de formação das divacâncias em grafeno, observamos uma inversão de estabilidade. 
Nos tubos a divacância (585) é a mais estável, enquanto que no grafeno a divacância (555777) apresentou uma menor energia de formação. Esta inversão está associada à quebra de duas ligações dos pentágonos do defeito 585, pois para diâmetros pequenos, essas ligações possuem comprimento da ordem de $1.5 \AA$, enquanto que no grafeno essas ligações possuem comprimentos da ordem de 1.77 Å. Estimamos o diâmetro no qual essa inversão ocorrerá: nos nanotubos armchair (zigzag) será no diâmetro $40 \AA$ (53 $\mathrm{A}$ ). Apresentamos o comportamento da transmitância, T(E), para as duas divacâncias e, em ambos os casos, observamos uma diminuição da transmitância de $2 G_{0}$ para $1.0 G_{0}$ no nível de fermi.

Além disso, estudamos os defeitos do tipo vacância-vacância, $V_{2}^{1}$ e $V_{2}^{2}$, em feixes de nanotubos de carbono. Mostramos que o defeito $V_{2}^{2}$ é mais estável do que o defeito $V_{2}^{1}$ e, comparando com os mesmos defeitos em grafite, esses apresentam menores energias de formação para nanotubos. Esse resultado é um indicativo de que os defeitos podem ser encontrados mais facilmente em feixes do que em grafite. Comparando esses sistemas com o defeito de Wigner em feixes, os defeitos do tipo vacância-vacância são menos estáveis do que o Wigner.

Investigamos o comportamento da ligação que conecta os tubos e, notamos, em ambos os casos, que a densidade de carga que passa por um plano perpendicular aos tubos, na região da conexão, possui valores máximos naquelas regiões. Este fato é um indicativo de que a ligação entre as paredes dos tubos é forte para ambos os defeitos.

Mostramos que a barreira de recombinação para o defeito $V_{2}^{1}$ é da ordem de $2.6 \mathrm{eV}$, que consiste na barreira para desfazer a conexão e formar um nanotubo com duas vacâncias (uma em cada tubo). O segundo processo investigado foi a barreira para desfazer a conexão, subtraindo um dos átomos da mesma e tendo, como produto final, um nanotubo puro e um nanotubo com duas vacâncias. Para o defeito $V_{2}^{1}$ calculamos uma barreira para este processo de $2.7 \mathrm{eV}$. Estudamos o primeiro 
processo para o defeito $V_{2}^{2}$ onde concluímos que não há barreira para formação do defeito $V_{2}^{2}$, logo o processo ocorre espontaneamente. Comparativamente com o defeito de Wigner, a barreira de recombinação do defeito $V_{2}^{1}$ é ligeiramente maior, no entanto, o defeito mais provável é o $V_{2}^{2}$ pois não existe barreira para formá-lo. Calculamos o módulo de cisalhamento e, para o defeito $V_{2}^{1}$, obtivemos $33 \mathrm{GPa}$ e, para o defeito $V_{2}^{2}$, o módulo de cisalhamento obtido foi de $68 \mathrm{GPa}$. Observamos um aumento no módulo de cisalhamento de $5-10$ vezes comparado com o feixe de nanotubo sem conexão.

Estudamos a influência do defeitos nas propriedades de nanotubos de parede dupla. Neste sistema, investigamos os defeitos do tipo vacância-interstício (VI) e vacância-vacância (VV) e, para o primeiro tipo, o defeito de Wigner apresentou quatro possibilidades. O estudo da estabilidade desses sistemas mostrou que o defeito de Wigner prefere ser criado na parede interna e os átomos do pentágono que são formados pelo defeito participam da conexão entre as paredes do tubo. Dentre todos os defeito estudados, o que apresentou a menor energia de formação foi o Wigner-I-a. Comparando tanto os defeitos do tipo VI quanto os VV em nanotubos de parede dupla com os mesmos defeitos em grafite, em todos os casos os defeitos em nanotubos de parede dupla são mais estáveis. Quando comparamos os defeitos em nanotubos de parede dupla com feixes de nanotubos observamos que os feixes são mais estáveis, em todos os casos.

Analisamos as conexões através da densidade de carga e, para todos os casos, observamos valores máximos na região onde a conexão é formada. Esse resultado corrobora a hipótese de que todas as conexões são fortes. Calculamos o módulo de cisalhamento, para os principais defeitos, em uma concentração de defeitos de $\rho_{d}=0.082\left[\right.$ def. $\left.\AA^{-1}\right]$. Observamos um aumento do módulo de cisalhamento de 10-18 vezes, dependendo do defeito, comparado com o sistema sem defeito. Consideramos os dois defeitos mais estáveis, Wigner-I-a e $V_{2}^{2}$, com uma concentração de $\rho_{d}=$ 
$0.164\left[\right.$ def. $\left.\AA^{-1}\right]$, duas vezes a concentração previamente estudada, e o módulo de cisalhamento sofreu um aumento por um fator de 3, comparado com o sistema com a conexão de defeitos de $\rho_{d}=0.082$ [def. $\left.\AA^{-1}\right]$. Investigamos o processo de rompimento das conexões através de deslocamentos longitudinais de um dos tubos. Para o defeito Wigner-I-a, observamos que a conexão se rompe, simetricamente, a um deslocamento de $0.7 \AA$, e este processo necessita de uma força de $3 \mathrm{nN}$. Quando a densidade de defeitos aumenta, observamos dois rompimentos referentes a cada uma das conexões rompidas. Neste caso, a força para desfazer a primeira conexão é de $\approx 8 \mathrm{nN}$, enquanto que, para arrebentar a segunda conexão, a força obtida foi de $\approx 5 \mathrm{nN}$. O defeito Wigner-I-b, no intervalo deslocado $( \pm 2.3 \AA)$, não apresentou ruptura na conexão, pois ocorre a reconstrução do defeito no sítio posterior. Para o defeito $V_{2}^{2}$ notamos que para deslocamentos positivos, a conexão se recombina no sítio posterior, formando um defeito de Wigner. Quando empregamos deslocamentos negativos a um dos tubos a conexão se rompe. Observamos que aumentando a concentração do defeito $V_{2}^{2}$ para $\rho_{d}=0.164$ [def. $\AA^{-1}$, notamos que somente uma da conexões se rompe. A segunda conexão se reconstrói no sítio posterior formando um defeito de Wigner. Esse resultado é válido para deslocamentos positivos e negativos em relação ao eixo do CNT.

O último resultado importante obtido nesta tese trata-se da transferência de tensão (LT) entre as paredes dos CNTs. Observamos que esta transferência depende da concentração de defeitos e do tipo de defeito que o DWCNT possui. Para os defeitos Wigner-I-a e $V_{2}^{2}$, a uma concentração de $\rho_{d}=0.164$ [def. $\AA^{-1}$ ], obtivemos uma transferência de tensão de $75 \%$ e $66 \%$, respectivamente. Para uma concentração de defeitos de $\rho_{d}=0.082\left[\right.$ def. $\left.\AA^{-1}\right]$, constatamos que a transferência de tensão, para os mesmo defeitos, diminui para $45 \%$ e 36\%, respectivamente. Este resultado é um indicativo de que essas conexões são importantes quando queremos que as propriedades mecânicas sejam melhoradas e, além disso, essas conexão fornecem 
uma boa performance no que diz respeito a tranferência de tensão entre as paredes dos tubos. Através de cáclculos microscópicos conseguimos descrever a transferência de tensão de um sistema macroscópico através de um modelo proposto.

Este estudo revelou que as imperfeições podem ser criadas em nanotubos e, como consequência, as propriedades dos mesmos são diretamente afetadas. É importante conhecer como cada defeito modifica essas propriedades para futuras aplicações. A caracterização do principais defeitos em nanotubos e o controle do tipos de defeitos, bem como sua concentração ainda é um desafio para os experimentais. No entanto, o presente estudo serve de guia para posteriores trabalhos nessa área. 


\section{Apêndice A}

\section{Metodologia}

Este apêndice é dedicado a apresentação da teoria que será empregada nesta tese, no entanto, antes de começar a descrevê-la vamos discutir quais foram as motivações que levaram a escolha da metodologia empregada nos cálculos. Vamos analisar o sistema de interesse e o objetivo principal desta tese que consiste em investigar sistemas nanoestruturados baseados em carbono com algum tipo de defeito estrutural. Esse problema pode resultar em processos tais como: sistemas com diferentes ligações químicas (hibridizações), quebra/rotação de ligação química, processo de recombinação química e rehibridização e, além disso, serão analisadas propriedades estruturais (energia de formação) e o processo de rompimento de conexões através de barreiras de recombinação etc. Como é sabido, os métodos empíricos não descrevem bem as diferentes hibridizações químicas, nem mesmo fornecem bons resultados para as energias de formação desses sistemas. Baseado nas propriedades que queremos calcular bem como nos argumentos apresentados acima, se faz necessária uma descrição totalmente quântica da estrutura eletrônica do sistema de interesse. Sendo assim, todos os nossos resultados se baseiam em cálculos ab initio de energia total Teoria do Funcional da Densidade (DFT) [83,84].

A DFT é uma das teorias mais usadas para descrição do estado fundamental 
de sólidos, superfícies e nanoestruturas, nos dias atuais. Este sucesso se dá pela conjunção de simplicidade e acurácia numa mesma teoria, possibilitando descrever sistemas cada vez maiores e com boa precisão.

Estamos interessados no estudo de materiais baseados em carbono, e a descrição desses materiais é um problema de muitos corpos. Para resolver este problema faremos, basicamente, três aproximações. A primeira aproximação é conhecida por Born-Oppeheimer, que devido à diferença da escala temporal no movimento dos elétrons e dos núcleos e pela diferença de massa entre eles, a função de onda de muitos corpos é sepada em duas partes, eletrônica e nuclear. É como se a cada movimento nuclear os elétrons se ajustassem instantaneamente a eles. Sendo assim, é possível resolver o problema eletrônico separadamente, com a posição dos núcleos sendo parâmetros no cálculo eletrônico. A segunda aproximação é feita para o potencial de correlação e troca, mostraremos que é possível separar toda a ignorância sobre o sistema neste termo, que é aproximado. Existem aproximações locais e semilocais para o potencial de correlação e troca (teremos uma seção neste apêndice sobre estas aproximações). Finalmente, a última aproximação importante que usaremos será a aproximação dos pseudopotencias. Nesta aproximação, é feita uma substituição do potencial Coulombiano do caroço iônico, fortemente divergente, por um potencial suave e finito na origem. Os elétrons de caroço, por sua vez, são despresados e não são levados em conta no cálculo. Este fato é permitido porque os elétron que participam das ligações químicas são os elétrons de valência e, sendo assim, mudar a função de onda na região de caroço não afeta significativamente as propriedades do sistema, e na região de valência o potencial não é mudado. Esta aproximação também será abordada posteriormente em maiores detalhes.

A próxima seção será dedicada à apresentação de aspectos básicos da DFT: os teoremas de Hohenberg-Kohn [83], e as equações de Kohn-Sham [84]. Em seguida, serão discutidas duas aproximações para os funcionais de correlação e troca: 
a Aproximação da Densidade Local (LDA), que considera somente aspectos locais da densidade eletrônica no cálculo da energia de correlação e troca do sistema; e a Aproximação Generalizada de Gradientes (GGA), que, por sua vez, é mais elaborada e considera aspectos semilocais da densidade eletrônica. Além disso, ao final deste apêndice será discutida a teoria dos pseudopotenciais [87,99-102].

\section{A.1 Teoria do Funcional da Densidade}

A DFT foi formulada em meados de 1960 por Walter Kohn e diversos colaboradores. O sucesso desta teoria rendeu a Kohn, no ano de 1998, o prêmio Nobel de Química, juntamente com Pople [103]. O problema tratado pela DFT é de um sistema de elétrons interagentes, sujeitos a um potencial externo ${ }^{1}$ e, além disso, essa teoria possibilita resolver este problema através do mapeamento de um sistema de partículas interagentes em um sistema de partículas não interagentes, sujeitas a um potencial efetivo. Este mapeamento é feito usando a densidade eletrônica como variável básica. As subseções seguintes têm como assunto a maneira como este mapeamento é feito e as aproximações que ele implica.

\section{A.1.1 Os teoremas de Hohenberg-Kohn}

O problema de $N$ corpos interagentes é tratado, usualmente, através da resolução da equação de Schroedinger. A função de onda de muitos corpos do sistema, $\Psi\left(\vec{r}_{1}, \vec{r}_{2}, \ldots, \vec{r}_{N}\right)$, é uma função complexa de $3 N$ variáveis, sem contar o spin do elétron. Entretanto, toda a informação contida na função de onda está em outra variável, a densidade eletrônica, que é uma função de apenas três coordenadas [104]. Resolver o problema de muitos corpos com esta nova variável consiste em uma sim-

\footnotetext{
${ }^{1} \mathrm{O}$ potencial externo corresponde, em geral ao potencial nuclear dos íons atuando no sistema eletrônico, e possivelmente ao potencial criado por campos externos ao cristal ou molécula que pretende-se estudar.
} 
plificação que torna o problema solúvel, na maioria das vezes. Então, a seguir, mostraremos como é possível resolver o problema com esta nova variável e, também como encontrar as propriedades do sistema com o conhecimento da densidade eletrônica do estado fundamental.

Consideremos o Hamiltoniano total do sistema de muitos corpos como:

$$
\hat{H}=\hat{T}_{n}+\hat{T}_{e}+\hat{V}_{n n}+\hat{V}_{e e}+\hat{V}_{n e}
$$

onde $\hat{T}_{i}$ é a energia cinética, $\hat{V}_{i i}$ é o potencial repulsivo, $\hat{V}_{i j}$ é o potencial atrativo, e o subíndice (n) é referente aos núcleos e o subíndice (e) aos elétrons. Considerando a aproximação de Born-Oppeheimer, devido a diferença na escala temporal no movimento dos núcleos comparado com a dos elétrons, e também pelo fato da razão entre as massas dos núcleos e os elétrons ser suficientemente pequena (1:1836), considera-se que os núcleos não acompanham a rápida mudança dos elétrons e, por isto, podem ser considerados fixos. Sendo assim é possível separar a função de onda de muitos corpos total em duas parters:

$$
\Psi(R, r, t)=\Theta(R, t) \Phi(R, r)
$$

uma função de onda eletrônica $(\Phi(R, r))$ e outra nuclear $(\Theta(R, t))$, agora desacopladas. Em unidades atômicas $\left(m_{e}=\hbar=1\right.$, os comprimentos em Bohr, energias em Hartree e uma unidade de carga sendo a carga do próton), podemos escrever o Hamiltoniano eletrônico na forma:

$$
\hat{h}_{e l}=\hat{T}_{e l}+\hat{V}_{e x t}+\hat{V}_{e-e}
$$

onde $\hat{T}_{e l}$ é a energia cinética dos elétrons, 


$$
\hat{T}_{e l}=-\frac{1}{2} \sum_{i=1}^{N} \nabla_{i}^{2}
$$

e o termo $\hat{V}_{\text {ext }}$ é o potencial externo ao sistema eletrônico, que pode incluir, além do potencial devido aos núcleos do sistema, potenciais resultantes de campos elétricos e magnéticos externos, por exemplo:

$$
\hat{V}_{e x t}=\sum_{i=1}^{N} \hat{v}_{i}=\sum_{i=1}^{N}\left(\sum_{I=1}^{P} \frac{-Z_{I}}{\left|\vec{r}_{i}-\vec{R}_{I}\right|}\right)+\hat{V}_{\text {mag }}+\hat{V}_{\text {elet }},
$$

onde $Z_{I}$ é a carga do $I$-ésimo núcleo, $N$ é o número total de elétrons do sistema, $P$ é o número total de núcleos no sistema e as coordenadas em letras minúsculas se referem aos elétrons, enquanto as coordenadas em maiúsculas se referem aos íons. Finalmente, teremos o potencial coulombiano, $\hat{V}_{e-e}$, que é o termo devido a repulsão entre os elétrons $\left(e^{-}-e^{-}\right)$, ou seja:

$$
\hat{V}_{e-e}=\sum_{i=1}^{N-1} \sum_{j=i+1}^{N} \frac{1}{\left|\vec{r}_{i}-\vec{r}_{j}\right|} .
$$

Os teoremas de Hohenberg-Kohn (HK) nos permitem reformular o problema de muitos corpos, de elétrons interagindo em um potencial externo, usando a densidade eletrônica como variável básica. Estes teoremas de HK nos diz que o valor esperado $O$ de um operador $\mathcal{O}$ é um funcional único da densidade eletrônica, $n(\vec{r})$ :

$$
O=O[n(\vec{r})]
$$

Se $n(\vec{r})=n_{0}(\vec{r})$, ou seja, se considerarmos a densidade eletrônica do estado fundamental em nosso sistema, então:

$$
O=O_{0}=O\left[n_{0}(\vec{r})\right]
$$

Em particular, um observável importante é a energia total do sistema. Então, a 
energia do sistema em seu estado fundamental é:

$$
E_{0}=E\left[n_{0}(\vec{r})\right]
$$

e, com o conhecimento de $n_{0}(\vec{r})$, podemos determinar diversas propriedades dos sólidos e moléculas que dependem da energia total.

O valor esperado para a densidade eletrônica pode ser escrito como o valor esperado do operador de densidade $\hat{n}$ :

$$
n(\vec{r}) \equiv\langle\Phi|\hat{\mathrm{n}}| \Phi\rangle
$$

Da mecânica quântica usual, temos o seguinte desenvolvimento:

$$
v(\vec{r}) \rightarrow \hat{h} \rightarrow \Phi\left(\vec{r}_{1}, \vec{r}_{2}, \cdots, \vec{r}_{N}\right) \rightarrow \underbrace{\langle\Phi|| \Phi\rangle}_{\text {observáveis }}
$$

ou seja, o potencial externo caracteriza o Hamiltoniano, pois $\hat{T}_{e l}$ e $\hat{V}_{e-e}$ são universais (possuem a mesma forma funcional para todos os sistemas), e $\hat{h}$ pode ser diagonalizado para obtermos os estados de muitos corpos, $\Phi$. Com esses estados podemos calcular todos os observáveis. Os teoremas de HK nos assegura que a sequência da equação A.11 pode ser invertida [105], da seguinte maneira:

$$
n_{0}(\vec{r}) \rightarrow \Phi\left(\vec{r}_{1}, \vec{r}_{2}, \cdots, \vec{r}_{N}\right) \rightarrow v(\vec{r}) \rightarrow \cdots \rightarrow \underbrace{\langle\Phi|\quad| \Phi\rangle}_{\text {observáveis }},
$$

e que esta inversão é única. Conhecendo a densidade eletrônica do estado fundamental, o Hamiltoniano do sistema é univocamente determinado, e o conhecimento dessa densidade permite que todos os estados e valores dos observáveis possam ser calculados. Desta forma sabe-se, em princípio, tudo sobre o sistema, incluindo estados excitados.

Então vamos enunciar o primeiro teorema de Hohenberg-Kohn: 
Teorema 1:O potencial externo é univocamente determinado pela densidade eletrônica, além de uma constante aditiva.

Começaremos a prova do primeiro teorema de HK [106] e, para isso, mostraremos que dois potenciais externos $\hat{V}_{e x t}$ e $\hat{V}_{e x t}^{\prime}$, distintos, necessariamente têm de diferir por mais de uma constante trivial, se não levarem ao mesmo Hamiltoniano. Estes potenciais nos levam a diferentes estados $\Phi_{0}$ e $\Phi_{0}^{\prime}$. A equação de Schroedinger para cada estados será dada pelas expressões:

$$
\begin{aligned}
& \left(\hat{T}_{e l}+\hat{V}_{e^{--e^{-}}}+\hat{V}_{e x t}\right) \Phi_{0}=\epsilon_{0} \Phi_{0} \\
& \left(\hat{T}_{e l}+\hat{V}_{e^{-}-e^{-}}+\hat{V}_{e x t}^{\prime}\right) \Phi_{0}^{\prime}=\epsilon_{0}^{\prime} \Phi_{0}^{\prime}
\end{aligned}
$$

onde $\epsilon_{0}^{\prime}$ e $\epsilon_{0}$ são energias do estado fundamental de cada sistema. Vamos supor que os estados são iguais, ou seja, $\Phi_{0}=\Phi_{0}^{\prime}$. Subtraindo a equação A.13 da A.14 obtemos:

$$
\left(\hat{V}_{e x t}-\hat{V}_{e x t}^{\prime}\right) \Phi_{0}=\left(\epsilon_{0}-\epsilon_{0}^{\prime}\right) \Phi_{0}
$$

O significado da equação A.15 é que, dados dois potenciais externos $\hat{V}_{\text {ext }}$ e $\hat{V}_{e x t}^{\prime}$, no caso em que $\Phi_{0}=\Phi_{0}^{\prime}$, estes podem diferir no máximo por uma constante, o que viola nossa hipótese inicial. Assim, concluímos inicialmente que, se $\hat{V}_{\text {ext }} \neq \hat{V}_{\text {ext }}^{\prime}$, então $\Phi_{0} \neq \Phi_{0}^{\prime}$.

Agora partiremos para a segunda parte da prova, ou seja, mostraremos que dados dois estados diferentes, estes não levam a uma mesma densidade eletrônica. A prova é feita por contradição . Vamos supor que nosso sistema é não-degenerado e que $n_{0}(\vec{r})=n_{0}^{\prime}(\vec{r})$. Mostraremos que esta consideração nos leva a um absurdo. Consideramos dois Hamiltonianos $\hat{h}$ e $\hat{h}^{\prime}$ e seus respectivos potenciais externos $\hat{V}_{\text {ext }}$ e $\hat{V}_{e x t}^{\prime}$, então, de acordo com o princípio variacional de Rayleigh-Ritz, teremos: 


$$
E_{0}=\langle\Phi|\hat{h}| \Phi\rangle<\left\langle\Phi^{\prime}|\hat{h}| \Phi^{\prime}\right\rangle
$$

Como $\Phi^{\prime}$ não é autofunção de $\hat{h}$, vamos reescrever $\hat{h}$ em função de $\hat{h}^{\prime}$ :

$$
\hat{h}=\hat{h}^{\prime}+\hat{V}_{e x t}-\hat{V}_{e x t}^{\prime}
$$

Substituindo a equação A.17 na A.16 podemos escrever:

$$
E_{0}<E_{0}^{\prime}+\int d \vec{r} n_{0}^{\prime}(\vec{r})\left[\hat{V}_{e x t}-\hat{V}_{e x t}^{\prime}\right]
$$

Analogamente podemos calcular o valor esperado para $\hat{h}^{\prime}$ através do princípio variacional:

$$
E_{0}^{\prime}<E_{0}+\int d \vec{r} n_{0}(\vec{r})\left[\hat{V}_{e x t}^{\prime}-\hat{V}_{e x t}\right]=E_{0}-\int d \vec{r} n_{0}(\vec{r})\left[\hat{V}_{e x t}-\hat{V}_{e x t}^{\prime}\right]
$$

Podemos somar as equações A.18 com a A.19, obtendo:

$$
E_{0}+E_{0}^{\prime}<E_{0}+E_{0}^{\prime}-\int d \vec{r}\left(n_{0}(\vec{r})-n_{0}^{\prime}(\vec{r})\right)\left[\hat{V}_{e x t}-\hat{V}_{e x t}^{\prime}\right]
$$

Usando a suposição inicial que $n_{0}(\vec{r})=n_{0}^{\prime}(\vec{r})$, chegamos ao seguinte absurdo:

$$
E_{0}+E_{0}^{\prime}<E_{0}+E_{0}^{\prime}
$$

A equação A.21 mostra, então, que dois estados fundamentais diferentes, nãodegenerados, necessariamente nos levam a densidades eletrônicas do estado fundamental.

Como o valor de qualquer operador $\mathcal{O}$ pode ser escrito como um funcional único da densidade eletrônica do estado fundamental $n_{0}(\vec{r})$, podemos em particular calcular a energia do estado fundamental. O funcional da energia pode ser escrito 
como:

$$
E[n] \equiv\left\langle\Phi_{0}[n]\left|\hat{T}_{e l}+\hat{V}_{e-e}+\hat{V}_{e x t}\right| \Phi_{0}[n]\right\rangle
$$

Vamos apresentar o segundo teorema de HK:

Teorema 2: A energia do estado fundamental, $E_{0}[n]$, é mínima para a densidade $n(r)$ exata.

A prova do segundo teorema se inicia considerando uma densidade $n(r)$, sendo uma densidade proveniente do estado $\Phi$, e que, por sua vez, não é necessariamente resultante do Hamiltoniano eletrônico $\hat{h}=\hat{T}+\hat{V}_{e e}+\hat{V}_{\text {ext }}$, que neste caso seria $n_{0}(r)$. Sendo assim, quando as densidades são diferentes $n(r) \neq n_{0}(r)$ implica que as funções de onda são distintas $\left(\Phi \neq \Phi_{0}\right)$, resultando em $E>E_{0}$. Por outro lado, se as densidade são iguais $\left(n(r)=n_{0}(r)\right)$, as funções de onda também serão $\left(\Phi=\Phi_{0}\right)$, resultando na igualdade das energias $\left(E=E_{0}\right)$. Escrevendo o funcional da energia da equação A.22, e separando em dois termos, teremos:

$$
E[n]=F[n]+\left\langle\Phi\left|\hat{V}_{e x t}\right| \Phi\right\rangle
$$

onde $F[n]=\left\langle\Phi\left|\hat{T}+\hat{V}_{e e}\right| \Phi\right\rangle$ é um funcional universal, válido para qualquer sistema coulombiano, e o termo $\left\langle\Phi\left|\hat{V}_{\text {ext }}\right| \Phi\right\rangle$ depende do sistema em questão. De forma análoga podemos escrever este mesmo funcional para a densidade $n_{0}$ :

$$
E\left[n_{0}\right]=F\left[n_{0}\right]+\left\langle\Phi_{0}\left|\hat{V}_{e x t}\right| \Phi_{0}\right\rangle,
$$

sendo $\Phi_{0}$ a função de onda do estado fundamental, e $n_{0}$ determina $\Phi_{0}$ tal como $n$ determina $\Phi$. Além disso, considera-se que tanto $n_{0}$ quanto todos os $n$ são determinados por algum potencial externo. Aplicando o teorema variacional $E\left[\Phi_{0}\right]<E[\Phi]$ : 


$$
\begin{aligned}
\left\langle\Phi_{0}\left|\hat{T}+\hat{V}_{e e}\right| \Phi_{0}\right\rangle+\left\langle\Phi_{0}\left|\hat{V}_{e x t}\right| \Phi_{0}\right\rangle & <\left\langle\Phi\left|\hat{T}+\hat{V}_{e e}\right| \Phi\right\rangle+\left\langle\Phi\left|\hat{V}_{e x t}\right| \Phi\right\rangle \\
F\left[n_{0}\right]+\left\langle\Phi_{0}\left|\hat{V}_{e x t}\right| \Phi_{0}\right\rangle & <F[n]+\left\langle\Phi\left|\hat{V}_{e x t}\right| \Phi\right\rangle
\end{aligned}
$$

obtém-se:

$$
E\left[n_{0}\right]<E[n]
$$

A energia do estado fundamental pode ser encontrada, então, variando-se a densidade eletrônica para minimizar a energia total na equação A.26.

Estes são os dois teoremas de HK, então, fazendo um sumário sobre a teoria apresentada até o presente momento, destacam-se os seguintes aspectos:

1. A densidade eletrônica $n_{0}$ determina univocamente $\Phi_{0}$;

2. $E[n]$ é minimizado por $n_{0}$;

3. $F_{H K}[n]$ é igual para todo sistema não relativístico e Coulombiano;

4. A densidade eletrônica $n_{0}$ determina univocamente o potencial externo.

Generalizações destes teoremas podem ser feitas tais como: considerações de sistemas degenerados, sistemas de spin, etc. Os teoremas de HK nos dizem que os observáveis do sistema, dentre os quais um dos mais importantes é a energia total, são funcionais únicos da densidade eletrônica do estado fundamental do sistema. No entanto, os teoremas não nos fornecem uma maneira prática de efetuar os cálculos de energia total. É preciso, portanto, encontrar uma forma prática que nos permita efetuar estes cálculos. Esta implementação será feita através das equações de KohnSham, de que trataremos na próxima subseção. 


\section{A.1.2 As equações de Kohn-Sham}

Estamos resolvendo o problema de muitos corpos interagentes e os teoremas de HK, como já foi dito, não nos fornecem uma maneira prática para tal questão. Então, usaremos o formalismo de Kohn-Sham (KS), que tem como idéia básica a utilização de um sistema de "referência" não-interagente ou auxiliar, mapeando o problema de muitos corpos em $N$ problemas de um corpo sujeito a um potencial efetivo. Neste sistema não-interagente, procuraremos um potencial efetivo $\left(\hat{V}_{s}\right)$ que produza a mesma densidade do estado fundamental do problema de um sistema de partículas interagentes. Para um sistema de $N$ elétrons não-interagentes, o estado fundamental é dado por um determinante de Slater composto por orbitais $\left(\phi_{i}\right)$ de partículas individuais. Como o potencial efetivo depende da densidade eletrônica, nos cálculos começamos com uma densidade inicial tentativa. Deste modo obtemos uma nova densidade eletrônica, que por sua vez nos fornece um novo $\hat{V}_{s}$. Esta equação é resolvida novamente, e o processo é repetido até alcançarmos a auto consistência, isto é, até que o valor da densidade antes e depois de uma interação coincidam dentro de uma precisão pré-estabelecida. Veremos agora como tudo isto se dá matematicamente.

Considerando um sistema de $N$ elétrons não interagentes em um potencial efetivo $\hat{V}_{s}$, podemos escrever o Hamiltoniano $\hat{\mathcal{H}}_{s}$ deste sistema como:

$$
\hat{\mathcal{H}}_{s}=\hat{T}_{s}+\hat{V}_{s}
$$

Aplicando os teoremas de HK, o funcional da energia é dado por:

$$
E_{s}[n]=T_{s}[n]+\int d \vec{r} v_{s}(\vec{r}) n_{s}(\vec{r})
$$

Podemos notar que, como agora nosso sistema é não interagente, então a quantidade $T_{s}[n]$ é diferente de $T[n]$ da equação A.22. A densidade eletrônica do sistema 
não-interagente pode ser escrita em termos dos orbitais $\phi_{i}$, da seguinte forma:

$$
n_{s}(\vec{r})=\sum_{i=1}^{N}\left|\phi_{i}(\vec{r})\right|^{2},
$$

sendo que cada orbital $\phi_{i}$ satisfaz a seguinte equação de Schroedinger:

$$
\left[\frac{-\hbar^{2}}{2 m} \nabla^{2}+\hat{V}_{s}\right] \phi_{i}(\vec{r})=\epsilon_{i} \phi_{i}(\vec{r}), \quad \epsilon_{1} \leq \epsilon_{2} \leq \ldots \leq \epsilon_{N}
$$

Aqui os orbitais $\phi_{i}$ são completamente diferentes dos $\Phi$. Os $\phi_{i}$ são auto-funções de elétrons não-interagentes individuais. Entretanto, o sistema de interesse é o sistema de partículas interagentes sujeitas a um potencial $\hat{V}_{\text {ext }}$. Uma pergunta pertinente pode ser feita neste momento: podemos determinar rigorosamente um $\hat{V}_{s}$, potencial efetivo de um sistema não-interagente, que nos leva a uma mesma densidade eletrônica do estado fundamental de um sistema de partículas interagentes sujeitas a um potencial externo $\hat{V}_{\text {ext }}$ ? Em princípio, sim. Para fazer este mapeamento no sistema não interagente vamos reescrever a equação A.22 da seguinte forma:

$$
E=T_{e l}+V_{e-e}+V_{e x t}+T_{s}-T_{s}+U_{H}-U_{H}
$$

onde as quantidades $T_{s}$ e $U_{H}$ são a energia cinética de elétrons não interagentes e a energia de Hartree (Coulombiana Clássica), respectivamente. Podemos escrever $U_{H}$ como:

$$
U_{H}=\frac{e^{2}}{2} \iint d \vec{r} d \vec{r}^{\prime} \frac{n(\vec{r}) n\left(\vec{r}^{\prime}\right)}{\left|\vec{r}-\vec{r}^{\prime}\right|} .
$$

Rearranjando a equação A.31, teremos:

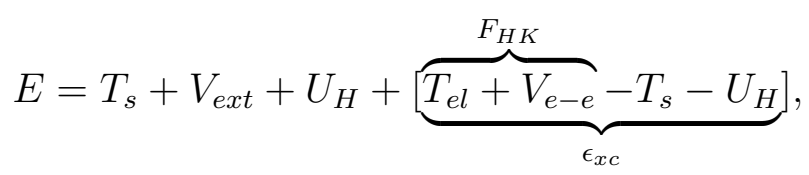

onde a definição de energia de correlação e troca aparece naturalmente na equação 
A.33, ou seja, o funcional $F_{H K}$, universal, menos a energia cinética de um gás de elétrons livres e o termo de Hartree. Então finalmente podemos escrever:

$$
E_{x c}[n] \equiv F_{H K}[n]-T_{s}[n]-U_{H}[n]
$$

O nosso desconhecimento sobre o sistema encontra-se neste termo, no sentido de que não sabemos escrevê-lo de maneira exata. Desta forma, todas as aproximações são feitas para este termo. De acordo com os teoremas de HK, a densidade eletrônica (n) que minimiza o funcional $E[n]$ é a densidade do estado fundamental $n_{0}$. A condição de mínimo para o funcional de energia $(\delta E[n(\vec{r})]=0)$ deve ser restrita, ou seja, sujeita ao vínculo de que o número de elétrons do sistema seja dado corretamente. O vínculo no número de elétrons pode ser expresso da seguinte maneira:

$$
\int d \vec{r} n(\vec{r})-N=0
$$

e este vínculo será incluído na equação para a energia total através de um multiplicador de Lagrange, $\mu$. O funcional que devemos minimizar será:

$$
E[n(\vec{r})]-\mu\left[\int d \vec{r} n(\vec{r})-N\right],
$$

e neste caso o multiplicador é o potencial químico $(\mu)$ do nosso sistema. Vamos procurar o mínimo da equação A.36, que consiste em fazer as derivadas funcionais e por fim igualar estas quantidades a zero da seguinte maneira:

$$
\delta\left\{E[n]-\mu\left[\int d \vec{r} n(\vec{r})-N\right]\right\}=0
$$

o que nos leva á seguinte expressão :

$$
\delta\left\{E[n]-\mu\left[\int d \vec{r} n(\vec{r})\right]\right\}=0
$$


Fazendo a derivada funcional em termos da densidade eletrônica para minimizar a energia, podemos escrever:

$$
\frac{\delta E[n]}{\delta n(\vec{r})}-\mu=\frac{\delta T_{s}}{\delta n(\vec{r})}+e^{2} \int d \vec{r}^{\prime} \frac{n\left(\vec{r}^{\prime}\right)}{\left|\vec{r}-\vec{r}^{\prime}\right|} v_{e x t}+v_{x c}[n(\vec{r})]=0
$$

Logo,

$$
\mu=\frac{\delta E[n]}{\delta n(\vec{r})}=\frac{\delta T_{s}}{\delta n(\vec{r})}+V_{s}[n(\vec{r})]
$$

onde $v_{x c}[n(\vec{r})]$ é definido como o potencial de correlação e troca:

$$
v_{x c}[n(\vec{r})] \equiv \frac{\delta E_{x c}[n]}{\delta n(\vec{r})}
$$

Pode-se, enfim, escrever a expressão para o potencial efetivo:

$$
V_{s}(\vec{r})=V_{e x t}(\vec{r})+e^{2} \int d \vec{r}^{\prime} \frac{n\left(\vec{r}^{\prime}\right)}{\left|\vec{r}-\vec{r}^{\prime}\right|}+v_{x c}(\vec{r})
$$

As equações A.30 e A.42 são conhecidas como equações de Kohn-Sham (KS). Agora podemos implementar a auto-consistência para as equações de KS da seguinte maneira:

1. Vamos escolher uma densidade inicial tentativa e substituir na equação A.42;

2. Resolveremos a equação de Schroedinger para $N$ partículas independentes, para obtermos os $\phi_{i}$ e a partir deles proceder o cálculo da densidade A.29. Assim, encontraremos a próxima densidade, $n(\vec{r})$;

3. O processo de autoconsistência deve ser repetido um número suficiente de vezes, até que um critério pré-establecido seja atingido.

Até o presente momento foi apresentada a teoria do funcional da densidade através dos teoremas de HK e as equações de KS. Não foi feita nenhuma aproximação 
além da Born-Oppenheimer para esta teoria, e na próxima seção serão discutidas duas aproximações para a energia de correlação e troca. Antes de começar a próxima seção, faremos algumas observações e comentários sobre esta teoria.

A DFT é, em princípio, um formalismo exato, no entanto, não possuimos um funcional de correlação e troca exato e, por isso, necessitamos de aproximações para este termo.

Os autovalores de KS não são objetos puramente matemáticos e, por isso, não tem significado físico. Entretanto, existe uma exceção para o último autovalor ocupado, que de acordo com o teorema de Janak é menos a energia de ionização $(-I)$. O teorema de Janak² é válido na DFT.

Os autovalores de KS podem ser definidos, matematicamente, como a derivada da energia total em relação a ocupação $\left(\frac{\partial E}{\partial n_{i}}=\epsilon_{i}\right)$.

Vamos apresentar na próxima seção duas aproximações para o potencial de correlação e troca.

\section{A.2 Os funcionais de correlação e troca}

Resumindo o que foi feito até agora, mostramos que a energia total pode ser escrita como um funcional único da densidade eletrônica do estado fundamental e também como proceder com os cálculos para este funcional. Minimizamos a energia total e escrevemos um potencial efetivo ao qual os elétrons estão sujeitos. Tudo isso foi feito através de um sistema de referência, isto é, mapeamos um sistema de $N$ elétrons interagentes em um sistema de elétrons não-interagentes. Porém esse funcional da energia que mencionamos possui um fator, ou um funcional, que desconhecemos - o

\footnotetext{
${ }^{2}$ Se o potencial de referência se anula para grandes distâncias (como para moléculas), o potencial de ionização é dado pelo último autoestado de energia de KS ocupado.
}

$$
I=-\mu=\epsilon_{n} .
$$


funcional de energia de correlação e troca. Esta ignorância sobre o sistema precisa ser, de alguma forma, aproximada.

Nas próximas seções serão discutidas dois tipos de aproximações feitas para a energia de correlação e troca dentre várias existentes na literatura. Usaremos a LDA (Local Density Approximation - Aproximação da Densidade Local) e a GGA (Generalized Gradient Approximation - Aproximação do Gradiente Generalizado).

\section{A.2.1 Aproximação da Densidade Local - LDA}

A LDA é uma das aproximações mais simples que pode ser usada para a energia de correlação e troca. Nesta aproximação, a densidade de energia de correlação e troca por elétron num ponto $\vec{r}, \varepsilon_{x c}(\vec{r})$, é considerada igual à densidade de energia de correlação e troca por elétron de um gás de elétrons homogêneo, isto é, para cada ponto $\vec{r}$ é considerado que o sistema pussui a densidade daquele ponto. É como se pudéssemos dividir o sistema em vários pedaços e, cada um deste tivesse a densidade de um gás de elétrons livres, com a densidade do ponto onde foi considerado. Isso nos leva a aspectos locais da densidade eletrônica, então, o funcional de correlação e troca pode ser escrito como:

$$
E_{x c}[n(\vec{r})]=\int d \vec{r} \varepsilon_{x c}(\vec{r}) n(\vec{r})
$$

com a densidade de energia de correlação e troca dada por:

$$
\varepsilon_{x c}(\vec{r})=\varepsilon_{x c}^{h o m}(\vec{r})[n(\vec{r})]
$$

Na prática, o termo de troca $\left(\varepsilon_{x}\right)$, para um gás de elétron homogêneo, pode ser obtido analiticamente. Então, podemos separar uma contribuição para o termo de troca e outro para a correlação. A forma analítica para o termo de troca é o seguinte: 


$$
E_{x}^{L D A}[n]=-\frac{3}{4}\left(\frac{3}{\pi}\right)^{\frac{1}{3}} n^{\frac{1}{3}} .
$$

Já o termo de correlação é obtido de forma precisa através de cálculos baseados no método de Monte Carlo quântico. Melhores resultados são obtidos por Ceperley e Alder [107]. Desta maneira a energia de correlação e troca é escrita da seguinte forma:

$$
E_{x c}[n(\vec{r})]=\int d \vec{r}\left(\varepsilon_{x}(\vec{r})+\varepsilon_{c}(\vec{r})\right) n(\vec{r})
$$

Apesar de sua simplicidade, a LDA fornece bons resultados para diversos tipos de sistemas. Pelo fato de ser baseada num gás de elétron livres (homogêneo), é esperado que a LDA funcione melhor em sistemas onde a densidade varie lentamente do que para átomos e moléculas, onde há grandes variações de densidade. Na maioria dos sistemas onde a densidade eletrônica não varia suavemente, precisamos de uma certa cautela ao fazer uso desta aproximação. Entretanto, a LDA é capaz de descrever, de maneira satisfatória, as propriedades do estado fundamental de diversos sistemas sólidos, especialmente sistemas metálicos, onde geralmente o sistema é mais homogêneo.

\section{A.2.2 Aproximação do Gradiente Generalizada - GGA}

Existem dois tipos de aproximações do gradiente generalizado: as semiempíricas, que são ajustadas a um conjunto de dados experimentais para algum material ou molécula de interesse; e as não empíricas, que satisfazem a um conjunto de vínculos teóricos. A aproximação GGA que iremos ilustrar será um funcional conhecido como PBE - Perdew, Burke e Ernzerhof [108], pertencente à segunda classe. Existem outras aproximações GGA, como por exemplo a PW91, que satisfazem outros vínculos teóricos. 
Os vínculos teóricos que o funcional PBE satisfaz são:

1. Reprodução dos limites assintóticos corretos para o caso limite onde a densidade eletrônica varia lentamente ou rapidamente;

2. A reprodução dos comportamentos de escala corretos para o spin e para a densidade uniforme de $E_{x}$;

3. Obedecer o limite inferior de Lieb-Oxford ${ }^{3}$.

No PBE a contribuição da parte da troca é dada por:

$$
F_{x}^{P B E}=1+\kappa-\frac{\kappa}{1+\frac{\mu}{\kappa} s^{2}}
$$

com $\kappa=0.804, \mu=0.21951$ e $s=|\nabla n| /\left(2 k_{F} n\right)$, onde $\mathrm{k}_{F}$ é o vetor de onda de Fermi.

Ao contrário da LDA, a GGA leva em conta aspectos não locais da densidade eletrônica no cálculo da energia de correlação e troca por elétron. Agora esta energia vai depender da densidade eletrônica no ponto $\vec{r}$, bem como do gradiente da densidade eletrônica naquele ponto. Podemos escrever:

$$
E_{x c}[n(\vec{r}),|\nabla n(\vec{r})|]=\int d \vec{r} \varepsilon_{x c}(n, \nabla n) n(\vec{r})
$$

Existem outros tipos de funcionais GGA que não serão discutidos aqui, pois todos os cálculos serão feitos com PBE e o PW91.

\section{A.3 Pseudopotenciais}

Antes de falar dos pseudopotenciais, podemos analisar a configuração de um átomo de carbono, como ilustrado na figura A.1. No centro tem-se o núcleo atômico,

\footnotetext{
${ }^{3}$ Este estabelece um valor mínimo para a energia de correlação eletrônica. Em 1981 eles provaram a forma deste limite que é da forma: $E_{x}[n] \geq E_{x c}[n] \geq C \int d^{3} \vec{r} n^{\frac{4}{3}}, \operatorname{com} 1,43 \leq C \leq 1,68$.
} 


\section{Carbono}

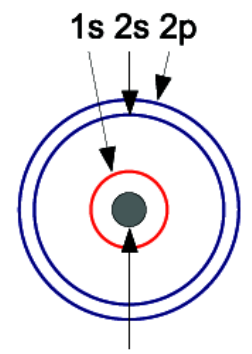

Núcleo
Pseudo-Carbono

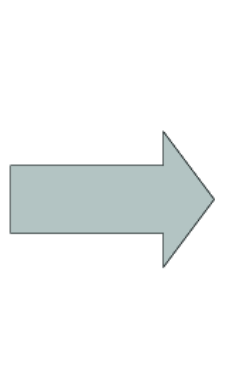

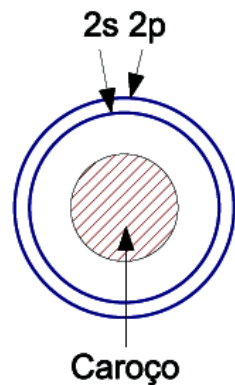

Caroço

Figura A.1: Figura ilustrativa de um átomo de carbono hipotético.

circundado por uma nuvem de elétrons de caroço que são fortemente ligados ao núcleo, e mais externamente, têm-se os elétrons de valência, todos representados pelas círculos em vermelho e azul, respectivamente. Como os elétrons de valência estão menos fortemente ligados ao núcleo, as propriedades dos sólidos dependem mais deles que dos elétrons de caroço. Desta forma, serão utilizadas pseudofunções de onda correspondentes apenas aos elétrons de valência, pois é sabido que, geralmente, elétrons de caroço não participam das ligações químicas e essencialmente não se alteram em diferentes ambientes químicos.

O método dos pseudopotenciais vem sendo utilizado desde a década de 40. Originalmente os pseudopotenciais foram introduzidos para simplificar o cálculo de estrutura eletrônica, substituindo os elétrons de caroço e o forte potencial iônico por um pseudopotencial atuando em pseudo-funções de onda de valência. Entretanto, os orbitais de Kohn-Sham, $\phi_{i}^{K S}$, devem ser expandidos em uma base de funções. Historicamente, as primeiras bases utilizadas foram as bases de ondas planas, pois estas já são bases naturais para o teorema de Bloch. Além disto, podemos expandir qualquer função como uma combinação linear de ondas planas. Como é sabido, as funções de onda dos elétrons de valência devem oscilar fortemente na região de caroço, para manter a ortogonalidade com as funções de onda dos elétrons desta 


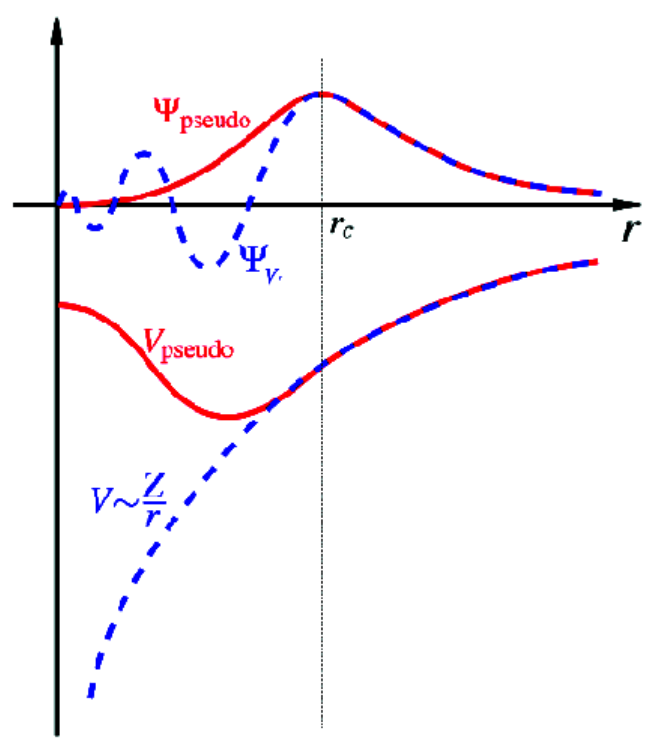

Figura A.2: Esquema do método dos pseudopotenciais e pseudofunções de onda. Temos uma função de onda que oscila na região de caroço e um potencial divergente em $r=0$. Esta função de onda é substituida por uma suave na região de caroço e, com isso, o potencial torna-se suave nesta região.

região. Sendo assim, torna-se impraticável representar estas funções de onda com ondas planas, pois muitas destas são necessárias para uma representação adequada das funções de onda na região de caroço. O uso de ondas planas tornou-se possível, na prática, com a teoria dos pseudopotenciais.

Tudo isso justifica a remoção dos elétrons de caroço e a substituição do forte potencial coulombiano por um potencial mais suave, o pseudopotencial, e a substituição das funções de onda de valência, que oscilam muito na região de caroço, por uma pseudofunção de onda de valência sem nós, suave na região de caroço e idêntica à função de onda de todos os elétrons na região de valência. A Fig. A.2 ilustra bem o que acabamos de descrever.

Com esta substituição, o número de ondas planas necessárias para a representação da pseudofunção de onda é menor que o necessário para representar a função de onda de valência resultante de um cálculo de todos os elétrons e, como 
consequência direta, há uma diminuição no tamanho da matriz hamiltonia, isto é, um menor esforço computacional é requerido.

Na literatura pode-se destacar duas linhas distintas no que diz respeito aos pseudopotenciais. A primeira corresponde aos pseudopotenciais empíricos, que envolvem um conjunto de parâmetros ajustáveis de forma a reproduzir algum conjunto de dados experimentais para um material específico. A segunda consiste nos pseudopotenciais ab initio obtidos através da resolução da equação de Schrödinger, relativística ou não, para o caso atômico. Nesta tese falaremos somente sobre a segunda classe, que será utilizada neste trabalho.

A teoria de pseudopotenciais foi desenvolvida por Phillips e Kleinman (PK) [100], e será descrita na próxima subseção. Logo após, falaremos dos pseudopotenciais com conservação da norma de Kerker [101] e dos pseudopotenciais de Troullier e Martins (TM) [102], que são uma generalização do psudopotencial de PK. Finalmente, na última subseção discutiremos outro tipo de pseudopotencial que, por sua vez, não conserva a norma. O pseudopotencial que será apresentado nesta subseção é conhecido como pseudopotencial ultrasuave (US) de Vanderbilt [87].

\section{A.3.1 Pseudo-potenciais de Phillips e Kleinman}

O método de pseudopotenciais de Phillips e Kleinman segue uma abordagem de ondas planas ortogonalizadas (OPW) [99], que consiste em uma expansão das funções de onda de valência em ondas planas, mais uma combinação linear de estados de caroço. Consideremos um átomo com um hamiltoniano, $\hat{\mathrm{H}}$, e um estado de valência, $|\Psi\rangle$, com autovalores de energia, $E$, isto é:

$$
\hat{H}|\Psi\rangle=E|\Psi\rangle
$$

Existem também estados de caroço, $\left|\chi_{n}\right\rangle$, e autovalores dos estados de caroço $E_{n}$. Phillips e Kleinman expressaram a função de onda de valência como uma combinação 
linear de uma função suave, $|\phi\rangle$, sem nós, e das funções de caroço, $\left|\chi_{n}\right\rangle$, ou seja:

$$
|\Psi\rangle=|\phi\rangle+\sum_{n} a_{n}\left|\chi_{n}\right\rangle
$$

Como os estados de caroço são ortogonais aos estados de valência, têm-se

$$
\left\langle\chi_{n} \mid \Psi\right\rangle=0=\left\langle\chi_{n} \mid \phi\right\rangle+a_{n}
$$

ou seja,

$$
a_{n}=-\left\langle\chi_{n} \mid \phi\right\rangle
$$

Podemos substituir (A.53) em (A.51), obtendo:

$$
|\Psi\rangle=|\phi\rangle-\sum_{n}\left|\chi_{n}\right\rangle\left\langle\chi_{n} \mid \phi\right\rangle
$$

Da mesma forma, podemos substituir (A.54) em (A.50):

$$
\hat{H}\left(|\phi\rangle-\sum_{n}\left|\chi_{n}\right\rangle\left\langle\chi_{n} \mid \phi\right\rangle\right)=E\left(|\phi\rangle-\sum_{n}\left|\chi_{n}\right\rangle\left\langle\chi_{n} \mid \phi\right\rangle\right) .
$$

Reescrevendo a equação (A.55), teremos:

$$
\hat{H}|\phi\rangle+\sum_{n}\left(E-E_{n}\right)\left|\chi_{n}\right\rangle\left\langle\chi_{n} \mid \phi\right\rangle=E|\phi\rangle,
$$

Desta maneira, vemos que $|\phi\rangle$ obedece a equação de Schrödinger de $|\Psi\rangle$, com um potencial extra, $\hat{V}_{n l}$ :

$$
\left[\hat{H}+\hat{V}_{n l}\right]|\phi\rangle=E|\phi\rangle
$$

onde, 


$$
V_{n l}=\sum_{n}\left(E-E_{n}\right)\left|\chi_{n}\right\rangle\left\langle\chi_{n} \mid \phi\right\rangle
$$

A função de onda mais suave, $|\phi\rangle$, é chamada pseudofunção de onda. A energia do pseudoestado suave é a mesma do estado de valência original, porém agora temos um potencial extra, $V_{n l}$, na equação de Schrödinger, que está localizado na região de caroço. Este potencial, de caráter repulsivo, cancelará parcialmente o forte potencial coulombiano atrativo, de maneira que o pseudopotencial fique suave na região de caroço, sem divergências nesta região. Os pseudopotenciais propostos por Phillips e Kleinman foram um dos primeiros trabalhos que apareceram na literatura, um marco na teoria dos pseudopotenciais. Muitas outras abordagens surgiram a partir deste trabalho através do refinamento como, por exemplo, os pseudopotenciais com conservação de norma. Tal refinamento consiste em impor:

$$
\int_{0}^{r_{c}} d r r^{2} R_{A E}^{*}(r) R_{A E}(r)=\int_{0}^{r_{c}} d r r^{2} R_{P S}^{*}(r) R_{P S}(r)
$$

o que automaticamente garante a conservação da carga de valência.

Nas próximas seções discutiremos dois tipos de pseudopotenciais que obedecem à condição de conservação de norma: os pseudopotenciais de Kerker e os pseudopotenciais de Troullier e Martins e posteriormente discutiremos os pseudopotenciais ultrasuaves.

\section{A.3.2 Pseudopotenciais de Kerker}

Nesta seção, apresentamos um dos tipos de pseudopotenciais que obedecem a condição de conservação de norma. Com este método, obtêm-se pseudopotenciais nãosingulares em $r=0$ a partir de cálculos atômicos autoconsistentes. Vamos definir um raio de corte, $r_{c}$, onde delimitamos a região de valência e de caroço. Na região de valência, $r>r_{c}$ sem nós, impõe-se que as partes radiais da pseudofunção de onda 
e a de todos os elétrons sejam idênticas. Para a região de caroço, $r<r_{c}$, onde as funções de onda dos elétrons de valência oscilam, substitui-se a parte oscilante por uma função analítica, suave, sem oscilações, e a fim de reproduzir as propriedades de espalhamento e eletrostáticas do caroço iônico real com um mínimo de erro, a pseudocarga na região de caroço é forçada a ter o mesmo valor da carga real nesta região. Para fazer isto, foi proposta uma substituição da forma da função de onda atômica de valência dentro da região de caroço por uma forma analítica conveniente:

$$
F(r)=r R(r)=r^{l+1} f(r)
$$

onde $R(r)$ é a pseudofunção de onda e $\ell$ corresponde a cada momento angular. A função $f(r)$ é escolhida de modo a obter uma forma não singular para o potencial, que por sua vez pode ser um polinômio, $p(r)$ :

$$
f(r)=\alpha r^{4}+\beta r^{3}+\gamma r^{2}+\delta=p(r),
$$

ou ainda uma função exponencial,

$$
f(r)=\exp [p(r)]
$$

Nota-se na equação (A.61) a falta do termo em $r$, para evitar uma singularidade em $r=0$ para o pseudopotencial. Para determinar os coeficientes em $p(r)$, algumas condições têm que ser satisfeitas:

1. Os cálculos para o átomo real e para o pseudoátomo devem fornecer os mesmos autovalores para uma determinada configuração eletrônica;

2. A pseudofunção de onda $R(r)$ é construída de modo a não ter nós para $r<r_{c}$, e ser idêntica à função de onda de valência para $r>r_{c}$;

3. As derivadas primeiras e segundas da função de onda, $R$, são igualadas em $r_{c}$; 
4. A pseudocarga contida numa esfera de raio $r_{c}$ é idêntica à carga "real" nesta esfera.

As condições (1) e (2) são básicas, usadas para tentar obter um pseudopotencial confiável, e a (3) assegura que a pseudofunção de onda de valência com a função de onda atômica, em $r=r_{c}$, seja contínua e diferenciável. Considerando um átomo esfericamente simétrico, é obtido o pseudopotencial blindado, $V_{p s}^{s}$, invertendo-se analiticamente a parte radial da equação de Schrödinger para $r \leq r_{c}$.

$$
\left[-\frac{d^{2}}{d r^{2}}+\frac{l(l+1)}{r^{2}}+V_{p s}^{s}(r)-E\right] R(r)=0
$$

ou seja, sabendo a forma de $R(r)$, basta isolarmos em (A.63):

$$
V_{p s}^{s}(r)=E-\frac{l(l+1)}{r^{2}}+\frac{R^{\prime \prime}(r)}{R(r)}
$$

A condição (4) garante a normalização da pseudofunção de onda. A carga total para a esfera de raio $r_{c}$, está relacionada com a primeira derivada da energia da derivada logarítmica de $R$ na esfera considerada, ou seja:

$$
-\left.R^{2} \frac{d}{d E} \frac{d}{d r} \ln R\right|_{r=r_{c}}=\int_{0}^{r_{c}} R^{2} d r
$$

Com isto a primeira derivada da energia da primeira derivada do logaritmo da pseudofunção radial fica idêntica ao resultado exato. Como consequência, as propriedades de espalhamento do caroço iônico real são transferidas para o pseudocaroço com um mínimo de erros. Para obter o pseudopotencial do caroço iônico sem blindagem, faz-se a subtração do potencial blindado de $V_{p s}^{s}$. Considera-se a mesma configuração eletrônica para o pseudo-átomo real. Uma vez escolhido o pseudopotencial que iremos utilizar, precisamos ajustar os raios de corte $r_{c}$ para cada orbital de valência em questão. Apesar da escolha ser arbitrária, existem algumas diretrizes para a escolha dos $r_{c}$ : 
1. Os $r_{c}$ devem ser tais que o máximo intervalo de concordância da pseudofunção de onda de valência com a de todos os elétrons seja obtido;

2. Os $r_{c}$ não podem ser arbitrariamente pequenos, pois o potencial torna-se "fundo" e deixa os cálculos mais custosos;

3. Os $r_{c}$ devem ser escolhidos de modo a termos uma melhor concordância possível entre os pseudoautovalores e também entre as derivadas logarítmicas, com os cálculos de todos elétrons;

O que geralmente é feito consiste em escolher os $r_{c}$ próximos ao pico mais externo da função de onda de valência. A escolha vai influenciar na trasferibilidade do sistema; um $r_{c}$ situado mais à direita do último pico, por exemplo, diminui a transferibilidade pois, a região de concordância com a função de onda de valência é menor, resultando em cálculos mais leves; entretanto, um $r_{c}$ situado mais à esquerda melhora a transferibilidade, pois a região de concordância aumenta, mas o custo computacional dos cálculos é bem maior. O ideal é, analisando o tipo de problema com o qual estamos lidando, chegarmos a uma boa relação de custo-benefício.

Os pseudopotenciais de Kerker são usados até hoje em alguns trabalhos. No entanto, não são os pseudopotenciais de conservação de norma mais suaves possíveis. Na subseção seguinte, falaremos de um pseudopotencial mais suave que o de Kerker, amplamente utilizado na literatura, o pseudopotencial de Troullier e Martins.

\section{A.3.3 Pseudopotenciais de Troullier e Martins}

Nesta seção vamos apresentar um outro tipo de pseudopotencial de norma conservada conhecido por Troullier e Martins (TM). Este método é considerado um refinamento do método de pseudopotencial de Kerker, apresentado previamente. TM modificaram o polinômio $(p(r))$ aumentando a ordem do mesmo; e com este acréscimo no grau do polinômio, consegue-se um maior grau de liberdade no que 
diz respeito á forma para os pseudopotenciais. A transferibilidade é feita da mesma maneira do método de Kerker. Eles mostram [102] que o comportamento assintótico dos pseudopotenciais é dependente do valor das derivadas ímpares dos pseudopotenciais na origem. Com isso, o comportamento das pseudofunções de onda pode ser melhorado se considerarmos todos os coeficientes ímpares do polinômio como sendo zero, isto é, o mesmo que considerar as derivadas ímpares dos pseudopotenciais como sendo zero na origem. Um possível polinômio a ser utilizado seria:

$$
p(r)=c_{0}+c_{2} r^{2}+c_{4} r^{4}+c_{6} r^{6}+c_{8} r^{8}+c_{10} r^{10}+c_{12} r^{12}
$$

Assim, para determinar os sete coeficientes, têm-se as seguintes condições: a primeira delas refere-se à conservação de norma; a segunda até a sexta refere-se à continuidade da pseudofunção de onda e das primeiras quatros derivadas em $r_{c}$ e a última refere-se à curvatura do pseudopotencial blindado na origem que considera-se igual a zero. Assim ele nos fornece uma boa forma para o pseudopotencial.

Estes pseudopotenciais nos fornecem bons resultados e são utilizados na literatura por diversos grupos de pesquisa. Na última subseção deste apêndice apresentaremos os pseudopotenciais ultrasuaves de Vanderbilt que, por sua vez, não apresentam a condição de conservação de norma.

\section{A.3.4 Pseudopotencial ultrasuave de Vanderbilt}

Os pseudopotenciais com o vínculo de conservação de norma podem ser duros, no sentido de serem não tão suaves, devido a este vínculo. Em alguns casos, pode ocorrer que não existam estados de caroço com o mesmo momento angular nos quais eles teriam que ser ortogonais. Podemos citar os elementos da primeira linha da tabela periódica com estados $p$, como por exemplo o oxigênio $2 p$. Neste caso, a função de onda de todos os elétrons é um pouco comprida, coparada com os outros estados de valência. Este fato acarreta um grande número de ondas planas para represen- 
tar corretamente essa função. Nos casos das duas subseções anteriores, o conceito de transferibilidade estava diretamente ligado com a condição de conservação da norma (equação A.65). No entanto, este fato não é estritamente necessário para que a norma da função de onda se coincidam (função de onda de todos os elétrons com a psedo), para que tenhamos uma boa transferibilidade do pseudopotencial. Um pseudopotencial sem um vínculo de conservação de norma e com uma transferibilidade muito boa foi proposto em 1990 por D. Vaderbilt [87], os pseudopotenciais ultrasuaves (US).

A construção dos pseudopotenciais de Vanderbilt inicia-se redefinindo o potencial não local de maneira generalizada como:

$$
\begin{aligned}
\Delta \hat{V}_{U S}^{\ell} & =\sum_{i, j} D_{i, j}^{\ell} \sum_{m=-\ell}^{\ell}\left|\beta_{i}^{\ell m}><\beta_{j}^{\ell m}\right| \\
\mid \beta_{i}^{\ell m}> & =\sum_{j}\left(B^{-1}\right)_{i j}^{\ell} \mid \zeta_{j}^{\ell m}>,
\end{aligned}
$$

$\operatorname{com} B_{i j}^{\ell}=\left\langle\phi_{P S}^{i \ell m} \mid \zeta_{j}^{\ell m}\right\rangle$ e, o $D_{i, j}^{\ell}$ é definido como:

$$
D_{i, j}^{\ell}=B_{i j}^{\ell}+\varepsilon_{i \ell} Q_{i j}^{\ell}
$$

então podemos reescrever o potencial $\left(\Delta \hat{V}_{U S}\right)$ da seguinte maneira:

$$
\Delta \hat{V}_{U S}^{\ell}=\sum_{i, j} B_{i j}^{\ell} \sum_{m=-\ell}^{\ell}\left|\beta_{i}^{\ell m}><\beta_{j}^{\ell m}\right|+\sum_{i, j} \varepsilon_{j \ell} Q_{i j}^{\ell} \sum_{m=-\ell}^{\ell}\left|\beta_{i}^{\ell m}><\beta_{j}^{\ell m}\right| .
$$

No caso do pseudopotencial de conservação de norma, o primeiro termo seria o mesmo da equação acima e o segundo seria zero, pois existe o vínculo $Q_{i j}^{\ell}=0$. Sendo assim, para o pseudopotencial ultrasuave a relação entre a norma da função de onda de todos os elétrons e a pseudofunção de onda será: 


$$
\begin{aligned}
\left\langle\Phi_{A E}^{i \ell m} \mid \Phi_{A E}^{j \ell m}\right\rangle_{r_{c}} & =\left\langle\Phi_{P S}^{i \ell m} \mid \Phi_{P S}^{j \ell m}\right\rangle_{r_{c}}+Q_{i j}^{\ell} \\
& =<\Phi_{P S}^{i \ell m}\left|\left(\hat{I}+\sum_{i, j} Q_{i j}^{\ell}\left|\beta_{i}^{\ell m}><\beta_{j}^{\ell m}\right|\right)\right| \Phi_{P S}^{j \ell m}>_{r_{c}}
\end{aligned}
$$

A equação acima pode ser escrita de forma mais compacta:

$$
\hat{S}=\hat{I}+\sum_{\ell} \sum_{i, j} Q_{i j}^{\ell} \sum_{m=-\ell}^{\ell}\left|\beta_{i}^{\ell m}><\beta_{j}^{\ell m}\right|,
$$

e então, a condição de conservação de norma é escrita da seguinte maneira:

$$
\left\langle\Phi_{A E}^{i \ell m} \mid \Phi_{A E}^{j \ell m}\right\rangle_{r_{c}}=\left\langle\Phi_{P S}^{i \ell m}|\hat{S}| \Phi_{P S}^{j \ell m}\right\rangle_{r_{c}}
$$

Logo, a pseudofunção de onda $\mid \phi_{P S}^{i \ell m}>$ é solução do problema de autovalor atômico generalizado:

$$
\begin{aligned}
H \mid \Phi_{P S}^{i \ell m}> & =\varepsilon_{i \ell}\left|\Phi_{P S}^{i \ell m}>+\sum_{\ell^{\prime}} \sum_{i, j} \varepsilon_{i \ell^{\prime}} Q_{i j}^{\ell^{\prime}} \sum_{m^{\prime}=-\ell^{\prime}}^{\ell^{\prime}}\right| \beta_{i}^{\ell^{\prime} m^{\prime}}><\beta_{j}^{\ell^{\prime} m^{\prime}} \mid \Phi_{P S}^{i \ell m}> \\
& =\varepsilon_{i \ell^{\prime}} \hat{S} \mid \Phi_{P S}^{i \ell m}>.
\end{aligned}
$$

Neste caso apenas a componente angular $\ell$ dos operadores (superposição e não local) produzem elementos de matriz não nulos e com um momento angular bem definido. A identidade generalizada, comparada com a equação A.65, terá uma contibuição diagonal da seguinte forma:

$$
-\frac{1}{2}\left\{\left[r R^{\ell}(\varepsilon, r)\right] \frac{d}{d \varepsilon} \frac{d}{d r} \ln R^{\ell}(\varepsilon, r)\right\}_{r_{c}}=<\psi_{P S}^{i \ell m} \mid \psi_{P S}^{j \ell m}>_{r_{c}}+Q_{i i}^{\ell}
$$

O critério de transferibilidade, neste caso, possui um elemento adicional $Q_{i i}^{\ell}$ e este elemento representa uma quantidade de carga que falta na pseudofunção de 
onda de momento angular $\ell$, calculada usando o potencial de referência.

Este esquema desenvolvido por Vanderbit tem tido grande sucesso desde a sua criação, pois este método leva a uma considerável diminuição na energia de corte das ondas planas. Para obter o mesmo tipo de cálculo (acurácia e convergência), a energia de corte das ondas planas para o oxigênio pode ser reduzida de 150 Ry para aproximadamente 40 Ry, usando este método.

Uma vez apresentada a teoria dos pseudopotenciais, faremos algumas observações sobre os métodos apresentados. A primeira observação é sobre a escolha dos pseudopotenciais ou um método mais preciso para proceder com os cálculos. Essa escolha vai depender do tipo de pergunta que queremos responder, bem como das limitações do tamanho do sistema. Quando o resultado que estamos buscando requer extrema acurácia e o sistema tiver cerca de 100 átomos, então um cálculo de todos os elétrons se faz necessário. Caso contrário os pseudopotenciais são uma boa escolha. Se a opção for por pseudopotenciais, a primeira questão pertinente é referente ao tipo de pseudopotencial. Basicamente, quando os cálculos são feitos com ondas planas, usualmente é escolhido o pseudopotencial US, isto porque esse método é muito mais eficiente, uma vez que é mais suave (o número de ondas planas é menor). Então o ponto que deve ser observado são as funções de base (ondas planas ou base localizada por exemplo). No caso das funções de base de átomos centrados, os pseudopotenciais de conservação de norma são mais recomendados pela sua maior simplicidade, e nesse último caso a acurácia é a mesma dos paseudopotenciais US. O custo computacional com pseudopotenciais US em base localizada não tem grandes melhoras e por isso que geralmente para esse tipo de função de base é usado o pseudopotencial de norma conservada. 


\title{
Apêndice B
}

\section{Estrutura eletrônica - Método}

\author{
tight-binding
}

\section{B.1 O método:}

Neste apêndice apresentaremos o método tight-binding (TB), sem discutir as parametrizações, com o objetivo de aprendermos sobre a estrutura eletrônica do grafite e nanotubos sem grandes sofisticações. Inicialmente vamos apresentar o método de forma geral e posteriormente fazer três aplicações.

Por simplicidade, vamos considerar apenas um átomo por célula unitária. Considerando uma função atômica $\chi_{\mu}(r-R)$ num dado sítio $R^{1}$. A combinação linear das funções atômicas será descrita por $\left(\phi_{\mu}\right)$, que por sua vez satisfaz o teorema de Bloch para um determinado $k$, sendo assim:

$$
\phi_{\mu}(k, r)=\frac{1}{\sqrt{N}} \sum_{R} e^{i k \cdot R} \chi_{\mu}(r-R),
$$

\footnotetext{
${ }^{1}$ No caso mais geral, onde consideramos mais de um átomo por célula unitária, teríamos um somatório sobre todos os sítios da célula e, neste caso, $\chi_{\mu}(r-R)$ passaria a ser $\chi_{\mu}\left(r-R-\tau_{a}\right)$, onde o orbital estaria localizado no sítio $R-\tau_{a}$, dentro da célula unitária dada por $R$.
} 
A função de Bloch para a n-ésima banda e para um dado vetor de onda $k$, pode ser escrita como uma combinação linear de $\phi_{\mu}(\mathrm{k}, \mathrm{r})$ :

$$
\psi_{n}(k, r)=\sum_{\mu} c_{n \mu}(k) \phi_{\mu}(k, r)
$$

e, então, os elementos de matriz para o Hamiltoniano $\hat{H}$ serão representados por:

$$
H_{\mu \nu}(k)=\int \phi_{\mu}^{*}(k, r) \hat{H} \phi_{\nu}(k, r) d^{3} r
$$

Se substituirmos a equação B.1 na equação B.3, obtemos a seguinte expressão:

$$
H_{\mu \nu}(k)=\frac{1}{N} \sum_{R R^{\prime}} e^{i k \cdot\left(R-R^{\prime}\right)} \int \chi_{\mu}^{*}(r-R) \hat{\chi}_{\nu}\left(r-R^{\prime}\right) d^{3} r .
$$

Além disso, usando o fato de que o Hamiltoniano é invariante sob translação, $\hat{H}(r+R)=\hat{H}(r)$, temos que:

$$
\begin{aligned}
H_{\mu \nu}(k) & =\sum_{R^{\prime \prime}} e^{i k \cdot\left(R^{\prime \prime}\right)} \int \chi_{\mu}^{*}(r) \hat{H} \chi_{\nu}\left(r-R^{\prime \prime}\right) d^{3} r \\
& =\sum_{R^{\prime \prime}} e^{i k \cdot\left(R^{\prime \prime}\right)} h_{\mu \nu}\left(R^{\prime \prime}\right)
\end{aligned}
$$

onde

$$
h_{\mu \nu}\left(R^{\prime \prime}\right)=\int \chi_{\mu}^{*}(r) \hat{H} \chi_{\nu}\left(R^{\prime \prime}\right) d^{3} r .
$$

Para as funções $\phi_{\mu}$ não ortogonais, os elementos de superposições ${ }^{2} S_{\mu \nu}$ são:

$$
\mathrm{S}_{\mu \nu}(K)=\int \phi_{\mu}^{*}(k, r) \phi_{\mu}(k, r) d^{3} r=\sum_{R^{\prime \prime}} e^{i k \cdot R^{\prime \prime}} S_{\mu \nu}\left(R^{\prime \prime}\right)
$$

\footnotetext{
${ }^{2}$ Estes elementos são conhecidos como termos de superposição (overlap).
} 
ou ainda:

$$
S_{\mu \nu}\left(R^{\prime \prime}\right)=\int \phi_{\mu}^{*}(r) \phi_{\mu}\left(r-R^{\prime \prime}\right)
$$

Resolver o problema consite em resolver a equação de autovalores:

$$
\sum_{\nu}\left[H_{\mu \nu}(k)-\varepsilon_{n} S_{\mu \nu}(k)\right] c_{n \nu}=0
$$

onde a equação B.9 é conhecida como combinação linear de orbitais atômicos $a b$ initio. O sentido de ab initio refere-se a um método sem recorrer a nenhuma aproximação.

Para de tratarmos do método TB, vamos considerar um Hamiltoniano como:

$$
\hat{H}=\sum_{i} \hat{T}_{i}+\sum_{R} V(r-R)
$$

e os termos deste Hamiltoniano são: $\hat{T}_{i}$ o operador energia cinética de todos os elétrons; e $V(r-R)$, o potencial completo do cristal no sítio $R$.

Podemos reescrever o Hamiltoniano da seguinte maneira:

$$
\hat{H}=\sum_{i} \hat{T}_{i}+V(r)+V\left(r+R^{\prime \prime}\right) \sum_{R \neq R^{\prime \prime}} V(r-R),
$$

e, além disso, supondo que a função atômica $\left(\chi_{\mu}(r)\right)$ é uma autofunção de $H_{i}=$ $T_{i}+V(r)$, então:

$$
\left[T_{i}+V\right] \chi_{\mu}(r)=\varepsilon_{\mu}^{0} \chi_{\mu}(r)
$$

e para $h_{\mu \nu}\left(R^{\prime \prime}\right)$

$$
h_{\mu \nu}\left(R^{\prime \prime}\right)=\varepsilon_{\mu}^{0} S_{\mu \nu}\left(R^{\prime \prime}\right)+\int \chi_{\mu}^{*}(r) V\left(r-R^{\prime \prime}\right) \chi_{\nu}\left(R-R^{\prime \prime}\right) d^{3} r+
$$




$$
\sum_{R \neq R^{\prime \prime}} \int \chi_{\mu}^{*}(r) V\left(r-R^{\prime \prime}\right) \chi_{\nu}\left(R-R^{\prime \prime}\right) d^{3} r .
$$

Faremos um tratamento para um caso simples, isto é, consideraremos um átomo por célula unitária e apenas um orbital por sítio. Neste caso, usando a equação B.9, teremos:

$$
\varepsilon_{\mu}(k)=\frac{H_{\mu \mu}}{S_{\mu \mu}}
$$

o que, de forma reduzida, seria:

$$
\varepsilon_{\mu}(k)=\varepsilon_{\mu}^{(0)}+\frac{\alpha(r)+\sum_{R \neq 0} \beta(R) e^{i k \cdot R}}{1+\sum_{R} \gamma(R) e^{i k \cdot R}} .
$$

Na equação acima, o termo $\alpha$ contém os efeitos dos potenciais distantes sobre a célula central (efeitos dos campos cristalinos), e então:

$$
\alpha(r)=\int\left|\chi_{\nu}(r)\right|^{2}\left[\sum_{R \neq 0} V(r-R)\right] d^{3} r .
$$

O termo $\beta(R)$ está relacionado com a superposição entre os sítios através do potencial. Neste caso não é incluído $R=0$, termo que define a largura das bandas e também é conhecido como termo de hopping. Este termo tem a seguinte forma:

$$
\beta(R)=\int \chi_{\mu}^{*}(r)\left[\sum_{R} V(r-R)\right] \chi_{\mu}(r) d^{3} r .
$$

E o último termo $\gamma(r)$ é conhecido como superposição entre orbitais atômicos centrados em diferentes sítios. A forma deste termo é a seguinte:

$$
\gamma(r)=\int \chi_{\mu}^{*}(r) \chi_{\mu}(r-R) d^{3} r
$$

Analisando a equação B.15, notamos que os termos $\beta(r)$ e $\gamma(r)$ podem ser menores do que $\alpha(r)$, pois estes dois primeiros termos decaem exponencialmente e o 
último, decai com potência de $\left|R-R^{\prime \prime}\right|$ quando os átomos se distanciam.

A partir da teoria apresentada, vamos fazer uma aplicação para o grafeno, e posteriormente para os nanotubos de carbono.

\section{B.2 Aplicação do modelo TB: Grafeno}

A primeira aplicação para o modelo TB deste apêndice é dedicada ao grafeno. Antes de começarmos qualquer desenvolvimento, consideremos apenas um orbital $\left(p_{z}\right)$ por sítio, e somente a interação entre os primeiros vizinhos. Como foi mostrados na figura 1.7 do capítulo 1, a rede hexagonal é representada por dois átomos na célula unitária $(A$ e $B)$, e todos os vizinhos do átomo $A$ são do tipo $\mathrm{B}$, e então, podemos determinar três vetores desses átomos $\left(R_{1}, R_{2}\right.$ e $\left.R_{3}\right)$. Usaremos as equações do tipo B.9, dentro da aproximação de Hückel $^{3}$, e escrevendo as seguintes combinações das funções atômicas, centradas em cada átomo da célula unitária, teremos:

$$
\begin{aligned}
\phi^{A}(k, r) & =\frac{1}{\sqrt{N}} \sum_{R} e^{i k \cdot R_{A}} \chi\left(r-R_{A}\right) \\
\phi^{B}(k, r) & =\frac{1}{\sqrt{N}} \sum_{R} e^{i k \cdot R_{B}} \chi\left(r-R_{B}\right),
\end{aligned}
$$

onde, dentro das nossas aproximações, a função $\chi$ será aproximada por um orbital $p_{z}$, centrado nos átomos $A$ e $B$. Sendo assim as autofunções serão formadas por:

\footnotetext{
${ }^{3}$ No método de Hückel são impostas três aproximações: (I) todas as integrais de superposição $S_{\mu \nu}$ que envolvem diferentes orbitais atômicos $\chi_{\mu}$ e $\chi_{\nu}$ são dados por $S_{\mu \nu}=\delta_{\mu \nu}$; (II) o termo diagonal $H_{\mu \mu}$ é considerado o mesmo para todos os átomos envolvidos $\left(H_{\mu \mu}=\alpha\right)$, o que representa a energia do elétron ligado ao sítio onde está localizado o orbital $\mu$, devido a presença dos outros centros atômicos; e (III) os termos fora da diagonal $H_{\mu \nu}$ assumem um valor constante $\beta(\beta<0)$, se os orbitais $\mu$ e $\nu$ pertencem a sítios vizinhos, então $H_{\mu \nu}=\beta$ se os átomos estão diretamente ligados, ou $H_{\mu \nu}=0$ nos demais casos
} 


$$
\psi_{n}(k, r)=\frac{1}{\sqrt{N}}\left(\sum_{R_{A}} e^{i k \cdot R_{A}} p_{z}^{A}\left(r-R_{A}\right)+\sum_{R_{B}} e^{i k \cdot R_{B}} p_{z}^{B}\left(r-R_{B}\right)\right) .
$$

Para os elementos diagonais teremos:

$$
H_{A A}=\left\langle\phi^{A}|H| \phi^{A}\right\rangle=\left\langle\phi^{B}|H| \phi^{B}\right\rangle=H_{B B}=\alpha .
$$

Para os elementos fora da diagonal, $H_{A B}$, considerando a origem no átomo $A$, então os três vizinhos se encontram nas posições: $R_{1}=\left(\frac{a}{\sqrt{3}}, 0\right), R_{2}=\left(\frac{-a}{2 \sqrt{3}}, \frac{a}{2}\right) \mathrm{e}$ $R_{3}=\left(-\frac{a}{2 \sqrt{3}}, \frac{-a}{2}\right)$. Sendo assim, teremos os termos fora das diagonais:

$$
\begin{aligned}
H_{A B} & =\left\langle\phi^{A}|H| \phi^{B}\right\rangle=\beta\left(e^{i k \cdot \overrightarrow{R_{1}}}+e^{i k \cdot \overrightarrow{R_{2}}}+e^{i k \cdot \overrightarrow{R_{3}}}\right) \\
& =\beta\left(e^{i k_{x} a / \sqrt{3}}+e^{-i k_{x} a / 2 \sqrt{3}} \cdot e^{i k_{y} a / 2}+e^{-i k_{x} a / 2 \sqrt{3}} \cdot e^{-i k_{y} a / 2}\right) \\
& =\beta\left(e^{i k_{x} a / \sqrt{3}}+2 e^{-i k_{x} a / 2 \sqrt{3}} \cos \left(\frac{k_{y} a}{2}\right)\right),
\end{aligned}
$$

onde $\beta$ é o termo de hopping. Resolvendo a seguinte equação secular, obtemos:

$$
\operatorname{det}\left[\begin{array}{cc}
H_{A A}-\varepsilon & H_{A B} \\
H_{B A} & H_{B B}-\varepsilon
\end{array}\right]=0
$$

ou ainda,

$$
\begin{aligned}
& (\alpha-\varepsilon)^{2}=H_{B A} H_{A B} \\
& \varepsilon=\alpha \pm \sqrt{H_{B A} H_{A B}},
\end{aligned}
$$


ou seja, a relação de dispersão para folha de grafeno é dada por:

$$
\varepsilon\left(k_{x}, k_{y}\right)=\alpha \pm \beta \sqrt{1+4 \cos \left(\frac{a \sqrt{3}}{2} k_{x}\right) \cos \left(\frac{a}{2} k_{y}\right)+4 \cos ^{2}\left(\frac{a}{2} k_{y}\right)} .
$$

Na figura B.1-a mostramos um gráfico da relação de dispersão do grafeno, obtida através da equação B.25, em função dos parâmetros $\alpha$ e $\beta$. E em detalhe na figura B.1-b, um gráfico da relação de dispersão do grafeno ao longo dos pontos de alta simetria $\Gamma, M$ e $K$.
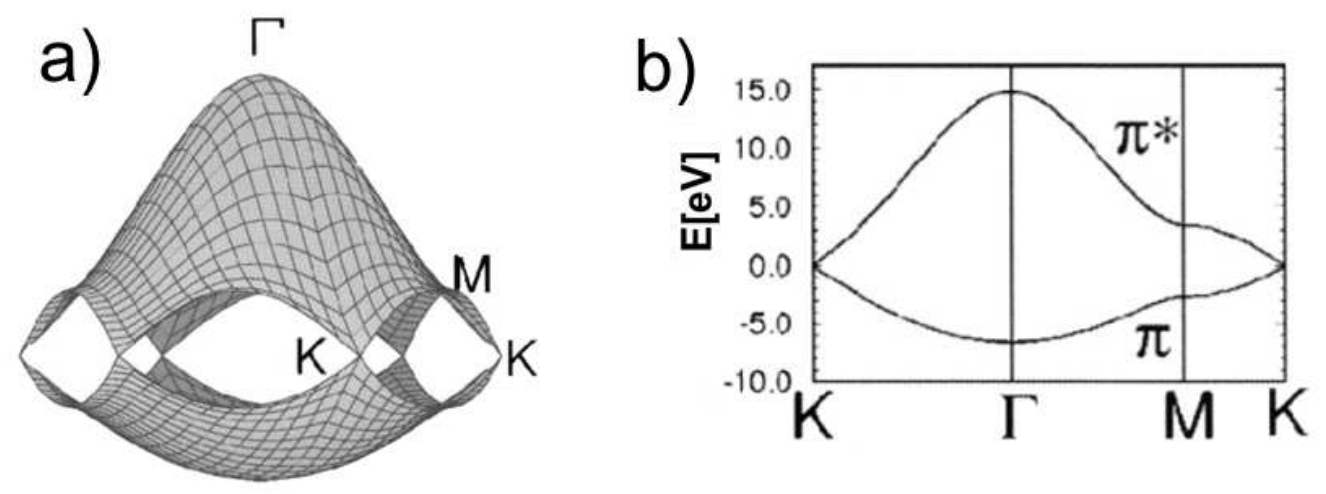

Figura B.1: Em (a) mostramos um gráfico da relação de dispresão e os pontos de alta simetria do grafeno; em (b), relação de dispersão ao longo das direções $\Gamma, K$ e $M$.

Consideremos que o grafeno possui dois átomos por célula unitária e cada átomo contribui com um elétron proveniente de $2 p_{z}$. Individualmente, os pontos de alta simetria serão ocupados por dois elétrons $(\uparrow$ e $\downarrow$ ). No ponto $K$, observa-se que não há lacuna $(g a p)$, pois existe uma degenerescência na energia, o que caracteriza o grafeno como um metal.

A partir da relação de dispersão do grafeno, faremos algumas considerações para encontrarmos a relação de dispersão dos nanotubos. Para tal, usaremos o fato de que o vetor quiral é enrolado e, desta forma, os vetores de onda que eram contínuos pas- 
sarão a ser discretos. Maiores detalhes dessa aplicação é apresentada diretamentente no capítulo 1. 


\section{Bibliografia}

[1] K. S. Novoselov, A. K. Geim, S. V. Morozov, D. Jiang, Y. Zhang, S. V. Dubonos, I. V. Grigorieva e A. A. Firsov. Derycke et al. Science 306, 666 (2004).

[2] S. Iijima. Nature 354, 56 (1991).

[3] S. Iijima e T. Ichihashi. Nature 363, 603 (1993).

[4] E. Salonen, A.V. Krasheninnikov e K. Nordlund. Nucl. Inst. and Mat. in Phys. Research B 216, 603 (2002).

[5] R. Saito, G. Dresselhaus e M. S. Dresselhaus. Physical Properties of Carbon Nanotubes. Imperial College Press, (1998).

[6] L.X. Zheng, M.J. O'Connell, S.K. Doorn, X.Z. Liao, Y.H. Zhao, E.A. Akhadov, M.A. Hoffbauer, B.J. Roop, Q.X. Jia, R.C. Dye, D.E. Peterson, S.M. Huang, J. Liu e Y.T. Zhu. Nature Materials 3, 673 (2004).

[7] A. B. Dalton, S. Collins, E. Mu noz, J. M. Razal, V. H. Ebron, J.P. Ferraris, N.J. Coleman, B.G. Kim e R.H. Baughman. Nature 423, 703 (2003).

[8] B.C. EDWARDS. Acta Astronautica 47, 735 (2000).

[9] P.L. McEuen, M. Fuhrer e H. Park. IEEE Trans. Nanotech. 1, 78 (2002).

[10] P. Avouris. Phys. World 20, 40 (2007). 
[11] R. Martel et al. Appl. Phys. Lett. 73, 2444 (1998).

[12] R. Martel et al. Phys. Rev. Lett. 87, 256805 (2001).

[13] V. Derycke et al. Nano Lett. 1, 453 (2001).

[14] F. Villalpando-Paez, A.H. Romero, E. Munoz-Sandoval, L.M. Martnez, H. Terrones, M. Terrones e P. Avouris. Chem. Phys. Lett. 386, 137 (2004).

[15] A. R. Rocha, M. Rossi, A. Fazzio e A. J. R. da Silva. Phys. Rev. Lett. 100, $176803(2008)$.

[16] J-C Charlier. Acc. Chem. Res. 35, 1063 (2002).

[17] A.J. Stone e D.J. Wales. Chem. Phys. Lett. 128, 501 (1986).

[18] L.G. Zhou e S.Q. Shi. Appl. Phys. Lett. 83, 1222 (2003).

[19] J.W. Wei, HF Hu, H. Zeng, ZY. Wang, L. Wang e P. Peng. Appl. Phys. Lett. 91, $092121(2007)$

[20] K. Suenaga, H. Wakabayshi, M. Koshino, Y. Sato, K. Urita e S. Iijima. Nature Nanotechnology 2, 358 (2007).

[21] E. Ertekin, D. C. Chrzan e M.S. Daw. Phys. Rev. B 79, 155421 (2009).

[22] A. Hashimoto, K. Suenaga, A Gloterand K. Urita e S. Iijima. Nature 7002, $870(2004)$.

[23] A.R. Rocha, J.E. Padilha, A. Fazzio e A.J.R da Silva. Phys. Rev. B 77, 153406 (2008).

[24] W. Orellana e P. Fuentealba. Surface Science 600, 4305 (2006).

[25] A.A. El-Barbary, R.H. Telling, C.P. Ewels, M.I. Heggie e P.R. Briddon. Phys. Rev. B 68, 144107 (2003). 
[26] A.J. Lu e B.C. Pan. Phys. Rev. Lett. 92, 105504 (2004).

[27] G.-D. Lee, C. Z. Wang, E. Yoon, N.-M. Hwang, D.-Y. Kim e K. M.Ho. Phys. Rev. Lett. 95, 205501 (2005).

[28] R.G. Amorim, A. Fazzio, A. Antonelli, F.D. Novaes e A.J.R. da Silva. Nano Lett. 7, 2459 (2007).

[29] J. Kotakoski, A.V. Krasheninnikov e K. Nordlund. Phys. Rev. B 74, 245420 (2006).

[30] S. Berber e A. Oshiyama. Phys. Rev. B 77, 165405 (2008).

[31] C.P. Ewels, R.H. Telling, A.A. El-Barbary, M.I. Heggie e P.R. Briddon. Phys. Rev. Lett. 91, 025505 (2003).

[32] R.H. Telling, C.P. Ewels, A.A. El-Barbary e M.I. Heggie. Nature Materials 2, $333(2003)$.

[33] A.J.R. da Silva, A. Fazzio e A. Antonelli. Nano Lett. 5, 1045 (2005).

[34] F. Banhart. Rep. Prog. Phys. 62, 1181 (1999).

[35] A. Hashimoto, K. Suenaga, A. Gloter, K. Urita e S. Iijima. Nature 430, 870 (2004).

[36] K. Suenaga, H. Wakabayashi, M. Koshino, , Y. Sato, K. Urita e S. Iijima S. Nature Nanotechnology 2, 358 (2007).

[37] C. Jin, K. Suenaga e S. Iijima S. Nano Lett. 8, 1127 (2008).

[38] J.C. Meyer, C. Kisielowski, R. Erni, M.D. Rossell, M.F. Crommie e A. Zettl. Nano Lett. 8, 3582 (2008). 
[39] M. Terrones, H. Terrones F. Banhart, J-C Charlier e P.M. Ajayan. Science 288, 1226 (2000).

[40] B. Ni, R. Andrews, D. Jacques, D. Qian, M.B.J. Wijesundara, Y.S. Choi, L. Hanley e S.B. Sinnott. J. Phys. Chem. B 105, 12719 (2001).

[41] A.V. Krasheninnikov e F. Banhart. Nature Materials 6, 723 (2007).

[42] A. Hashimoto, K. Suenaga, K. Urita, T. Shimada, T. Sugai, S. Bandow H. Shinohara e S. Iijima. Phys. Rev. Lett. 94, 045504 (2005).

[43] A. Kis, G. Csnyi, J.-P. Salvetat, Thien-Nga Lee, E. Couteau, A. J. Kulik, W. Benoit, J. Brugger e L. Forro. Nature Materials 3, 153 (2004).

[44] J.A. Astrom, A.V. Krasheninnikov e K. Nordlund. Phys. Rev. Lett. 93, 215503.

[45] E. Assari, M. Kitajima, K.G. Nakamura e T. Kawabe. Phys. Rev. B 74, 11143 (1993).

[46] A.V. Krasheninnikov, K. Nordlund e J. Keinonen. Phys. Rev. B 65, 16423 (2002).

[47] A.V. Krasheninnikov e K. Nordlund. J. Vac. Sci. Technol B 20, 728 (2002).

[48] A.V. Krasheninnikov e K. Nordlund. Nucl. Inst. and Mat. in Phys. Research $B$ 216, 355 (2004).

[49] M. Sammalkorpi, A. Kuronen, A.V. Krasheninnikov, K. Nordlund e K. Kaski. Phys. Rev. B 70, 245416 (2004).

[50] A.V. Krasheninnikov, K. Nordlund, M. Sirvio, E. Salonen e J. Keinonen. Phys. Rev. B 63, 245405 (2001).

[51] B. W. Smith e D. E. Luzzi. Jour. of Appl. Phys. 90, 3509 (2001). 
[52] W. Orellana e P. Fuentealba. Surface Science 600, 4305 (2006).

[53] J.M. Carlsson. Phys. Stat. Sol. 13, 3452 (2006).

[54] C. Gómez-Navarro, P.J. de Pablo, J. Gómez-Herrero, B. Biel, F.J. GarciaVidal, A. Rubio e F. Flores. Nature Materials 4, 534 (2005).

[55] C. Gómez-Navarro, P.J. de Pablo, J. Gómez-Herrero, B. Biel, F.J. GarciaVidal, A. Rubio e F. Flores. Phys. Rev. Lett. 95, 266801 (2005).

[56] E.W. Mitchell e M.R. Taylor. Nature 208, 638 (1965).

[57] M. Cadek, J. N. Coleman, V. Barron, K. Hedicke e W. J. Blau. Appl. Phys. Lett. 81, 5123 (2002).

[58] A. H. Barber, S. R. Cohen e H. D. Wagner. Appl. Phys. Lett. 82, 4140 (2003).

[59] S.K. Pregler e S.B. Sinnott. Phys. Rev. B 73, 224106 (2006).

[60] A.V. Krasheninnikov, F. Banhart, J.X. Li e et al. Phys. Rev. B 72, 125428 $(2005)$.

[61] F. Banhart, J.X. Li e A.V. Krasheninnikov. Phys. Rev. B 71, 241408 (2005).

[62] A.V. Krasheninnikov e K. Nordlund. Phys. Rev. B 71, 245408 (2005).

[63] A.V. Krasheninnikov, K. Nordlund e et al. J. Appl. Phys. 96, 2864 (2004).

[64] A.V. Krasheninnikov e K. Nordlund. Phys. Rev. B 70, 045404 (2004).

[65] B. Peng, M. Locascio, P. Zapol, S.Y. Li, S.L. Mielke, G.C Schatz e H.D. Espinosa. Nature Nanotechnology 3, 626 (2008).

[66] M. Locascio, B. Peng, P. Zapol, Y. Zhu, S. Li, T. Belytschko e H.D. Espinosa. Exp. Mech. 49, 169 (2009). 
[67] S. Akita e Y. Nakayama. Jpn. J. Appl. Phys. 42, 3933 (2003).

[68] S. Akita e Y. Nakayama. Jpn. J. Appl. Phys. 42, 4830 (2003).

[69] W. Ding, L. Calabri, K.M. Kohlhaas, X. Chen, D.A. Dikin e R.S. Ruoff. Exp. Mech. 47, 25 (2007).

[70] M.F. Yu, B.I. Yakobson e R.S. Ruoff. J. Phys. Chem. B 104, 8764 (2000).

[71] M.F. Yu, B.I. Yakobson e R.S. Ruoff. Science 287, 637 (2000).

[72] D.S. Bethume et al. Nature 363, 605 (1993).

[73] M. Meyyappan. Carbon Nanotubes - Science and Applications. CRC Presss, (2004).

[74] Bhushan. Handbook of nanotechnology. Springer, (2004).

[75] C. Journet, W.K. Maser e P. Bernier. Nature 388, 756 (1997).

[76] H. Dai. Acc. Chem. Res. 35, 1035 (2002).

[77] M.M.J. Tracy, T.W .Ebbesen e J.M.Gibson. Nature 381, 678 (1996).

[78] A. V. Eletskii. Phys. Uspekhi 50, 225 (2007).

[79] R. Martel, T. Schmidt, H.R. Shea, T. Hertel e P. Avouris. Appl. Phys. Lett. 73, 2447 (1998).

[80] J. Andzelm, N.Govind e A. Maiti. Chem. Phys. Lett. 421, 58 (2006).

[81] A.Tolvanen, J. Kotakoski, A.V. Krasheninnikov e K. Nordlund. Appl. Phys. Lett. 91, 173109 (2007).

[82] J.C. Mayer, C. Kisielowski, R. Enri, M.D. Rossel, M.F. Crommie e A. Zettl. Nano Lett. 8, 3582 (2008). 
[83] P. Hohenberg e W. Kohn. Phys. Rev. B 136, 864 (1964).

[84] W. Kohn e L.J. Sham. Phys. Rev. A 140, 1133 (1965).

[85] G. Kresse e J. Hafner. Phys. Rev. B 47, 588 (1993).

[86] G. Kresse e J. Furthmuller. Phys. Rev. B 54, 11169 (1996).

[87] L. Vanderbilt. Phys. Rev. B 32, 8412 (1985).

[88] F. Novaes, A.J.R. da Silva e A. Fazzio. Braz. Joun. Phys. 36, 799 (2006).

[89] J. M. Soler, E. Artacho, J.D. Gale, A. García, J. Junquera, P. Ordejón e D. Sanchez-Portal. 54, 2745 (2002).

[90] Gun-Do, C.Z. Wang, Enijoon Yoon, Nong-Moon Hwang, Doh-Yoon e K.M. Ho. Phys. Rev. Lett. 95, 205501 (2005).

[91] C. Li e T-W Chou. Int. J. of Sol. and Struc. 40, 2487 (2003).

[92] S.Datta. Quantum Transport - Atom to Transistor. Cambridge, (2005).

[93] M. L. Cohen. Phys. Rev. B 32, 7988 (1985).

[94] M. Zhang, K.R. Atkinson e R.H. Baughman. Science 306, 1358 (2004).

[95] G. Henkelman, B.P. Uberuaga e H. Jónsson. J. Chem. Phys. 113, 9901 (2000).

[96] G. Henkelman, e H. Jónsson. J. Chem. Phys. 113, 9978 (2000).

[97] E.W. J. Mitchell e M.R. Taylor. Nature 208, 638 (1965).

[98] M. Huhtala, A.V. Krasheninnikov, J. Aittoniemi, S. J. Stuart, K. Nordlund e K. Kaski. Phys. Rev. B 70, 045404 (2004).

[99] C. Herring. Phys. Rev. 57, 1169 (1940). 
[100] J. C. Philips e L. Kleinman. Phys. Rev. 116, 880 (1959).

[101] G. P. Kerker. J. Phys. C 13, 1993 (1991).

[102] N. Troullier e J. L. Martins. Phys. Rev. B 43, 1993 (1991).

[103] W. Kohn. Rev. Mod. Phys. 71, 1253 (1999).

[104] N.H. March e S. Lundquvist. Theory of Inhomogeneous Electron Gas. Plenum Press, (1983).

[105] K. Capelle. cond-mat, 0211443 (2003).

[106] M. Dreizler Reiner e E.K.U.Gross. Many Particule Theory. Springer-Verlag, (1991).

[107] D.M. Ceperley e B.J. Alder. Phys. Rev. Lett. 45, 566 (1980).

[108] J. P. Perdew, K. Burke e M. Ernzerhof. Phys. Rev. Lett. 77, 3865 (1992). 